\title{
MASS SPECIROMETRIC INVESTIGATION OF LASER-INDUCED \\ VAPORIZATION OF BINARY SOLID COMPOUNDS
}

\section{Contents}

Abstract

I. History of Laser Solld Interactions . . . . . . . . . . . . 1

A. Introduction . . . . . . . . . . . . . . . 1

B. Experimental Observations . . . . . . . . . . 3

1. Melting and Vaporization .............. 3

2. Electron Entssion . . . . . . . . . . . . 4

3. Positive Ion Emlssion .. . . . . . . . . . . 5

4. Neutral Molecule EnIsaton . . . . . . . . 7

5. Plasma Production . . . . . . . . . . . . 8

C. Qualitative Model of Lasez Interaction at High Power

Densities .................. 9

II. Experimental . . . . . . . . . . . . . . . . 11

A. Purpose . . . . . . . . . . . . . . . . . 11

B. Experimental Apparatus . . . . . . . . . . . 13

1. Introduction . . . . . . . . . . . . 13

2. Laser Apparatus . . . . . . . . . . 17

3. Vacuum System . . . . . . . . . . . . 20

4. Mass Spectrometer . . . . . . . . . . . . . 21

C. Laser Parameter Measurement . . . . . . . . . . 23

1. Energy Incident on the Target . . . . . . . . . 23

2. Laser Power . . , . . . . . . . . . . . . . 25

3. Spot S1ze and Incident and Absorbed Energy Density . 25 
D. Surface Reflectivity Measurement . . . . . . . . 32

I. Iron Reflectivity ............... 32

2، Zirconium Hydride. Ref lectivity ......... 33

E. Mass Spectrometer Calibration . . . . . . . . . . 34

1. Calibration on Iron ............. 34

2. Calibration on Molecular Hydrogen . . . . . . 38

3. Mass Spectrometer Time Constant . . . . . . . 41

F. Fabrication of Zirconium Hydride Samples . . . . . . 41

G. Laser Shots on Iron . . . . . . . . . . . 45

H. Laser Shots on Zirconiun Hydride . . . . . . . . 47

III. Theory-Predicted Mass Spectrometer Signal . . . . . . . 49

A. Equilibrium Model for Vaporization from the Surface . 49

B. Calculated Density of Molecules at the Ionizer . . . . 51

C. Measured Density of Molecules at the Ionizer . . . . 53

IV. Temperature Calculations . . . . . . . . . . . . 61.

A. Energy Equation for Iron ............... 61

B. Approximate Solutiors for Iron Temperature . . . . . 63

1. Approxinate Energy Equation . . . . . . . . . 63

2. Rectangular Heat Source Over Entire Planc . . . . 64

3. Triangular Heat Source Over Entire Plane . . . . 64

4. Steady Heat Source Over Circular Area of the Plane 65

5. Steady Volumetric Heat Source Over Er.tire Plane Decreasing Exponentially into the Materlal . . 66

6. The Effect of Spikes in the Conventional Mode Pulse ................. 
C. Energy and Hydrogen Diffusion Equations for Zirconium Hydride . . . . . . . . . . . . . . 72

V. Material Properties Used in the Numerical Calculations . . 78

A. Iron Properties . . . . . . . . . . . 78

1. Vapor Pressure ............... 78

2. Heat of Vaporization . . . . . . . . . 78

3. Specific Heat ................. 79

4. Thermal Conductivity ............. 81

5. Density . . . . . . . . . . . . . 81

6. ReflectIvity ................. 82

B, Zirconium Hydride Properties. . . . . . . . . 82

1. Zirconium-Hydrogen Phase System . . . . . . . 82

2. Vapor Pressure . . . . . . . . . . . 86

3. Total and Partial Molar Enthalpies of $\mathrm{ZrH}_{\mathbf{y}}$. . . 87

4. Heat of Vaporization . . . . . . . . . . . 92

5. Specific Heat . . . . . . . . . . . . 92

6. Thermal Conductivity ............. 93

7. Diffusion Coefficient . . . . . . . . . 94

8. Heat of Transport ............. 95

9. Density .................. 96

VI. Results ...................... 97

A. Iron Results . . . . . . . . . . . . . . . 97

1. Numerical Results . . . . . . . . . . . 97

2. Experimental Results . . . . . . . . . . 104

3. Comparison Between Calculated and Experimental Results ................. 112 
B. ZIrcontum Hydrilde Results . . . . . . . . . . 117

1. Numerical kesults . . . . . . . . . . 117

2. Experimental Results for Low Energy Denstties . . 128

3. Comparison Between Calculated and Experimental

Results (Low Energy Dens1ty) . . . . . . . . 133

4. Experimental Results for High Energy Densities . 146

c. Conclustons . . . . . . . . . . . . . 152

Acknowledgements . . . . . . . . . . . . . . . . 155

Appendices

A. Average Peaking Factor in the Iontzer . . . . . . . 156

B. Numerical Solution to the Conduction and Diffusion

Equations .................. 163

A. Description of the Crank-Nicolson Method . . . . 163

B. Numerical Solution of the Conduction Equation in

Iron ................... . 165

C. Numerical Solution of the Conduction and Diffusion

Equations in $\mathrm{ZrH}_{\mathrm{y}}$. . . . . . . . . . . 167

References . . . . . . . . . . . . . . . . . 171 


\section{MASS SPECTROMETRIC INVESTIGATION OF LASER-INDUCED \\ VAPORIZATION OF BINARY SOLID COMPOINNDS}

Robert Allan olstad

Incrganic Materials Research Division, Lawrence Berkeley Laboratory and Department of Nuclear Engineerirg, College of Engineering; University of California, Berkeley, California

\section{ABSTRACT}

The laser-induced vaporization of iron and of a binary solld compound, zirconium hydride, was studled using a quadrupole mass spectrometer. A Q-swltch ruby laser with pulse width of 80 nanoseconds was used to heat zircontum hydride samples under high vacuum to tenperatures up to $2500^{\circ} \mathrm{C}$. The mass spectrometer lonizer was located in a line-of-sight path $40 \mathrm{~cm}$ from the target. By an analysis of the measured mass spectroneter signals, the rate of vaporiation of hydrogen durlng the rapld temperature transient could be determined.

Application of an equilibrium model to the vaporization process predicts that predominantly $\mathrm{H}_{2}$ (rather than H-atoms) should be emitted. The vaporized $\mathrm{H}_{2}$ should have a Maxwellian veloctty distribution characteristic of the instantaneous surface temperature, and the rate of vaporization should be related to the $\mathrm{H}_{2}$ vapor pressure by the Langmuir equation. Since the $H_{\text {, }}$ vapor pressure is a function of both surface temperature and surface hydrogen concentration, it was necesaary to solve simultaneousiy the time-dependent heat conduction and hydrogen diffusion equations in the heated zirconfum hydride in order to predict the vaporization rates.

It was found that $\mathrm{H}$-atom and $\mathrm{H}_{2}$ molecules were emitted at thermal equilibrium with the surface. At low laser power density, the magnitude of the $\mathrm{H}_{2}$ signals agreed with the equilibrium model. At high laser 
power density, the magnitude of the $\mathrm{H}_{2}$ signals was less than predicted, possibly because of a diffusion barrier at the surface. The H-atom signals were much larger than predicted, indicating that they were produced by a non-equflibrium surface process.

Conventional mode laser pulses ( $1 \mathrm{msec}$ duration) were used to vaporize iron samples. The measured mass spectrometer signals were in agreement with equilibriun calculatiors if the flow of molten iron was taken into account. 


\section{HISTORY OF LASER SOLID INTERACTIONS}

\section{A. Introduction}

Since the development of the laser in the early $1960^{\prime} \mathrm{s}$, there has been much experimental and thecretical effor to understand the interaction of laser radiation with matter. The interaction of laaers with many elements and compounds, including metals, semiconductors, insulator, and gases, have all been investigated. In discussing lasers and laser-materlal interactions, there are sever 1 laser parameters useful in characterlzing the process:

1) Laser energy is the total energy contained in a laser pulse. Laser power is the instantaneous rate of energy emitted by the 1aser.

2) Energy density and power density are the laser energy and power per unit target area respectively. Whereas energy and power are characteristic of a particular laser, the enersy density and power density also depend on the spot size to which the laser is focused. Lasers can deliver high power densities to a target because the emitted radiation is coherent as well. as Intense. The coherence property causes the laser energy to be emitted in a slightly diverging beam which can be focused by a lens to a small spot.

3) Absorbed energy density and power density are the fraction of the incident energy density and power density, reepectively, thut are absorbed at the surface of reflectivity $R$, and are equal to (1-R) times the Incident values. 
Many materials can exhibit lasing action under suitable optical pumping, but only several are of use in high power laser interactions. The solid state lasers, ruby (0.6943 micron wavelength) and neodymiumglass ( 1.06 micron wavelength) can obtain peak powers of $10^{8}-10^{9}$ watts when operated in the Q-switch mode with pulse duration 10 - 100 nanoseconds. When operated in the conventional mode, the peak powers are $10^{4}$ to $10^{5}$ watts for pulses of $10^{-4}$ to $10^{-3} \mathrm{sec}$ duration. When mode-locked operation is used, pulses of picosecond duration are produced with peak power greater than $10^{12}$ wats.

The effects observed when laser radiation is absorbed at a meta.1 surface, in order of increasing power density, are: (a) increase in target temperature, melting, and vaportzation of neutral thermal-energy species, (b) emission of electrons and thermal ions, (c) emission of high energy lons and neutrals, and (d) formation of a highly ionized plasma in front of the target surface. The experimental results of studying these effects are reported by such quantities as total yield (number of atoms removed from the target), depth of craters produced, energy and spectes of the emitted particles, and apparent surface and plasma temperatures. Among the reasons for studying these effects are: (a) desire to understand the physical principles involved in the interaction, (b) determination of material behavior under rapid thermal transients and at higher temperatures than can be maintained at steady state, (c) practical applications such as laser cutting and welding, (d) eventual. possibłlity of obtaining piasma temperatures high enough for controlled thermonuclear fusion, and (e) possible use of lasers as weapons. 
The literature on the interaction of laser radiation with matter has been extensively reviewed in two recent publications. ${ }^{1,2}$ The literature data generally exhibit a large amount of scatter because experimental results are very sensitive to the particular experimental conditions. Comparisons of resuits obtained by different investigators are often difficult to make because of uncertainties in the laser energy and power densities used.

\section{B. Experfmenta1 Observat1ons}

\section{Melting and Vaporization}

The most apparent effect observed when a high power laser is focused onto a metal surface is the formation of a crater at the focal spot. The laser radiation absorbed at the metal surface can heat it to several thousand degrees Kelvin. A crater is formed because of vaporization and the removal of molten metal from the center of the interaction area by the preasure exerted by the recoiling molecules. The depth of the craters produced by conventional and Q-switch pulses on different metals was determined experimentally by Ready. ${ }^{3}$ The measured depths generally agreed with the depths calculated assuming that the surface temperature was given by the solution to the conduction equation with constant material properties. Ready's calculations 1,3 show that for a particular energy density a high power density heats a small amount of material to high temperatures while a low power density heats a large amount of material to lower temperatures. Therefore, conventional mode pulses can melt a substantial amount of a metal target and form deep craters while Q-switch pulses form shallow craters by 
vaporizing atoms from the surface at very high temperatures. Ready ${ }^{3}$ has proposed that at very high power densities, the pressure of the recoiling atoms is sufficlent to prevent significant vaporization until the critical temperature is reached. Calculations and yield measurements by Varsi ${ }^{4}$ using focused Q-switch pulses on metals indicate that vaporization occurs at temperatures below the critfcal temperature and that In fact the critical tamperature is seldom reached.

As discussed In Ref. 1, several studies have examined the morphology of the craters produced by lasers on metal and semiconductor surfaces. Typically, a crater produced by a conventional pulse has a raised rim because of the flow of liquid metal. Damage areas produced by Q-switch pulses show microcraters surrounding a central melt zone. An electron microsccpe observation of the damage area produced by low intensity laser radiation on germanium showed a structure of hillocks and etch pits. 5

\section{Electron Emission}

Historically, electron emission was the first aspect of particie production from laser heated surfaces to be studied. The electrons emitted by a target under vacuum typically are drawn to a nearby collector which is at a positive potential relative to the target. An early experiment ${ }^{6}$ using a conventional mode pulse on carbon and tungsten showed that the electron emission colnoided with the individual laser spikes. Calculations of the translent surface temperature showed that the electron currents could be attributed to thermionic emission according to the Richaxdson equation. In another study, it was shown that the emission of electrons from tungsten and platinum targets heated by Q-switch pulses was thermionic in origin. 
As discussed in Ref. 1, several invest1gators have measured the emisstion of electrons because of a multiphoton photoelectric effect. The energies of laser photons (1.78 eV for ruby, $1.17 \mathrm{eV}$ for Nd-glass) are lower than the typical work functions of metals and semiconductors (2-5 eV). If two or three laser photons are simultanenusly absorbed by an electron, it can have sufficlent energy to overcome the work function barrier and be emitted. This effect is small and can be observed only when the surface temperature is low enough to prevent masking the effect by thermionic emisolon.

\section{Positive Ion Enission}

The positive Ions produced in a laser-surface interaction are most easily detected by the method of charge collection. In this method, the ions produced are dram to a nearby collector which is at a negative potentlal relative to the target. The current pulse measured across a load resistance contains information on the total ion current produced as well as the time of flight of the lons from target to collector. If the Ion mass is known, the energy of the lons can be determined from an analysis of the ion current pulse shape. 1,6

Mass spectrometry has of ten been used to detect the Ions and neutrals emitted in laser-surface interactions. As discussed in Ref. 9, the types of mass spectrometers used include magnetic, time of flight (TOF), and quadrupole mass spectrometers. In order to be detected, neutrals must first be lonized, usually by an electron berm. Magnet1c mass filters use a magnetic field to spatially separate lors of different mass. TOF mass spectrometers separate lons of different mass in time rather than space because of the different velocities given 
the lons by an accelerating potential. Special modifications of TOF spectrometers have been made to study laser surface Interactions. 10,11 Quadrupole mass spectrometers detect lons of a selected mass which have a stable orbit in a combined RF and DC field applied to a quadrupole structure. Ions are most of ten detected by an electron multiplier located after the mass filter, but fon sensitive plates have also been used.

Thermionic emission of lons from laser heated metals has been observed in several studies using charge collection techniques. 1,12 The measured Ion currents are consistent with the values expected for thermionic emission of lons according to the RIchardson-Smith equation. These thermionic ions were observable at sufficiently low laser power dersities that no cratering of the surface occurred $\left(\sim 1 \times 10^{5}\right.$ watts $/ \mathrm{cm}^{2}$ for conventional mode, $\sim 8 \times 10^{7}$ watts $/ \mathrm{cm}^{2}$ for Q-switch mode).

Several studies have used the charge collection technique to determine the energy of the lons emitted under high laser intensities. I inlor ${ }^{13}$ mecrured lons with energy as large as $1000 \mathrm{eV}$ emitted from various materfals irradiated by Q-switch pulses with power density $\sim 5 \times 10^{9}$ watts $/ \mathrm{cm}^{2}$. Using an electron mul.tiplier to detect the fons emitted from a magnesium target, Isenor $^{14}$ found that Ion energies increased with Increasing power density. Ion energles varled from $10-400 \mathrm{eV}$ for power densities $\sim 10^{9}$ watts $/ \mathrm{cm}^{2}$. At very high power densities $\left(\sim 10^{11}\right.$ watts $\left./ \mathrm{cm}^{2}\right) \mathrm{Gregg}^{15}$ measured lons with energy as high as $2000 \mathrm{eV}$ emitted from various materials. 
A TOF spectrometer was used to study the masses and energies of ions desorbed from a tunsten surface. ${ }^{16}$ Even though relatively low Q-switch fower densities were used $\left(2-8 \times 10^{7}\right.$ watts $\left./ \mathrm{cm}^{2}\right)$, some Ions with energy greater than $170 \mathrm{eV}$ were detected. The ions observed were primar1ly $\mathrm{Na}^{+}$and $\mathrm{K}^{+}$, but $\mathrm{C}^{+}, \mathrm{H}_{2} \mathrm{O}^{+}, \mathrm{CO}^{+}, \mathrm{CO}_{2}^{+}$and $\mathrm{W}^{+}$were also detected. It was estimated that the cotal number of particles, including neutrals, was orders of magnitude greater than the number of lons enitted.

\section{Neutral Molecule Emission}

A quadrupole mass spectrometer was used to determine the species of neutral molecules desorbed from a tungsten surface. ${ }^{17}$ A Q-switch laser pulse delivering $2 \times 10^{7}$ watts $/ \mathrm{cm}^{2}$ was used. The species detected were $\mathrm{CO}, \mathrm{CO}_{2}, \mathrm{H}_{2}, \mathrm{H}_{2} \mathrm{O}$ and hydrocarbons. Calculations showed that the desorption was a thermal process in that the observed desorption rates were consistent with calculated surface temperatures.

In another study, a quadrupole spectrometer was used to observe high energy neutrals produced by a Q-switch laser on $W, N 1, T I, C$ and $\mathrm{Na}$ targets. ${ }^{18}$ Power densities were from $5 \times 10^{7}$ to $10^{8}$ watts $/ \mathrm{cm}^{2}$. The spectrometer was tuned opaque and the Ionization chamber was turned off so that no lons or low energy molecules were detected. High energy neutrals were detected directly by the electron multiplier, which was in a line-of-sight path with the target. The energies of the neutral molecules were determined to be up to $100 \mathrm{eV}$. The species of molecules detected depended on which target material was used, but $H_{2}, \mathrm{CO}$, and $\mathrm{CO}_{2}$ were most commonly observed. 
In an early study, a magnetic mass spectrometer was used to measure the composition of the neutral molecules emitted from laser heated grapht土e. 19 A conventional mode laser was used to obtain carbon vapor temperatures of approximately $4000^{\circ} \mathrm{K}$. The results showed that carbon molecules from $C_{1}$ to $C_{1,1}$ were emftted with an odd-even variation in intensities as a function of the number of atoms per molecule.

In a recent study, ${ }^{20}$ a TOF spectrometer was used to detect the molecules emitted from graphite heated by a Q-switch laser. Temperatures were estimatef to be at the carbon triple point $\left(4100\right.$ to $\left.4600^{\circ} \mathrm{K}\right)$. The intensities of the $C_{2}$ to $C_{5}$ peaks relative to the $C_{1}$ peak were approximately $30 \%$ of the intensities expected for an equilibrium process. This indicates that the formation of the complex molecules was 1 imfted by the kinetics of association and subsequent vaporization of the molecules.

The vaporization of selenium by a conventional mode laser was investigated with a TOF spectrometer. 21 The most predominant ionic spec's produced was $\mathrm{Se}_{5}^{+}$, but all molecular lons from $\mathrm{Se}_{2}^{+}$to $\mathrm{Se}_{9}^{+}$were detected. Excited neutral species $f \operatorname{rom~} \mathrm{Se}_{2}^{*}$ to $\mathrm{Se}_{8}^{*}$ were detected.

\section{Plasma Production}

At laser power densities greater than about $10^{9}$ watts $/ \mathrm{cm}^{2}$, the blowoff materlal in front of the target surface 1s highly lonized and can be considered a plasma. The nature of the plasma has been examined experimentally using photography, interferometry, spectroscopy, mass spectrometry and charge collection. Photographic measurements of the ionized plume have shown that the velocity of the plasma luminous front Increases rapidly aftei the material has been emitted from the 
target, Indicating that laser energy ts absorbed by the bilowoff material Itself. Results of plamn studies show that plasma temperatures up to hundreds of electron volts can be obtalned for laser power densfty up to $10^{13}$ watts $/ \mathrm{cm}^{3}{ }^{1}$

In one study, ${ }^{22}$ 11thlum hydride particles were heated by a Q-switch laser with power density $3 \times 10^{11}$ watts $/ \mathrm{cm}^{2}$. The measured and calculated plasma temperatures were on the order of $100 \mathrm{eV}$. After the plasma is heated the thermal energy is converted to a directed motion of expansion which gives Ion kinetic energles up to $1300 \mathrm{eV}$.

\section{Qualitative Mode1 of Laser Interaction at High Power Denelties}

Laser radiation incldent on a metal surface is partiaily reflected and partially absorbed by electrons beneath the surface. When an electron absorbs the photon energy, 1t is ralsed to a higher energy level In the conduction band. The electron collides with lattice phonons and other electrons, thereby converting the photon energy to thermal energy of the lattice. As the lattice heats up, thermionic electrons and ions are emitted as well as neutrals. As laser power density Increases, the degree of Ionfzation of the emitted vapor Increases. The electrons In the vapor can absorb laser photons by the Inverse Bremsstrahlung process. 1 In order for momentum to be conserved, the process must occur within the fleld of an ion. The plasma becomes heated by collisions between the energetic electrons and the ions. The plasma is heated by the laser photons to temperatures of the order of tens or hundreds of electron volts unt1l the plasma expands and becomes transparent. When highly Ionized, the dense plasma shields the surface from the laser so that most vaporization occurs early in 
a high power density pulse. As analyzed in Ref, 22, the plasma expansion is driven by pressure gradients within the plasma. After the plasma is heated, the total plasma energy goes into a directed energy of expanston way from the target. The kfnetic energies of lons of the expanded plasma are typically an order of magnitude larger than the thermal energy of the plasma. Th1s model therefore explains the large ion kinetic encrgies that have been measured in varlous experiments. 


\section{II . EXPERIMENTAL}

\section{A. Purpose}

The purpose of this research is to examine the behavior of a binary solid compound under the rapid transient heating by a pulsed laser. In contrast, most previous studies have examined the interaction of laser radiation with elemental solids, especlally metals. The binary compound zirconium hydride was chosen for several reasons: (a) the large partial pressure of hydrogen In equilibrium with zirconfum hydride at elevated temperatures should allow easy detection of the emitted particles; (b) the materlal properties of zirconium hydride have been studied extensively; and (c) the behavior of zirconim hydride under transient heating conditions is of interest because of its nuclear applications.

TRIGA research reactors and SNAP (Syatems for Nuclear Auxillary Power) reactors use a uranfum-zirconfum hydride alloy for the fuel and moderator. The urantum exists 28 a fine dispersion of metallic uranium in the zirconium hydride matrix, so the material properties of the mixture are approximately the same as those of pure zirconium hydride. The hydrogen atoms in the zircontum hydride are an effective moderator because of thelr low mass number and high concentration. The behavior of the urantum-zirconium hydride fuel under rapld transient heating is of interest for the safety analysis of the fuel under accident conditions.

In the present experiment, a quadrupole mass spectrometer is used to detect the molecules emitted from a zirconium hydride sample heated by a Q-switch laser. By analyzing the mass spectrometer signals, the following information was sought: (a) whether the hydrogen is emitted as $\mathrm{H}_{2}$ molecules, as expected from equilibrium considerations, or whether it is emitted as $H$ atoms; (b) whether the velocity distribution of the 
emitted particles is that expected for thermal equilibrium at the surface; (c) whether the amount of emitted particles is that expected for an equilibrium process; and (d) whether the temperature transfent at the surface is satisfactorily described by the solution to the transient heat conduction equation with a heat source equal to the absorbed laser power. Although the time scale o: the temperature trans: ant is on the order of $10^{-9}$ seconds, heat and mass transport in the solid will be analyzed by application of the usual conservation equations. The latter are usually applied to situations in which local thermodynamic equilibrium is approached. The justification for considering an equilibrium model of transport within the solid is that the time scale of the laser pulse $\left(10^{-9} \mathrm{sec}\right)$ is much larger than the electron collision and latice vibration times $\left(10^{-13} \mathrm{sec}\right)$. Since the photons are absorbed by the electrons of the material, the photori energy should be converted to heat instantaneously. Since heat is transported by lattice vibrations and electrons, the concept of thermal conductivity should be valid. However, the vaporization processes occurring at the surfice may not be well approximated by equilibrium considerations usually applied to steady state or slow transient situations. It is the surface vaporization phenomena rather than the solid heat and mass transport processes to which the present investigation is directed. However, because of the close coupling of surface and bulk processes during the transient initiated by a laser pulse, the surface phenomena can be evaluated only if the transport processes in the solid are assumed to be adequately described by conventional theory. 
The qualitative model proposes for the transient behavior of zirconium hydride is ae followe: (a) the laser radiation is absorbed at the surface and causes a temperature translent according to the time-dependent heat conduction equation; (b) $\mathrm{H}_{2}$ molecules (and perhaps $\mathrm{H}$ atoms) are emitted from the heated surface at a rate which depends on surface temperature and hydrogen content of the solld; and (c) the depletion of hydrogen near the surface because of the $\mathrm{H}_{2}$ flux is described by the time-dependent diffusion equation. The major question Is whether: step (b) is alequately described by a model based upon equilibrium thermodynamics and detalled balancing (1.e., Langmuir type vaporization, see Ref. 23)).

The behavior of zircontum hydrlde at moderate maximum surface temperatures (less than $\approx 2500^{\circ} \mathrm{K}$ ) was of interest in this study. The vaporization of the zirconfur lattice and production of an ionized plume $0:-$ vapor at high laser power densitles vere not of direct interest.

In addition to studying the behavior of zirconium hydride heated by a Q-switch laser, the laser-Induced vaporization of iron was also investigated. This was done because the vaporization of a monatomic substance is a much simpler phenomenon than the vaporization of a binary compound. When calculations and experiments on Iron are compared, the validity of certain aspects of the equilibrium model and axperfmental technique may be established.

\section{B. Experimental Apparatus}

\section{Introduction}

The experimencal apparatus shown In Figs. 1 and 2 consists of three main components: (a) the laser and equipment for measurement of laser power and energy, (b) vacuum system containing the target and the 


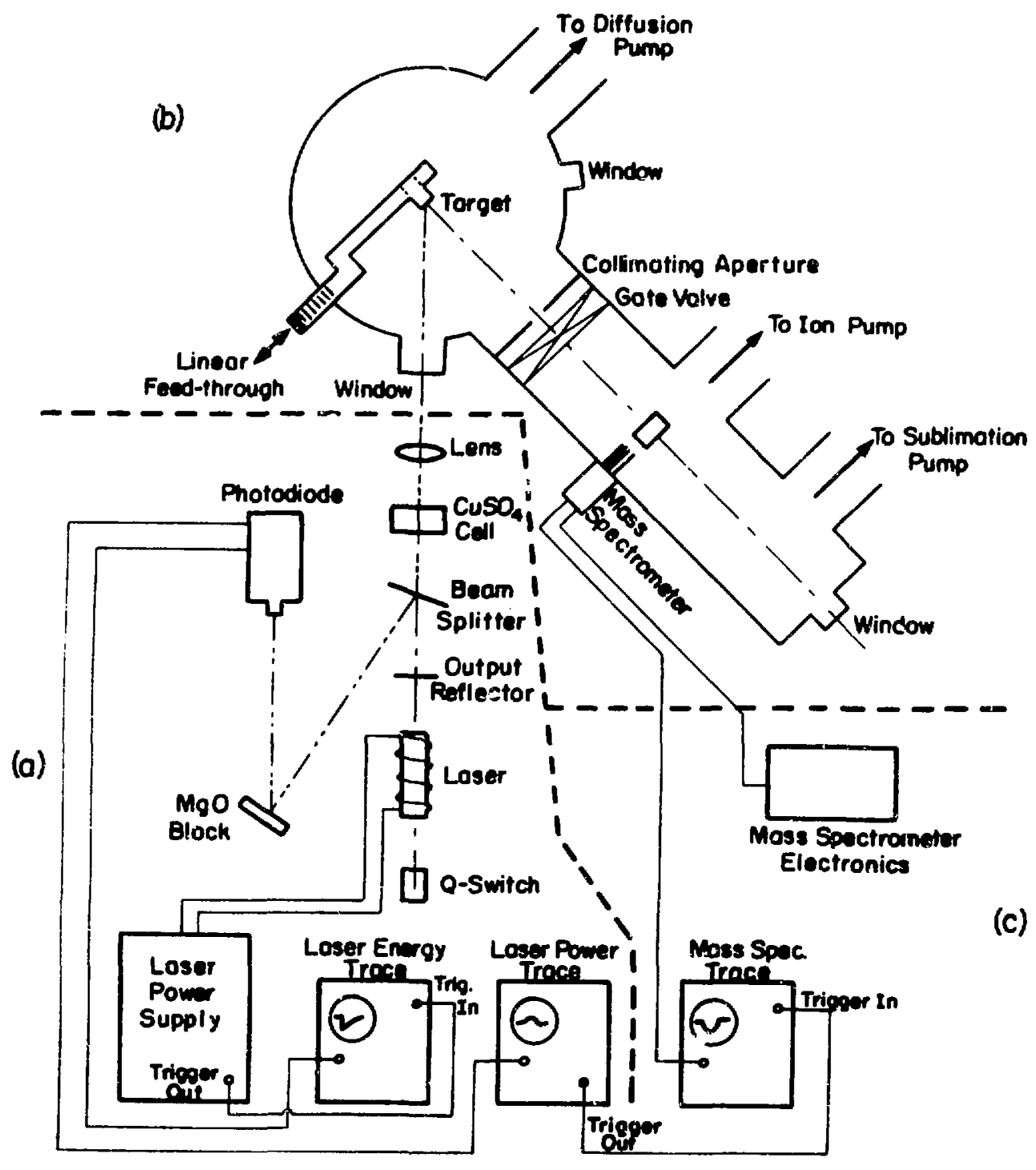

XBL 7211-7231

Fis. 1 Schematic oi experimental setup: The three regions separated by the dashed lines are (a) laser equipment for measuring laser power and energy: (b) vacuum syitimi containing the target and mass spectrometer: (c) the mass spectromecex signal processing equipment. 


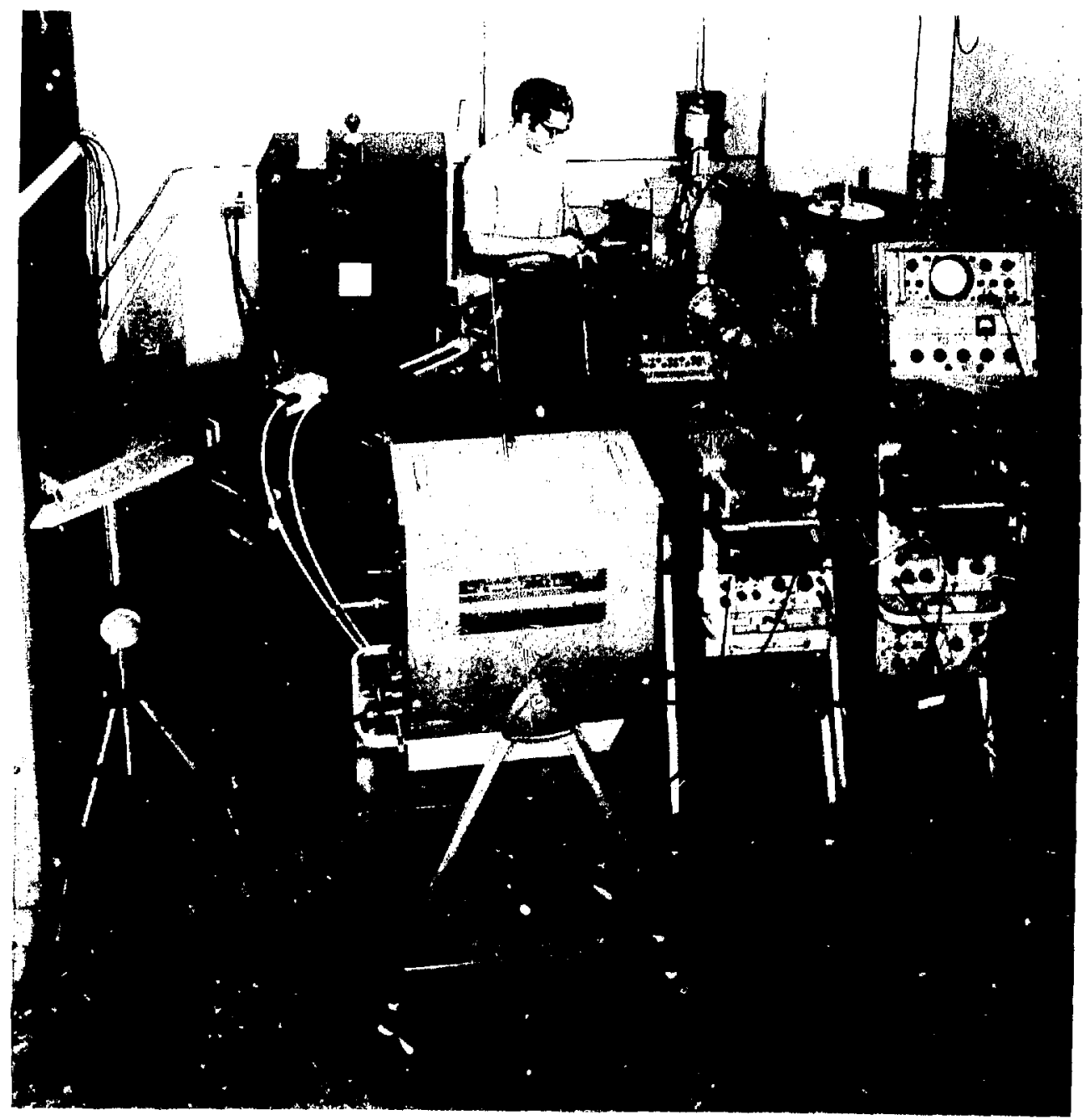

XBB 7210-5420

Fig. 2a Expeimental apparatus. From back to front: on left, laser power supply, laser and laser power scope; in center, target chamber, mass spectrometer chamber and laser energy scope; on right, mass spectrometer electrometer electronics and mass spectrometer scope. 


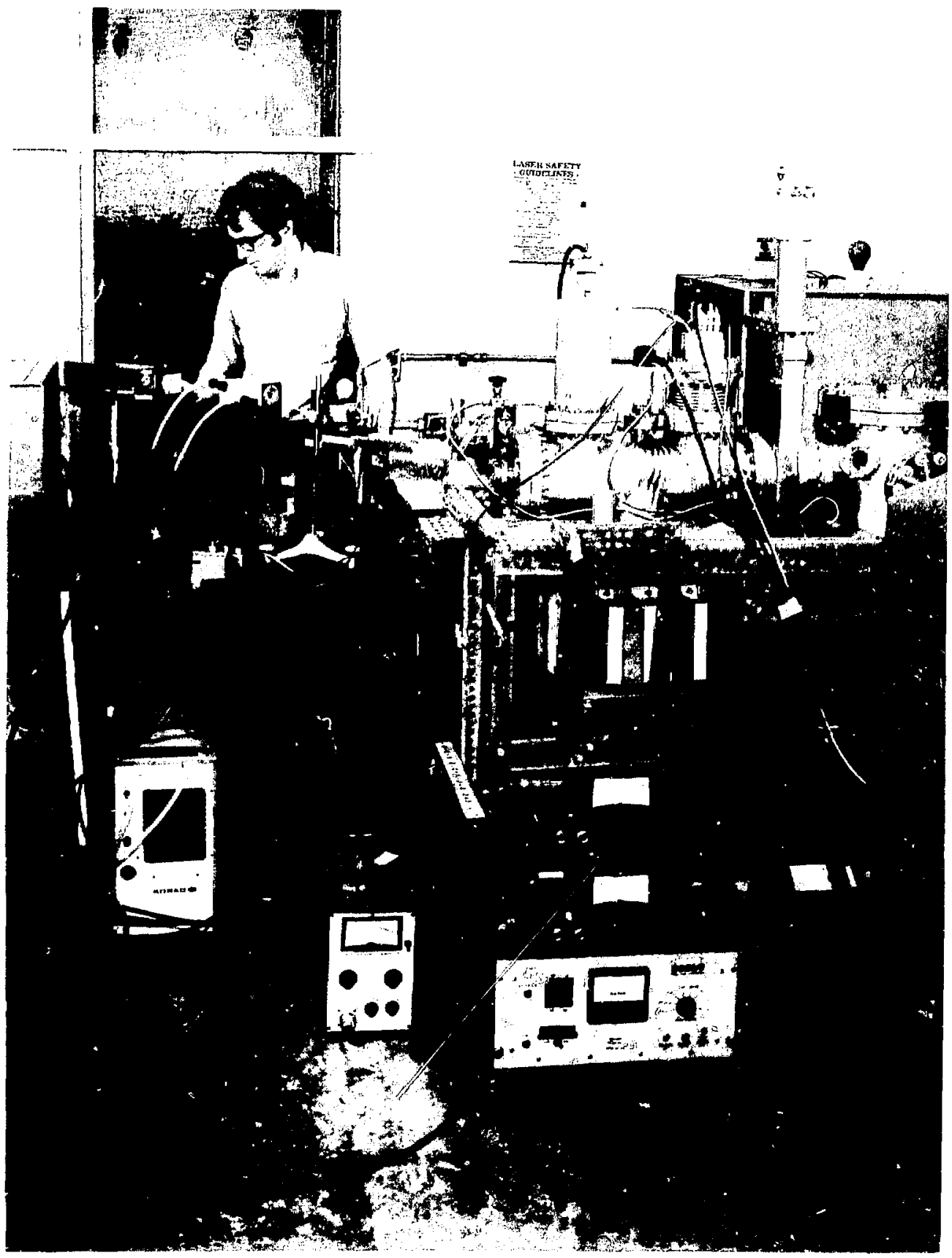

XBБ 7210-5420

Fig. 2b Experimental apparatus. From left to right are the laser, mass spectrometer chamber, and target chamber. Below the mass spectrometer chamber are the ion pump and ion gauge controllers. 
mass spectrometer, and (c) the signal processing equipment. The laser pulse is focused onto the solfd target under vacuum at an angle of $45^{\circ}$ from the normal. As a result of heating by the laser, the target enits moIecules or fons. A small Eraction of the emitted particles pass through the collimating aperture between the target and mass spectrometer chambers and pass through the mass spectrometer 1onizer. A small percentage of the molecules passing through the fonizer are lontzed by electron impact and those of a particular mass pa-sed througi the mass f1lter are detected by an electron multiplier. The current produced at the electron multiplier output is displayed on an oscilloscope. This measured signal contains information on the amount of a particular species enitted as well as the time of flight (hence velocity or energy) of the emitted spectes.

\section{Laser Apparatus}

The laser used is a Korad KQ-1 system. A 4 in. $\times 9 / 16$ in, ruby rod of standard doping $\left(0.5 \% \mathrm{Cr}^{3+}\right)$ is pumped by a helical xenon flashlamp. The laser can operate in either the conventional or Q-switch mode. In the conventional mode the rear reflector is $100 \%$ reflecting at the laser wavelength $6943 \AA$, and the output reflector used is a $13 \%$ transmitting sapphire etalon. The output is a series of vertically polarized spikes with a total duration of about 1.0 msec and total energy of up to 10 foules. In the Q-switch mode, lasing is suppressed by a passive cell at the rear reflector until the light intensity is sufficient to bleach the cryptocyanine dye in the cell. When the dye is bleached, the rear reflector becomes $100 \%$ reflecting, allowing stimulated emission of the highly inverted 
population of the $\mathrm{Cr}^{3+}$ energy levels. In this case the laser output is a single "giant pulse" lasting abous 50 nanoseconds and containing energy of about 1 joule.

The optical elements following the laser output reflector are a beam splitter, a cell containing a solution of $\mathrm{CuSO}_{4}$ in water, a focusing lens, and a pyrex window in the vacuum chamber.

The transmissivity of the $\mathrm{CuSO}_{4} \operatorname{cell}$ is calibrated as a function of $\mathrm{CuSO}_{4}$ concentration. Therefore the lager energy incident on the target can be varied by varying the $\mathrm{CuSO}_{4}$ concentration. The focusing lens serves three purposes: a) it determines the spot size at the focal plane and hence determines the energy density at the target, b) It produces the far-field pattern at the focal plane which has a simpler spatial characterization than the near field pattern, and c) it permits easy alignment of the laser on the target by vertical or horizontal adjustment of the lens position.

A glass laboratory slide is used for a beam splitter, which reflects several per cent of the incident laser radiation to an MgO diffuser. Since the MgO block is a diffuse reflector, on Iy a small amount of the laser radiation incident on it is detected by the Korad KD1 photodiode. For each laser pulse, the Rorad photodiode produces a signal proportional to the laser power and a signal proportional to the laser energy (that is, the time integral of the power signal). The power signal is fed Into a Textronics Type 519 ssope which has a risetime of less than 1 nanosecond. Since a 519 scope does not have any gain control, the distance between the photodiode and the $\mathrm{MgO}$ block must be adjusted so the power signal gives almost full scale 
deflection on the scope. The power trace ls triggered internally by use of an internal delay line. The energy signal is measured on a Textronics Type 585A dual trace scope which is triggered by a pulse at the time the flashlamp is fired. There is a delay of approxinately 0.5 m1111second between the time the flashlamp is fired and the onset of lasing. When the laser is operated in the conventional mode, the power algnal on the 519 scope 18 too small to messure, but the power can be determined by differentiating the total energy glgnal.

The energy contained in a laser pulse is determined by using a factory-calibrated Korad KJ-2 calorimater. The calorimeter is aligned to detect the full unfocused laser beam (a focused laser beam can damage the window of the calorimeter absorbing cell). The calorimeter output is fed into a Kelthey Model 150A microvoltmeter, which 1s connected to a strip chart recorder. The laser is fired into the calorineter, the photor dlode energy trace is photographed, and the calorimeter sigeal is measured. Knowing the calorimeter callbration factor (1.e., microvolts output per joule Input), the energy trace can be calibrated. The transmissivity of the $\mathrm{CuSO}_{4}$ cell as a function of concentration is determined in a simllar manner by measuring the transmitted energy with the calorimeter placed behind the cell.

The laser is aligned on the target by use of a He-ke continuous gas leser. The gas laser is aligned so that it is coaxial with the ruby laser. Thts is done by firing the ruby laser at a polaroid print placed In front of the vacuum chamber window. The gas laser is aligned so that 1t passes through the center of the ruby and hits the center of the damage area on the print. 
A partially successful attempt was made to measure the laser energy reflected from the target. A Unfted Detector Technology PIN8/LCA silicon photodiode with a $1 \mathrm{~cm}^{2}$ active area was mounted in the vacuum chamber to detect the specularly reflected laser beam. In order to reduce the laser intensity oufficiently for detection, a sealed cell of concentrated $\mathrm{CuSO}_{4}$ solution and a red and green glass f 11 ter were placed in front of the dlode. The glass filters blocked out the white light from the flashlamp during the photodiode calibration with the direct laser beam. The photodiode was in a circult similar to that of the Korad photodiode. The energy detected by the photodiode is proportional to the voltage drop across a capacitor partially discharged during the laser pulse. This voltage drop is measured simultaneously with the Korad energy trace on the dual trace 585A scope. See Section D for a discussion of these results.

\section{Vacuum System}

The Target is mounted on a linear feed-through, so that the target could be displaced slightly after each shot, thereby providing fresh areas of the target for successive laser pulses. The target chamber 18 pumped to $10^{-7}$ torr by a 500 11ter/sec, 6-inch oil diffusion pump with liquid nitrogen cooled baffle. A $1 / 8$ in. diameter collimating aperture is located between the target and mass spectrometer chambers at a distance of $8 \mathrm{in.} \mathrm{from} \mathrm{the} \mathrm{target.}$

The mass spectrometer chamber is pumped by a 20011 ter/sec ion pump and a titanium sublimation pump. A gate valve is located between the two chambers so that the mass spectroneter is kept under high vacuum when changing the target. With the gate valve closed, the pressure can be maintained in the $10^{-10}$ torr range. During experimental runs 
with the gate valve open, the pressure in the mass spectrometer chamber is about $8 \times 10^{-9}$ torr.

The mass spectrometer Lonizer is located 8 in. from the collimating aperture. A beam flag mounted on a lineer feed-through can be positioned between the orffice and the fonizer in order to block the molecules emitted by the target. The aligment of the laser spot on the target, collimator, and lonizer is made by sighting through a window in the mass spectrometer chamber down the molecular beam axis.

\section{Mass Spectrometer}

The detector used is an EAI Quad 250 quadrupole mass spertrometer with its lonizer modified to permit a molecular beam to pass through unobstructed. Some of the molecules passing through the Ionizer are ionized by electrons emitted from a heated tungsten filament. Some of these iontzed molecules are drawn into the quadrupole region by the fringe field reaching into the lonizer from an electrostatic focusing lens at a potential of 115 volts relative to the lonizer (see Fig. 13). For detecting lons enltted from the target, the lonizing electrons are removed by not heating the tungsten filament. The lons are deflected by $90^{\circ}$ to enter the quadrupole structure by the fringe field of the 115 volt potential. Only Lons with Initlal energy greater than $15 \mathrm{eV}$ can be detected because the fonizer is at a potential of 15 volts relative to the target and ground. The quadrupole structure has an applied RF and DC field which determines whether an Ion of a particular charge-to-mass ratio has a stable orbit down the structure or not. If the voltages are such that the Ion has a stable orbit, the Ion is detected by an electron multiplier mounted at the end of the analyzer. 
The current produced at the electron miltiplier output is measured on a Textronics Type 532 oscilloscope, and the trace is photographed. For the laser in the Q-switch mode, the scope is triggered by the gate pulse from the 519 scope at the beginning of the glant pulse. For the laser in the conventional mode, It was found more rellable to trigger the mass spectrometer trace by the trigger pulse produced at the time the flashlamp is fired.

The time dependence of the mass spectrometer signal measured when the target is bombarded by a glant pulse contains direct information on the energy of the detected molecule or 1on. This is because the duration of the laser pulse is much shorter than the time of flight of the lons or molecules from the target to the 1onizer. Hovever, the magnitude of the ineasured signal shuild be much less than the signal from steady state vaporization because the molecular velocity distribution causes the signal to spread out in time.

In the conventional mode, the time of flight and the spread in tIme due to the velocity ilstribution are on the same order as the duration of the laser pulse. Therefore, In this case, the mass spectrometer signal is primarily a measure of the. amount rather than the energy of the vaporized materlal. 


\section{Laver Parameter Measurement}

\section{Energy Incident on the Target}

The energy incident on the target is given by:

$$
e_{\text {tnc }}=e_{0} \tau_{\mathrm{CuSO}_{4}} \tau_{\text {lens }} \tau_{\text {window }}
$$

where

$$
\begin{aligned}
e_{0} & =\text { laser energy determined by the energy calibration } \\
& =V_{\text {K.E. }} \times\left(\frac{\mu V}{V_{\text {K.E. }}}\right) /\left(\frac{\mu V}{\text { joule }}\right)
\end{aligned}
$$

$\left(\frac{\mu V}{j o u l e}\right)=$ Korad-supplied caloriaterer calibration factoi

$\left(\frac{\mu V}{V_{K . E .}}\right)=$ experimentally determined ratio of calorimeter signal to the voltage of the Korad energy trace.

$$
\tau_{\mathrm{CuSO}_{4}}=\text { experimentally determined transmissivity of the } \mathrm{CuSO}_{4} \text { cell }
$$

$\tau_{\text {lens }} \tau_{\text {window }}=$ transmiesivity of the lens and vacuun chembex window

The transmissivity of the $\mathrm{CuSO}_{4}$ cell as a function of eaturated $\mathrm{CuSO}_{4}$ concentration is shown in Fig. 3. As expected, the transmissivity decreases exponentially with concentration.

The reflectivity of a plane electromagnetic wave normal to a dielectric with index of refraction $n$ is given by 24

$$
\frac{I_{\text {reflect }}}{I_{\text {Incident }}}-\left(\frac{n-1}{n+1}\right)^{2}
$$

Assuming the Index of refraction for the lens and window is 1.5 and considering that the laser is reflected at each of the four surfaces gives

$$
\tau_{\text {lens }} \tau_{\text {window }}=\left[1-\left(\frac{1.5-1}{1.5+1}\right)^{2}\right]^{4}=0.85
$$




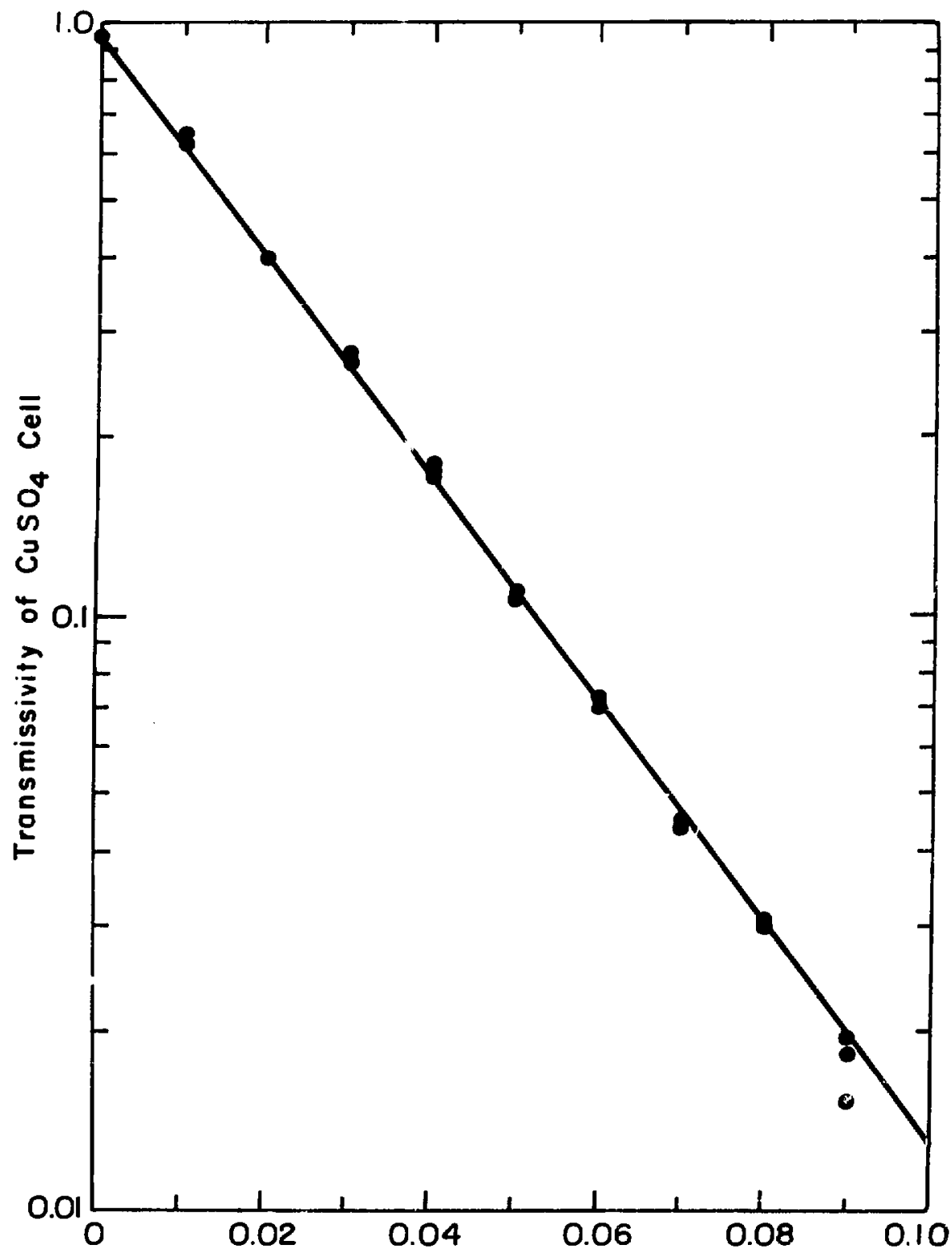

$\mathrm{CuSO}_{4}$ Concentration (cc saturated $\mathrm{CuSO}_{4}$ solution/total c c)

XBL.7211-7249

Fig. 3 Calibration curve of the transmissivity of the $\mathrm{CuSO}_{4}$ cell. 


\section{Laser Power}

The shape in time of the glant pulse power trace measured on the 519 scope varies somewhat from shot to shot. For the laser cavity configuration used, the shape is approximataly triangular with the peak at approximately 40 nanoseconds and the end of the pulse at 80 nanoseconds. The time corresponding to the peak and the width of individual pulees may vary from this by \pm 15 nanoseconds. The shape 1 s very sensitive to the alignment of the laser reflectore relative to the riby. A characteristic giant pulse power trace is shown in Fig. 4.

The power of a conventional mode pulse is actually a series of spikes, as shown in Fig. 5. By measuring the Individual spikes of a conventional mode pulse it is found that each spike has a duration of from 0.3 to 1 microsecond with 0.5 usec being representative. The time spacing between spikes is approximately $1.5 \pm 1 \mu \mathrm{sec}$. The average power as a function of time can be found by differentiating the Korad energy trace with respect to time. As shown in Fig. 6, the shape of the average power curve for a conventional mode pulse is approximately triangular, with the peak at time $\tau_{1}=0.15 \mathrm{msec}$ and the end of the pulse at time $\tau_{2}=1.0 \mathrm{msed}$.

\section{Spot Size and Incident and Absorbed Energy Density}

An unfocused laser beam has a very nonuniform spatial energy density. This is because some regions of the ruby lase more efficiently than others and the optical pumping is not perfectly uniform. The particularly active regions are called filaments or hot spots and have a diameter much less than the ruby diameter:. In addition, lasing can occur in off-axis modes. 


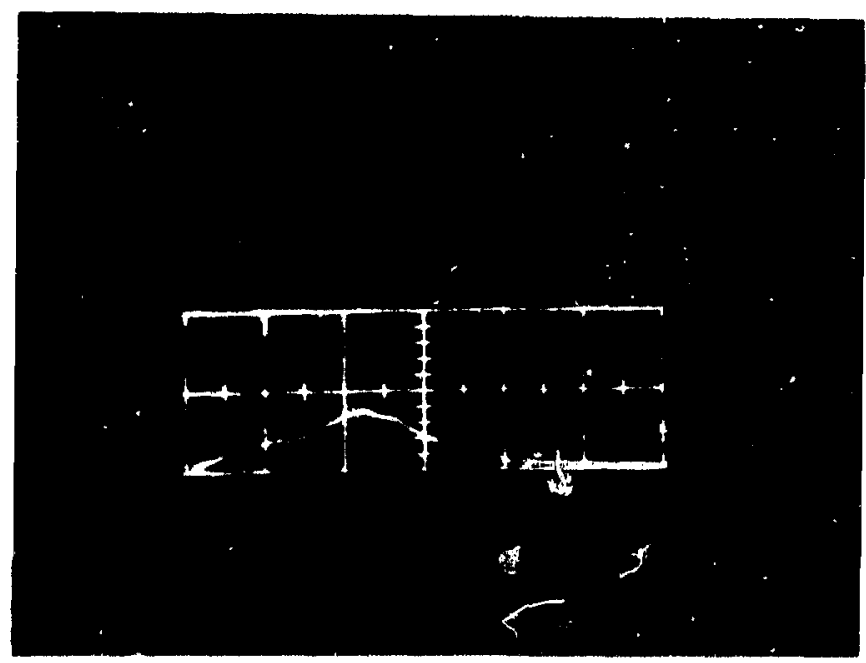

Flg. 4 Typical t-swjeh laser power signal. Horizontal scale is 20 nsec ter tivision.

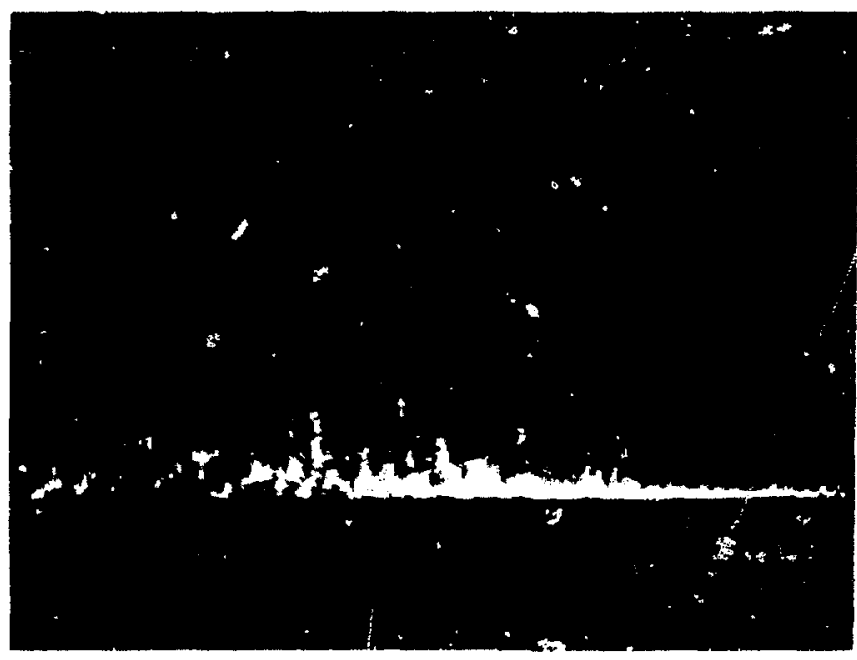

XBB 7210-5371

Fig. 5 Typical convenional mode laser power output. Horizontal scale is $0.1 \mathrm{msec}$ per division. 


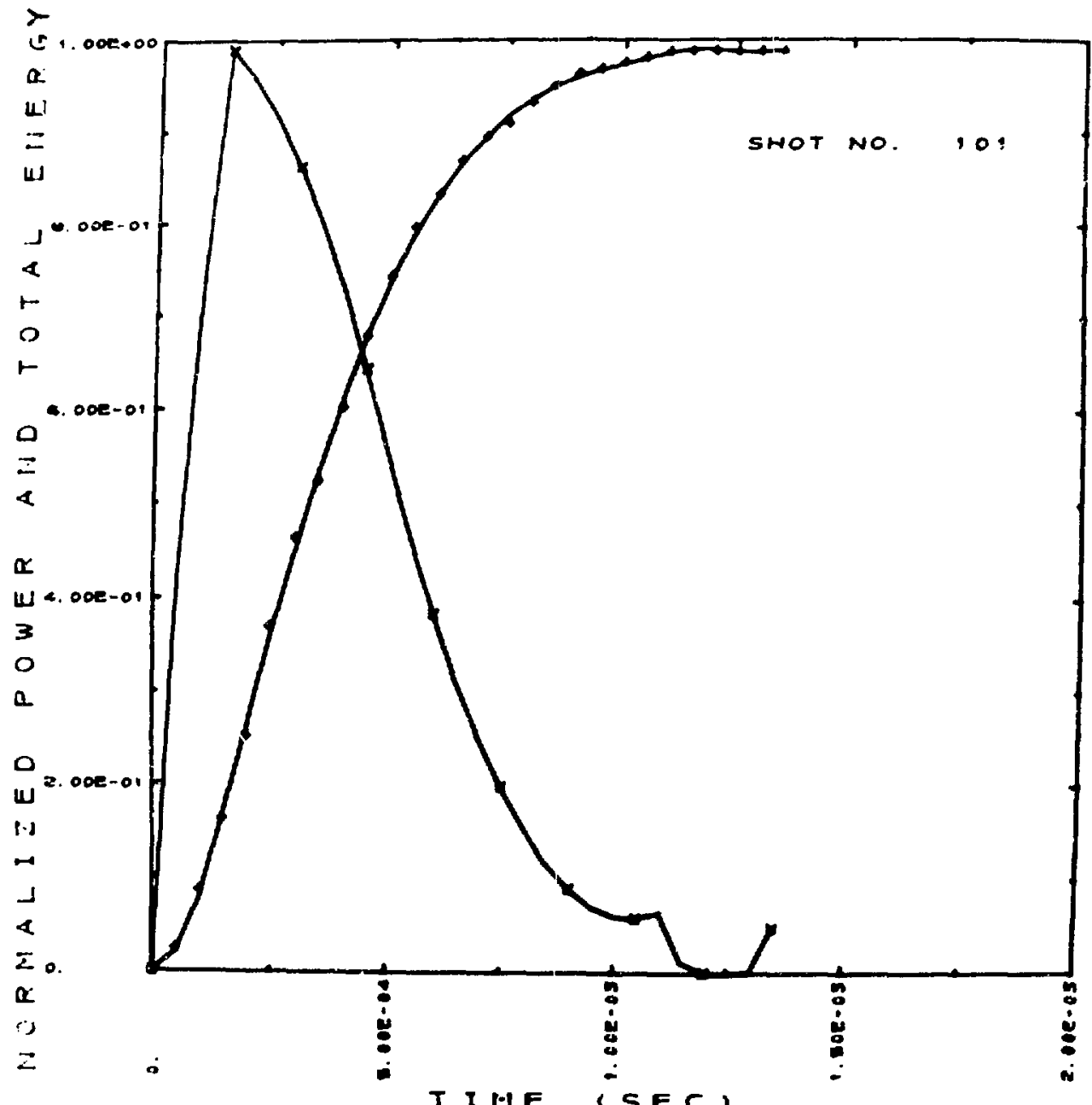

$X B L$ 7210-5781

FIg. 6 Typical conventional mode total energy signal and Its tine derivative. $+=$ energy signal, $x=$ derivative of the energy signal, which is proportional to laser power. 
If it is assumed that the primary mode is the TEM mode, the intensity variation in the bean as function of angle $\theta$ frow the axis has a Gausbian shape: 25

$$
E_{\text {Inc }}(\theta)=\frac{e_{\text {inc }}}{\pi \delta^{2}} \exp \left(-\theta^{2} / \delta^{2}\right)
$$

where $E_{\text {inc }}(\theta)=$ incident energy/solid angle at angle $\theta$

$$
\begin{aligned}
& \text { e Inc }=\text { total incident energy } \\
& \delta \text { - mean angular radius of the Gaussian beam }
\end{aligned}
$$

By using geometrical optics, it can be shown that a ray at angle $\theta$ to the axis Incident on a elople lens of focal length $f$ is a distance fo from the axis at the focal plane. In other words, a cone of idght with half-angle $\theta$ is focused by a lens to a spot oize of radius $f \theta$ at the focal plane. Therefore, the incident energy density of a Gusatan beam at the focal plane is found using Eq. (2.4):

$$
E_{\text {inc }}(r) d \Lambda=E_{\text {inc }}(\theta) d \Omega
$$

where $d A=r d r d \phi=r f d \theta d \phi$

$$
d \Omega=\sin \theta \operatorname{d\theta d} \phi \geq \theta d \theta d \phi=\frac{r}{f} \operatorname{d\theta d} \phi
$$

So, the incident energy density as a function of radius at the focal plane 18:

$$
E_{\text {Inc }}(r)=\frac{e_{\text {Inc }}}{\pi(\sigma)^{2}} \exp \left(\frac{-r^{2}}{\sigma^{2}}\right)
$$

where $\sigma=\delta f$

Korad Corporation made aeasuresents of the laser angular divergence on the ruby used in the pzesent experinent. Based on cheir data, a value for $\delta$ was calculated to be 2.56 mllifradians. Therefore, the radius o at which the power density is l/e times the peak power density is 


$$
\begin{aligned}
& \sigma=0.0512 \mathrm{~cm} \text { for } f=20 \mathrm{~cm} \\
& \sigma=0.256 \mathrm{~cm} \text { for } f=100 \mathrm{~cm}
\end{aligned}
$$

Equation (2.5b) is act:ally only an approxination to the actual case. The bean divergence 1s larger if modes other than TEM are present, as happens if there 10 slight misaligment of the laser reflectora. Also, diffraction effecte of the lens limit the ultimate apot size to the order of a wavelength. Experimentally observed damage areas agree wth the general behavior of $\mathrm{Eq} .(2.5 \mathrm{~b})$ since damage 1 oore pronounced in the center then at the edges. However, two observations show that the form of Eq. (2.5) is only approxinate: a) for the glant pulse power a: the threshold for viable dange to the zirconium hydride target, a diffraction pattern is viatble (Fig. 7), and b) a conventional pulse on an etched iron sample showe damage areas due to individual off-axis spikes $\left(F \perp_{B} \cdot 8\right)$.

Finally, aince the laser is Incident on the target at an angle of $45^{\circ}$. the energy density et the target is reduced by $\cos 45^{\circ}$ and has an elliptlcal shape. The actual incldent energy density at the target is then:

$$
E_{\text {Inc }}\left(r^{\prime}, \phi^{\prime}\right)=\frac{\cos 45^{\circ} e_{\text {Inc }}}{\pi \sigma^{2}} \exp \left(\frac{r^{2}\left(1-\sin ^{2} \cdot 45^{\circ} \cos ^{2} \phi^{\prime}\right)}{\sigma^{2}}\right)
$$

where $r^{\prime}=$ radial position on the target

$\phi^{\prime}$ - aztnuthal angle at the target measured from hortzontal

To conate the calculated results with the experimental results, It Is necessary to relate the absorbed energy density $E_{\text {ubg }}\left(I^{\prime}, \phi^{\prime}\right)$ to the Incident energy deneity $E_{\text {Inc }}\left(r^{\prime}, \phi^{\prime}\right)$. Assuming the surface of the target has a constant reflectivity $R$, 


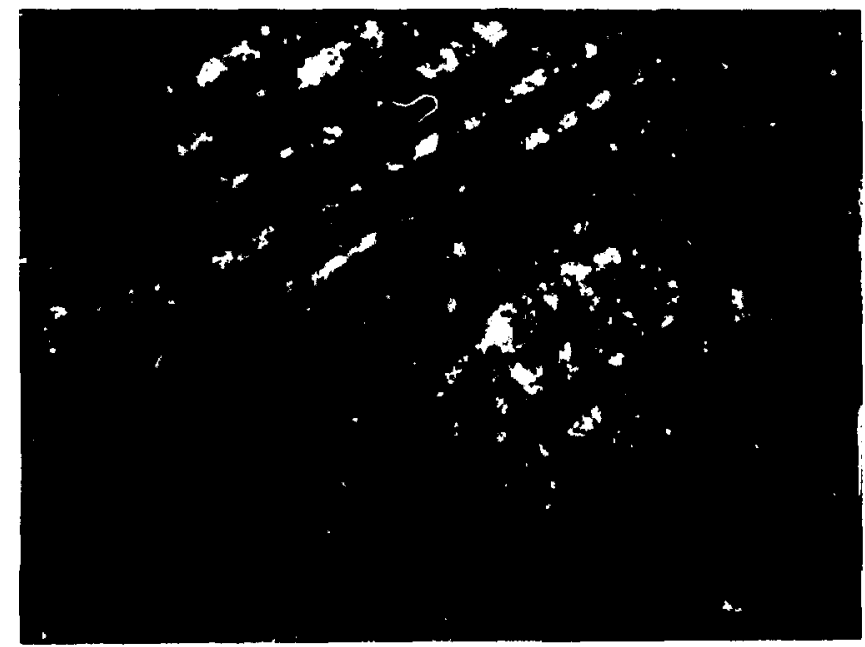

Fig. 7 Diffraction pattern produced by Q-switch laser on zirconium hydride. Dark bands are the damaged area. Incident energy density $=0.27 \mathrm{cal} / \mathrm{cm}^{2}$. (50x magnification)

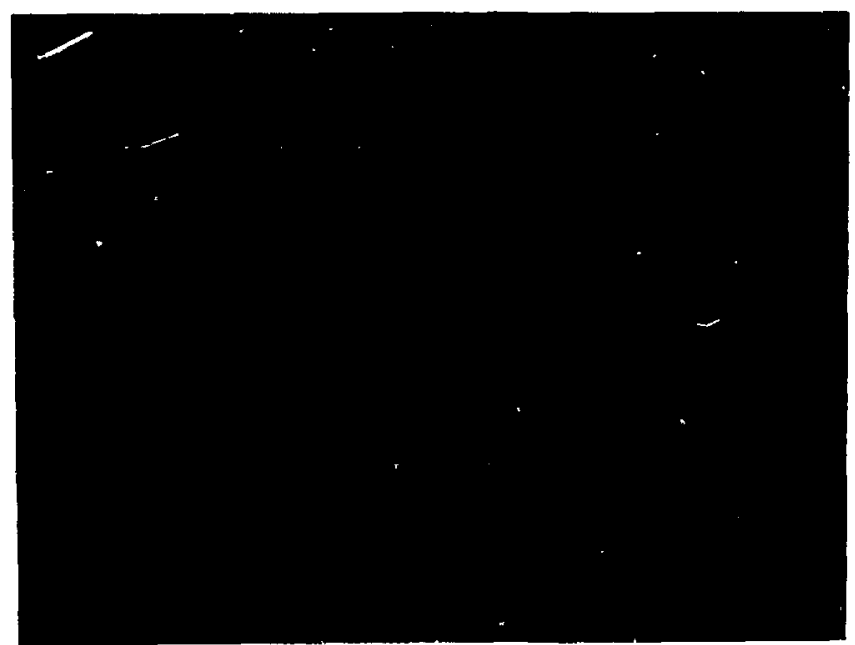

XB.B $7210-5372$

Fig. 8 Conventional mode laser damage to etched iron surface. Spots are damaged areas due to individual spikes around the periphery of the central damage zone. Incidert energy density at center of damaged zone $=77 \mathrm{cal} / \mathrm{cm}^{2} . \quad(200 \times$ magnification $)$ 


$$
E_{a b s}\left(r^{\prime}, \phi^{\prime}\right)-(1-R) E_{\text {Inc }}\left(r^{\prime}, \phi^{\prime}\right)
$$

As shown In Section $G$ and $H$, the energy density over the face of the zirconium hydride samples is approximately constant, but the energy density over the interaction area of the Iron samples is a function of $\mathbf{r}^{\prime}$ and $\phi^{\prime}$ according to $\mathrm{Eq} .(2.7)$. Since the numerical calculations are made assuming a unfform energy density at the surfare, an effective laser spot size on the Iron samples is defined as follows: Consider a differential area of the target at positiori ' ', $\phi^{\prime}$. The total energy absorbed by this surface region during the laser pulse is $E_{\text {abs }}\left(r^{\prime}, \phi^{\prime}\right) \mathrm{dA}$. The vaporization rate from dA due to this energy input depends on the temporal shape of the laser pulse, the thermal properties of the solid, and the vapor pressure of the solid. Given these quantities, the transient vaporfzation rate for the differentlal area dh can be conputed. In general, the rate of vaporization at first increases, passes through a maximum, and then decreases. The maximum vaporization rate depends upon the energy density at the location of region $\mathrm{dA}_{\mathrm{n}}$ and may be denoted by $\Phi_{\max }\left[E_{a b s}\left(r^{\prime}, \phi^{\prime}\right)\right]$ dA. The maximum vaporization rate due to the entire target area 18 the integral of this expression over all $r^{\prime}$ and $\phi^{\prime}$. Define an effective target area $A_{\text {eff }}$ as that area of the target which would give the same maximus vaporization rate as that of the entire target if the centerline absorbad energy density were conotant over $A_{\text {eff }}$. Thus, the effective target areat is defined by:

$$
\Phi_{\max }\left[E_{a b s}\left(r^{\prime}=0\right)\right] A_{e f f}=\int_{0}^{\infty} \int_{0}^{2 \pi} \Phi_{\max }\left[E_{a b s}^{\prime}\left(r^{\prime}, \phi^{\prime}\right\rangle\right] r^{\prime} d r^{\prime} d \phi^{\prime}
$$


Change the variables $r^{\prime}$ and $\phi^{\prime}$ to the radial position $r$ in the focal plane, where $r=r^{\prime}\left(1-\sin ^{2} 45^{\circ} \cos ^{2} \phi^{\prime}\right)^{1 / 2}$. Since $E_{a b s}\left(r^{\prime}, \phi^{\prime}\right)=$ $E_{a b s}(r)=E_{a b s}(0) \exp \left(-r^{2} / \sigma^{2}\right)$, the right-hand side of $\mathrm{Eq}$. (2.9) becomes

$$
\int_{0}^{\infty} \int_{0}^{2 \pi} \Phi_{\max }\left(E_{a b s}(r)\right) r^{\prime} d r^{\prime} d \phi^{\prime}-\int_{0}^{\infty} \int_{0}^{2 \pi} \Phi_{\max }\left(E_{a b s}(r)\right) \frac{r d r d \phi^{\prime}}{\left(1-\sin ^{2} 45^{\circ} \cos ^{2} \phi^{\prime}\right)}
$$

The integral over $\phi^{\prime}$ equals $2 \pi / \cos 45^{\circ}$, so the effective target area is

$$
A_{\text {eff }}=\frac{2 \pi}{\cos 45^{\circ} \Phi_{\max }\left[E_{a b s}(0)\right]} \int_{r=0}^{\infty} \Phi_{\max }\left[E_{a b s}(0) \exp \left(-\frac{r^{2}}{\sigma^{2}}\right)\right] r d r
$$

where $\mathrm{E}_{\mathrm{abs}}(0)=$ absorbed energy density at the center of the target area

The above integral is calculated numerically using the results of the numerical calculations for $\Phi_{\max }$ as a function of absorbed energy density (see Section VI-A-1.). For the $20 \mathrm{~cm}$ focal length lens, $\sigma=0.0512 \mathrm{~cm}$, which gives calculated values of $A_{\text {eff }}$ from $0.4 \times 10^{-3} \mathrm{~cm}^{2}$ for $\mathrm{E}_{\mathrm{abs}}(0)=13 \mathrm{cal} / \mathrm{cm}^{2}$ to $5.0 \times 10^{-3} \mathrm{~cm}^{2}$ for $\mathrm{E}_{\mathrm{abs}}(0)-60 \mathrm{cal} / \mathrm{cm}^{2}$. This corresponds to effective spot diameters of $0.023 \mathrm{~cm}$ and $0.080 \mathrm{~cm}$, respectively.

\section{Surface Reflectivity Mesaurement}

\section{Iron Reflectivity}

The reflected energy diode was used to measure the average reflectivity of polished Iron during a conventfonal pulse. For energy densities of 20 to $100 \mathrm{cal} / \mathrm{cm}^{2}$, the measured reflectivity varied from 0.3 to 0.7 with a large amount of scatter. While these values are reasonable they are not conofdered reliable because 
a) At high energy denaities, values of reflectivity greater than unity were measured, Indicating either faclty calibration or possibly the detection of other radiations produced during the interaction.

b) When the surface nelta, the reflected laser radiation is not rellably intercepted by the $1 \mathrm{~cm}^{2}$ active area photodiode.

c) During calibration it was difficult to ascertain that all the incident laser energy was detected by the photodiode.

It was therefore considered more rellable to assume the Iron reflertivity was given by the literature value during the pulse.

\section{Zirconium Eydride Reflectivity}

The zirconium hydride samples were found not to scatter specularly but rather in a broad band in the opecular direction. Rather than attempt to measure the reflectivity during a leser pulse, a room temparature value was measured. A He-Ne continuous gas laser bean was attenuated and directed at a zirconium hydride ample. A photomultiplier tube was used to measure the reflected band as well as the incident intensity. The reflectivity was determined to be $0.45 \pm 0.05$ at the He-Ne laser wavelength 6328A. Assuming that the zirconium hydride reflectivity is a slowly varying function of wavelength, the measured reflectivity is approximately that at the ruby laser wavelength 69431 . 


\section{E. Mass Spectrometer Calibration}

\section{Callbration on Iran}

To callbrate the mass spectrometer, an fron molecular beam was generated by electron beam heating an iron disk at the target position. The iron temperature was measured by an optical pyrometer, and the mass spectrometer signal was recorded on a strip chart recorder. Figure 9 shows the electron beam heater con iguration.

The disks were high purity polycrystalline Iron polished with 6 micron diamond paste. They were 0.46 in diameter $\times 0.11$ in thick. A 1/32 in diamete, ,lack body hole with depth to diameter ratio of about three was drilled below the center of the disk at an angle of 45 degrees. The disk was held in a tantalum crucible with a tantalum cover ring. The face of the Iron was covered by a circular tungsten foil with a $1 / 16$ in. or $3 / 16$ in diameter hole in the center plus an opening to expose the black body hole. A tantalum shield prevented molecules vaporlzed from the black body hole from reaching the mass spectrometer.

The tantalum holder was heated from the rear by electrons accelerated from a heated tungsten filament. The holder was held in place by two molybdenum screws and a tungsten spring to allow for thermal expansion. The Iron temperature was quite uniform because of the few contact points between the holder and the electron beam heater.

The Iron temperature was measured by viewing the black body hole through a $90^{\circ}$ prism and the vacuum chamber window. Except during actual temperature measurements, the window was shielded to prevent the deposition of an Iron coat. The shield could be moved away from the window by a magnet. 


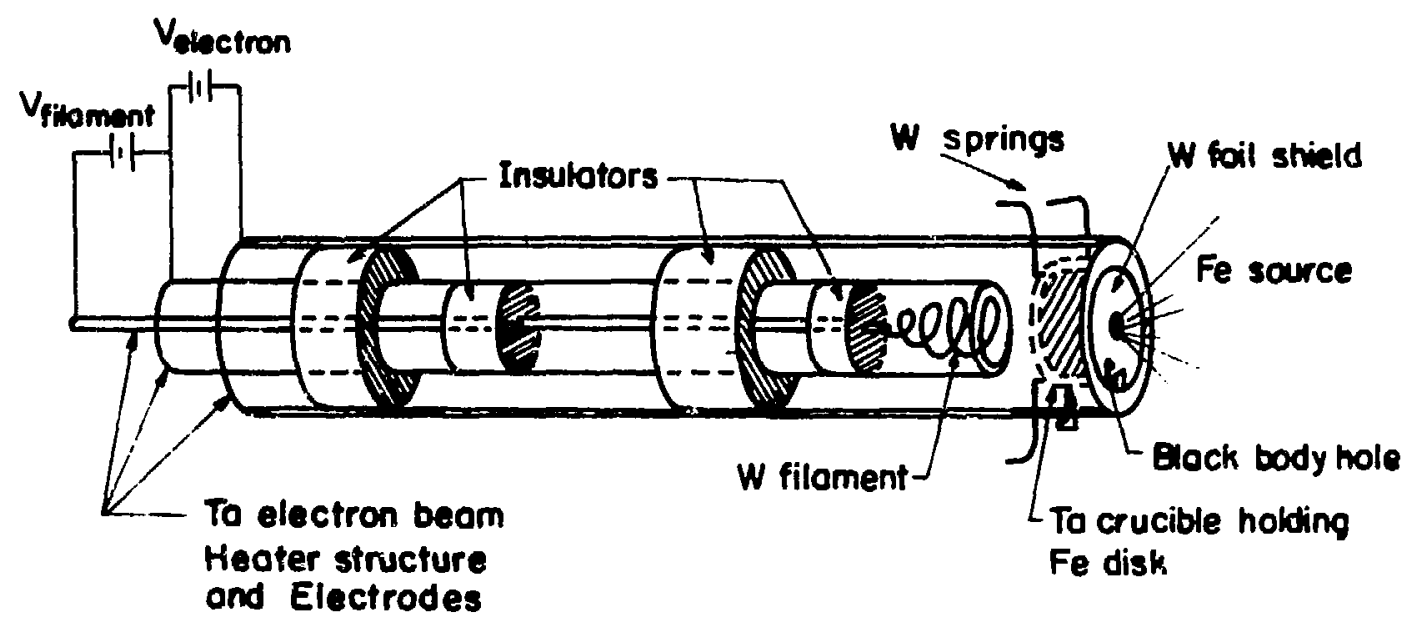

XBL 7211-7227

Fig. 9 Schematic of electron beam heater and iron molecular beam source. 
If it is assumed that the surfaces of the black body hole have an emlssivity of 0.5 , numerical calculations show that the apparent emissivity of the hole 180.98 for a depth to dlameter ratio of three. ${ }^{26}$ This apparent emissivity is sufficiently close to unity that the hole Is considered to be an Ideal black body.

The apparent temperature as measured by the optical pyrometer has to be corrected for the transmissivity of the priam and window. The prical pyrometer determines temperature by comparing radiation intensities at wavelength $\lambda_{p}=0.65$ microns. The observed intensity at this wavelength is less than that from an ideal black body because the transmissivity is less than unity. The relation between true and apearent temperature is: 27

$$
\frac{1}{T_{\text {true }}}-\frac{1}{T_{\text {app }}}=\frac{k}{h c} \lambda_{p} \ln t
$$

For $\tau=\tau_{\text {plism }} \tau_{\text {window }}$ close to unity:

$$
I_{\text {true }}-T_{\text {app }} \cong-T_{\text {app }}^{2} \frac{k \lambda p}{h c}\left[\ln \tau_{\text {prism }}+\ln \tau_{\text {window }}\right]
$$

The constants $k, h$ and $c$ are Boltzmann's constant, Planck's constant, and speed of 1 ight respectively. Rather than neasure $\tau_{\text {window }}$ and ' correction terms supplied by the pyrometer manufacturer were used. Equation (2.11b) shows that the total correction tern is the sum of the correction terms for the window and prism as a function of $T_{\text {app }}$. The mass spectrometer calibration was made for iron temperatures from $1135^{\circ} \mathrm{C}$ to $1385^{\circ} \mathrm{C}$. The mass 56 sigaral was zeasured continuously 
with the 532 scope in perallel with a etrip chart recorder. The load resistance was $1 \mathrm{M}$ for all neasurements. For each dat, point, the fron signal above background was determined by taking the difference between the mass 56 signal witt. and without the bean flag in front of the lonfzer.

The mass spectrometer settings used for the calibration and all other experiments were:

$$
\begin{aligned}
& V_{\text {electron }}=90 \mathrm{v} \cdot 1 \text { ts }=\text { electron potent1al } \\
& V_{\text {ion }} \quad 15 \text { volts - Ion potential relative to the fonfzer at the } \\
& \text { entry to the quadrupole structure } \\
& \mathrm{V}_{\text {focus }}=100 \text { volts }=\text { ion focusing potential } \\
& V_{\text {extractor }}=40 \text { volts "- electron extraction potential } \\
& v_{\text {multiplier }}=-3000 \text { volts }=\text { potential across the eleatron nultiplier } \\
& \text { dynodes } \\
& I_{\text {emiss }} \quad=1.0 \mathrm{milliamp} \text { - eatted electron current } \\
& I_{\text {extractor }}=0.92 \mathrm{ma}=\text { collected electron current }
\end{aligned}
$$

The mass spectrometer resolution setting at mass 56 was adjusted so that the valley between adjacent mass peaks just touched the base line. This resolution is called unit resolution. On measurements of hydrogen frox the zirconium hydride, the resolution control was set for unit resolution at mass 18 rather than mass 56 .

Two calibration runs were made-one with a $1 / 16$ in. and one with a 3/16 In. diameter source aperture. As derfved in Section III-B, the steady state current should be proportional to $P_{\text {eq }} / T$. According to the Clausius-Clapeyron equation, the vapor pressure of a condensed phase is given by 


$$
P_{\text {eq }}=P_{0} \exp \left(-\Delta H_{v a p} / R T\right)
$$

where $\Delta H_{\text {vap }}=$ heat of vaporization per mole, approximately constant

$R=$ Ras constant

$T=$ absclute temperature

Therefore, a plot of $\log$ (IT) vs $1 / \mathrm{T}$ should have slope $-\Delta \mathrm{H}_{\mathrm{vap}} / \mathrm{R} \ln 10$, where I is tive measured current in amps. The product IT is plotted againgt $1 / \mathrm{T}$ in F1g. 10 for the two cal1bration runs. Least squares fits cf these data give the results:

$$
\begin{aligned}
& \text { for } 1 / 16 \mathrm{in} \text {. aperture: } \\
& \begin{array}{l}
\log (\mathrm{IT})=7.101-20.10\left(10^{3} / \mathrm{T}\right) \\
\text { which gives } \Delta \mathrm{H}_{\text {vap }}=92.0 \pm 2 \mathrm{kcal} / \mathrm{mole}
\end{array}
\end{aligned}
$$

for $3 / 16 \mathrm{in}$. aperture:

$$
\begin{aligned}
& \log (\mathrm{IT})=8.184-20.681\left(10^{3} / \mathrm{T}\right) \\
& \text { which gives } \Delta \mathrm{H}_{\text {vap }}=94.6 \pm 1.4 \mathrm{kcal} / \mathrm{mole}
\end{aligned}
$$

The 3/16 in. aperture data is more rellable than the $1 / 16 \mathrm{in}$. aperture data because the sfgnals were larger and covered a vider range of temperature.

The heat of vaporization given by the JANAF cables ${ }^{28}$ for Iron varies from 95.6 to $94.5 \mathrm{kcal} /$ mole over the remperature range of the caldbration. Since the meagured value of heat of vaporization is in excellent agreement with the literature value, the calibration technique is considered rellable。

\section{Callbiation on Molecular Hydrogen}

A rough calibration of the mass spectrometer was made on molecular sydrogen. An accurate celibration would require the corstruction of a molecular hydrogen beas of known source strength located at the 


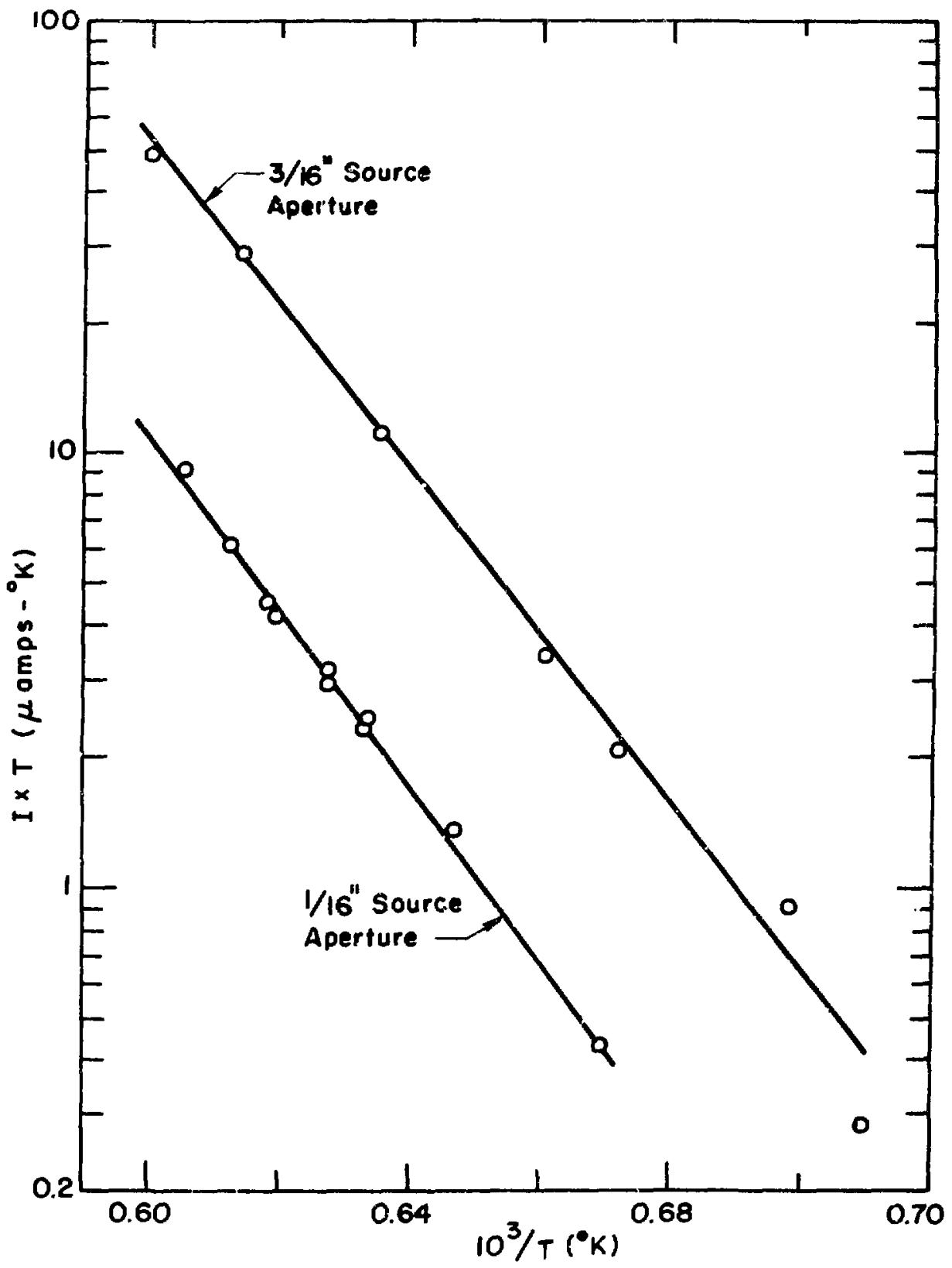

XBL 72|1-7247

Fig. 10 Mass spertrometer callbration curve for atomic iron. 
target position. By chopping the beam with a mechanical chopper and measuring the modulated $\mathrm{H}_{2}$ signal, the calibration could be determined. Instead of doing this, however, the calibration was made by measuring the $\mathrm{H}_{2}$ signal due to a large background $\mathrm{H}_{2}$ pressure in the mass spectrometer chamber. Hydrogen was introduced into the target chamber through a variable leak. The $\mathrm{H}_{2}$ pressure in the mass spectrometer chamber Increased because of the flow of hydrogen through the $1 / 8 \mathrm{In}$. diameter aperture between the two chambers.

The pressure in the mass spectrometer chamber was measured with an ionization gauge. The $\mathrm{H}_{2}$ signal was measured with the same mass spectrometer settings as for the Iron calibration except that the resolution control was set for unit resolution at mass 18 rather than mass 56. The $\mathrm{H}_{2}$ and $\mathrm{H}_{1}$ signals measured across a $1 \mathrm{M}$ load at different mass spectrometer chamber pressures where:

$$
P_{m s} \text { (torr) } \quad V_{\mathrm{H}_{2}} \text { (volts) } \quad \mathrm{V}_{\mathrm{H}_{1}} \text { (volts) }
$$

\begin{tabular}{llll}
\hline $5 \times 10^{-8}$ & 0.33 & 0.04 & (Var1able 1eak off) \\
$1 \times 10^{-7}$ & 4.3 & 0.14 \\
$2 \times 10^{-7}$ & 14.0 & 0.4 \\
\hline
\end{tabular}

The mass spectrometer signals on the other background gases were approximately constant, so the increase in pressure was attributed entirely to hydrogen. The true pressure of hydrogen 181.8 times the pressure measured by an tonization gauge. The calibration on $\mathrm{H}_{2}$ expressed in amps/torr is therefore given by:

$$
\frac{\operatorname{amps}}{\text { torr }}=\frac{10^{-6}\left(\mathrm{~V}_{\mathrm{H}_{2}}-\mathrm{V}_{\mathrm{H}_{2}}^{\circ}\right)}{1.8\left(\mathrm{P}_{\mathrm{ms}}-\mathrm{P}_{\mathrm{ms}}^{\circ}\right)}
$$


where $\mathrm{V}_{\mathrm{H}_{2}}^{\circ}$ and $\mathrm{P}_{\mathrm{ms}}^{\circ}$ are the $\mathrm{H}_{2}$ voltage and mass spectrometer chamber pressure respectively when the varlable leak is of $f$. The mass spectrometer calibration on $\mathrm{H}_{2}$ calculated $F$ rom the above equation $1 \mathrm{~s} 48$ amps/torr.

The $\mathrm{H}_{1}$ signal is due to lons with charge to mass ratio of unity. These can be elther $\mathrm{H}_{1}^{+}$lows produced by cracking of $\mathrm{H}_{2}$ molecules or $\mathrm{H}_{2}^{++}$Ions produced by double ionization of the molecules. The ratio of $\mathrm{H}_{1}$ to $\mathrm{H}_{2}$ signal due to cracking and double ionization 1 s equal to $\mathrm{v}_{\mathrm{H}_{1}} / \mathrm{v}_{\mathrm{H}_{2}} \simeq 3 \%$.

\section{Mass Spectrometer Time Constant}

The time constant of the mass spectrometer signal measurement circuit was measured. The RC time constant is due to the cable, connectors, and oscilloscope capacitances. Individual mass spectrometer pulses were photographed on a high gain Hewlett-Packard $130 \mathrm{C}$ oscilloscope. The measurements were made with a scope load of $I M$ in parallel with a $0.3 \mathrm{M}$ resistor. The time constant of the traces was calculated to be 29 usec. Therefore, the total capacitance is 126 picofarads. The Textronics 532 scope has a capacitance 2 pf larger than the HP 130C. Therefore, when using the 532 scope, the time constant is

$\tau=30 \mu$ sec for load $0.3 \mathrm{M}$ in parallel with $1 \mathrm{M}$

$\tau=12$ isec for load $0.1 \mathrm{M}$ in parallel with $1 \mathrm{M}$

\section{F. Fabrication of Zirconium Hydrjde Samples}

Since bulk sampies of zirconiun hydride are not readily avallable commercially, zircontum hydride samples were fabricated for the experiment. The method used to hydride zirconium rod was simflar to that described in Ref. 30. The experimental setup used is shown in Fig. 1I. The hydrogen 


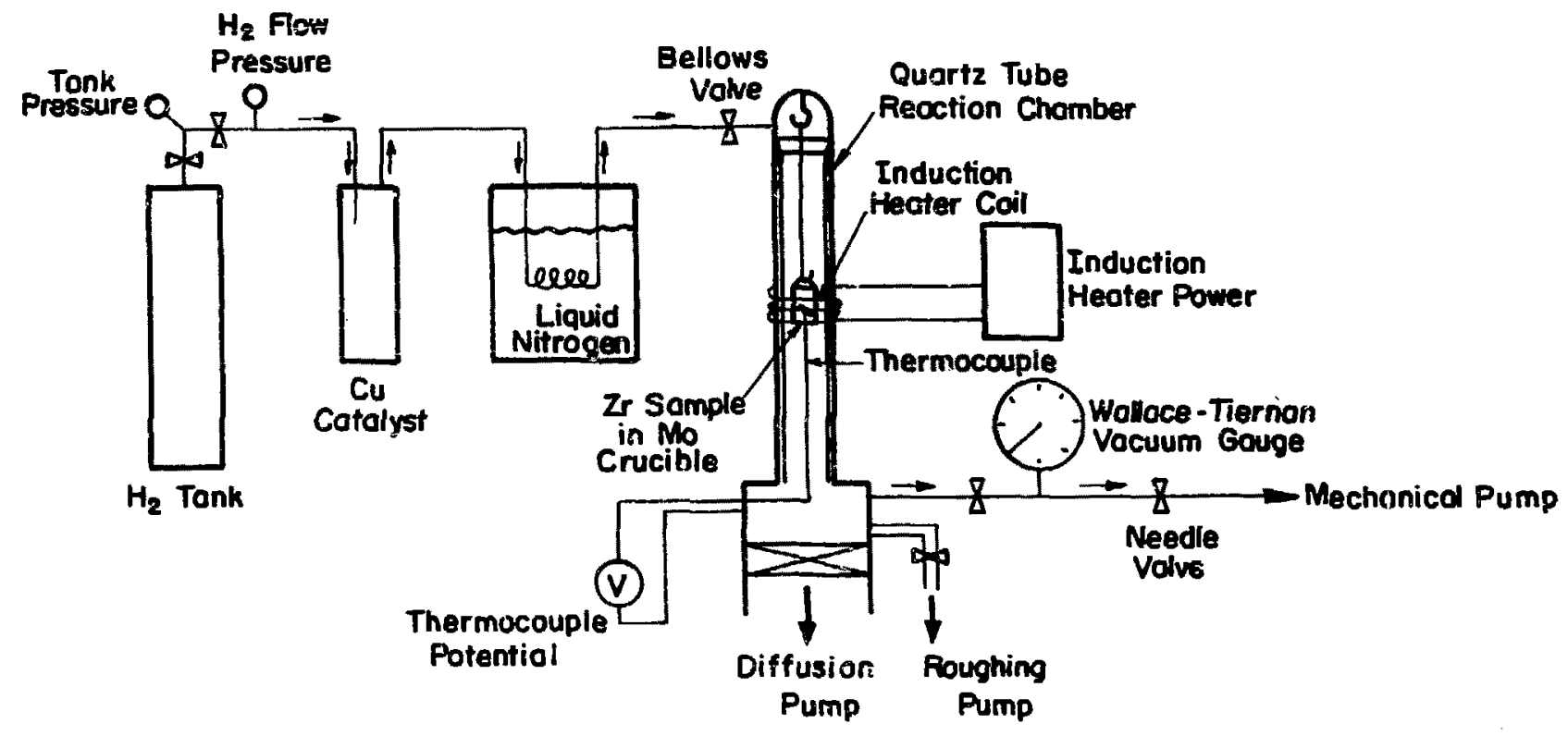

Fig. 11 Schematic of experimental setup for production of zirconium hydride. 
flow system consisted of a tank of high purity hydrogen $(99.999+)$, a copper catalyst to remove oxygen, a liquid-nftrogen-cooled cold trap to condense out water produced in catalizing the oxygen, a bellows valve, the reaction chamber, a Wallace-Tiernan vacuum gauge, a needle valve, and a forepump. The copper calayst, designated as BTS, is described in Ref. 31 . It consists of $30 \%$ copper in a very finely dispersed form stabllized on an inert alumina-based carrier, and getters oxygen very effectively when maintained at $200^{\circ} \mathrm{C}$.

Each zirconium hydride sample was made from high purity $(99.995 \%$ pure) $1 / 8 \mathrm{in}$. diamoter zirconium rod. Before hydriding, the sample was mechanically polished and etched In a solution of 5 parts $\mathrm{H}_{2} \mathrm{O}$, 5 parts $\mathrm{HCl}$, and 1 part $\mathrm{HF}^{\prime}$ to remove the ourface oxide.

The sample was put in a molybdenum crucible and suspended in a artz tube reaction chamber. The cructble was heated by an induction coil around the quartz tube. The temperature was measured by an iron-constantan thermocouple that penetrated a hole in the cructble. The cructble acted like a black body in uniformly heating the sample. Hydrogen pressure and flow rate were controlled by adjugting the bellows and needle valves.

It was decided to made delta phase zirconium hydride because it does not undergo a phase change at the eutectold temperature $550^{\circ} \mathrm{C}$ and has a high hydrogen content. See Section V-B-1 (especially Fig. 15) for a discussion of the ztrconfum-hydrogen phase system. The destred composition was $\mathrm{ZrH}_{1.63^{\circ}}$ The vapor pressure at this composition as a function of temperature is given by Libowitz ${ }^{32}$ The actual composition produced was determined by the welght gain from hydriding. Knowing the initial weight $W_{1}$ and $f I n a l$ weight $W_{f}$, the $H / Z r$ atom ratto $y$ is: 


$$
y=\frac{M_{Z r}}{M_{H}} \frac{W_{f}-W_{I}}{W_{1}}=\frac{91.22}{1.008} \frac{W_{f}-W_{1}}{W_{1}}
$$

Before performing the hydriding operation, the heated copper catalyst was cleaned by pumping on the system with the diffusion pump for about six hours. Next the sample was inserted Into the reaction chamber, which was then pumped down to the $10^{-7}$ torr range. Hydrogen was flushed through the system for over an hour, the hydrogen Inlet valve to the reaction chamber was closed, anc the chamber was again pumped with the diffuston pump for several hours. The zirconium was slowly heated to $700^{\circ} \mathrm{C}$ and held for 30 minutes to outgas the chamber walls. The diffusion punp was then closed and a hydrogen flow established at $10-12 \mathrm{~mm} \mathrm{Hg}$ pressure. The sample was held at $700^{\circ} \mathrm{C}$ at this pressure for over an hour to bring the composition to $\mathrm{ZrH}_{0.9}$ at the $\beta-(\beta+\delta)$ phase boundary. The final stage of hydriding was done by Incre.using the hydrogen pressure to $106 \mathrm{~mm} \mathrm{Hg}$, the equilihrium vapor pressure of $\mathrm{ZrH}_{1.63}$ at $700^{\circ} \mathrm{C}$. ThIs pressure and temperature were maintained for $11 / 2$ hours to ensure complete hydriding of the sample. The sample was then slowly cooled to room temperature whtle maintaining the corresponding equilibrium vapor pressure.

Three crack-free samples were made by this procedure. After hydriding, each sample had a faint golden color, Indicating the formation of a nitride layer at the surface. The initial welght, final weight, and $\mathrm{H} / \mathrm{Zr}$ ațom ratio calculated by $\mathrm{Eq}$. (2.15) for the samples are: 


\begin{tabular}{cccc} 
Sample it & $W_{1}(\mathrm{gms})$ & $W_{f}$ (gms) & $y$ \\
\hline 1 & 0.6493 & 0.6609 & 1.62 \\
2 & 0.6399 & 0.6515 & 1.64 \\
3 & 0.5575 & 0.5676 & 1.64 \\
\hline
\end{tabular}

The close agraement between the calculated values of $\mathrm{H} / \mathrm{Zr}$ atom ratio and the desired value of 1.63 indlcates that the samples were fully hydrided.

\section{G. Laser Shots on Iron}

The iron samples for the laser vaporization experiments were machined from the same high purity polycrystalline stock as used for the Iron calibration measurements. The samples were $3 / 16$ in. diameter by $1 / 2 \mathrm{in.} \mathrm{long} \mathrm{rods.} \mathrm{The} \mathrm{ends} \mathrm{of} \mathrm{the} \mathrm{rods} \mathrm{were} \mathrm{machined} \mathrm{flat} \mathrm{and}$ brought to a final polish with 6 micron dlamond paste. Two rods were mounted on the end of the linear feed-through in the target vacuum chamber. Each rod could be positioned so that the normal to the end face was coaxial with the collimating aperture and mass spectrometer ionizer.

The mass spectrometer signal from Iron atoms vaporized by a Q-switch laser pulse could not be detected above the background signal at the same mass number. The signal produced is much smaller than in steady state because iron atoms are emitted over a very short time compared tc the expected width of the signal. As calculated in Section IV-B-6, the spread of velocities of the Iron atoms emitted from a surface at $2000^{\circ} \mathrm{K}$ leads to an expected width of the signal of approximately $400 \mathrm{\mu sec}$. If the atoms are enitted over the duration of 
40 nanoseconds, the resulting signal has amplitude approximately $0.04 / 400=10^{-4}$ times the steady state algnal. At high Q-switch laser energy densitles, Iron tons wh energy of approximately $30 \mathrm{eV}$ were produced which could be detected by the mass opectrometer. The sensitivity of the mass spectroneter to Ions 18 much greater than to neutrals because the efficlency of lonizing neutrals by electron bombardment is low. The production of Iron lons was attributed to the formation of an Ionized plume of vapor in front of the Iron surface. This phenomenon was not of interest in this investigations.

Measurable mass apectrometer Bignals were obtained, hovever, when conventional mode laser pulses were fired on the iron ourface. In this case the iron atous are vaporized from the surface for approxinately 100 jsec. For the sane peak temperature, the amplitude of the signal Is therefore on the ordar of $10^{3}$ times that when the Iron is heated by a Q-switch pulse. In order to get a large enough energy density for measurable vaporization, the laser was focused with a $20 \mathrm{~cm}$ focal length lens. The resulting spot size was approximately $1 \mathrm{~mm}$ diameter, so several laser shots could be made on each end face of the Iron rods. Measurements were made for incident energy densitles from 50 to $140 \mathrm{cal} / \mathrm{cm}^{2}$ by varying the concentration of the $\mathrm{CuSO}_{4}$ cell. The results of these measurements are discussed and analyzed In Section VI-A. All mass spectrometer measurements were made with a $0.3 \mathrm{~N}$ resistor In para11el with the $1 \mathrm{M}$ load of the oscilloscope to minimize the effect of the time constant on the shape of the measured signal. 
In principle, the temperature of the iron surface during a conventional mode pulse could be measured with an infrared pyrometer with response time much less than the duration of the laser pulse. in indium antimonide photodetector with response time of less than 10 microsconds was available for the purpose. The characteristics and calibration of this pyrometer were reported in Ref. 33. The pyrometer was not used, however, because an accurate callbration could be made only if it viewed an foothermal aurface of at least $1 / 3 \mathrm{in}$. diameter. Since this is considerably larger than the laser spot size, the infraned pyrometer could not be used. Even if the laser spot size were large enough, the pyrometer would have to be callbrated on an iron surface of known temperature in order to account for the emissivity of the iron in the 2 to 6 micron wavelength region. Also a filter would have to be used to assure that the infrared pyrometer did not detect any of the reflected laser radiation.

\section{H. Laser Shots on Zirconium Hydride}

The ends of the three zirconiun hydride rods were polished with 6 micron diamond paste and mounted on the end of the linear feed-through in the target chamber. After one laser shot on the end of each rod, the rods were removed and repollshed before firing on them again. This was done so that the initial sur ace $\mathrm{H} / \mathrm{Zr}$ atom ratlo was known and equal to 1.63 . 
Measurable $\mathrm{H}_{2}$ and $\mathrm{H}_{1}$ sLgnals vere obtalned when the ifrcontum hydride rods were heated with Q-owteh laser pulses. The laser was focused with a lồ cm focal length len:. The calculated laser spot size of approxinately $0.5 \mathrm{cn}$ dianeter $1 \mathrm{~s}$ larger than che $0.32 \mathrm{~cm}$ diancter of the rods, so the enurgy denelty over the face of the rods was approximately constant. Measurements were made for Incident energy densities from 0.02 to $0.15 \mathrm{cal} / \mathrm{cm}^{2}$. For energy densities greater than about $0.2 \mathrm{cal} / \mathrm{cm}^{2}$, atomlc hydrogen lons and zirconium ions were detected. The signals were known to be due to Ions because they were obtained even when the ionizer electron current was sex to zero. The results obtained on zirconium hydride are discussed and analyzed in Section VI-B.

For a particular current produced by the mass spectrometer, the time constant and the measured voltage are proportional to the reaistive load. Since the currents produced were small, it was desirable to heve a large load. On the other hand, it was desirable to have a small load in order to minimize the effect of the time constant wn the shape of the measured signal. An acceptable compromise between these two effects was trade by choosing the load to be elther a $0.1 \mathrm{M}$ or $0.3 \mathrm{M}$ resistor in parallel with the 1 load of the oscilloscope. 
III. THEORY--PREDICTED MASS SPECTROMETER SIGNAL

A. Equilibrium Model for Vapozization from the Surface

An equilibrium model $1 . s$ used to describe the vaporization of the molecules from the surface. According to the princs of detailed balance, ${ }^{34}$ for a system in equilibrium, all processes which asintain the equilibrium occur at the same rate in a forward and backward direction. As applied to a condensed phase in equilibrtum with its vapor, the rate of condensation of vapor molecules of a given velocity is exactly equal to the rate of vaporization of molecules of the same velocity.

Assume that the vapor in thermal equilibrium with the condensed phase has a Maxwell velocity distribution. This is true for ideal gases, for which the potential eneigy of interaction between molecules is negligible. The Maxwell veloctty distribution is given by: ${ }^{35}$

$$
F(v) d v d \Omega-\frac{P_{e q}}{k T}\left(\frac{m}{2 \pi k T}\right)^{3 / 2} v^{2} \exp \left(\frac{-m v^{2}}{2 k T}\right) d v d \Omega
$$

where $F(v) d v d \Omega=$ number of molecules of speed $v \rightarrow v+d v$ in solid angle d $\Omega$ per unit voiume

$p_{\text {eq }}=$ equilibrium vapor pressure

m = molecular mass

$k=$ Boltzmann constant

$T=$ absolute temperature

The number of vapor molecules with speed $v+v+d v$ in $d \Omega$ that strike a unit surface area per unit time is equal to:

$$
v \cos \theta \mathbf{F}(v) \mathrm{dvd} \Omega
$$

where $\theta$ is the angle between. the surface normal and the direction of the incident molecule. 
The rate at which molfcules actually condense on the surface may be less than the rate at which they strike the surface. This difference can be accounted for by a temperature dependent condensation coeffictent $\alpha(T)$, which is defined ${ }^{36}$ as the fraction of gaseous molecules striking a surface which condense. Assuming that this fraction is independent of the velocity and direction of the molecules and using the princtple of detalled balance to equate the condensation rate to the vaporization rate for molecules of all velocities at equilibrium, the number of molecules vaporized from a unit area of the surface in speed $v \rightarrow v+d v$ Into solid angle d $\Omega$ per unit area per unit tim: is equal to:

$$
\alpha(T) \frac{P_{e q}(T)}{k T}\left(\frac{m}{2 \pi k T}\right)^{3 / 2} v^{3} \exp \left(\frac{-m v^{2}}{2 k T}\right) \cos \theta d v d \Omega
$$

If It assumed that the process of vaporization 18 independent of the preaence of the vapox phase in equilibrium with the condensed phase, the vaporization rate in vacuo is equal to the vaporization rate at equilibrium. Therefore under this assumption, the vaporization rate in vacuum is given by Eq. (3.3). Integrating Eq. (3.3) over all speeds and the hemisphere above the surface gives the total rate of vaporization from the surface:

$$
\Phi=\alpha(T) \frac{P_{e q}(T)}{\sqrt{2 \pi m k T}} \quad \text { molecules } / \mathrm{cm}^{2} \mathrm{sec}
$$


The vaporization rate given by $\mathrm{Eq} .(3.4)$ is just $\alpha(\mathrm{F})$ tines the maximum rate of vaporization as calculated by Langmuir. ${ }^{37}$ According to the definition of evaporation coefficlent given by Somorjai ${ }^{23}$ the condensation coefficient $\alpha(T)$ is identically equal to the evaporation coefflcient under the assumptions made in deriving Eq. (3.4). For nost metals and other simple substances, evaporation coefficients (and therefore condensation coefficients) are close to unity. ${ }^{36}$ If the concentration of surface st.tes from which vaportzation can occur is smaller than the concentration of surface atoms, the evaporation coefficient is 1ess than unity. 23

\section{B. Calculated Density of Molecules at the Ionizer}

In order to calculate th? mass spectrometer signal that the vaporized molecules would produce, it 1s necessary to calculate the density of molecules at the mass spectrometer ionizer as a function of tire. Consideration must be given to the fact that faster molecules arrive at the ionizer before slower ones and that molecules leave the surface at different times during the temperature transient. The analysis that follows is simflar to that done by Saltsburg for flash evaporation studies. 38 Let

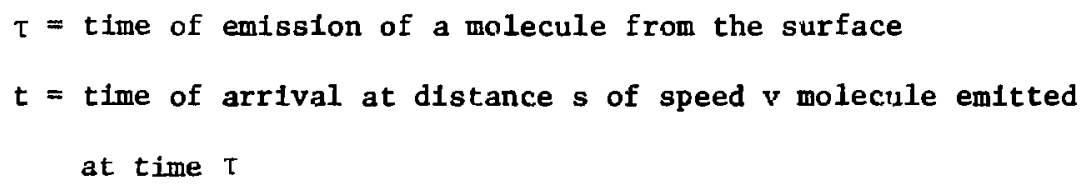

Therefore,

$$
\begin{gathered}
v=\frac{s}{(t-\tau)} \\
d v=\frac{s d \tau}{(t-\tau)^{2}} \quad \text { for a particular } t \text { and } s
\end{gathered}
$$


Let $\phi(t, \tau) d \tau d \Omega A_{S}=$ number of molecules per second arriving at distance s along the normal to the surface at time $t$ which are emitted at time $\tau \rightarrow \tau+d \tau$ into solid angle $d \Omega$ from the surface area $A_{s}$. This is just equal to $\mathrm{A}_{s}$ times the rate given by $\mathrm{Eq}$. (3.3) with $\mathrm{v}$ replaced by Eq. (3.5) and $\theta=0$ :

$\phi(t, \tau) d \tau d \Omega=A_{s} \alpha(T) \frac{P_{e q}(T)}{k T}\left(\frac{m}{2 \pi k T}\right)^{3 / 2} \frac{s^{4}}{(t-\tau)^{5}} \exp \left(\frac{-m s^{2}}{2 k T(t-\tau)^{2}}\right) \times d \tau d \Omega$ Since $d \Omega=d A / s^{2}$, where $d A$ is a differential area at distance $s$, the number of incident molecules at $s$ and $t$ per unit area at $s$ emitted at $\tau \rightarrow \tau+d \tau$ is $\frac{1}{s^{2}} \phi(t, \tau) d \tau$. The number of molecules per unit volume at $s$ and $t$ emitted at $\tau \rightarrow \tau+d \tau$ is the number incident per unit area divided by their velocity $s /(t-\tau)$, or:

$n(t, \tau) d \tau=A_{s} \alpha(T) \frac{P_{e q}(T)}{k T}\left(\frac{m}{2 \pi k T}\right)^{3 / 2} \frac{s}{(t-\tau)^{4}} \exp \left(\frac{-m s^{2}}{2 k T(t-\tau)^{2}}\right) d \tau$

The total density of molecules at distance $s$ is the integral of Eq. (3.7) over $\tau$ where $T=T(\tau)$. Assuming $\alpha$ to be temperature independent, integration yields:

$$
n(t)=\frac{s \alpha A_{s}}{k}\left(\frac{m}{2 \pi k}\right)^{3 / 2} \int_{\tau=0}^{t} \frac{P_{e q}(T(\tau))}{(T(\tau))^{5 / 2}(t-\tau)^{4}} \exp \left(\frac{-m^{2}}{2 k T(\tau)(t-\tau)^{2}}\right) d \tau
$$

The average density of vapor molecules at the mass spectrometer iontzer (which is a distance $s$ from the surface) is less than that calculated from Eq. (3.8) because the collimating aperture obstructs some of the field of view. This reduction is accounted for by an average "peaking factor", $\bar{X}$, which is defined as the ratio of the 
actual molecular beam Intensity everaged over the Ionizer electron sheet to the Intensity irom an unobstructed point cosine source of the same source strength. (For the geometry used in the experiment, $\bar{X}$ is calculated In Appendix A.) The average vapor denstty over the tontzer electron sheet is $\bar{X}$ times $n(t)$ from Eq. (3.8):

$$
\bar{n}_{c a l c}(t)=\frac{\bar{\chi}_{s} \alpha A s}{k}\left(\frac{m}{2 \pi k}\right)^{3 / 2} \int_{0}^{t} \frac{P_{e q}(\tau)}{T^{5 / 2}(t-\tau)^{4}} \exp \left(\frac{-q_{s}^{2}}{2 k T(t-\tau)^{2}}\right) d \tau
$$

For the steady state case such as that used in calibrating the mase spectrometer with an iron molecular beam, $T$ is independent of $\tau$, the above integral is independent of $t$, and the lower limit of integration is replaced by $-\infty$. Performing the integral gives for the steady state density:

$$
\bar{n}_{s s}=\frac{\bar{\chi} \alpha A_{B} P_{e q}(T)}{4 \pi s^{2} k T}
$$

\section{Measured Density of Molecules at the Ionizer}

The geometry and electrical clrcult of the mass spectrometer Ionizer and mass filter are shown In Figs. 12 and 13. Electrons are emitted from a hot tungsten filament and accelerated to energy eV electron * The ions formed by electron-molecule collisions are drawn from the ionizer by the potential $v_{\text {focus }}+v_{\text {ion }}$, focused by the potentlal $v_{\text {focus }}$, and directed down the quadrupole structure with energy eV ion for singly charged 1ons. The lons are detected at the end of the quadrupole structure by an electron multiplier which produces a current gain of the order $10^{6}$.

$$
\begin{aligned}
& \text { number of lons } \\
& \text { produced/sec } 1 \mathrm{n}=\bar{n}(t) V_{i} \Phi_{e} \sigma \\
& \text { the Ionizer }
\end{aligned}
$$




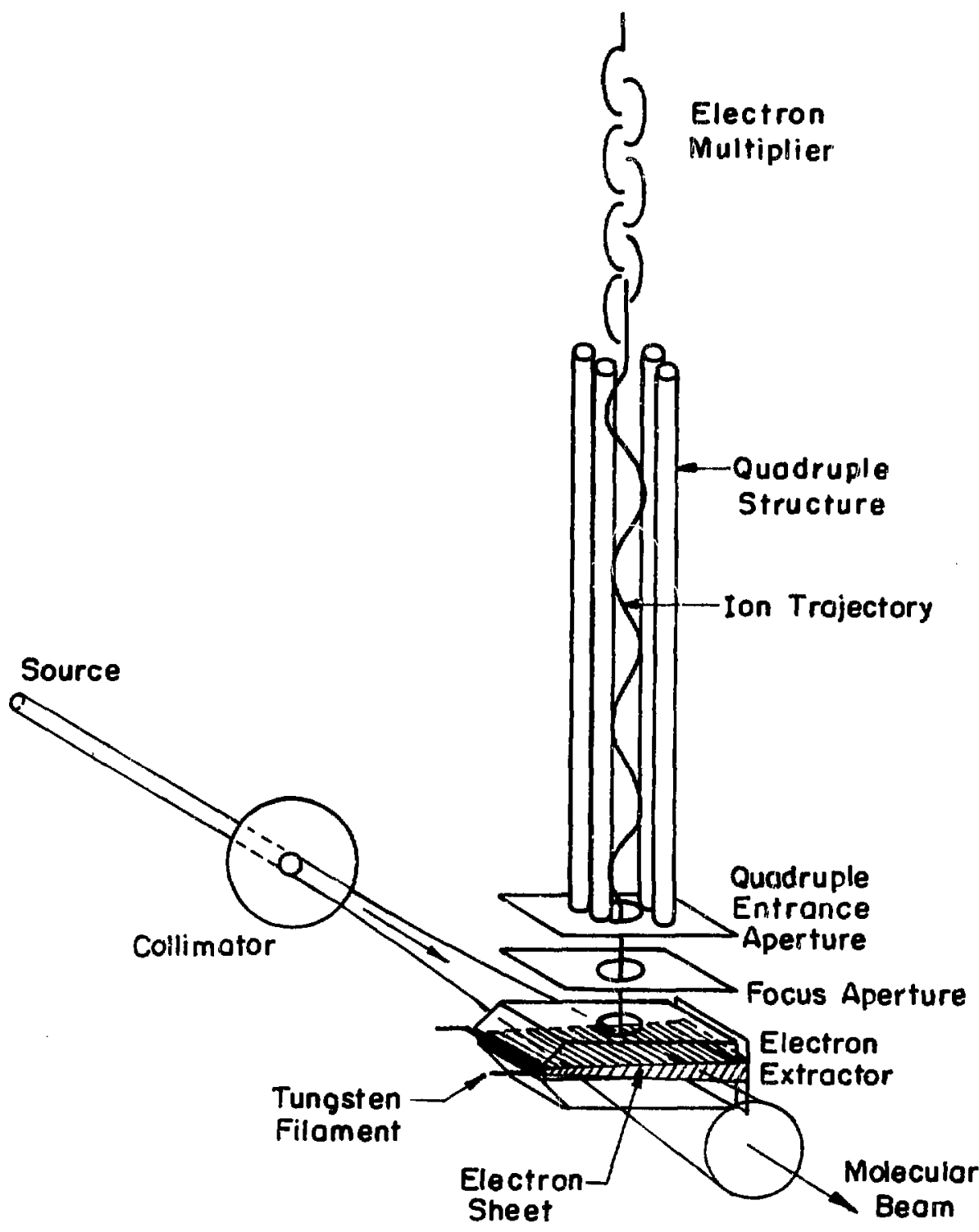

XBL 7211-7226

Fig. 12 Geometry of the mass spectrometer ionizer and mass filter. 


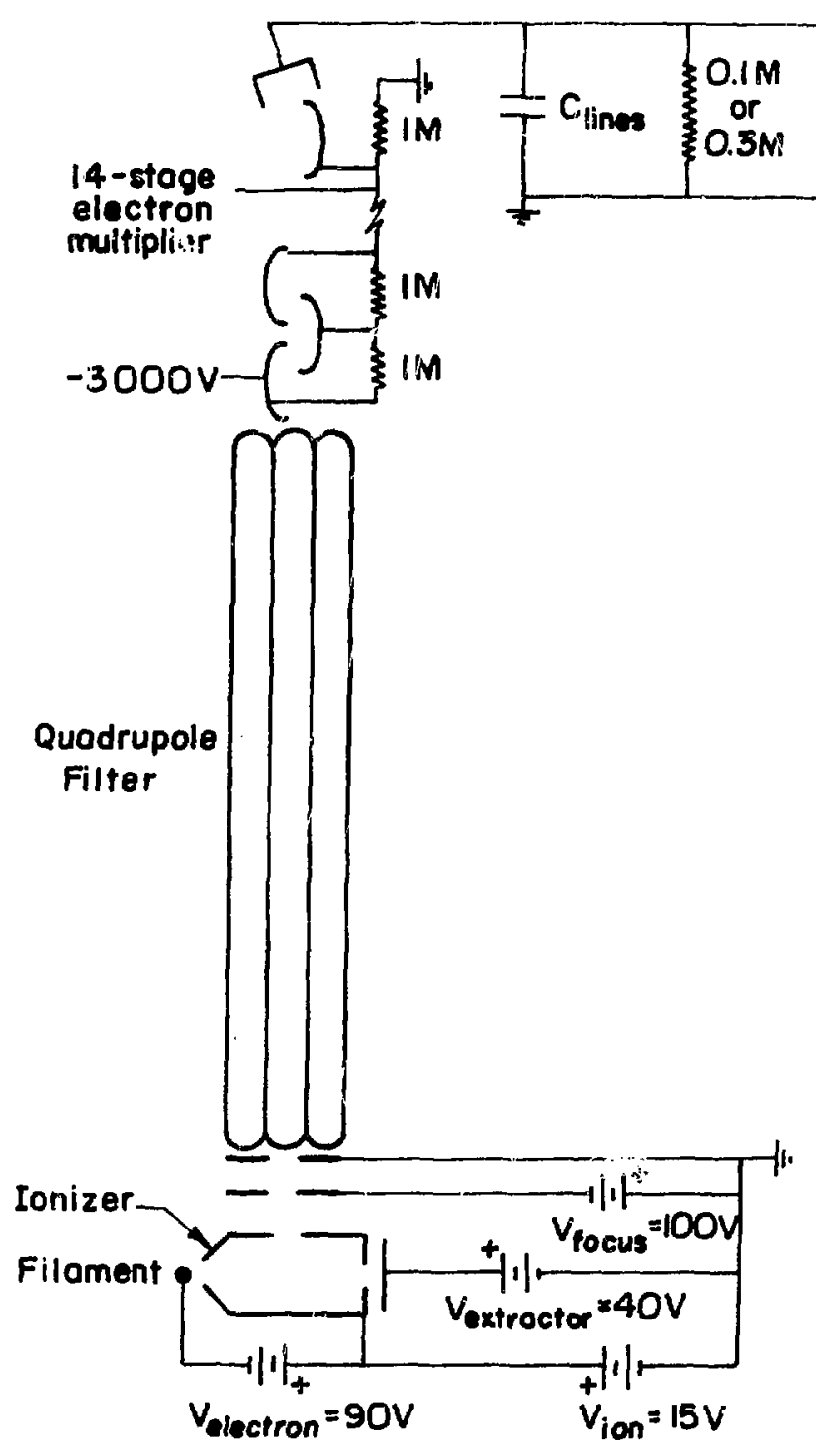

XBL72II-7232

Fig. 13 Electrical circuit of mass spectrometer ionizer and circuit for detection of the mass spectrometer signal. 
where $v_{1}=$ volune of interaction $\left(\mathrm{cm}^{3}\right)$

$$
\begin{aligned}
\phi_{e} & \left.=\text { electron flux (electrons } / \mathrm{cm}^{2} \mathrm{sec}\right) \\
\sigma & =\text { Ionfzation cross section }\left(\mathrm{cm}^{2}\right) \\
\bar{n}(t) & \left.=\text { average molecular density (molecules } / \mathrm{cm}^{3}\right)
\end{aligned}
$$

But $V_{1}=A_{1} L$, where $L=$ length of the electron sheet $(\mathrm{cm})$ and $A_{1}=$ cross sectional area of the electron sheet $\left(\mathrm{cm}^{2}\right)$; and $\phi_{e}=I_{e} / e A_{1}$, where $I_{\mathrm{e}}=$ electron current (coulombs/sec) and e - electron charge (coulombs/ electron). Therefore:

$$
\text { number of tons produced/sec }=\frac{1}{e} \bar{n}(t) I_{e} \sigma L
$$

Only a fraction of the ions produced are drawn Into the quadrupole structure, and not all those of the proper mass actually reach the electron multiplier. The overall efficlency of collection of tons of a particular mass depends on the resolution setting of the mass spectrometer as well as the focus and fon potentiale. Therefore, the rate of arrival of lons at the electron multiplifer is given by:

$$
r\left(t+t_{d}\right)=\gamma \times\left[\begin{array}{l}
\text { number of lons } \\
\text { produced } / \text { sec }
\end{array}\right]=\frac{\gamma}{e} \bar{n}(t) I_{e} \sigma L
$$

where $r\left(t+t_{d}\right)=$ rate of arrival of lons at the electron multiplier which are produced at time $t$ in the lonizer

$\gamma=$ fraction of lons produced that actually reach the electron multiplier

$t_{d}=$ acceleration time plus the drift time of lons down the quadrupole structure

The rate of arrival of lons $1_{s}$ delayed by the time $t_{d}$ relative to $\bar{n}(t)$ because of the time required to accelerate and focus the fons and because of the drift time of the lons down the quadrupole structure. 
As calculated by Jones ${ }^{39}$ the acceleration time is much less than the drift time so it will be neglected. Since an fon enters the quadrupole structure with kinetic energy $\mathrm{eV}_{\text {Ion? }}$

$$
e v_{i o n}=\frac{1}{2} m v_{z}^{2}=\frac{1}{2} m\left(\frac{L_{d}}{t_{d}}\right)^{2}
$$

Solving for $t_{d}$ gives

$$
t_{d}=L_{d} \sqrt{\frac{m}{2 e V_{\text {Ion }}}}
$$

where $L_{d}=$ length of quadrupole structure $(\mathrm{cm})$

$$
\begin{aligned}
\mathrm{m} & =\text { mass of Ion (gms) } \\
\mathrm{e} & =\text { ion charge (coulombs) } \\
\mathrm{V}_{\text {Ion }} & =\text { ion potential (voltsi) }
\end{aligned}
$$

or

$$
t_{d}=1.83 \times 10^{-6} L_{d} \sqrt{\frac{M}{V_{1 o n}}}
$$

where $L_{d}$ is in inches, $M$ is in $A M U, V_{\text {ion }}$ is in volts. For $L_{d}=5.5$ inches and $v_{\text {Ion }}=15$ volts:

$$
\begin{aligned}
t_{d} & =2.6 \mu \mathrm{sec} \text { for } M=1 \text { (hydrogen atom) } \\
& =3.7 \mu \text { sec for } M=2 \text { (hydrogen molecule) } \\
& =19.4 \mu \mathrm{sec} \text { for } M=56 \text { (Iron atom) } \\
& =24.6 \mu \mathrm{sec} \text { for } M=90 \quad \text { (zirconium atom) }
\end{aligned}
$$

An ion impinging on the first dynode of the electron multiplier causes the emission of $\beta$ electrons on the average. These secondary electroms are accelerated to the second dynode where many more electrons are emitted. The process is repeated down the series of dynodes until the final charge of electrons released is: 


$$
q_{0}=B e G
$$

where $\beta=$ number of secondary electrons produced at the first dynode per Incident Ion

$q_{0}=$ total charge released per incident ion

e = electron charge

$G=$ electron multiplier gain

Figure 13 shows the electrical circuit following the electron multiplier. For the RC time constant of the circult much larger than the time of deposit of the charge $q_{0}$, an Individual pulse produces a voltage across the load given by: 40

$$
V(t)=V_{0} \exp (-t / \tau) H(t)
$$

$$
\text { where } \begin{aligned}
H(t)= & 1 \text { for } t>0 \\
= & 0 \text { for } t<0 \\
\tau= & R C=t 1 m e \text { constant } \\
R= & 0.091 \mathrm{M} \text { or } 0.231 \mathrm{M} \text { for } 0.1 \mathrm{M} \text { or } 0.3 \mathrm{M} \mathrm{load,} \mathrm{respect1vely,} \\
& \text { in parallel with the } 1 \mathrm{M} \text { scope load } \\
\mathrm{C}= & \mathrm{C}_{\text {scope }}+C_{\text {lines }}
\end{aligned}
$$

Since $\int_{t=0}^{\infty} \frac{V(t)}{R} d t=q_{0}$ by the conservation of charge, $v_{0}=q_{0} R / \tau$. The current pulse to ground produced by an Individual ion is equal to $V(t) / R:$

$$
I_{0}(t)=\frac{q_{0}}{\tau} \exp (-i / \tau) H(t)
$$


The current at time $t+t_{d}$ due to those ions reaching the electron multiplier at time $t^{\prime} \rightarrow t^{\prime}+d t^{\prime}$ is

$$
\begin{aligned}
d I\left(t+t_{d}\right)= & \text { number of lone arriving In time } t^{\prime} \rightarrow t^{\prime}+d t^{\prime} \\
& \text { times the current at tine } t+t_{d}-t^{\prime} \text { fer Ion } \\
& \text { arriving at } t \text { ime } t^{\prime} \\
= & r\left(t^{\prime}\right) d t^{\prime} I_{o}\left(t+t_{d}-t^{\prime}\right)
\end{aligned}
$$

Therefore, the total current at time $\tau+t_{d}$ is the 1ntegral of Eq. (3.21) over $t^{\prime}:$

$$
I\left(t+t_{d}\right)=\int_{t^{\prime}=t_{d}}^{t+t_{d}} I_{0}\left(t+t_{d}-t^{\prime}\right) r\left(t^{\prime}\right) d t^{\prime}
$$

In Eq. (3.22) let $t^{\prime \prime}=t^{\prime}-t_{d}$, and use Eq. (3 i.3) for $r\left(t^{\prime \prime}+t_{d}\right)$, $E q \cdot(3.20)$ for $I_{0}\left(t-t^{\prime \prime}\right)$, and $E q \cdot(3.18)$ for $q_{0}$, which gives:

$$
I\left(L+t_{d}\right)=\frac{K}{\tau} \int_{0}^{t} \exp \left[-\frac{\left(t-t^{\prime \prime}\right)}{\tau}\right] \bar{r}\left(t^{\prime \prime}\right) d t^{\prime \prime}
$$

where

$$
K=\gamma I_{e} \sigma L B G
$$

Rather than compare $I\left(t+t_{d}\right)$ predicted by Eqs. (3.23)

with the measured current, the latter is analyzed to calculate a measured vapor density at the ionizer, which 18 then compared with the calculated vapor density. Taking the Laplace transfurm of both sides of Eq. (3.23a) and inverting gives the result:

$$
\bar{n}_{\text {neas }}(t)=\left[I\left(t+t_{d}\right)+\tau \frac{d I}{d t}\left(t+t_{d} j\right] / K\right.
$$

Therefore the measured current $I\left(t+t_{d}\right)$, which 1 s equal to the measured $V_{\text {scope }}\left(t+t_{d}\right)$ divided by $R$, can be shifted in time by $t_{d}$ and differentiated to calculate the mcasured $\bar{n}(t)$ according to the above equation. The effec. of the time constant $\tau$ is to shift the 
measured signal to larger times relactve to $\bar{n}(t)$. $\tau$ may be determined by analyzing individual mass spectrometer pulses (see Section II-E-3).

The parameters comprising the instrumerital constant. $K$ of Eq. (3.23b) are not all known a prlorí, but their product can be determined by measuring the signal due to a steady and known density of molecules in the lonizer. At steady state, $\bar{n}$ and $I$ are independent of time, so Eqs. (3.24) and (3.10) give the steady state current $I_{s s}$ :

$$
I_{s 8}=k_{s 8}^{-}=\frac{K \bar{\chi} \alpha A_{s} P_{e q}(T)}{4 \pi \theta^{2} k T}
$$

The value of $\mathrm{K}$ for ircn and hydrogen can be determined from Eq. (3.25) using the results of the calibration on the atomic fron beam and on the background pressure of molecular hydrogen. The values of $\mathrm{K}_{\mathrm{Fe}}$ and $\mathrm{K}_{\mathrm{H}_{2}}$ that are obtained are discussed in Section $\mathrm{VI}-\mathrm{A}-2$ and Section VI-B-3, respectively.

Once $\mathrm{K}$ is known, Eqs. (3.9) and (3.24) can be used to compare theory with experiment. 


\section{TEMPERATURE CALCULATIONS}

\section{A. Energy Equation for Iron}

In order to predict the rate of vaporization from the surface, it is necessary to calculate the time variation of the temperaturc of the surface resulting from the heating by the laser pulse. The heat and mass transport processfs in the solid are assumed to occur at constant volume in order to simplify the calculations. If thermal expansion were considered, it would be necessary to calculate the convection currents in the heared solid and would unduly complicate the problem. The energy equation for a single component solid at constant volume is: 41

$$
\rho C_{v} \frac{\partial T}{\partial t}=\bar{\nabla} \cdot(k \bar{\nabla} T)+A(x, y, z, t)
$$

where $C_{v}=$ specific heat at constant volume $\left(\mathrm{cal} / \mathrm{cm}{ }^{3} \mathrm{~K}\right)$

$\rho=\operatorname{density}\left(\mathrm{gm}^{\mathrm{m}} / \mathrm{cm}^{3}\right)$

$k=$ thermal conductivity (cal/cm $\left.\sec ^{*} \mathrm{~K}\right)$

$T$ = temperature of the material $\left({ }^{\circ} \mathrm{K}\right)$

$\mathrm{A}(\mathrm{y}, \mathrm{y}, \mathrm{z}, \mathrm{t})=$ volumetric heat source $\left(\mathrm{cal} / \mathrm{cm}^{3}{ }^{\circ} \mathrm{K}\right)$

For pulsed laser heating of the surface, it w11l be shown that for the laser configuration used, the depth of material heated is much less than the dimensions of the surface area heated. Therefore, to good approximation, heat conduction occurs only in a direction normal to the surface, For uniform heating over the surface, Eq. (4.1) becomes:

$$
\rho C_{v} \frac{\partial T(x, t)}{\partial t}=k \frac{\partial^{2} T}{\partial x^{2}}+\left(\frac{\partial T}{\partial x}\right)^{2} \frac{d k(T)}{d T}+A(x, t)
$$

To account for the possibility of significant ablation from the surface, the semi-infinite solid $(x>0)$ can be considered to be moving 
In the negative $x$-ifrection at speed $v\left(T_{s}\right)$ relative to the surface. Consider $x$ as the distance from the moving surfaca rather than the original surface (that is, consider Lagranglan coordinates rather than Eulerian). Therefore, replace the partial derivati; with respect to time by the substantial or total derivative, 42 that is, replace $\frac{\partial T}{\partial t}$ by $\frac{\partial T}{\partial t}-v\left(T_{s}\right) \frac{\partial T}{\partial x}$. Equation (4.2) then becomes $\frac{\partial^{2} T(x, t)}{\partial x^{2}}=\frac{1}{k(T)} \frac{\partial T(x, t)}{\partial t}-\frac{v(T s)}{K(T)} \frac{\partial T(x, t)}{\partial x}-\frac{1}{k(T)} \frac{d k(T)}{d T}\left(\frac{\partial T}{\partial x}\right)^{2}-\frac{A(x, t)}{k(T)}$

subject to the boundary cond1tions

$$
\begin{gathered}
T(x, 0)=T_{0} ; T(\infty, t)=T_{0} \\
-\left.k \frac{\partial T}{\partial t}\right|_{X=0}=-\Phi\left(T_{s}\right) \Delta H_{v a p}\left(T_{s}\right)-\varepsilon \sigma\left(T_{s}^{4}-T_{0}^{4}\right)+A_{s}(t)
\end{gathered}
$$

where

$$
\begin{aligned}
& \underline{T}_{0}=\text { inftial temperature } \\
& \mathrm{T}_{\mathrm{S}}=\text { surface temperature } \\
& \Phi\left(T_{S}\right)=f 1 \text { ux of vaporized molecules (moles } / \mathrm{cm}^{2} \mathrm{sec} \text { ) given } \\
& \text { by Eq. (3.4) } \\
& \Delta H_{\text {vap }}\left(T_{s}\right)=\text { heat of vaporization (cal/mole) } \\
& \varepsilon \sigma\left(T_{s}{ }^{4}-T_{o}^{4}\right)=\text { heat loss from the surface by thermal radiacion } \\
& \text { ( } \mathrm{cal} / \mathrm{cm}^{2} \mathrm{sec} \text { ) } \\
& \mathrm{K}=\text { thermal diffusivity }=\mathrm{k} / \rho \mathrm{C}_{\mathrm{v}}\left(\mathrm{cm}^{2} / \mathrm{sec}\right) \\
& A_{s}(t)=\text { surface heat source }\left(\mathrm{cal} / \mathrm{cm}^{2} \mathrm{sec}\right) \\
& \mathrm{v}\left(\mathrm{T}_{\mathrm{s}}\right)=\text { ablation speed }(\mathrm{cm} / \mathrm{sec})
\end{aligned}
$$

If the laser radiation is considered as a volumetric heat scurce $A(x, t)$, then $A_{S}(t)=0$. If it is considered a surface source $A_{S}(t)$, then $A(x, t)=0$. 
The ablation speed is related to the total flux of molecules vaporizing from the surface by the relution

$$
V\left(T_{s}\right)=\Phi\left(T_{s}\right) M / \rho
$$

where $M$ is the molecular welght of the vaportaing spectes in $M$ MU and $\Phi\left(T_{s}\right)$ depends on the vapor pressure and temperature of the surface according to Eq. (3.4).

Equations (4.3) are non-IInear because of the temperature dependence of the materlal properties and because at high temperatures the boundary condition at the surface is strongly temperature dependent. Therefore, It is destrable to calculate the temperature by a numerical procedure as described In Appendix $\mathrm{B}$.

\section{B. Approximate Solutions for Iron Temperature}

\section{Approximate Energy Equation}

There are several approximate analyt1c solutions to Eq. (4.3) that are of use either to check numerical solutions or to show the relative importance of certain effects. Make the approximation that $\Phi\left(T_{s}\right)=A(x, t)=\varepsilon=0$ and that material properties are independent of temperature. Equation (4.3) then becomes:

$$
\begin{aligned}
& \frac{\partial^{2} T(x, t)}{\partial x^{2}}=\frac{1}{K} \frac{\partial T}{\partial t} \\
& T(x, 0)=T_{0} ; T(\infty, t)=T_{0} \\
& \left.k \frac{\partial T}{\partial x}\right|_{x=0}=-A_{s}(t)
\end{aligned}
$$


2. Rectangular Heat Source Over Entire Plane

The solution to Eq. (4.5) for the surface heat flux $A_{s}(t)$ a rectangular pulse in time is the simplest approximation for the temperature transient resulting from a laser pulse. The solution for

$$
\begin{array}{rlrl}
A_{s}(t) & =F_{0} & \text { for } & 0<t<\tau \\
& =0 \text { for } & t>\tau
\end{array}
$$

is given by Carslaw and Jaeger. ${ }^{43}$ The surface temperature is:

$$
\begin{aligned}
T_{s}(t)-T_{0} & =\frac{2 F_{0}}{k}\left(\frac{K t}{\pi}\right)^{1 / 2} \text { for } 0<t<T \\
& =\frac{2 F_{0}}{k}\left(\frac{K}{\pi}\right)^{1 / 2}\left[t^{1 / 2}-(t-\tau)^{1 / 2}\right] \text { for } t>\tau
\end{aligned}
$$

\section{Trlangular Heat Source Over Entire Plane}

The solution to Eq. (4.5) for a triangular surface heat flux in time is useful as an approximation for the temperature piofile resulting from a Q-switch pulse (see Fig. 4), the average power of the conventional mode pulse (Figs. 5 and 6 ), and the power shape of the Individual spikes in the conventional mode pulse, Let $A_{s}(t)$ be given by:

$$
\begin{aligned}
A_{s}(t) & =\frac{F_{p} t}{\tau_{1}} \text { for } 0<t<\tau_{1} \\
& =\left(\frac{\tau_{2}-t}{\tau_{2}-\tau_{1}}\right) F_{P} \text { for } \tau_{1}<t<\tau_{2} \\
& =0 \text { for } t>\tau_{2}
\end{aligned}
$$

where $F_{P}=$ absorbed power density at the peak of the triangular pulse

$\tau_{1}=$ time corresponding to the peak of the pulse

$\tau_{2}=$ time of the end of the triangular pulse 
Equation (4.5) can be wlred with the above $A_{s}(t)$ by the wethod of Laplace transforms. The solution for $T(x, t)$ evaluated at $x=0$ s:

$$
\begin{aligned}
T_{s}(t)-T_{0} & =\frac{4 F}{3 k}\left(\frac{K}{\pi}\right)^{1 / 2}\left[\frac{t^{3 / 2}}{\tau_{1}}-\frac{\tau_{2}}{\tau_{1}} \frac{\left(t-\tau_{1}\right)^{3 / 2}}{\left(\tau_{2}-\tau_{1}\right)} H\left(t-\tau_{1}\right)\right. \\
& \left.+\frac{\left(t-\tau_{2}\right)^{3 / 2}}{\tau_{2}-\tau_{1}} H\left(t-\tau_{2}\right)\right]
\end{aligned}
$$

where $H\left(t-\tau_{1}\right)$ is the Heavyside function:

$$
\begin{aligned}
H\left(t-\tau_{1}\right) & =1 \text { for } t>\tau_{1} \\
& =0 \text { for } t<\tau_{1}
\end{aligned}
$$

4. Steady Heat Source Over Circular Area of the -Plane

Constder the solution to Eq. (4.5) with $\frac{\partial^{2}}{\partial x^{2}}$ replaced by $\frac{\partial^{2}}{\partial r^{2}}+\frac{1}{r} \frac{\partial}{\partial r}+\frac{\partial^{2}}{\partial z^{2}}$ and $A_{s}(t)$ given by

$$
\begin{aligned}
& A_{s}(t)=F_{0} \text { for } t>0 \text { and } 0<r<a \\
& =0 \text { for } t>0 \text { and } r>a
\end{aligned}
$$

The solution to this problem is useful to show the validity of neglecting conduction parallel to the surface. The solution at $r=0$ given by Carslaw and Jaeger ${ }^{44}$ evaluated at the surface is:

$$
\left.T_{s}(t)\right|_{r=0}=T_{0}+\frac{2 F o}{k}\left(\frac{K t}{\pi}\right)^{1 / 2}\left[1-\sqrt{\pi} \text { ierfo }\left(\frac{a}{2 \sqrt{K t}}\right)\right]
$$

of Interest is the fractional difference between this solution and the solution obtained for untform flux over the entire plane. Using Eq. (4.6) (with $\tau \rightarrow \infty$ ) for the uniform $f$ lux solution gives: 


$$
\left.\frac{T_{s}(t)(p l a n e)-T_{s}(t)(c i r c l e)}{T_{s}(t)}\right|_{(p \text { lane })} ^{-T_{0}}=0=\sqrt{\pi} \operatorname{terfc}\left(\frac{a}{2 \sqrt{K} t}\right)
$$

The function ierfc(x) is a very rapidly decreasing function of $x$. For $x=2.5, \sqrt{\pi}$ ierf $f(x) \simeq 10^{-4}$, so the assumption of a plane source is good at $r=0$ for $\frac{a}{2 \sqrt{\mathrm{Kt}}}>2.5$. For a Q-8witch pulse the assumption is very good since $\frac{a}{2 \sqrt{\mathrm{K}} \text { : }} \cong 100$. The worst case to constder is a conventional mode pulse focused on lron. For spot size radius a $=0.05 \mathrm{~cm}$, $K=0.1 \mathrm{~cm}^{2} / \mathrm{sec}$, and $t=10^{-3} \mathrm{sec}, \frac{\mathrm{a}}{2 \sqrt{\mathrm{Kt}}}=2.5$. Therefore, even in this case the assumption is st111 quite good, but the assumption gets worse for longer times and smaller spot sizes.

5. Steady Volumetrid: Heat Source Over Entire Plane Decreasing

Exponentially Into the Material

Consider the solution to $E q$. (4.5) with an exponentialiy decreasing volumetric source rather than a surface source. That is:

$$
\begin{aligned}
& A(x, t)=A_{0} \exp (-x / \delta) \text { for } t>0 \\
& A_{s}(t)=0 \text { for a11 } t
\end{aligned}
$$

where $\delta=$ absorption depth $\simeq 100 \AA$ for metals 45

$A_{0}=\frac{F_{0}}{\delta}$

$F_{0}=$ absorbed power density $\left(\mathrm{cal} / \mathrm{cm}^{2} \mathrm{sec}\right)$, assumed constant for $t>0$

Since the laser radiation is actually absorbed in this manner it is of interest to compare this solution with the solution for a plane source at the surface. Again, according to Carslaw and Jaeger ${ }^{46}$ the solution In this case at $x=0$ 16: 


$$
T_{s}(t)=T_{0}+\frac{2 F}{k}\left(\frac{K t}{\pi}\right)^{1 / 2}-\frac{F_{0} \delta}{k}\left[1-\exp \left(\frac{K t}{\delta}\right) \operatorname{erfc}\left(\frac{\sqrt{K t}}{\delta}\right)\right]
$$

Therefore, the fractional difference between this solution for $\frac{\sqrt{\mathrm{K}} t}{\delta} \gg 1$ and the surface source solution (Eq. (4.6), with $\tau=\infty$ ) is:

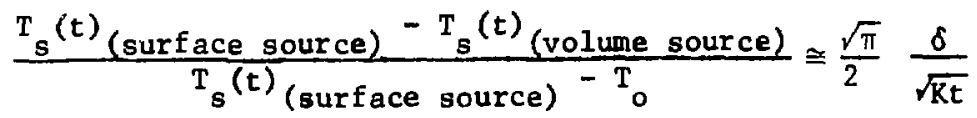

For a conventional mode pulee on Iron $(K \simeq 0.1$ and $t$ of Intereet $\left.\approx 10^{-5}+10^{-4} \mathrm{sec}\right):$

$$
\frac{T_{s} \text { (surface source) }-T_{s} \text { (volume source) }}{T_{s \text { (Burface source) }}-T_{0}} \leqslant 10^{-3}
$$

so in this case the surface source assumption is good.

For a Q-switch pulse on 1ron, $t$ of interest. is greater than $25 \times 10^{-9}$ sec giving:

$$
\frac{T_{s \text { (surface source) }}-T_{s \text { (volume source) }}}{T_{s \text { (surface source) }}-T_{0}} \leqslant 0.02
$$

so in this case the surface source assumption is in error by several per cent.

\section{The Effect of Spikes in the Convent1onal Mode Pulse}

As seen in $\mathrm{Fig}_{\mathrm{g}}$. 5, the conventional mode power output consists of a series of discrete splkes rather than a smooth triangular pulse. To account for the effect of the power spikes on the temperature translent, the following simpler problem is considered: Assume that the laser heat input to the surface consists of a series of Individual symmetric spikes each with the same peak power $F_{p}$, full width $t_{1}=0.5$ usec, and spacing $t_{2}=1.5$ jsec. This does not represent the real conventional 
mode pulse because the peak power of the spikes first increases with time, then decreases in a roughly triangular pattern. The spikes are also more closely spaced in time early in the pulse than at the end of the pulse (see Fig. 5).

The effect of the spikes on the temperature transient at the surface can be determined by first calculating the surface temperature due to this serles of uniformly spaced spikes of equal peak power. Then the temperature of the surface is calculated for a constant surface heat flux equal to the time average of the heat flux of the series of splkes. A comparison of these two calculated temperature profiles gives an Indication of the effect of the spikes on the temperature transient which should be applicable to the real case where the spikes are not uniformly spaced and not of equal peak power.

First consider the case of a series of spikes of equal peak power. Let $T_{\text {spike }}\left(F_{p}, t-i t_{2}\right)$ be the change in surface temperature at time $t$ produced by a single spike of peak power $F_{p}$ which started at time it ${ }_{2}$ with the initial solid temperature equal to $T_{0} \cdot T_{\text {gpike }}\left(F_{p}, t-i t_{2}\right)$ is given by $E q .(4.7 b)$ with $t$ replaced by $t-i t_{2}, \tau_{2}=t_{1}$ and $\tau_{1}=t_{1} / 2$. The surface temperature due to a series of such spikes spaced in time by $t_{2}$ is given by the superposition principle:

$$
T_{\text {series }}\left(F_{p}, t\right)=T_{0}+\sum_{i=0}^{j} T_{\text {spike }}\left(F_{p}, t-1 t_{2}\right)
$$

where $j$ is the largest value of $i$ such that $\left(t-1 t_{2}\right)>0$, (1.e., $f$ is the number of spikes up to time $t$ ),

No: consider the case in which the surface is subject to a constant heat flux whose magnitude is given by the average of the spikes, 
$F_{\text {avg }}=F_{p} t_{1} / 2 t_{2}$. The surface temperature is given by Eq. (4.6) with $\tau \rightarrow \infty$ :

$$
T_{\text {avg }}(t)=T_{0}+\frac{2 F_{\text {avg }}}{k}\left(\frac{K t}{\pi}\right)^{1 / 2}
$$

Therefore the temperature oscillation induced by the spikes if stven by

$$
\Delta T\left(F_{p}, t\right)=T_{\text {serles }}\left(F_{p}, t\right)-T_{\text {avg }}(t)
$$

The surface temperature calculated by Eqs. (4.10) and (4.11) is shown in Fig. 14 for early times. It is apparent that after several spikes, the shape of the temperature oscillation stablizes. By expanding Eq. (4.12) in a Taylor serles for large $\mathrm{f}$ is seen that for $\mathrm{f} \sim 15, \Delta \mathrm{T}$ is a function only of $t^{\prime}$ (the time from the beginning of a spike) and not $t$, that is, the shape has stabllized. The result for $\Delta \mathrm{T}$ for $\mathrm{j}>15$ is:

$$
\left.\begin{array}{rl}
\Delta T\left(F_{p}, t^{\prime}\right) & =T_{\text {spike }}\left(F_{p}, t^{\prime}\right) \\
& -\frac{2 F_{\text {avg }}}{k} \sqrt{\frac{\mathrm{Kt}_{2}}{\pi}}\left\{\begin{array}{l}
\left(l-\frac{1}{2}\right)^{1 / 2}+\frac{t^{\prime}}{2 t_{2}\left(l-\frac{1}{2}\right)^{1 / 2}} \\
-\frac{8}{3} \sqrt{\frac{t_{2}}{t_{1}}} \sum_{1=1}^{l-1}\left[g_{1}^{3 / 2}+\left(g_{1}-1\right)^{3 / 2}-2\left(g_{1}-\frac{1}{2}\right)^{3 / 2}\right]
\end{array}\right\}
\end{array}\right\}
$$

where $g_{i}=\left(t^{\prime}+i t_{2}\right) / t_{1}$

$1 \simeq 15$

The summation in $\mathrm{Eq}$. (4.13) is required because the terms under the sumation are not accurately given by a Taylor series expansion for small $i$ and the summation is not accurately approximated by an integral for $\operatorname{sma11} 1$.

For the real case of temperature dependent materlal properties and time dependent peak spike power, it is assumed that the temperature 

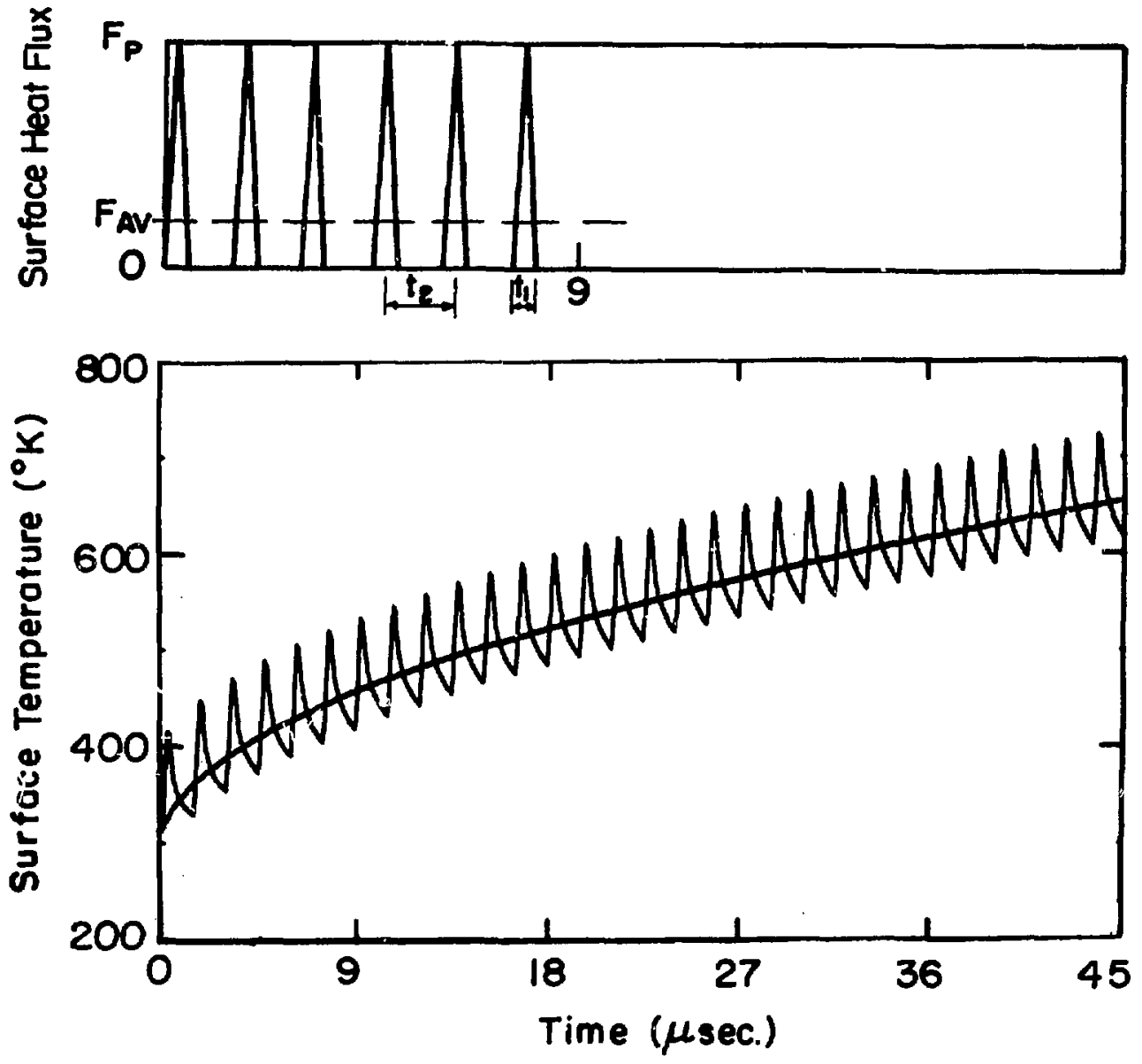

XBL 7210-5785

Fig. 14 Surface temperature resulting from a series of equally space spikes of equal height (oscillating curve) and from a constant surface heat flux whos's magnitude is equal to the average of the power in the series of spikes. 
oscillation is still given by Eq. (4.13). However, $F_{p}$ and $F_{\text {avg }}$ are now functions of time, and the thermal conductivity $k$ and thermal diffusivity $\mathrm{K}$ are taken at the average temperature calculated numericaldy. This assumption should be valid if $k$ and $K$ are approximately constant during a spike and if $F_{\text {avg }}$ varies slowly during several splkes.

The most probable velocity of an atom cf mass m vaporized from a surface at temperature $T$ is $\vec{v}=\sqrt{3 \mathrm{kT} / \mathrm{m}}$. The time of flight of an iron atom vaporized from a surface at $2000^{\circ} \mathrm{K}$ to the mass spectrumeter ionizer is 400 usec. For an Instantaneous pulse of atoms from the surfice, the time spread of the pulse observed by the mass spectrometer is also $\sim 400 \mu \mathrm{sec}$, as can be shown by calculating the velocity at which vF(v) is a factor of e less than $\tilde{v} F(\tilde{v})$ and converting the former to time. Since tize width in time due to the velocity spread of the atoms is much greater than the time between laser spikes, the mass spectrometer signal does not see the individual temperature oscillations. Since the vapor pressure is an exponentially increasing function of reciprocal temperature, the average vapor pressure during one temperature oscillation is greater than the vapor pressure at the average temperature during the oscillation. Lils effect was found to give predicted mass spectrometer signals approximately $10 \%$ larger than would be obtained by taking the vapor pressure at the average temperature. The effect of the spikes on the temperature transient was therefore neglected, and the conventional mode pulse was approximated by the average power determined by taking the time derivative of the Korad energy $t_{r u c e}$. As shown in Section II-C-2, the shape of the average power is approximately trianguiar with the peak at $0.15 \mathrm{msec}$ and the end of the pulse at $1.0 \mathrm{msec}$. 


\section{Energy and Hydrogen Diffuston Equations for Zircontum Hydride}

For a two-component material such as zirconium hydride in which one component is very mobile, the energy and species conservation equations are interrelated. The diffusing species transports energy as well as mass, and, In addition, a temperature gradient implies the existence of the Soret mass flux and Dufour energy flux according to the thermodynamics of 1rreversible processes. The general energy equation for a binary system neglecting terms involving convective velocity and body forces 1 s: ${ }^{47}$

$$
\rho \frac{d E}{d t}=-\nabla \cdot q-\nabla \cdot \sum_{1=1}^{2} 1_{1} \bar{h}_{1}+A(x, y, z, t)
$$

where

$$
\rho=\text { mass density }
$$$$
E=\text { spectfic Internal energy }
$$$$
\underline{q}=\text { "second law heat flux" }
$$

$\dot{i}_{1}=$ diffusive mass flux of component 1 relative to the mass average velocity

$\bar{h}_{1}=$ partial spectfic enthalpy of component $i$

$$
A(x, y, z, t)=\text { external volumetric energy source }
$$

For the case of hydrogen $d \pm f$ fusing in zirconfum, make the following assumptions :

a) Each volume element maintains constant volume during the heating and diffusing process.

b) The zirconium atoms are on a fixed, rigid lattice so that the zirconium is immobile and there is no change in the number of zirconium atoms in each volume element during the process.

c) Since the mass of hydrogen 1s only about $1 \%$ of the mass of zirconium, the mass average velocity will be considered to be zero. 
Note that accorcing to assumption (b), surface ablation which produces the recession velocity in iron vaporfation is absent in this case.

To evaluate $\frac{d E}{d T}$ consider an element of volume of energy e containing $m_{H}$ grams of $H$ and $m_{Z_{r}}$ geams of $Z r$. By the defintion of $E$, $E=\mathrm{e} /\left(\mathrm{m}_{\mathrm{Zr}}+\mathrm{m}_{\mathrm{H}}\right)$ which is approximately equal to $\mathrm{e} / \mathrm{m}_{\mathrm{zr}}$ since $\mathrm{m}_{\mathrm{H}}$ is much amaller than $\mathrm{m}_{\mathrm{Zr}}$. Since the volume and number of zirconium atoms are assumed constant, $e$ (and therefore $E$ ) are functions only of $m_{H}$ and $T$. Since the mass average veloctty is assumed to be zero, the substantial dervative $\frac{d E}{d t}=\frac{\partial E}{\partial t}$. Therefore,

$$
\frac{\partial E}{\partial t}=\left(\frac{\partial E}{\partial m_{H}}\right)_{T}\left(\frac{\partial m_{H}}{\partial t}\right)+\left(\frac{\partial E}{\partial T}\right)_{m_{H}}\left(\frac{\partial T}{\partial t}\right)
$$

By the definition of specific heat at constant volume:

$$
\left(\frac{\partial E}{\partial T}\right)_{\mathbf{m}_{H}}=\left(\frac{\partial E}{\partial T}\right)_{\mathbf{m}_{H}, m_{\mathbf{Z r}}, v}=C_{v}
$$

Since $E \simeq e / m_{2 r}$,

$$
\left(\frac{\partial E}{\partial m_{H}}\right)_{T}=\frac{1}{m_{Z r}}\left(\frac{\partial e}{\partial m_{H}}\right)_{T}=\frac{1}{m_{Z r}}\left(\frac{\partial e}{\partial m_{H}}\right)_{T, p, m_{Z r}}
$$

where the last equality 18 due to assumptions (a) and (b). By the definition of partial speciflc quantities:

$$
\begin{aligned}
& \left(\frac{\partial e}{\partial m_{H}}\right)_{T, P, m_{Z r}} \equiv \bar{e}_{H}=\text { partial specific energy of } \mathrm{H} \\
& \left(\frac{\partial h}{\partial m_{H}}\right)_{T, P, m_{Z r}} \equiv \bar{h}_{H}=\text { partial specific enthalpy of } H \\
& \left(\frac{\partial v}{\partial m_{H}}\right)_{T, P, m_{Z r}} \equiv \bar{v}_{H}=\text { partial specific volume of } H
\end{aligned}
$$


From the thermodynamic definition of enthalpy it can be shown that

$$
\overline{\mathrm{h}}_{\mathrm{H}}=\overline{\mathrm{e}}_{\mathrm{H}}+\mathrm{p}_{\mathrm{H}}
$$

Because of the constant volume assumption, $\bar{v}_{\mathrm{H}}=0$, so

$$
\overline{\mathrm{e}}_{\mathrm{H}}=\overline{\mathrm{h}}_{\mathrm{H}}
$$

Combining Eqs. (4.17), (4.18) and (4.20) gives

$$
\left(\frac{\partial E}{\partial m_{H}}\right)_{T}=\frac{1}{m_{Z_{r}}} \overline{h_{H}}
$$

Therefore,

$$
\begin{aligned}
\rho \frac{\partial E}{\partial t} & =\rho C_{v} \frac{\partial T}{\partial t}+\frac{\rho}{m_{Z r}} \bar{h}_{H} \frac{\partial m_{H}}{\partial t} \\
& =\rho C_{v} \frac{\partial T}{\partial t}+\bar{h}_{H} \frac{\partial c_{H}}{\partial t}
\end{aligned}
$$

where $c_{H}$ is the mass density of $H$ in the solid (gms $H / \mathrm{cm}^{3}$ ). By assumptions (b) and (c), $I_{Z r}=0$ so the energy equation (with spatial variation in the $x$ direction only) becomes:

$$
\rho c_{v} \frac{\partial T}{\partial t}+\bar{h}_{H} \frac{\partial c_{H}}{\partial t}=-\frac{\partial q}{\partial x}-\frac{\partial}{\partial x}\left(\bar{h}_{H} f_{H}\right)+A(x, t)
$$

The equation representing the coneervation of hydrogen mass is:

$$
\frac{\partial c_{H}}{\partial t}=-\frac{\partial}{\partial x} f_{H}
$$

Using this in Eq. (4.23) gives:

$$
\rho \widetilde{C}_{V} \frac{\partial T}{\partial t}=-\frac{\partial q}{\partial x}-j_{H} \frac{\partial \bar{h}_{H}}{\partial x}+A(x, t)
$$

Because $j_{Z r}=0$ and $\bar{e}_{H}=\bar{h}_{H}$ the second law heas flux is equal to the first law heat flux of ordinary heat condition. ${ }^{47}$ The heat flux and hydrogen flux are given by Shewmon: ${ }^{48}$ 


$$
\begin{aligned}
q & =-\frac{D Q^{*}}{M_{H}} \frac{\partial c_{H}}{\partial x}-k \frac{\partial T}{\partial x} \\
j_{H} & =-D \frac{\partial c_{H}}{\partial x}-\frac{D Q^{*} c_{H}}{R_{T}^{2}} \frac{\partial T}{\partial x}
\end{aligned}
$$

where $D=$ diffusion coefficient of hydrogen in zircontum hydride

$Q^{*}=$ heat of transport of hydrogen in zirconium hydride

$k=$ thermal conductivity of the zirconium hydrid $\%$

$\mathrm{M}_{\mathrm{H}}=$ molecular weight of $\mathrm{H}$

The first term In Eq. (4.26) is the Dufour energy flux due to a concentration gradient in the material. The form given is derived assuming that the diffusing spectes is dilute and obeys Henry's law. Although this is not true for a large concentration of hydrogen in zirconium, the difference is neglected since the Dufour flux is generally very small. The second term in Eq. (4.27) is the Soret mass flux due to a temperature gradient in the material. This can be a significant term in the presence of large temperature gradients guch as exist in the laser-heated material.

Substituting Eqs. (4.26) and (4.27) in Eqs. (4.24) and (4.25) gives the hydrogen and energy conservation equations in the form:

$$
\frac{\partial c_{H}}{\partial t}=\frac{\partial}{\partial x}\left[D \frac{\partial c_{H}}{\partial x}+\frac{D Q * c_{H}}{R T^{2}} \frac{\partial T}{\partial x}\right]
$$

$\rho C_{v} \frac{\partial T}{\partial t}=\frac{\partial}{\partial x}\left[\frac{D Q *}{M_{H}} \frac{\partial C_{H}}{\partial x}+k \frac{\partial T}{\partial x}\right]+\left[D \frac{\partial C_{H}}{\partial x}+\frac{D Q * c_{H}}{R^{2}} \frac{\partial T}{\partial x}\right] \frac{\partial \bar{h}_{H}}{\partial x}+A(x, t)$

The initial and boundary conditions for $T$ and $c_{B}$ are:

$$
\begin{aligned}
& T(x, 0)=T_{0} ; T(\infty, t)=T_{0} \\
& c_{H}(x, 0)=c_{0} ; C(\infty, t)=C_{0}
\end{aligned}
$$




$$
\begin{gathered}
-\left.j_{H}\right|_{x=0}=\left.D \frac{\partial c_{H}}{\partial x}\right|_{x=0}+\left.\frac{D Q * C_{H}}{R T^{2}} \frac{\partial T}{\partial x}\right|_{x=0}=2 \Phi\left(T_{s}, c_{s}\right) M_{H} \\
-\left.q\right|_{x=0}=\left.\frac{D Q *}{M_{H}} \frac{\partial c_{H}}{\partial x}\right|_{x=0}+\left.k \frac{\partial T}{\partial x}\right|_{x=0}=-A_{s}(t)+\varepsilon \sigma\left(T_{s}^{4}-T_{0}^{4}\right) \\
+2 \Phi\left(T_{s}, c_{s}\right) \Delta H_{\text {vap }}\left(T_{s}, c_{s}\right)
\end{gathered}
$$

where the coefficient " 2 " of $\Phi$ is due to the fact that Eq. (3.4) gives the flux of $\mathrm{H}_{2}$. $\quad \Delta \mathrm{H}_{\text {vap }} \frac{1}{2} \mathrm{H}_{\mathrm{H}_{2}}^{\circ}-\overline{\mathrm{H}}_{\mathrm{H}}$ is the heat of vaporization per mole of $\mathrm{H}$ atoms which equals the negative of the relative partial molar enthalpy of $H$ in zirconium hydride, where $\bar{H}_{H}$ is simply equal to $M_{H} \bar{h}_{H}$. $\Delta \mathrm{H}_{\text {vap }}$ is found in terms of the $\mathrm{H}_{2}$ vapor pressure, as described in Section $\mathrm{V}-\mathrm{B}-4$. The remaining terms in $\mathrm{Eq} \cdot(4.30)$ have been defined previously.

The boundary conditions can be separated to find $\left.\frac{\partial c_{H}}{\partial x}\right|_{x=0}$ and $\left.\frac{\partial T}{\partial x}\right|_{x=0}$ explicitly. It is also conventent to put the equations in terms of $\mathrm{H} / \mathrm{Zr}$ atom ratio $\mathrm{y}$ rather than mass concentration $c_{H}$. Af ter making these changes, the conservation equations becone:

$$
\begin{gathered}
\frac{\partial y}{\partial t}=\frac{\partial}{\partial x}\left[D \frac{\partial y}{\partial x}+\frac{D Q^{*}}{R T^{2}} \frac{\partial T}{\partial x}\right] \\
\partial C_{v} \frac{\partial T}{\partial t}=\frac{\partial}{\partial x}\left[D Q^{*} N_{0} \frac{\partial y}{\partial x}+k \frac{\partial T}{\partial x}\right]+D_{0}\left[\frac{\partial y}{\partial x}+\frac{Q^{*} y}{R T^{2}} \frac{\partial T}{\partial x}\right] \frac{\partial \bar{H}_{H}}{\partial x}+A(x, t)
\end{gathered}
$$


with boundary conditions:

$$
\begin{gathered}
T(x, 0)=T_{0} ; T(\infty, t)=T_{0} \\
y(x, 0)-y_{0} ; y(\infty, t)=y_{0} \\
k-\frac{\partial \Phi\left(\Delta H_{v a p}-Q *\right)-A_{B}(t)+\varepsilon \sigma\left(T_{s}^{4}-T_{0}^{4}\right)}{D *^{2} N_{0} y_{s}} \\
R T_{s}^{2} \\
\left.\left(\frac{\partial y}{\partial x}\right)\right|_{x=0}=\frac{2 \Phi}{N_{0} D}-\left.\frac{Q^{*} y_{s}}{R T_{B}^{2}}\left(\frac{\partial T}{\partial x}\right)\right|_{x=0}
\end{gathered}
$$

where $\mathrm{N}_{0}=\rho_{0} /\left(\mathrm{M}_{\mathrm{Zr}}+\mathrm{y}_{\mathrm{O}} \mathrm{M}_{\mathrm{H}}\right)=$ number of zirconium atoms per untt volume

$\rho_{0}=$ initial density $\left(\mathrm{gm} / \mathrm{cm}^{3}\right)$

$y_{0}=$ initial $\mathrm{H} / \mathrm{Zr}$ atom ratio

$y_{S}=H / Z r$ atom ratio at the surface

$\mathrm{T}_{\mathrm{s}}=$ surface temperature

An approximate solution for the zirconium hydride temperature can be obtained analytically from Eqs. (4.31b, c and e) by assuming $Q *, \Phi$, and $\frac{\partial \bar{H}_{H}}{\partial x}$ are zero and that $k$ and $C_{v}$ are constant. The solution for a triangular pulse is the same as that given for heating of iron by Eq. (4.7). However, there is no useful analytic solution for $y$ because of the strong temperature dependence of $D$ and the strong temperature and $\mathrm{H} / \mathrm{Zr}$ ratio dependence of $\Phi$. Therefore, it is desirable to calculate both $T$ and $y$ by a numerical solution as described in Append1x B. 
V. MATERIAL PROPERTIES USED IN THE NUMERICAL CALCULATIONS

\section{A. Iron Properties}

\section{Vapor Pressure}

The vapor pressure of tron is given by Nesmetanov ${ }^{49}$ as:

$$
\log _{10} P=19.00206-21.67992 \times\left(\frac{10^{3}}{T}\right)+0.09398 \times\left(\frac{T}{10^{3}}\right)-2.59964 \log _{10} T
$$

$$
\text { for solid iron } 29^{n \circ} \mathrm{K}<\mathrm{T}<1812^{\circ} \mathrm{K}
$$

$$
\log _{10} P=-25.93396-14.1245 \times\left(\frac{10^{3}}{T}\right)-1.1331 \times\left(\frac{T}{10^{3}}\right)+10.59505 \log _{10} T
$$

for liquid iron $1812^{\circ} \mathrm{K}<\mathrm{T}<3045^{\circ} \mathrm{K}$

where $P$ is the vapor pressure in $m \mathrm{Hg}$, and $\mathrm{T}$ is in ${ }^{\circ} \mathrm{K}$.

For temperatures greater than the boiling point $\left(3045^{\circ} \mathrm{K}\right)$ it is assumed that the vapor pressure is still given by Eq. (5.1b). The vapor pressure is a very rapidly increasing function of temperature. The vapor pressure at the melting point $\left(1812^{\circ} \mathrm{K}\right)$ is only $0.0546 \mathrm{~mm} \mathrm{Hg}$, while at $3045^{\circ} \mathrm{K}$ it is 1 atmosphere or $760 \mathrm{~mm} \mathrm{Hg}$ (by definition of boiling point).

\section{Heat of Vaporization}

The heat of vaporiration is determined from the expression for the vapor pressure (Eqs. (5.1)) using the Clapeyron equation: 50

$$
\Delta H_{\text {vap }}=-R \frac{d \ln P}{d(1 / T)}
$$

where $\mathrm{R}=$ gas constant $=1.987 \mathrm{cal} /{ }^{\circ} \mathrm{K}$ mole.

The value of $\Delta \mathrm{H}_{\text {vap }}$ varies from $96.7 \mathrm{kcal} / \mathrm{mole}$ at $298^{\circ} \mathrm{K}$ to $80 \mathrm{kcal} / \mathrm{mole}$ 
at $3045^{\circ} \mathrm{K}$. These values are about $3 \%$ lower than those given in the JANAF tables. 28

\section{Specific Heat}

The specific heat of Iron exhlbits several discontinuities in going from room temperature to above the melting point because of changes In cryatal etructure. According to the JANAF tables ${ }^{28}$ there 18 an alpha to gammatransition at $1184^{\circ} \mathrm{K}$ with a heat of transition $\Delta \mathrm{H}_{\mathrm{t}_{1}}=0.225 \mathrm{kcal} / \mathrm{mole}$, a gamma to delta transition at $1665^{\circ} \mathrm{K}$ with a heat of transition $\Delta \mathrm{H}_{\mathrm{t}_{2}}$ " $0.260 \mathrm{kcal} / \mathrm{mole}$, and a solid to 1 iquil transition at $1809^{\circ} \mathrm{K}$ with $\Delta \mathrm{H}_{\mathrm{m}}=$ $3.630 \mathrm{kcal} / \mathrm{mole}$. In addition, the specific heat exhibits a sharp peak at the Curle point $\left(1042^{\circ} \mathrm{K}\right)$ because of a magnetic transformation.

The molar enthalpy of a materlal at temperature $T$ can be expressed in terms of the heats of transition and melting and the molar heat capacity at constant pressure $C_{p}$ as follows:

$$
H^{\circ}(T)=H_{298}^{\circ}+\sum_{1} \Delta H_{t_{1}}+\int_{298}^{T} c_{p} d T^{\prime}
$$

where $H_{298}^{\circ}$ standard molar enthalpy at $T=298^{\circ} \mathrm{K}$ and the sum of $\Delta H_{1}$ includes all transitions occurring between $298^{\circ} \mathrm{K}$ and $\mathrm{T}$.

The heats of transition and melting could be taken into consideration by defining an apparent rolar heat capacity $C_{p}^{\prime}$ equal to:

$$
C_{p}^{\prime}(T)=C_{p}(T)+\sum_{1} \Delta H_{t_{1}} S\left(T-T_{t_{1}}\right)
$$

where $\delta\left(T-T_{t_{i}}\right)=$ Dirac delta function

$T_{t_{1}}=$ transition or melting temperature

Since the integral of the delta function across a transition temperature is unity: 


$$
H^{\circ}(T)=H_{298}^{\circ}+\int_{298}^{T} C_{p}^{\prime} d^{\prime}
$$

Since discontinuities in material properties are not desirable in the numerical solution of the conduction equation, the heat capacity is approximated by a continuous function of temperature. Instead of using a delta function to account for the heat of melting, a Gaussian function of finfte width centered at the melting point is used. The sharp peak at the Curfe point is also approximated by a Gaussian function. The heats of transition are taken into account by uniformly increasing the specific heat in the range between the two transition temperatures. The numerical values for heat capacity and enthalpy given in the JANAF tables ${ }^{28}$ were used in conjunction witil the graph of heat capacity vs temperature given by Lange 51 to obtain the following approxinate form for the apparent spectfic heat in $\left(\mathrm{cal} / \mathrm{gm}^{\circ} \mathrm{K}\right)$.

$$
\begin{aligned}
& C= \frac{1}{55.85}\left[\frac{766}{\sqrt{\pi \sigma_{1}}} \exp \left(-\frac{(T-1000)^{2}}{\sigma_{1}^{2}}\right)+\frac{3630}{\sqrt{\pi} \sigma_{2}} \exp \left(-\frac{(T-1809)^{2}}{\sigma_{2}}\right)\right] \\
&+\frac{1}{55.85}\left[\begin{array}{l}
3.369+7.289\left(\frac{T}{10^{3}}\right) \text { for } 298^{\circ} \mathrm{K}<\mathrm{T}<800^{\circ} \mathrm{K} \\
9.2 \text { for } 800^{\circ} \mathrm{K}<\mathrm{T}<1200^{\circ} \mathrm{K} \\
13.768-7.748\left(\frac{\mathrm{T}}{10^{3}}\right)+3.284\left(\frac{\mathrm{T}}{10^{3}}\right)^{2} \text { for } 1200^{\circ} \mathrm{K}<\mathrm{T}<1809^{\circ} \mathrm{K} \\
10.50+4.0 \times 10^{-4}(\mathrm{~T}-1809) \text { for } \mathrm{T}>1809^{\circ} \mathrm{K}
\end{array}\right.
\end{aligned}
$$

where $\sigma_{1}=$ half width of the Curie peak $=130^{\circ} \mathrm{K}$

$\sigma_{2}=$ half width of the heat of melting peak $=50^{\circ} \mathrm{K}$ 
The fit was made so that the $\int_{298}^{T} \operatorname{cd} T^{\prime}$ was approximately equal to the Increase in specific enthalpy in going from $298^{\circ} \mathrm{K}$ to $\mathrm{T}$. The above equation gives the specific heat at conotant prossure rather than constant volume as used in the conduction equation (Eq. (4,3)). The gmall difference between these is neglected since the actual process probably occurs closer to constant pressure than constant volume.

\section{Thermal Conductivity}

Like the specific heat, the thermal conductivity of iron exhlbits discontinuities at the phase transition temperatures. An approximate continuous form was made by a least squares fit of $U$. S. National Bureau of Standards data ${ }^{52}$ for temperature less than $1200^{\circ} \mathrm{K}$ and by linear approximations of the Lange data ${ }^{51}$ for temperature greater than $1200^{\circ} \mathrm{K}$. The thermal conductivity is assumed to be constant in the liquid range. The form used for $k$, given in (cal/cm sec $K$ ) is:

$$
\begin{aligned}
k & =0.2770-0.3144\left(\frac{T}{10^{3}}\right)+0.1173\left(\frac{T}{10^{3}}\right)^{2} \text { for } 298^{\circ} \mathrm{K}<\mathrm{T}<1200^{\circ} \mathrm{K} \\
& =0.0395+0.02428\left(\frac{\mathrm{T}}{10^{3}}\right) \text { for } 1200^{\circ} \mathrm{K}<\mathrm{T}<1700^{\circ} \mathrm{K} \\
& =-0.0858+0.0980\left(\frac{\mathrm{T}}{10^{3}}\right) \text { for } 1700^{\circ} \mathrm{K}<\mathrm{T}<1900^{\circ} \mathrm{K} \\
& =0.100 \text { for } \mathrm{T}>1900^{\circ} \mathrm{K}
\end{aligned}
$$

\section{Density}

Although the conduction equation was derived under the assumption of constant volume and therefore constant density, the small variation of density with temperature was considered in order to give a more 
realistic value for the thermal diffusivity. The density data of Lange ${ }^{51}$

$$
\begin{aligned}
\rho & =7.990-0.368\left(\frac{T}{10^{3}}\right) \text { for } 298^{\circ} \mathrm{K}<\mathrm{T}<1700^{\circ} \mathrm{K} \\
& =10.82-2.05\left(\frac{\mathrm{T}}{10^{3}}\right) \text { for } 1700^{\circ} \mathrm{K}<\mathrm{T}<1900^{\circ} \mathrm{K} \\
& =8.63-0.90\left(\frac{\mathrm{T}}{1.0^{3}}\right) \text { for } \mathrm{T}>1900^{\circ} \mathrm{K}
\end{aligned}
$$

where $\rho$ is in $\left(\mathrm{gm} / \mathrm{cm}^{3}\right)$.

\section{Reflectivity}

The reflectivity of iron at $6943 \AA$ is the most difficult of the Iron properties to characterize. Data from Ref, 53 indicates that the reflectivity of solfd iron varies from 0.45 to 0.66 depending on the surface condition and temperature.

Since the reflectivity is not well known, the numerical calculations are made assuming the reflectivity has some adjustable constant value $R$. The calculations are made for varying absorbed energy densities. The incident energy density is then hypothesized to be equal to the absorbed energy density divided by $(1-R)$.

\section{B. Zircontum Hyäride Properties}

\section{Zircontum-Hydrogen Phase System}

Zirconium is an exothermic absorber of hydrogen which forms solid solutions and hydrides of varying composition depending on temperature and hydrogen content. The phase dlagram of the $\mathrm{Zr}-\mathrm{H}$ system as given by Beck and Mueller ${ }^{54}$ is shown in F1g. 15. The alpha and beta phases are low and high temperature solid solutions of hydrogen in alpha and 


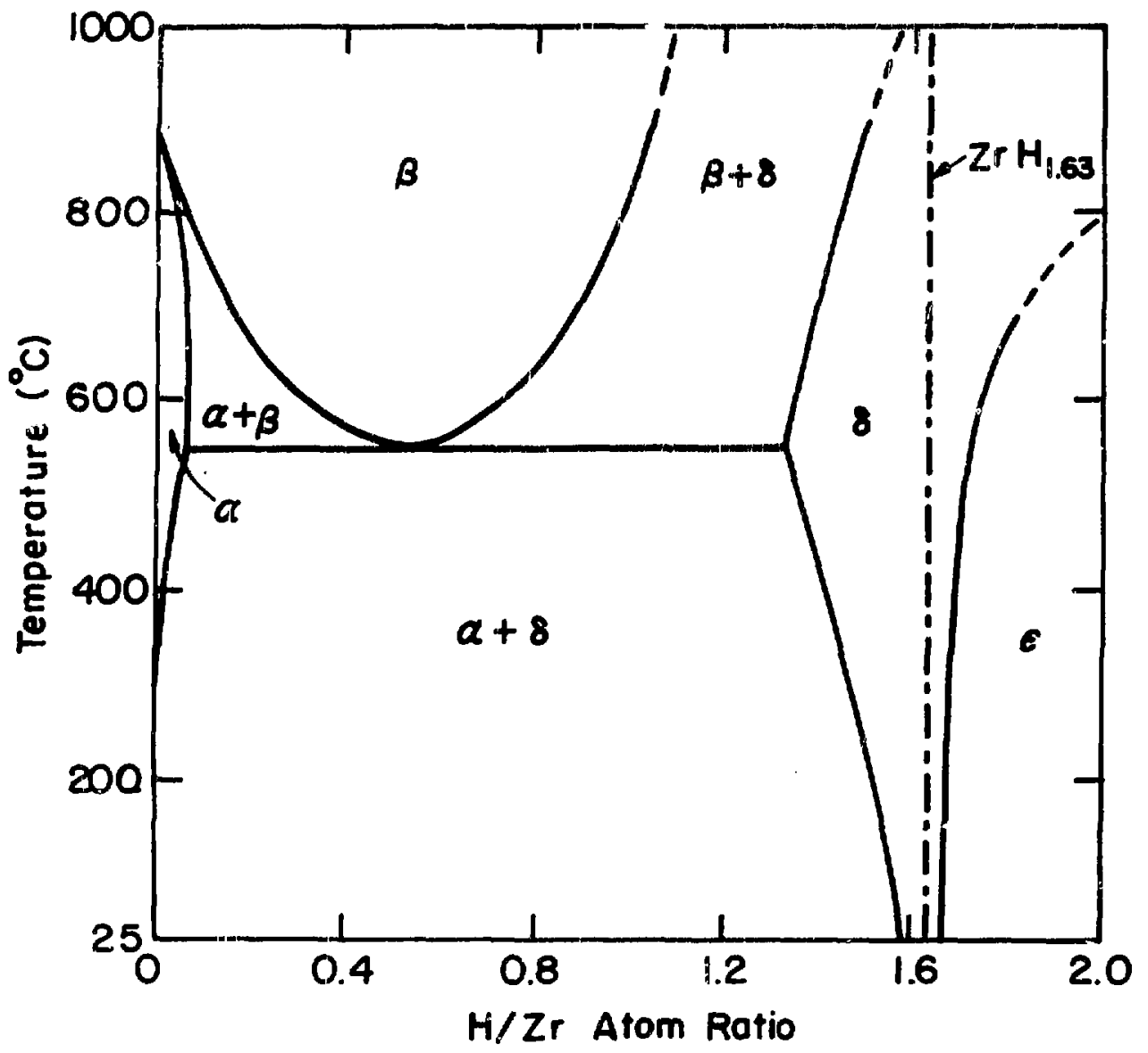

XBL $7211-7225$

Fig. 15 Zirconium-hydrogen phase diagram. $\mathrm{ZrH}_{1.63}$ was the composition used in the present studies. 
beta zirconfum respectively. The delta and epsilon phases are high hydrogen content hydride phases with maximum hydrogen content at the stoichlometric composition $\mathrm{ZrH}_{2}$.

Experimental evidence indicates that the hydrogen exists as $\mathrm{H}$ atoms rather than $\mathrm{H}_{2}$ molecules in the zirconfum lattice. At low hydrogen concentration the solubility of hydrogen is proportional to the square root of $\mathrm{H}_{2}$ pressure. 55 This is the behavior predicted by Sieverts 1 aw 56 for the hydrogen existing as atoms in solution. Neutron diffraction studies have shown that the delta phase has a fluorite structure with the zirconium atoms on a face-centered cubfc lattice and the hydrogen atoms in tetrahedral sites. 54 The beta phase consists of zirconium atoms on a body-centered cubic lattice with the $H$ atoms in solid solution.

If the behavior of the zircontum hydride during the Q-switch laser pulse is truly an equilibrium process, the phase structure at all times would be given by the equillbrium phase diagram FIg. 15 . As the delta phase hydride heats up, vaporization from the surface depletes the hydrogen concentration. When the temperature and hydrogen concentration are at the boundary between the delta and beta plus deita reglons, further depletion of hydrogen would bring the material Into the beta plus delta phase reglon. Delta shase hydride sould be converted to beta phase until all delta phase is corverted. Still further hydrogen depietion would be all in the beta phase.

In order for this complete equllibrium model to hold, the delta to beta phase transition would have to occur in times the order of $10^{-8}$ seconds, which is many orders of magnitude smaller than times of normal phase changes. In the process of changing from delta to beta phase, 
the zirconium lattice must change from FCC to BCC structure and the hydrogen must redistribute so that the beta phase has a low hydrogen concentration. It is possible, but not probable, that these changes could take place in such a short time since the time scale is large compared to atom oscillation times $\left(10^{-13} \mathrm{sec}\right)$, the hydrogen atoms are very mobile at high temperatures, and since hydroger migration need occur only over very short distances $\left(.20^{-6} \mathrm{~cm}\right)$. Experiments on pulse-heating of zirconium-uranium hydride rods have shown ${ }^{57}$ that the delta to beta phase change can occur at least in times on the order of $10^{-1}$ sec.

If the temperature transient is too rapid for the phase change to occur, the sample would stay in the delta phase configuration but could have hydrogen content lower than that given by the equilibrium phase diagram. This will be denoted as the quasi-equilibrium case since the phase structure is not that given by the equilibrium phase diagram for hydrogen content less than that at the delta-beta plus delta boundary. Material properties for this case are extrapolated Erom known values in the delta phase.

Both the equilibrium ani quasi-equilibrium models are used to predict the behavior of the zirconfum hydride when heated by a 4 -switch laser pulse. The actual behavior is probably somewhere between the two models. Possibly, the quast-equilibrium model is valld for hydrogen concentration not much less than that at the delta-beta plus delta boundary. For hydrogen cuncentrations much less than at this boundary the delta phase atrcontum lattice vould probably collapse to the equilibrium beta zirconium lattice. 


\section{Vapor Pressure}

\section{a. Equilibrium model}

The equilibrium vapor pressure of hydrogen over $\mathrm{Zr}-\mathrm{H}$ is a strong function of both hydrogen content and temperature. Simnad and Dee 58 give an impirical fit by Raymond for the vapor pressure of delta and epstlon phase as follows:

$$
\begin{aligned}
& \log _{10} P_{\delta}=-3.8415+38.6433 y-34.2639 y^{2}+9.4821 y^{3} \\
&+ {\left[-31.2982+23.5741 y-0.0280 y^{2}\right]\left(\frac{10^{3}}{T}\right) } \\
& \text { for } y>y_{\delta}
\end{aligned}
$$

where $\mathrm{P}_{\delta}=$ vapor pressure of $\mathrm{H}_{2}$ in atmcspheres

$$
\begin{aligned}
T & =\text { temperature } 1{ }^{\circ} \mathrm{K} \\
\mathrm{y} & =\mathrm{H} / \mathrm{Zr} \text { atom ratio } \\
\mathrm{y}_{\delta} & =\mathrm{H} / \mathrm{Zr} \text { atom ratio at the delta-beta plus delta boundary }
\end{aligned}
$$

A least squares fit of the vapor pressure data for the beta plus delta region compiled by Beck and Mueller ${ }^{54}$ is:

$$
\text { In } P_{\beta+\delta}=28.684-25.496\left(\frac{10^{3}}{\mathrm{~T}}\right) \text { for } \mathrm{y}_{\beta}<y<y_{\delta}
$$

where $\mathrm{P}_{B+\delta}$ = vapor pressure of $\mathrm{H}_{2}$ in $\mathrm{mm} \mathrm{H}_{8}$

$$
y_{B}=H / 2 r \text { ratio at the beta-beta plus delta boundary }
$$

An approximate fit of the Beck and Muelles data 54 for the beta phase vapor pressure (in m $\mathrm{Hg}$ ) is:

$$
\begin{gathered}
\ln P_{B_{1}}=10.753+15.750 y-(10.610+12.503 y)\left(\frac{10^{3}}{T}\right) \\
\text { for } 0.1<y<y_{\beta}
\end{gathered}
$$




$$
P_{\beta_{2}}=\left.P_{B_{1}}\right|_{y=0.1} \times\left(\frac{y}{0.1}\right)^{2} \text { for } 0<y<0.1
$$

Equation (5.9d) requires the vapor pressure to obey sleverts law for $y$ less than 0.10 . Figure 16 shows the $\log _{10} P$ vs $y$ as given by Eqs. (5.9) for temperature increments of $50^{\circ} \mathrm{C}$ from $\mathrm{T}=550^{\circ} \mathrm{C}$ to $1100^{\circ} \mathrm{C}$.

b. Quas1-equ111brium mode1

For no delta to beta phase change, the vapor pressure is assumed to be given by Eq. (5.9a) for y greater than 1.425. For y less than 1.425, two models are proposed: a) the vapor pressure at constant temperature is extrapolated to lower y with some constant slope (see Fig. 17) or b) It is extrapolated with a continuous slope that depends on temperature (see F1g. 18). In both cases, Sieverts law is assumed for $y$ less than 0.1 .

3. Total and Partial Molar Enthalples of $\mathrm{ZrH}_{\mathrm{y}}$

The total enthalpy of a mole of $\mathrm{ZrH}_{\mathrm{y}}$ is equal to

$$
\mathrm{H}=\overline{\mathrm{H}}_{\mathrm{Zr}}+\mathrm{y} \overline{\mathrm{H}}_{\mathrm{H}}
$$

where $\ddot{\mathrm{ir}}_{\mathrm{Zr}}=$ partial molar enthalpy of $\mathrm{Zr}$

$\overline{\mathrm{H}}_{\mathrm{H}}=$ partial molar eñthalpy of $\mathrm{H}$

In $a$ one phase region, the relative partial molar enthalp $y$ of $\mathrm{H}$ is given in terms of the slope of the vapor pressure curve at constant y by the relation: 56

$$
\overline{\mathrm{H}}_{\mathrm{H}}-\frac{1}{2} \quad \mathrm{H}_{\mathrm{H}_{2}}^{\circ}=\frac{\mathrm{R}}{2}\left[\frac{\partial}{\partial(\bar{l} / \mathrm{T})}\right]_{y}
$$




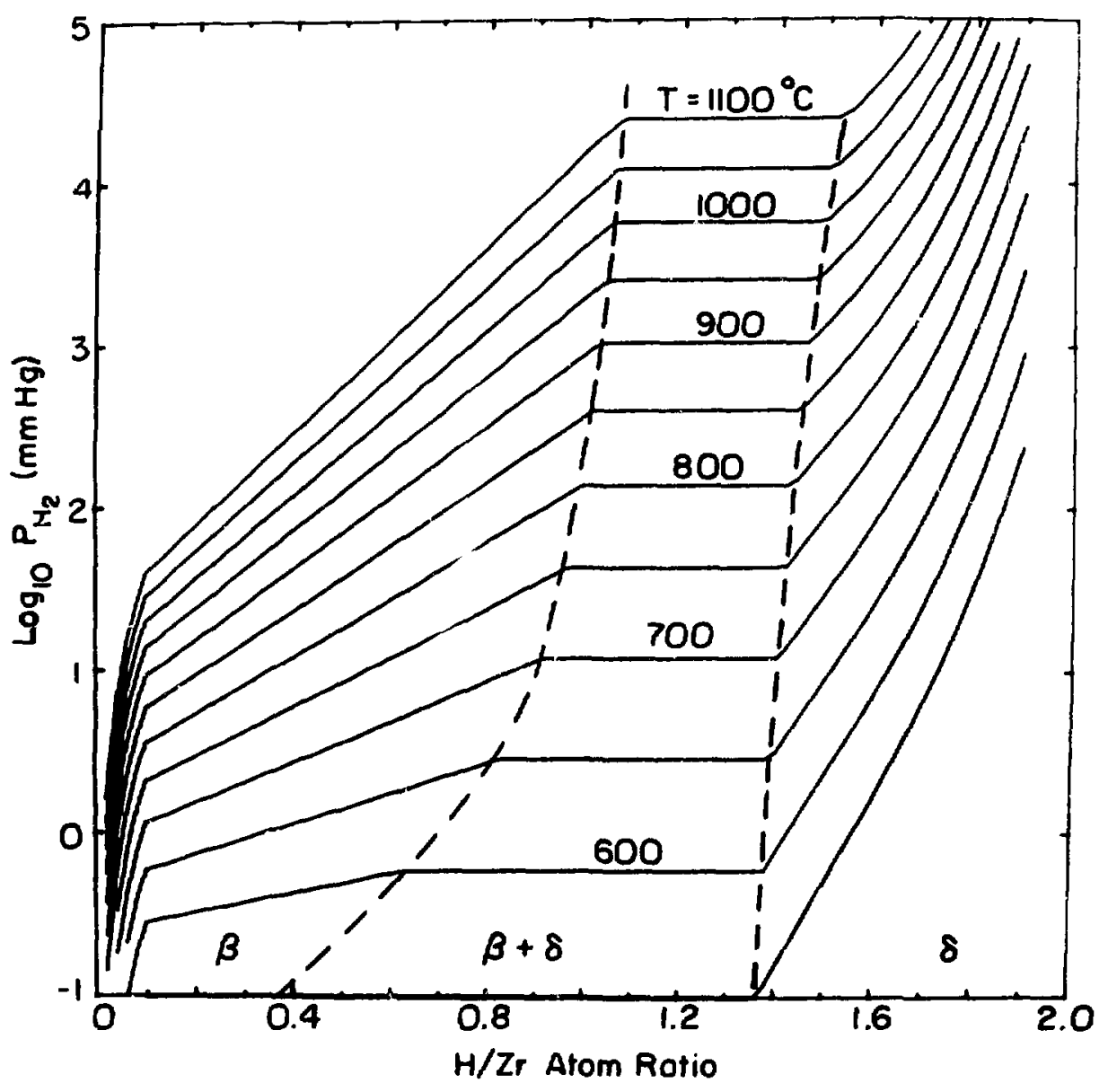

XBL $7210-5778$

Fig. $16 \mathrm{H}_{2}$ pressure-composition isotherms for zirconfum-hydrogen system, equilibrium model. 


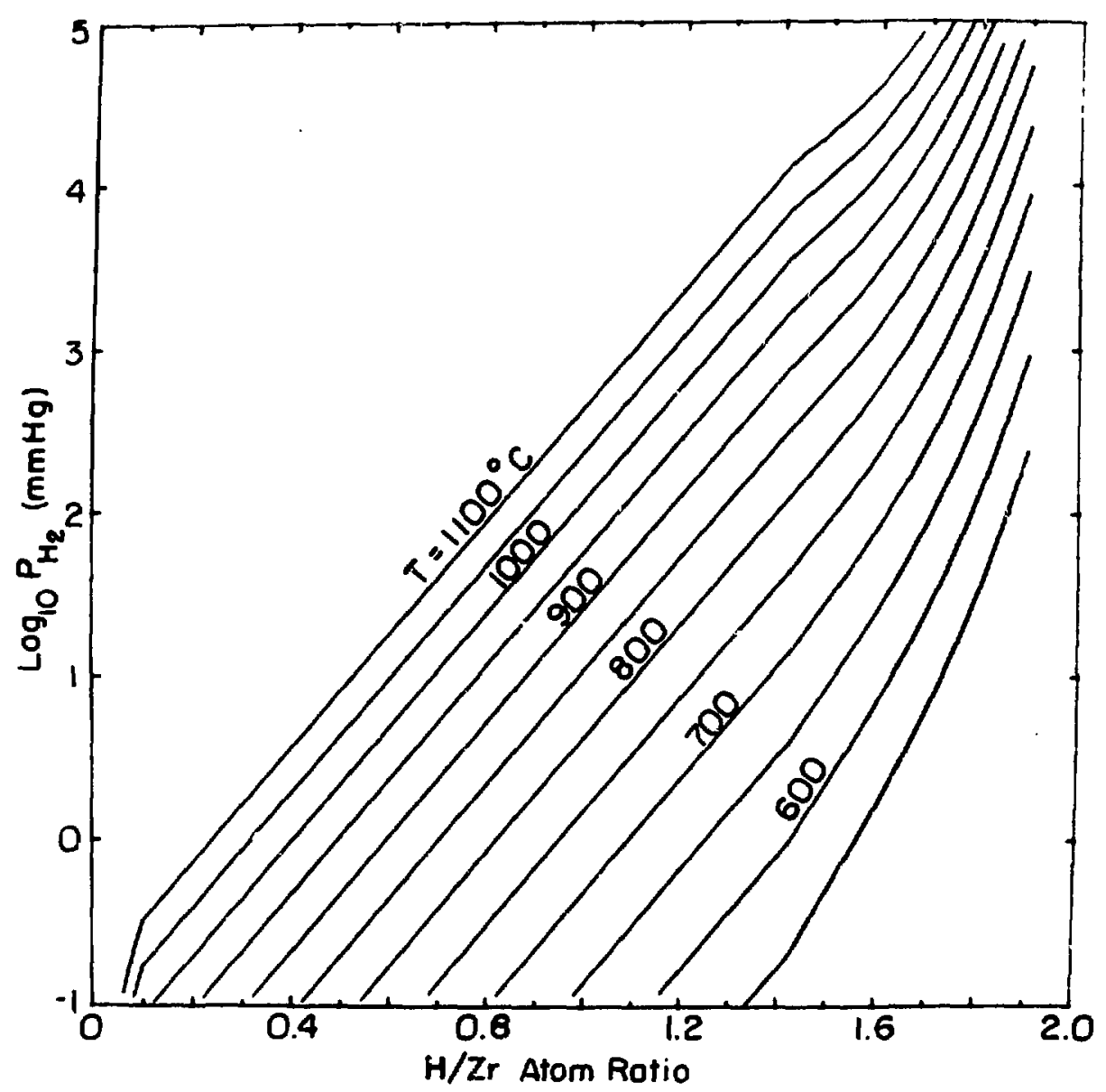

XBL $7210-5779$

F1g. $17 \mathrm{H}_{2}$ pressure-composition 1sotherms, quasi-equilibrium model with vapor pressure extrapolated to lower composition with constant slope. 


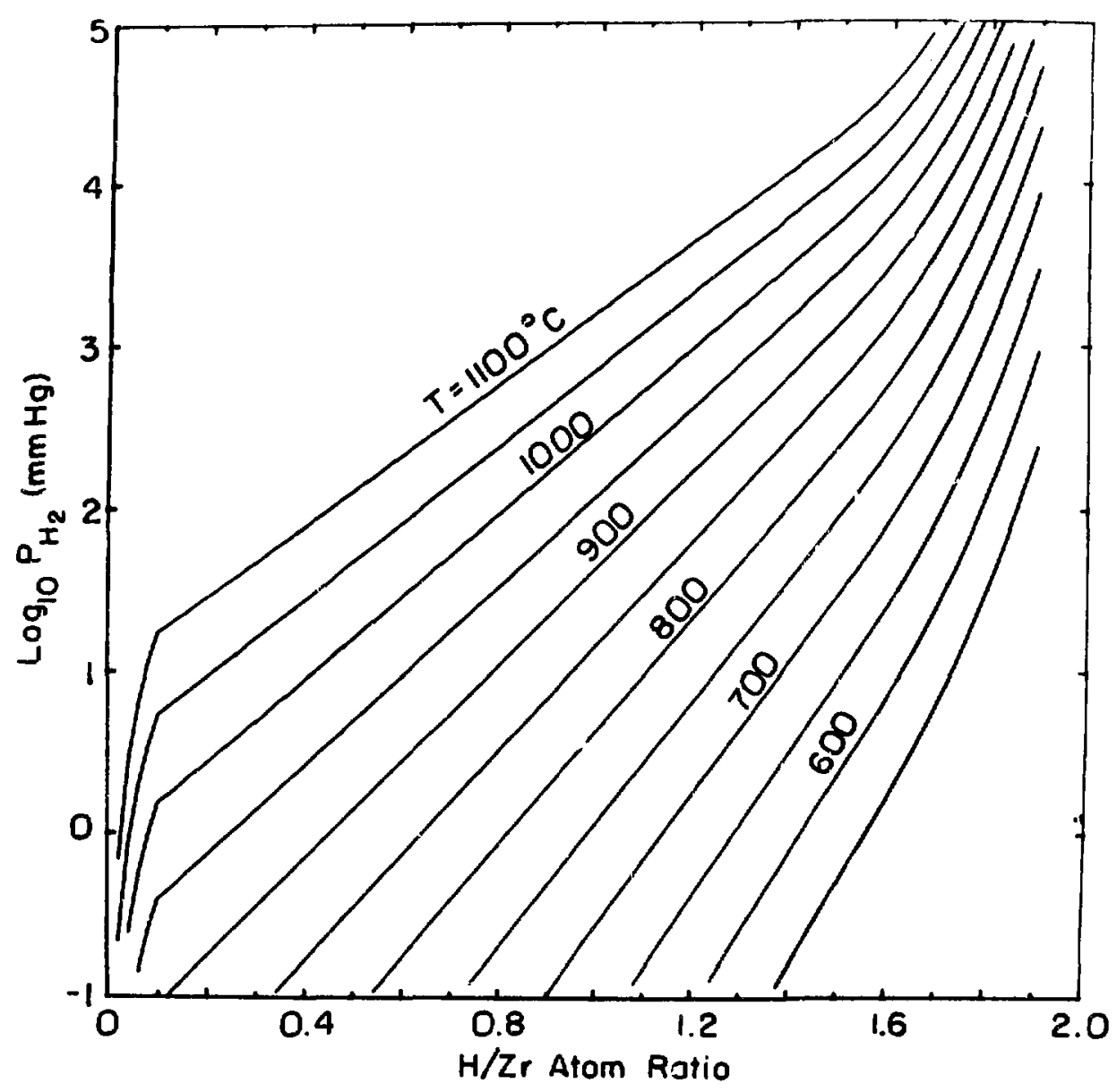

XBL $7210-5780$

Fig. $18 \mathrm{H}_{2}$ pressure-composition 1sotherms, quasi-equilibrium model with vapor pressure extrapolated to lower composition with continuous slope. 
where $\mathrm{H}_{\mathrm{H}_{2}}^{\circ}=$ standard molar enthalpy of $\mathrm{H}_{2} \mathrm{~g}$

$R=$ gas constant

$P$ - vapor pressure in a single phase region given by

Eq. $(5.9 a, c, d)$

In the two ghase beta pulse delta region in the equilibrium model, the true composition of $2 \mathrm{rH}_{\mathrm{y}}$ in terws of $\mathrm{ZrH}_{\mathrm{y}_{B}}$ and $2 \mathrm{rH}_{\mathrm{y}_{\delta}}$ is given by the lever rule:

$$
\operatorname{zrH}_{y}=\frac{\left(y_{\delta}-y\right)}{\left(y_{\delta}-y_{\beta}\right)} \quad \operatorname{rrH}_{y_{B}}+\frac{\left(y-y_{B}\right)}{\left(y_{\delta}-y_{B}\right)} \quad \operatorname{rrH}_{y_{\delta}}
$$

The total enthalpy of $\mathrm{ZrH}_{\mathrm{y}}$ in this two phase region is then:

$$
H=\frac{\left(y_{\delta}-y\right)}{\left(y_{\delta}-y_{\beta}\right)}\left[\bar{H}_{2 x_{y_{\beta}}}+y_{\beta} \bar{H}_{\mathrm{H}_{y_{\beta}}}\right]+\frac{\left(y-y_{\beta}\right)}{\left(y_{\delta}-y_{\beta}\right)}\left[\bar{H}_{z_{y_{\delta}}}+y_{\delta} \bar{H}_{\mathrm{H}_{y_{\delta}}}\right]
$$

Identifying $\overline{\mathrm{H}}_{\mathrm{Zx}}$ and $\overline{\mathrm{H}}_{\mathrm{H}}$ from EqB. (5.10) and (5.13) gives

$$
\tilde{\mathrm{u}}_{\mathrm{zr}}=\frac{\left(\mathrm{y}_{\delta}-\mathrm{y}\right)}{\left(\mathrm{y}_{\delta}-\mathrm{y}_{\beta}\right)} \overline{\mathrm{t}}_{\mathrm{zr} \mathrm{y}_{\beta}}+\frac{\left(\mathrm{y}-\mathrm{y}_{\beta}\right)}{\left(\mathrm{y}_{\delta}-\mathrm{y}_{\beta}\right)} \overline{\mathrm{H}}_{\mathrm{zr}}
$$

and

$$
\overline{\mathrm{H}}_{\mathrm{H}}=\frac{\mathrm{y}_{\beta}}{\mathrm{y}} \frac{\left(\mathrm{y}_{\delta}-\mathrm{y}\right)}{\left(\mathrm{y}_{\delta}-\mathrm{y}_{\beta}\right)} \overline{\mathrm{H}}_{\mathrm{H}_{\mathrm{y}}}+\frac{y_{\delta}}{\mathrm{y}} \frac{\left(y-y_{\beta}\right)}{\left(y_{\delta}-y_{\beta}\right)} \overline{\mathrm{H}}_{\mathrm{H}_{\delta}}
$$

where $\bar{H}_{y_{B}}=$ partial molar enthalpy of $\mathrm{H}$ in betal phasp at composition $\mathrm{y}_{\beta}$ $\overline{\mathrm{H}}_{\mathrm{y}_{\delta}}=$ partial molar enthalpy of $\mathrm{H}$ in delta phase at composition $y_{\delta}$ 


\section{Heat of Vaporization}

The heat of vaporlzation is equal to the negative of the relative partial molar enthalpy of $\mathrm{H}$. Therefore, for a single phase region $\Delta \mathrm{H}_{\text {vap }}$ Is given by Eq. $(5.11)$ :

$$
\Delta H_{\text {vap }}=-\left(\bar{H}_{H}-\frac{1}{2} H_{H_{2}}^{\circ}\right)=-\left.\frac{R}{2}\left[\frac{\partial \ln P}{\partial(1 / T)}\right]\right|_{y}
$$

For a two phase region, $\Delta H_{\text {vap }}$ is found from Eqs. (5.15) and (5.16a):

$$
\Delta H_{\text {vap }}=\frac{y_{\beta}}{y} \frac{\left(y_{\delta}-y\right)}{\left(y_{\delta}-y_{\beta}\right)} \Delta H_{\text {vav }}+\frac{y_{\delta}}{y} \frac{\left(y-y_{\beta}\right)}{\left(y_{\delta}-y_{\beta}\right)} \Delta H_{v a p_{y_{\delta}}}
$$

The heat of vaporfzation calculated from Eqs. (5.16) and the given vapor pressure equations varies with composition, but is on the order of $20 \mathrm{kcal} / \mathrm{mole}$ of $\mathrm{H}$ atoms.

\section{Spec1fic Heat}

The heat capacity data given in Ref. 54 was found to fit the form:

$$
c_{p}=c_{Z r}+y \bar{c}_{H}
$$

where $C_{p}=$ heat capacity of $\mathrm{ZrH}_{\mathrm{y}}$ per mole of $\mathrm{Zr}$

$\mathrm{C}_{\mathrm{Zr}}=$ molar heat capacity of pure $\mathrm{Zr}$

$\overline{\mathrm{C}}_{\mathrm{H}}$ = partial molar heat capactty of hydrogen in $\mathrm{ZrH}_{\mathrm{y}}$

$\mathrm{C}_{\mathrm{Zr}}$ in (cal/ ${ }^{\circ} \mathrm{K}$-mole $\mathrm{Zr}$ ) is $\mathrm{f} 1 \mathrm{t}$ to the form:

$$
\begin{aligned}
C_{Z r} & =5.3+3.33\left(\frac{T}{10^{3}}\right) \text { for } \mathrm{T}<600^{\circ} \mathrm{K} \\
& =6.46+1.4\left(\frac{\mathrm{T}}{10^{3}}\right) \text { for } 600^{\circ} \mathrm{K}<\mathrm{T}<1100^{\circ} \mathrm{K} \\
& =8.0 \text { for } \mathrm{T}>1100^{\circ} \mathrm{K}
\end{aligned}
$$


$\overline{\mathrm{C}}_{\mathrm{H}}$ was fit to the form for lattice heat capacity according to the Einstein model: 59

$$
\bar{c}_{H}=7.0\left(\frac{\theta_{E}}{T}\right)^{2} \frac{\exp \left(\theta_{E} / T\right)}{\left(\exp \left(\theta_{E} / T\right)-1\right)^{2}}\left(\frac{\operatorname{cal}}{{ }^{\circ} \mathrm{K} \text { mole } H}\right)
$$

where $\theta_{E}=$ Elnstein temperature, which was chosen to be $1650^{\circ} \mathrm{K}$. This relatively large value for the EInsteln temperature is due to the low hydrogen atom mass, which causes a high frequency of vibration of hydrogen atoms in the lattice.

The specific heat is equal to the heat capacity given by Eqs. (5.17) divided by the gram molecular weight of $\mathrm{ZrH}_{\mathrm{y}}$. That is,

$$
c \cong \frac{c_{p}}{92.2}\left(\frac{c a l}{{ }^{\circ} \mathrm{K} g \mathrm{~m}}\right)
$$

In the beta plus delta region in the equilfibrium model, there is an additional contribution to the apparent heat capacity because of the change in enthalpy in converting delta phase to beta phase at constant $y$. This contribution is neglected, however, because its effect is small.

As in the iron case, the value of specific heat at constant pressure Is used Instead of the specific heat at constant volume.

\section{Thermal Conductivity}

The thermal conductivity data given in Ref. 54 shows a large amount of scatter and no regular variation with hydrogen concentration or temperature. The only exception to this is an apparent decrease of thermal conductivity of delta phase hydride with increasing temperature. The thermal conductivity values fall in the range $0.05 \pm 0.02 \mathrm{cal} / \mathrm{cm} \mathrm{sec}{ }^{\circ} \mathrm{C}$ for varying compositions and temperatures. 
For the equilibrium model, the ti ermal conductivity is assigned the constant value

$$
\mathrm{k}=0.05\left(\mathrm{cal} / \mathrm{cm} \mathrm{sec}{ }^{\circ} \mathrm{C}\right)
$$

For the quasi-equilibrium model, the thermal conductivity is that of delta phase hydride, given ap :oximately by

$$
\begin{aligned}
& k=0.05+0.01[1-\exp (-(723-T) / 150)] \text { for } \mathrm{T}<723^{\circ} \mathrm{K} \\
& k=0.05-0.01[1-\exp (-(\mathrm{T}-723) / 150)] \text { for } \mathrm{T}>723^{\circ} \mathrm{K}
\end{aligned}
$$

\section{Diffuaton Coefficlent}

The diffusion coeffictent of delta phase zircontum hydride as measured by Albrecht and Goode (given In Ref. 54) is

$$
D_{\delta}=599 \exp (-, 4,900 / \mathrm{RT}) \quad\left(\mathrm{cm}^{2} / \mathrm{sec}\right)
$$

How ever, the activation energy fo: diffusion measured in two nuclear magnetic resonance studies has the value 12.3 kcal/mole ratier than $34.7 \mathrm{kcal} / \mathrm{mole}$. Beck and Mueller attribute this difference to the fac- that some of the Albrecht and Guode data were made on epsilon pha ie hydride rather than delta phase. This could have given an approximat iy correct magnitude for $D_{\delta}$ in the temperature range of the measuremen $s$, but an inaccurately determined activation energy.

Therefore, a more realistic diffusion coeffictent is defined to have the magnitude at $700^{\circ} \mathrm{C}$ given by Eq. $(5.21)$ but whth activation ener zy of $12.3 \mathrm{kcal} / \mathrm{mole}$. This modified form for $D_{\delta}$ used $1 \mathrm{n}$ the nume : 1 cal calculations is:

$$
D_{\delta}=5.02 \times 10^{-3} \exp (-12,300 / R T)
$$


In the equilibrium model, the diffusion coefficient in the beta phase region is that measured by Gelezunas, et al. (gIven in Ref. 54):

$$
D_{\beta}=5.32 \times 10^{-3} \exp (-8320 / R T)\left(\mathrm{cm}^{2} / \mathrm{sec}\right)
$$

In the beta plus delta region, the diffusion coefflctent is taken as the average of $D_{\delta}$ and $D_{\beta}$ weighted by the relative amount of each phasa present according to Eq. (5.12). That 1s:

$$
D_{\beta+\delta}=\frac{\left(y_{\delta}-y\right)}{\left(y_{\delta}-y_{\beta}\right)} D_{\beta}+\frac{\left(y-y_{\beta}\right)}{\left(y_{\delta}-y_{\beta}\right)} D_{\delta}
$$

\section{Heat of Transport}

The heat of transport $Q *$ of hydrogen in delta phase zirconfum hydride was measured by Sommer and Dennison ${ }^{60}$ to be:

$$
Q_{\delta}^{*}=1.3 \mathrm{kcal} / \mathrm{mole} \text { of } \mathrm{H} \text { atoms }
$$

The heat of transport of hydrogen in beta phase zirconium was measured by Droege (given tn Ref. 54) to vary from $5.5 \mathrm{kcal} / \mathrm{mole}$ at $630^{\circ} \mathrm{C}$ to $11.5 \mathrm{kcal} / \mathrm{mole}$ at $860^{\circ} \mathrm{C}$ and was found independent of composition. Since the results of the numerical calculations depend only weakly on the heat of transport, a representative value of $Q^{*}{ }_{\beta}$ is used:

$$
Q{ }^{*}=9 \mathrm{kcal} / \mathrm{mole} \text { of } \mathrm{H} \text { atoms }
$$

In the beta plus delta region, $Q *$ is taken as the average of $Q{ }^{*}$ and $Q *_{\beta}$ weighted by the amount of $H$ in each phase:

$$
Q{ }_{\beta+\delta}=\frac{y_{\beta}}{y} \frac{\left(y_{\delta}-y\right)}{\left(y_{\delta}-y_{\beta}\right)} Q *_{\beta}+\frac{y_{\delta}}{y} \frac{\left(y-y_{\beta}\right)}{\left(y_{\delta}-y_{\beta}\right)} Q{ }^{*}
$$




\section{Density}

The density of delta phase hydride according to Ref. 54 is approximately:

$$
\rho_{\delta}=5.70\left(\mathrm{gm} / \mathrm{cm}^{3}\right)
$$

Although the energy and H conservation equations (Eqs. 4.31) were derived on the assumption of constant density, a concentration dependent density is used in the equilibrium model. A linear fit between the density at $y=0$ ind that at $y=1.63$ is used:

$$
t_{\text {equ11 }}=6.50-0.521 \text { y }\left(\mathrm{gm} / \mathrm{cm}^{3}\right)
$$




\section{RESULTS}

\section{A. Iron Results}

\section{Numerical Results}

For a particular absorbed energy density, the numerical program calculates the complete temperature history of the fron, the fe flux from the surface, and the density of Iron atoms in the lonizer by Eq. (3.9). The following values of the parameters in Eq. (3.9) were exployed: $\bar{X}=0.44, \alpha=1,8-40 \mathrm{~cm}$, and $A_{g}-A_{\text {eff }}$ given by $\mathrm{kq} .(2.10)$. It was assumed that the lager is absorbed at the surface and that the absorbed power density has a triangular shape in time with the peak at $0.15 \mathrm{msec}$ and the end of the pulse at $1.0 \mathrm{msec}$.

The surfare cemperature as a function of time 1s shown in F18. 19 for various absorbed energy densities. Significant features of these curves are (a) tine maximim temperature occurs after the peak of the absorbed power. (b) the tine corresponding to the maximum temperature (and therefore maximum Fe $f(u x$ ) decreases as energy density increases, (c) the spacing between temperature curves decreasee with increasing energy density because of 1rcreasing energy loss from the surface by vaporization and (d) after the end of the laser pulse, the surface temperature temporar1ly stays near the melting point because of the energy returned from the heat of fusion.

The relative Fe flux ve time for various absorbed energy densities is shown in Fig. 20. The duration of time over which there is significalt Fe flux is approximately $400 \mu s e c$ and increases sith increasing energy density.

The relative mass spectroneter signal in shown in Fig. 21. The time corresponding to the peak gignal decreases with increasing energy 


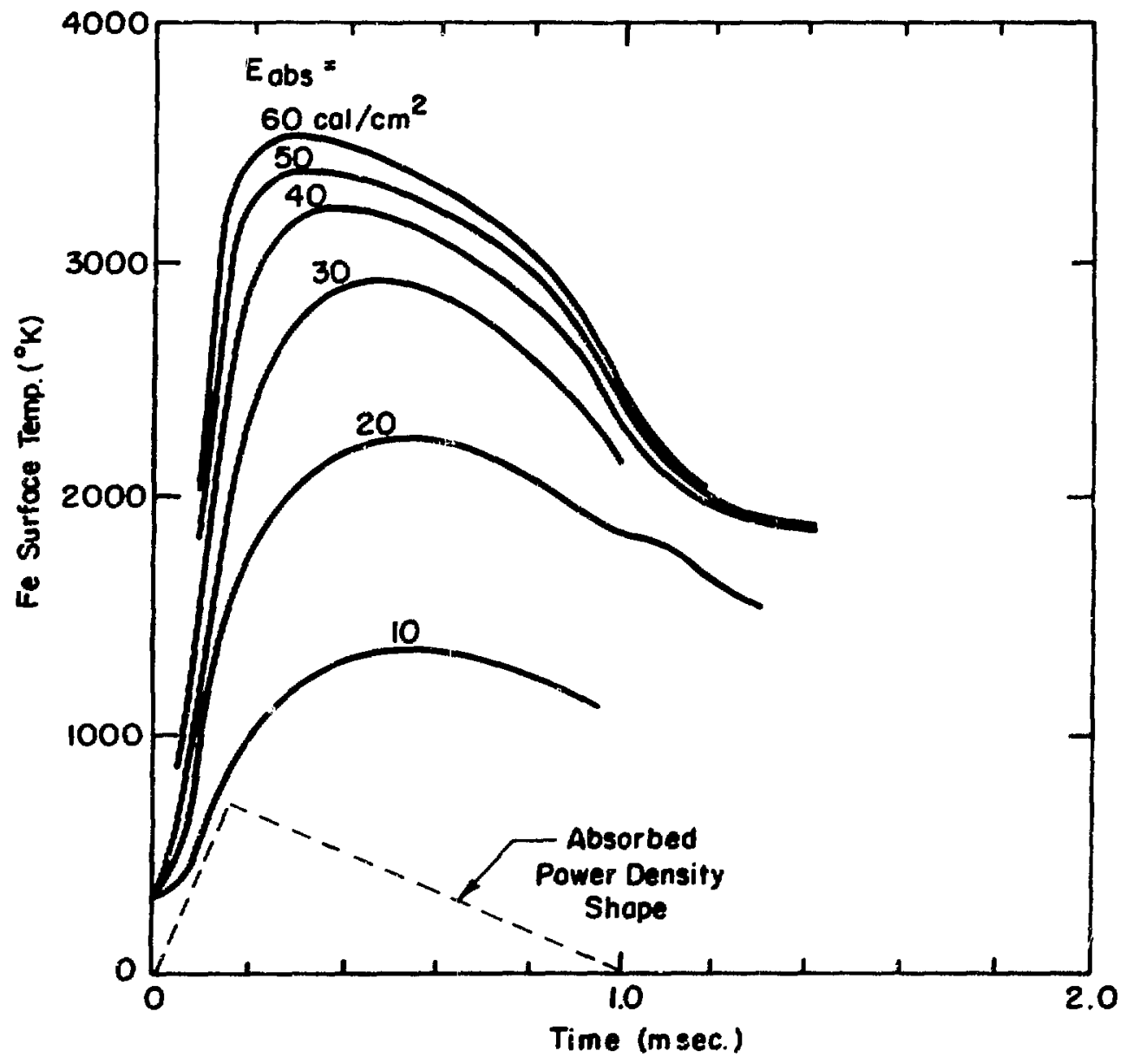

XBL7211-7239

Fig. 19 Calculated tron surface temperature profiles. 


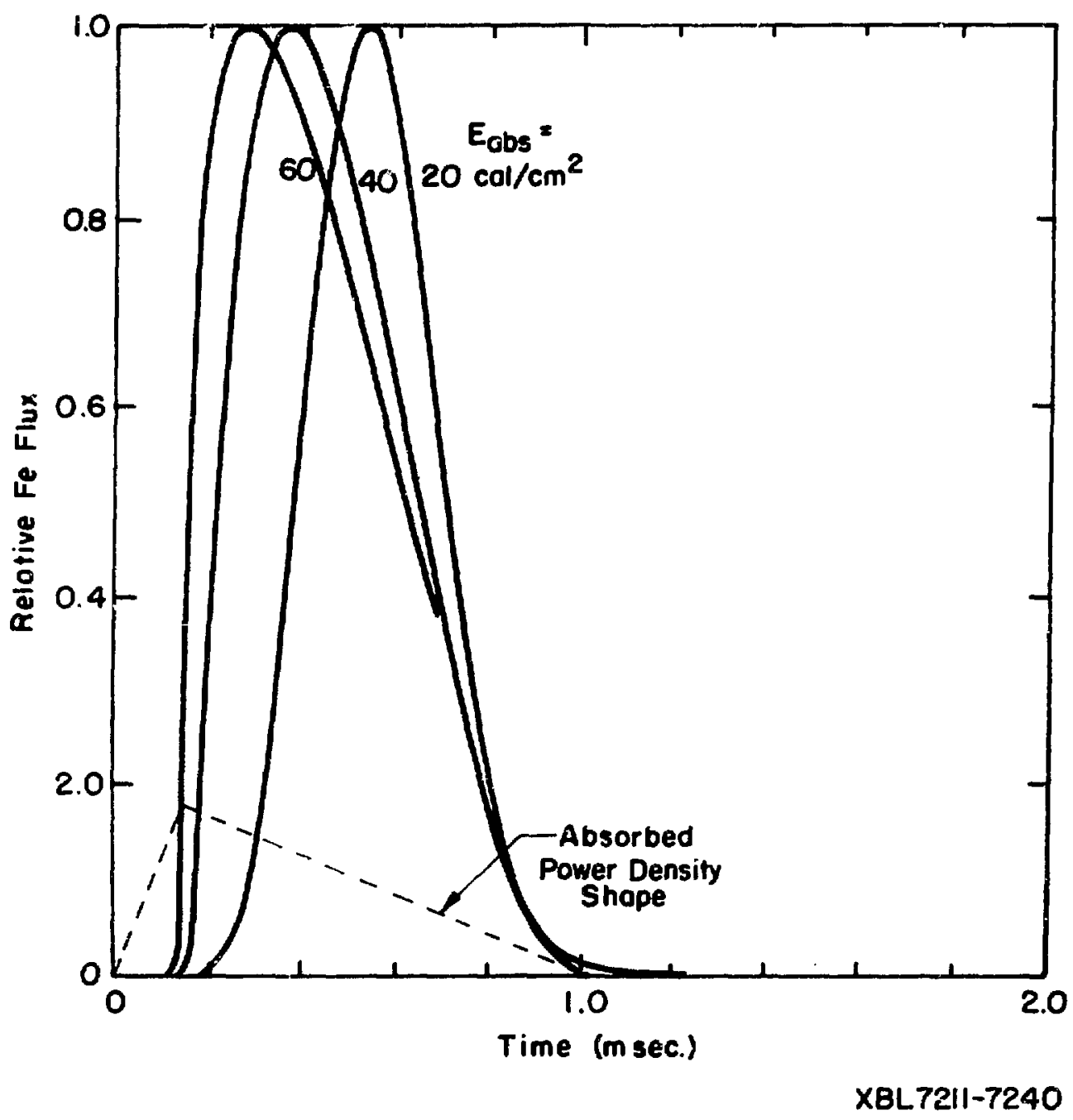

Fig. 20 Calculated relative flux of iron atoms emitted from the surface. 


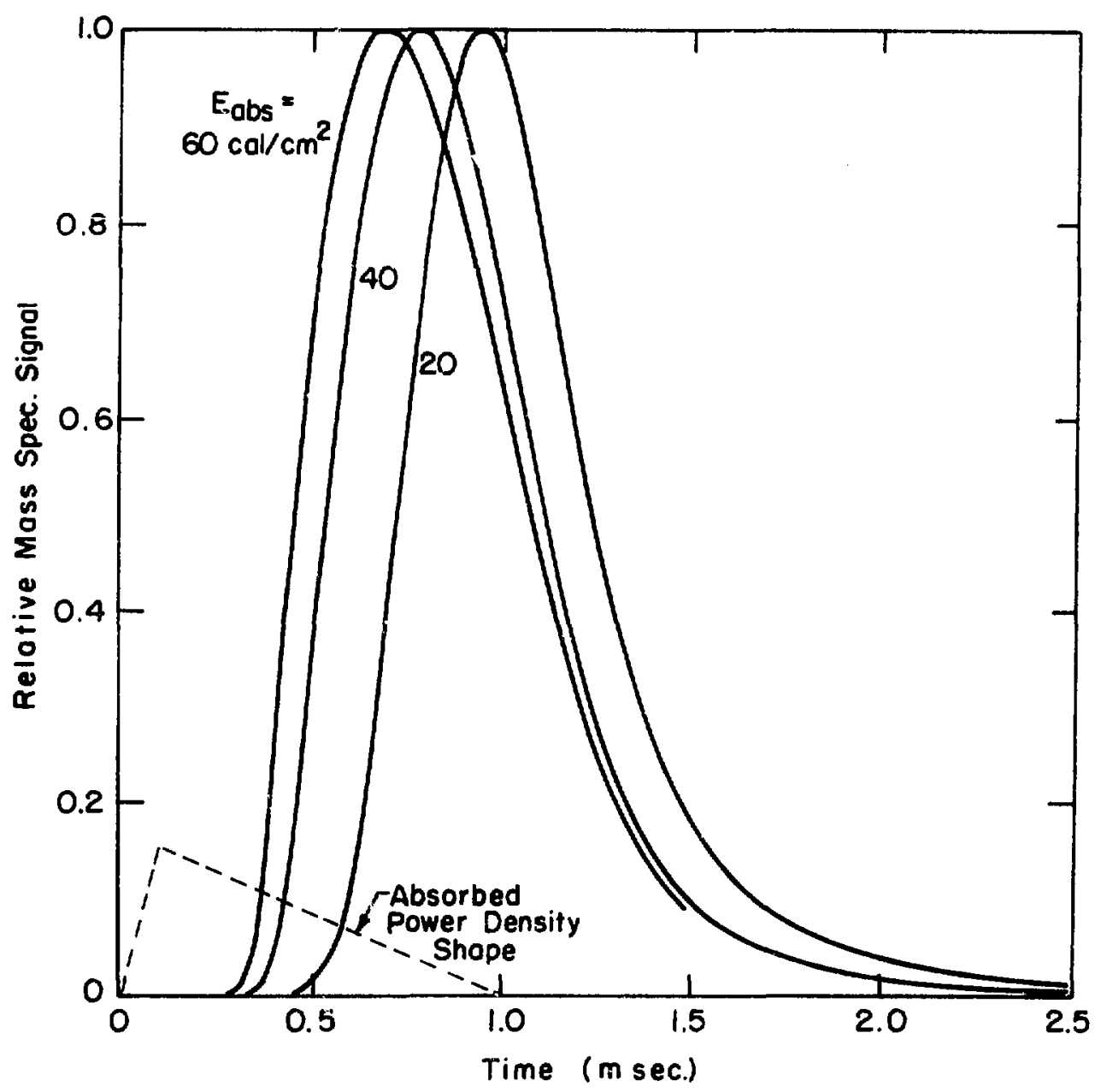

XBL72\|-724B

Fig. 21 Calculated relative 1ron signal. 


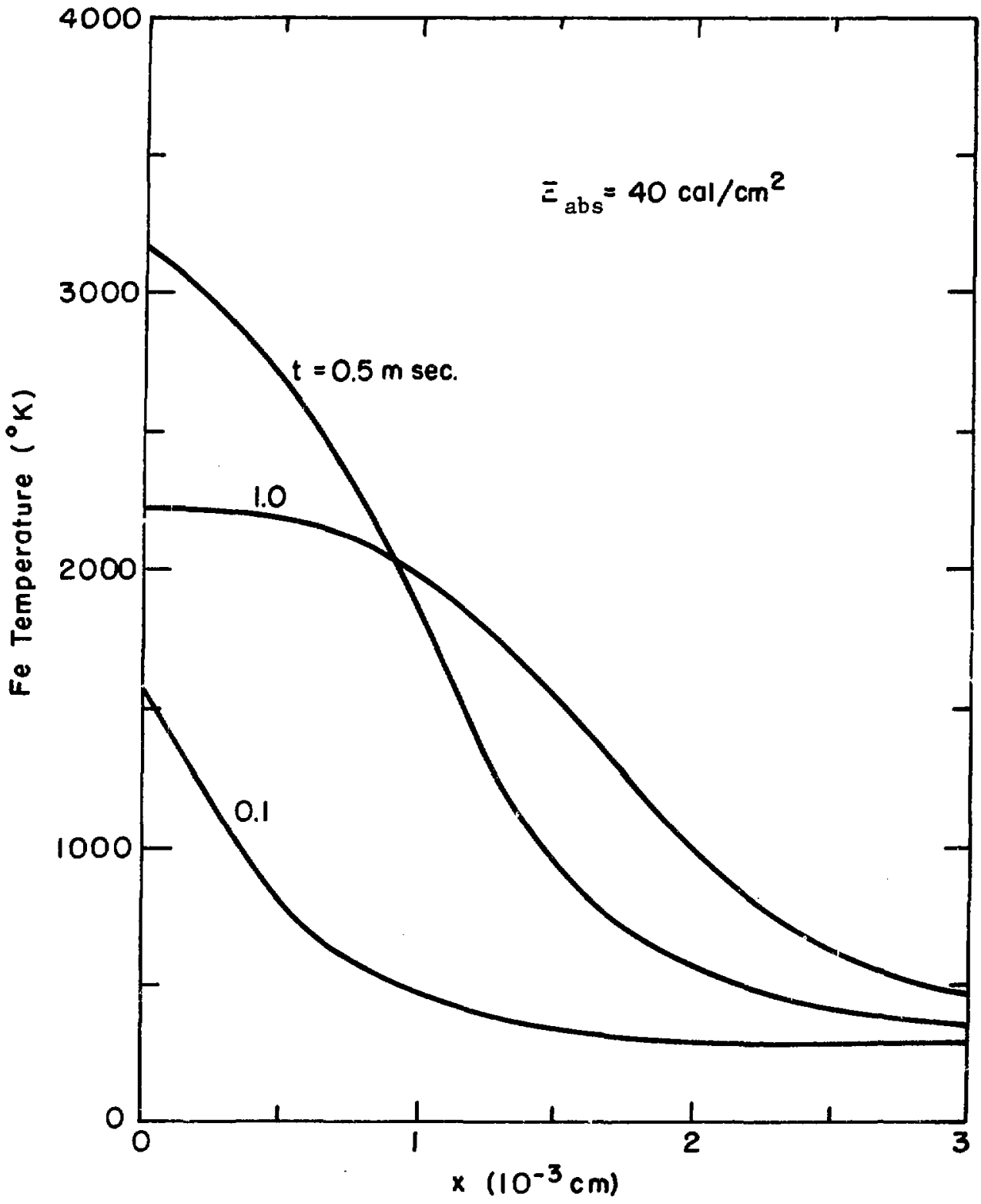

XBL 72II-7245

FIg. 22 Iron temperature as a function of distance from the surface. 
Table 1. Calculated Fe results.

\begin{tabular}{|c|c|c|c|c|c|c|c|}
\hline $\begin{array}{c}E_{a b s}(0) \\
\left(\mathrm{cal} / \mathrm{cm}^{2}\right)\end{array}$ & $\begin{array}{c}T_{\max } \\
(\text { Deg. K) }\end{array}$ & $\begin{array}{c}\Phi_{\max } \\
\left(\operatorname{moles} / \mathrm{cm}^{2} \mathrm{sec}\right)\end{array}$ & 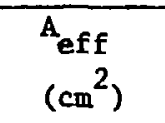 & $\begin{array}{c}\mathbf{n}_{\max } \\
\left(\text { atoms } / \mathrm{cm}^{3}\right)\end{array}$ & $\begin{array}{l}\text { tpeak } \\
\text { (msec) }\end{array}$ & $\underbrace{t_{\text {peak }}-t_{1 / 2}^{-}}_{\text {(msec) }}$ & $t_{1 / 2^{-t} \text { peak }}^{+}$(msec) \\
\hline 13 & 1709 & $2.23 E-6$ & $4.19 \cdot E-4$ & $2.99 E+5$ & 0.99 & 0.196 & 0.292 \\
\hline 15 & 1875 & $2.12 \mathrm{E}-5$ & $7.84 \quad E-4$ & $6.00 \mathrm{E}+6$ & 1.01 & 0.230 & 0.300 \\
\hline 18 & 2092 & 2.27 E-4 & $9.52 \mathrm{E}-4$ & $7.26 \mathrm{E}+7$ & 0.97 & 0.222 & 0.310 \\
\hline 20 & 2251 & $9.44 \mathrm{E}-4$ & $8.69 \mathrm{E}-4$ & $2.68 \mathrm{E}+8$ & 0.95 & 0.217 & 0.292 \\
\hline 25 & 2639 & $1.43 \mathrm{E}-2$ & $9.94 \mathrm{E}-4$ & $4.50 \quad E+9$ & 0.90 & 0.209 & 0.293 \\
\hline 30 & 2911 & $5.96 \mathrm{E}-2$ & $1.47 \mathrm{E}-3$ & $2.79 \mathrm{E}+10$ & 0.85 & 0.216 & 0.310 \\
\hline 40 & 3202 & 2.02 E-1 & $2.69 \mathrm{E}-3$ & $1.78 \mathrm{E}+11$ & 0.78 & 0.237 & 0.338 \\
\hline 50 & 3372 & $3.64 \mathrm{E}-1$ & $3.58 \mathrm{E}-3$ & $4.32 \mathrm{E}+11$ & 0.73 & 0.237 & 0,364 \\
\hline 60 & 3496 & $5.35 \mathrm{E}-1$ & $5.02 \mathrm{E}-3$ & $9.01 \mathrm{E}+11$ & 0.70 & 0.233 & 0.383 \\
\hline
\end{tabular}


density. This is expected because at higher energy densities the atoms are emftted sooner and with a higher velocity than at lower energy densities.

The width of the predicted mass specirometer signal Increases with Increasing energy densities densities because the atoms are emitted over a longer duration at higher energy densities. This effect obscures the narrowing of the predicted signal due to the increase in spread of velocities at higher surface temperatures. The width of the predicted signal is only about $20 \%$ larger than the width of the corresponding flux curve. This indicates that the signal width is primarily a measure of the duration of significant vaporization rather than the spread in time due to the velocity distribution of the emitted atoms.

Calculated solid temperature profiles presented in Fig. 22 show that iron becomes melted to a depth of approximately $10^{-3} \mathrm{~cm}$, and that temperature gradients of approximately $10^{6} \mathrm{C} / \mathrm{cm}$ exist near the surface.

The various results of the calculations useful in comparing theory with the measurei mass spectrometer signal are:

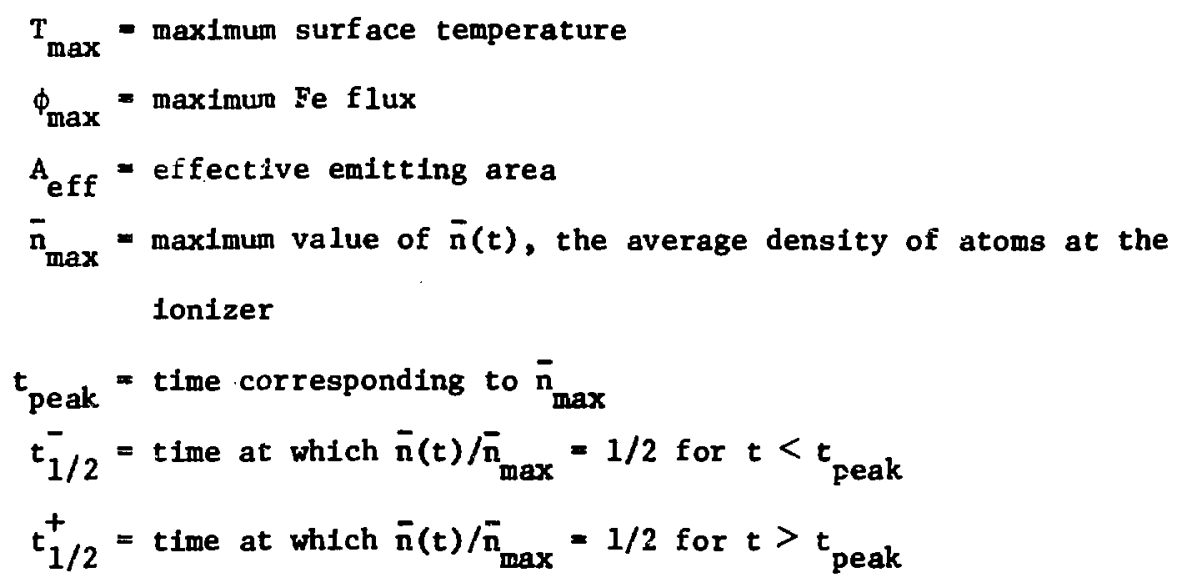


These results are given in Table 1 for varfous values of $\mathrm{E}_{\mathrm{abs}}(0)$, the energy density at the center of the interaction area.

\section{Exper1mental Results}

A typical measured mass 56 signal is shown in Fig. 23. The origin respresents the time the laser is triggered rather than the time of the beginning of the laser pulse. The time delay between triggering and the onset of lasing can be determined from the trace of the Korad energy pulse. The mass spectrometer signal relative to the beginning of the laser pulse and corrected for the drift time of lons down the quadrupole structure is shown in Fig. 24 for incident energy denstties at $r=0$ of $49.5,77.6 \therefore 133 \mathrm{cal} / \mathrm{cm}^{2}$. The time constant correction given by Eq. (3.24) is small for the iron signals because the time constant of $30 \mu \mathrm{sec}$ is much less than the duration of the measured signal. The net effect of $\tau$ in Eq. (3.24) is to shift the measured signal $30 \mu s e c$ toward the origin.

The results shown in Figs. $24 a, b, c$ are proportional to the measured atom density in the lonizer. The proportionality constant $\mathrm{K}_{\mathrm{Fe}}$ can be determined from the fron calibration results of Section II-E-1 using Eq. (3.25). Using the calibration measurements for the $3 / 16 \mathrm{In}$. source aperture (for which $\bar{\chi}=0.44$, see Appendix A) at $1573^{\circ} \mathrm{K}$ (where $P_{\text {eq }}=1.14 \times 10^{-3}$ torr) and increasing the measured signal by the factor $1 / 0.92$ to account for the 1sotopic bundance of $\mathrm{Fe}^{56}$ in Eq. (3.25) yields $\mathrm{K}_{\mathrm{Fe}}=2.8 \times 10^{-16}$ amp $\mathrm{cm}^{3} /$ atom. If the callbration data on the 1/16 In. source aperature data had been used, the value of $\mathrm{K}_{\text {Fe }}$ would have been 1.8 times that obtained uslog the 3/16 in. aperture. As calculated in Appendix A, the average peaking factor $\bar{X}$ is approximately 


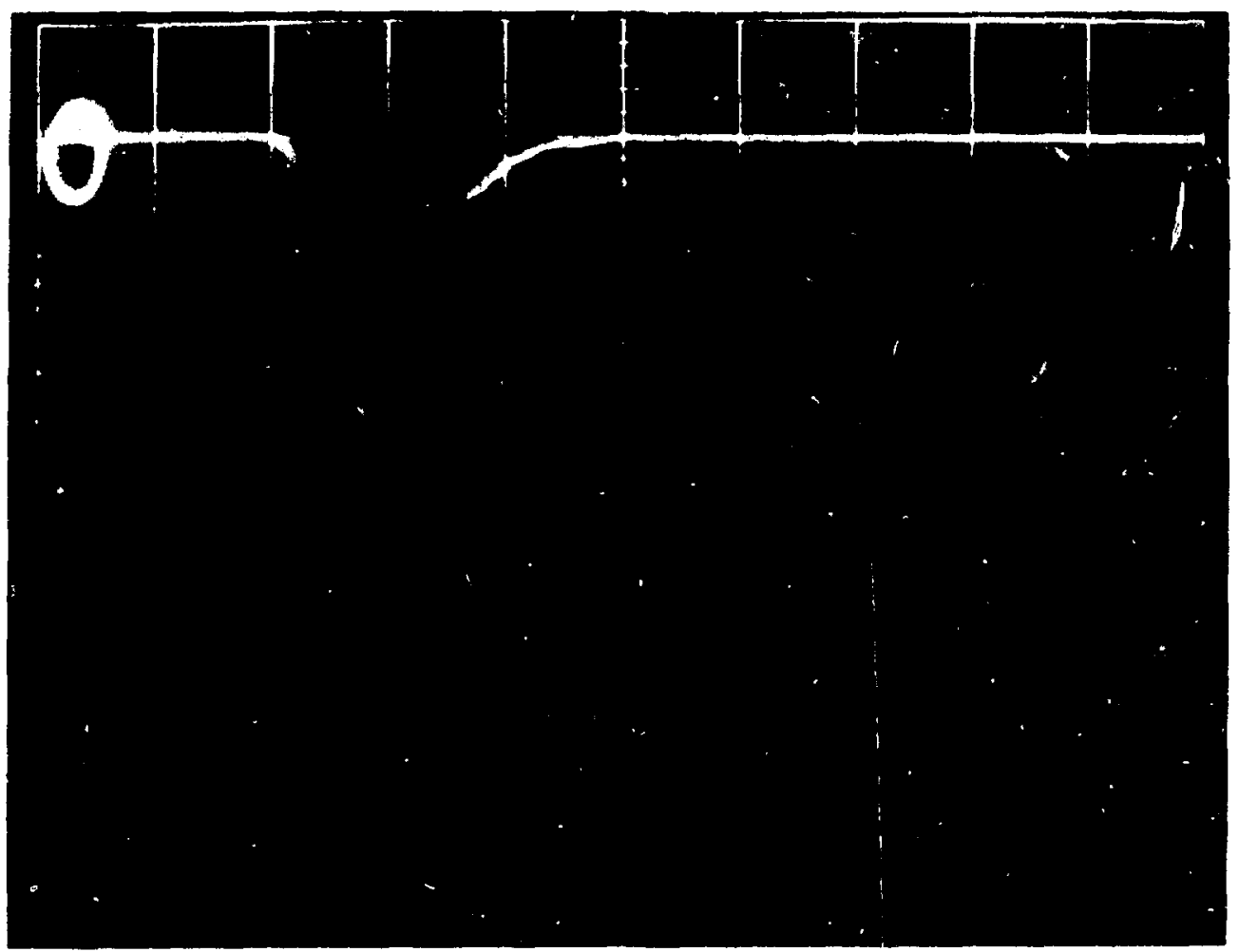

$\mathrm{XBB} 7210-5370$

Fig. 23 Typical measured iron signal. Horizontal scale is $0.5 \mathrm{msec}$ division. The circle at the origin is due to a malfunction of the oscilloscope. 


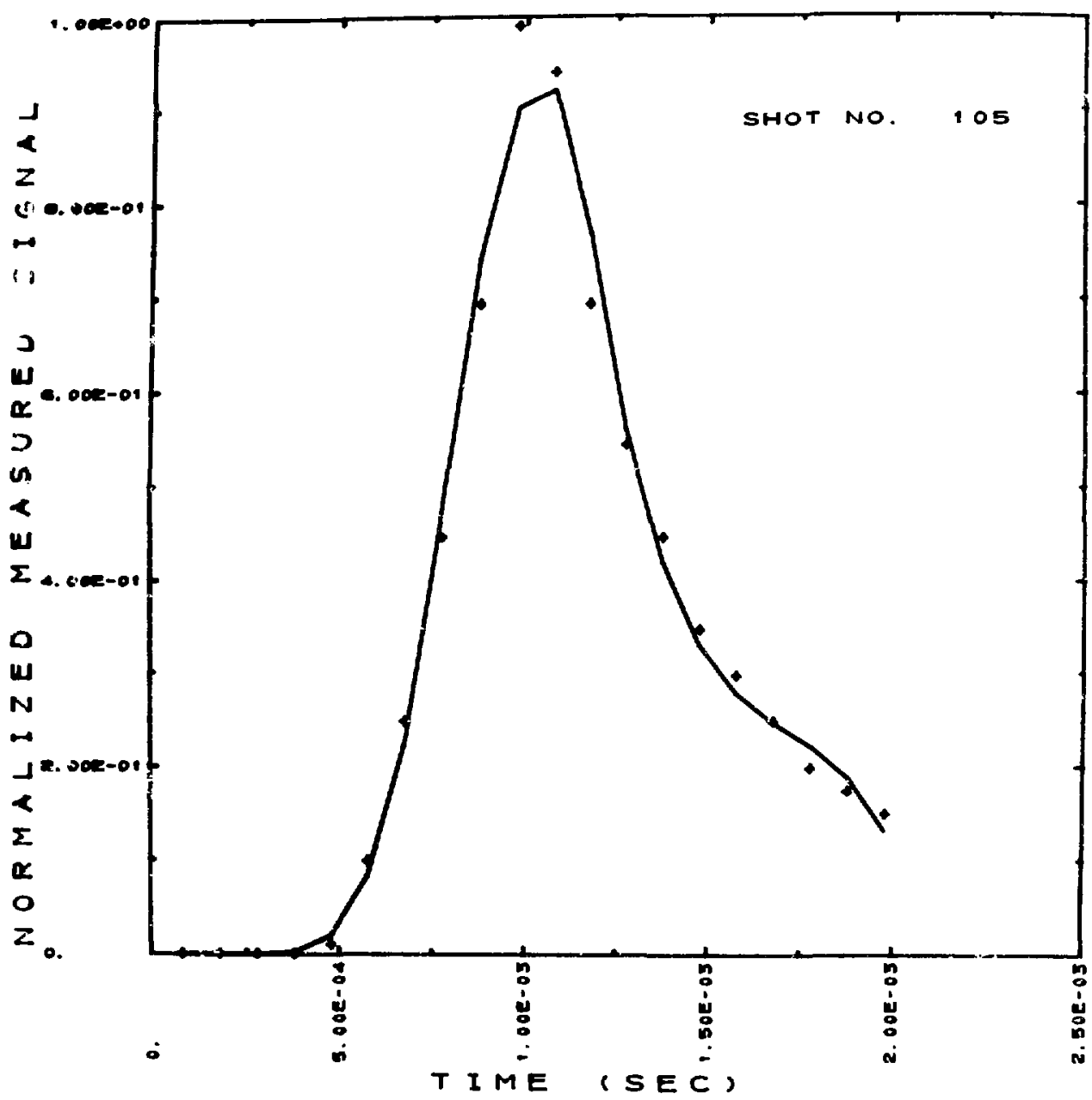

XBL. 7216-5792

Fig. 24a Measured iron signal. Incident energy density at center of interaction area $=49.5 \mathrm{cal} / \mathrm{cm}^{2}$. 


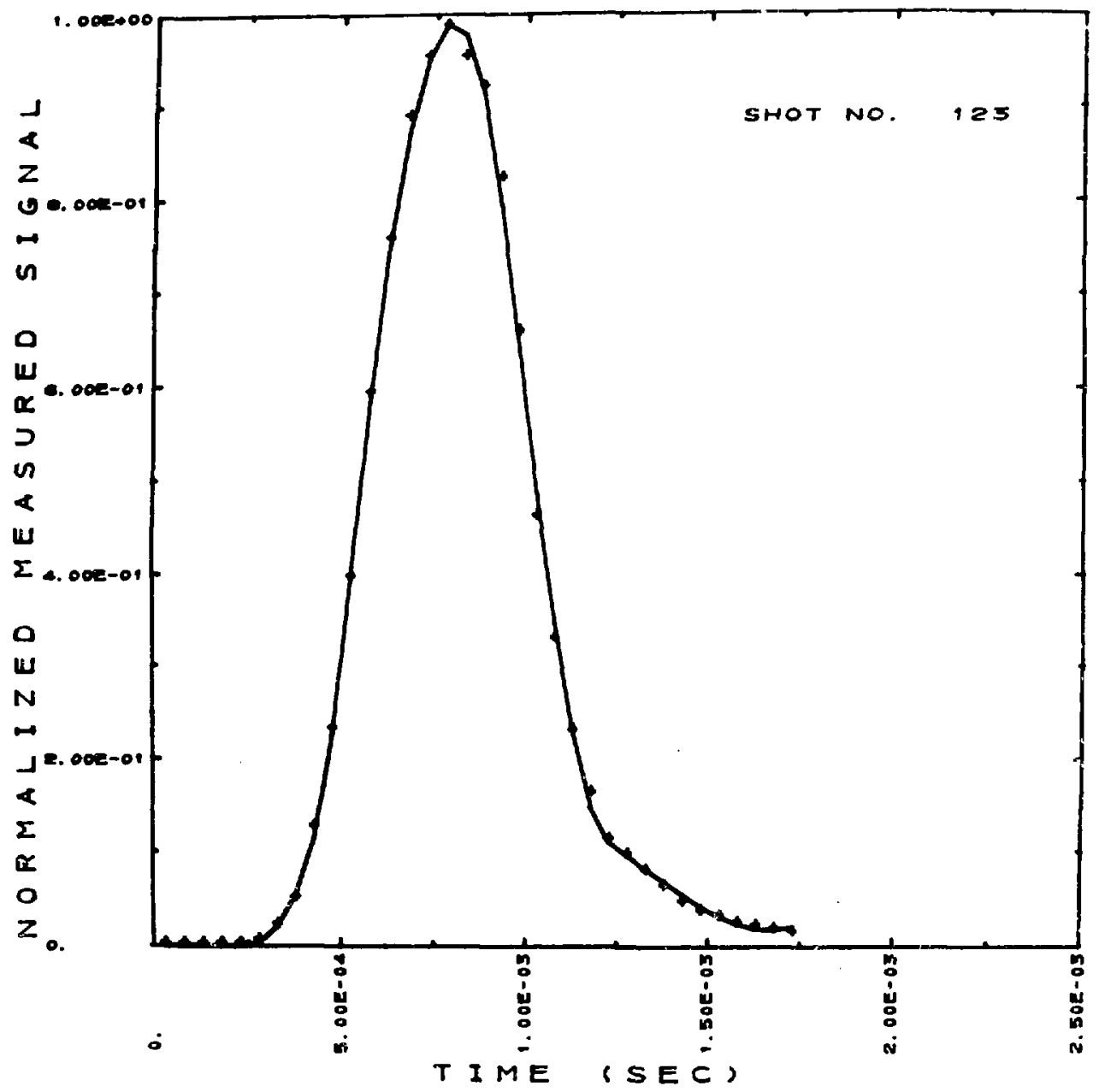

XBL 7210-5784

Fig. 24b Measured iron signal. Incident ellergy density at center of interaction area $=77.6 \mathrm{cal} / \mathrm{cm}^{2}$. 


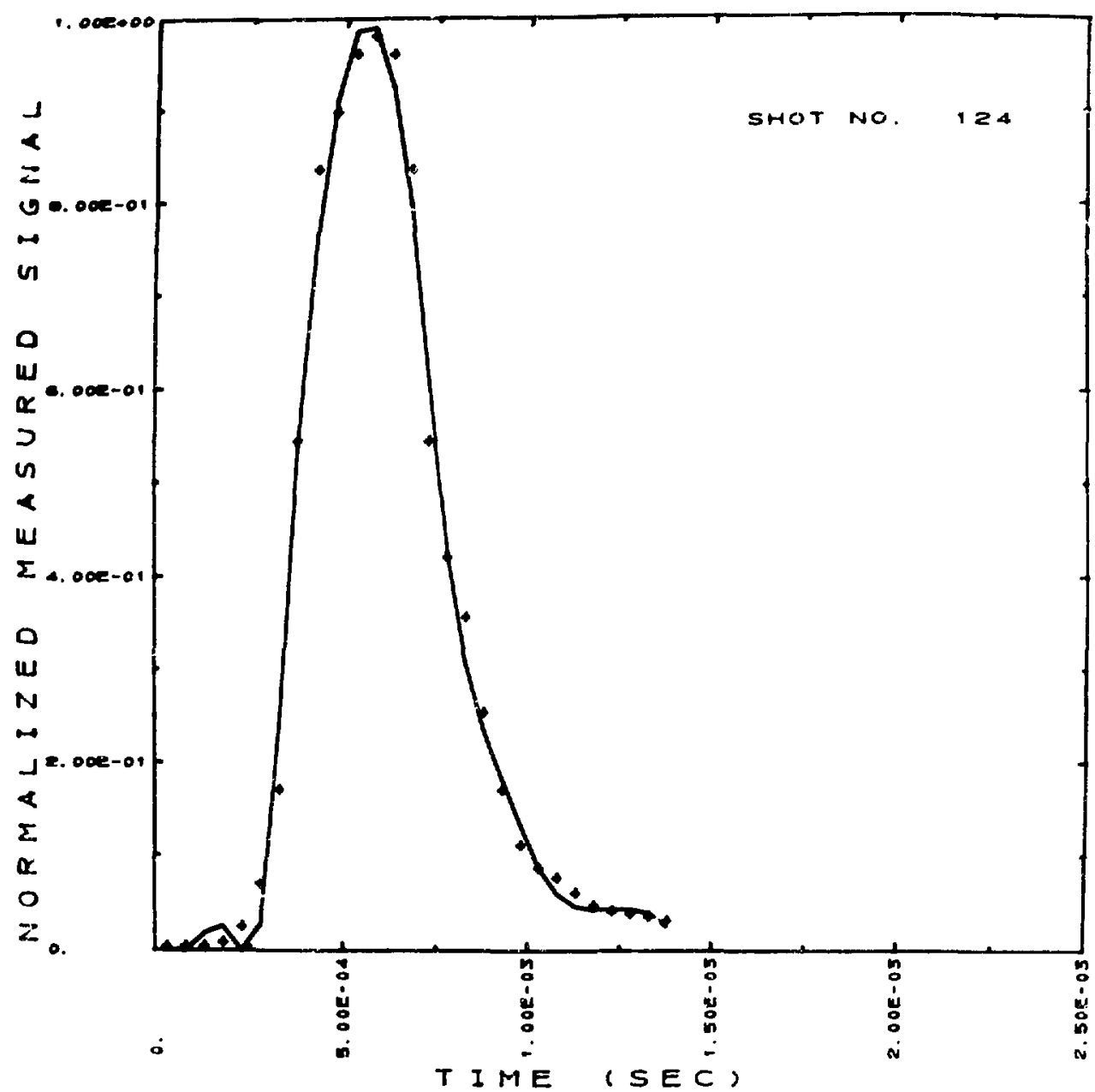

XBL $7210-5782$

Fig. 24c Measured 1ron signal. Incidegt energy density at center of interaction area $=133 \mathrm{cal} / \mathrm{cm}^{2}$. 
Table 2. Results of Fe measurements.

\begin{tabular}{|c|c|c|c|c|c|}
\hline $\begin{array}{l}\text { Shot } \\
\text { Number }\end{array}$ & $\begin{array}{l}\mathrm{E}_{\operatorname{Inc}}(0) \\
\left(\mathrm{cel} / \mathrm{cm}^{2}\right)\end{array}$ & $\begin{array}{c}t_{\text {peak }} \\
\text { (msec) }\end{array}$ & 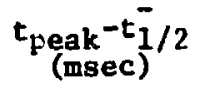 & $t_{1 / 2_{(\text {msec })}^{+t} \text { peak }}^{+}$ & $\underset{\left(\operatorname{atoms} / \mathrm{cm}^{3}\right)}{\bar{n}_{\max }}$ \\
\hline 105 & 49.5 & 1.00 & 0.25 & 0.28 & $1.69 E+8$ \\
\hline 108 & 71.8 & 0.75 & 0.24 & 0.19 & $9.05 E+9$ \\
\hline 116 & 73.7 & 0.70 & 0.22 & 0.25 & $5.48 E+9$ \\
\hline 117 & 75.6 & 0.75 & 0.22 & 0.15 & $3.58 \mathrm{E}+9$ \\
\hline 119 & 75.6 & 0.79 & 0.27 & 0.15 & $6.30 E+9$ \\
\hline 120 & 77.6 & 0.84 & 0.29 & 0.09 & $6.30 E+9$ \\
\hline 121 & 77.6 & 0.72 & 0.23 & 0.20 & $5.28 E+9$ \\
\hline 122 & 73.7 & 0.69 & 0.18 & 0.18 & $1.02 E+10$ \\
\hline 123 & 77.6 & 0.75 & 0.25 & 0.22 & $5.16 \mathrm{E}+9$ \\
\hline 124 & 133.4 & 0.55 & 0.20 & 0.19 & $4.06 E+10$ \\
\hline
\end{tabular}


independent of the source diameter for diameters less than $3 / 16$ Inch. However, if the efficiency of extracting lons from the lonizer into the quadrupole structure is greater naar the center of the ionizer than at the ends, the effective $\bar{X}$ for the $1 / 16$ in. aperture will be larger than the effective $\bar{\chi}$ for the $3 / 16 \mathrm{in}$. aperture. This effect would explain the diffeient vaiues of $K_{F e}$ determined from the different calibration source apertures. This behavior is typical of the fact that, In general, estimates of absolute mass spectrometer sensitivities are generally no better than a factor of 2 to $3^{61}$

The measured signals may be compared to the predictions of the equilibrium model given in Table 1 by the measured values of $t$ peak', $t_{1 / 2}^{+}, t_{1 / 2}^{-}$and $\bar{n}_{\max }$ (the only quantity listed that depends on $k_{F e}$ ). Values of these quantities are given in Table 2 for the conventional mode laser shots on iron of varying incident centerline energy densities $E_{\text {inc }}(0)$, which have been determined from the tusal incident energy by using Eq. (2.7). Several low energy density points were rejected because the signals were attributed to degassing from the Iron surface. The evidence for this was that for $\mathrm{E}_{\text {Inc }}(0) \approx 45 \mathrm{cal} / \mathrm{cm}^{2}$, the signal measured on a fresh surface was much larger than the signal from a previcusly pulsed surface. In addition, the signal widths were about twice as large as calculated and as measured on previously pulsed surfaces.

The appearance of the iron surface after a laser shot is shnwn in Fig. 25 for $E_{\text {Inc }}(0)=45$ and $72 \mathrm{cal} / \mathrm{cm}^{2}$. The central crater has approximate area $1 \times 10^{-3} \mathrm{~cm}^{2}$ for $\mathrm{E}_{\text {inc }}(0)=45 \mathrm{cal} / \mathrm{cm}^{2}$ and area $3 \times 10^{-3} \mathrm{~cm}^{2}$ for $\mathrm{E}_{1 \mathrm{nc}}(0)=72 \mathrm{cal} / \mathrm{cm}^{2}$. If it $1=$ assumed that the 


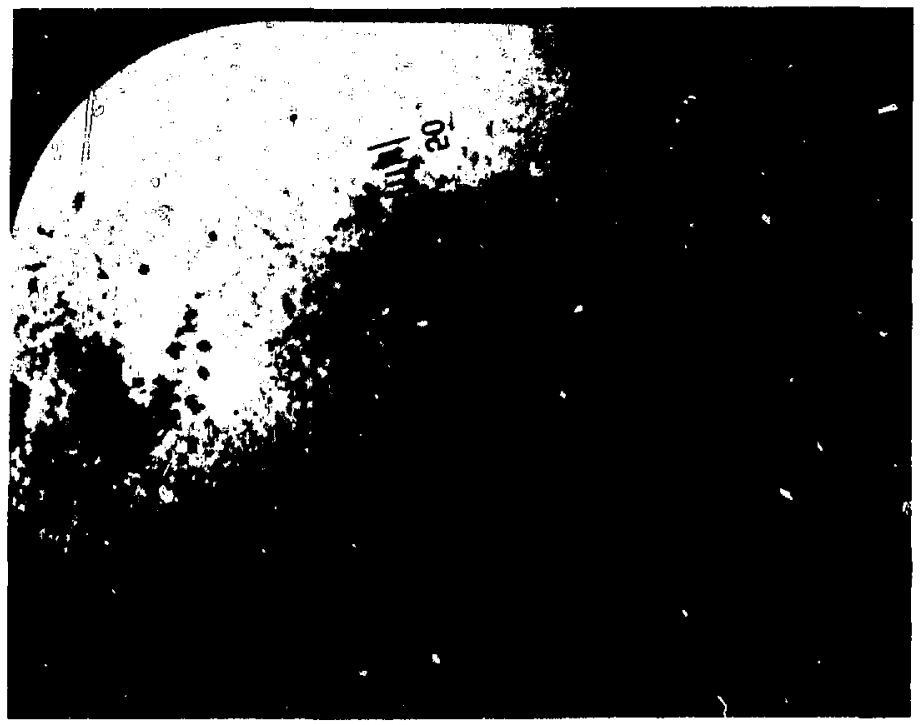

Fig. 25a Crater produced by conventional mode laser on 1ron. Incident energy density at center of interaction area $=45 \mathrm{cal} / \mathrm{cm}^{2}$. (50x magnification)

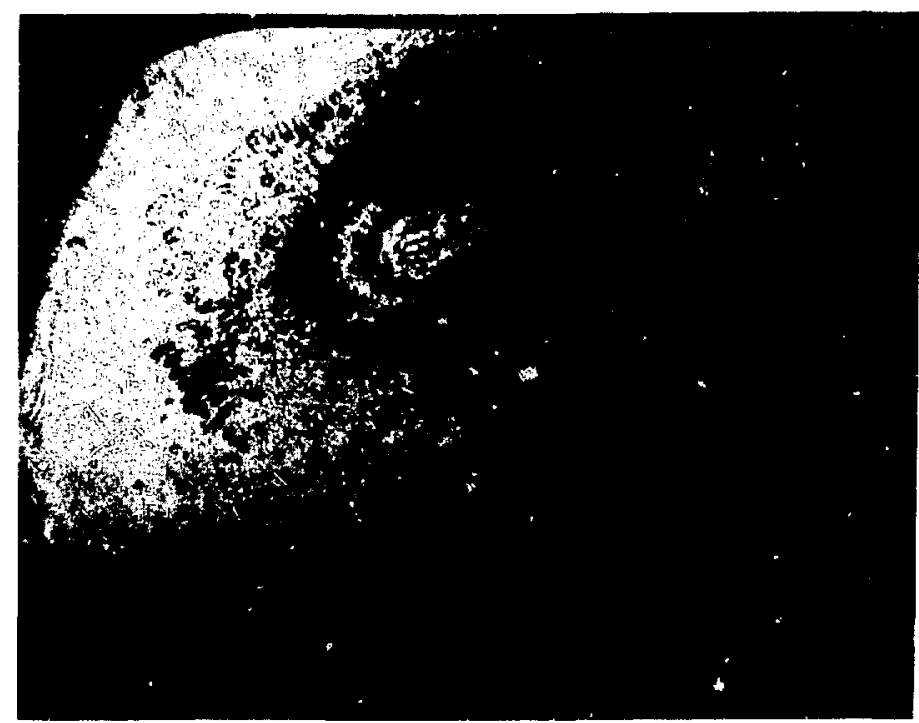

$\mathrm{XBB} \quad 7210-5373$

Fig. 25b Crater produced by conventional mode laser on iron. Incident energy density at center of interaction area $=72 \mathrm{cal} / \mathrm{cm}^{2}$. (50x magnification) 
reflectivity is approximately 0.5 , the calculated effective areas A eff are $0.99 \times 10^{-3}$ and $2 \times 10^{-3} \mathrm{~cm}^{2}$ respectfvely. This agreement is very good cc..... idering that the edge of the crater occurs where the energy density is suffictent for significant melting, while the boundary of A eff occurs where the energy density is suffictent for significant vaporization.

No $\mathrm{Fe}^{+}$tons emftted from the surface were detected. Thermal ions cannot be detected since the mass spectrometer can only detect fons with energy greater than $15 \mathrm{eV}$. No high energy ions were detected because the laser power density was not high enough for the formation of a plasma and subsequent conversion of the plasma thermal energy into a large directed energy of expansion.

\section{Comparison Between Calculated and Experimental Results}

Calculated and experimental values of $\bar{n}_{\max }, t_{\text {peak }},\left(t_{\text {peak }}-t_{1 / 2}\right)$, and $\left(t_{i / 2}^{+}-t_{\text {peak }}\right)$ are plotted vs $E_{\text {Inc }}(0)$ In Figs. 26.27 and 28 . The data exhibit quite a large amount of scatter because ." variations in surface reflectivity, nonuniformities in the incident energy density, and because $t_{\text {peak }}, t_{1 / 2}^{+}$and $t_{1 / 2}^{-}$can be determined experimentaliy only to within $\pm 0.04 \mathrm{msec}$.

The calculated and experimental values of $t_{\text {peak }}$ and $\left(t_{\text {peak }}-t_{1 / 2}\right)$ are in good agreement for $R \simeq 0.5$. The calculated values of $\bar{n}_{\max }$ are larger than the experimental values for $R$ in the expected range 0.5 to 0.6 . At low energy denstty, the calculated and experimental values of $\bar{n}_{\text {max }}$ are in satisfactory agrerinent, but as the energy density increases, the calculated value becomes approximately an order of magnitude larger than the measured value. 


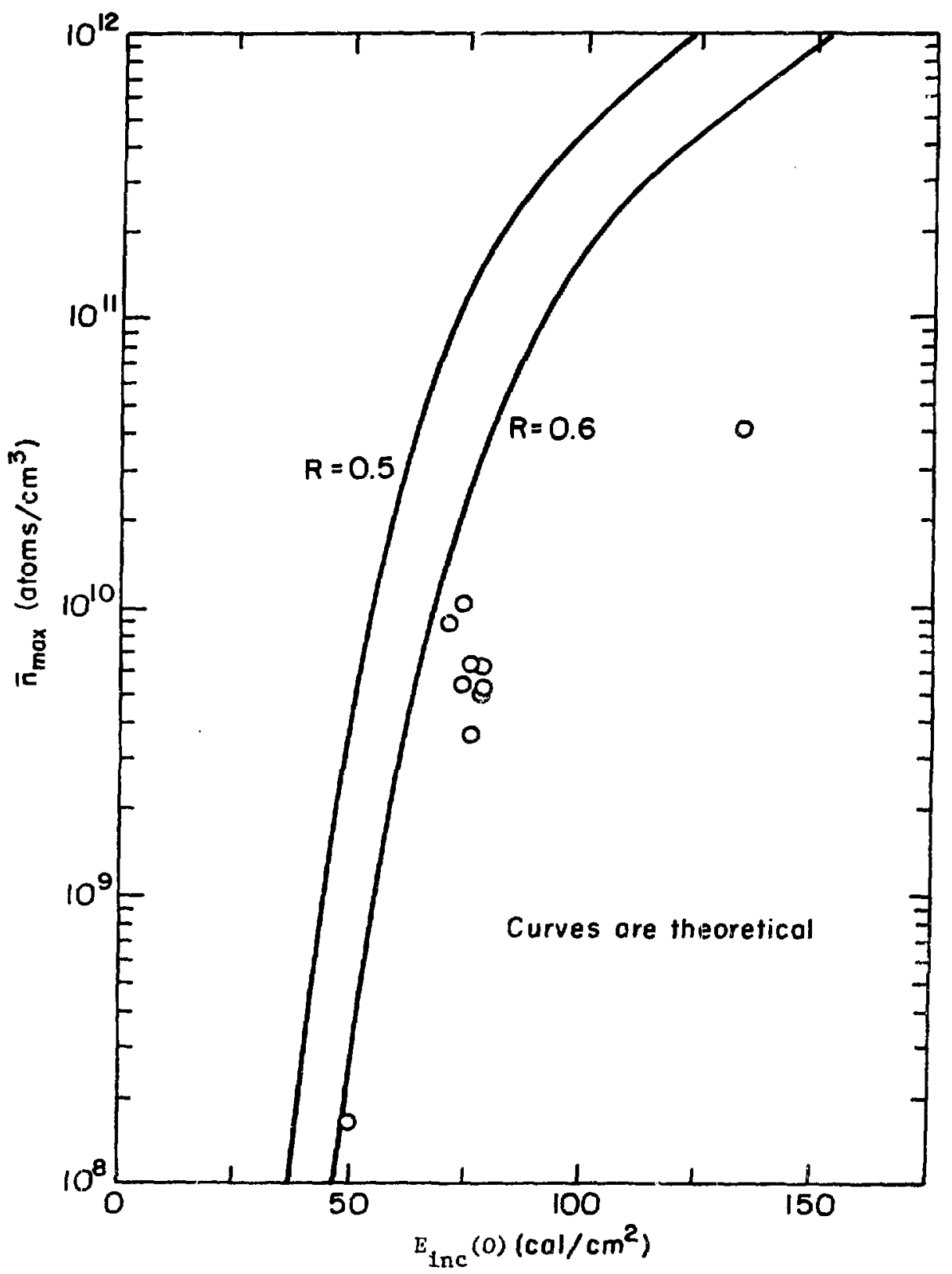

XBL $7211-7250$

Fig. 26 Comparison between the experimental and calculated $\bar{n}_{\max }$ vs $E_{\text {inc }}(0)$, for iron. 


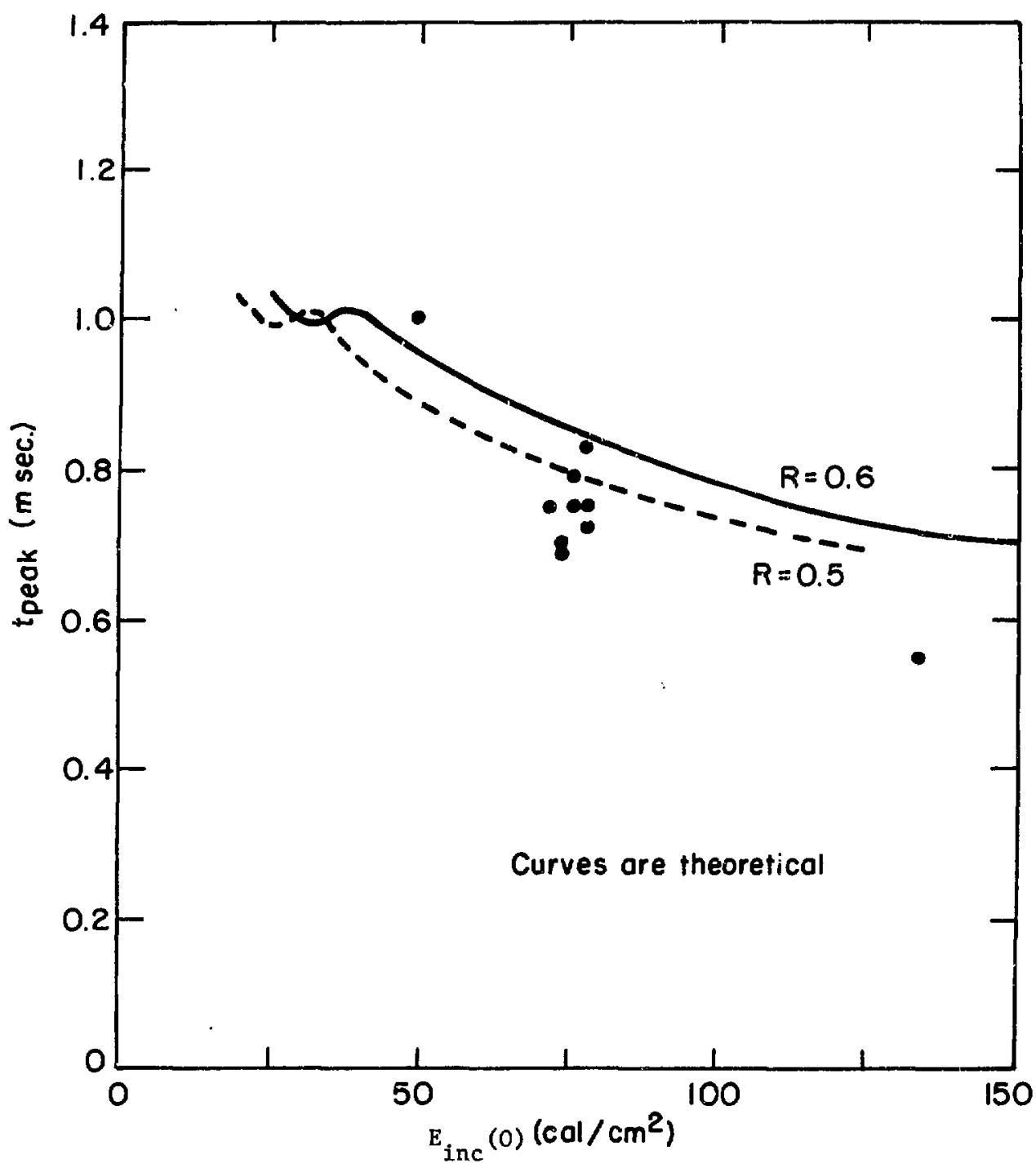

XBL7211-7246

Fig. 27 Comparison beiween the experimental and calculated tpeak vs $\mathrm{E}_{\text {inc }}(0)$, for tron. 

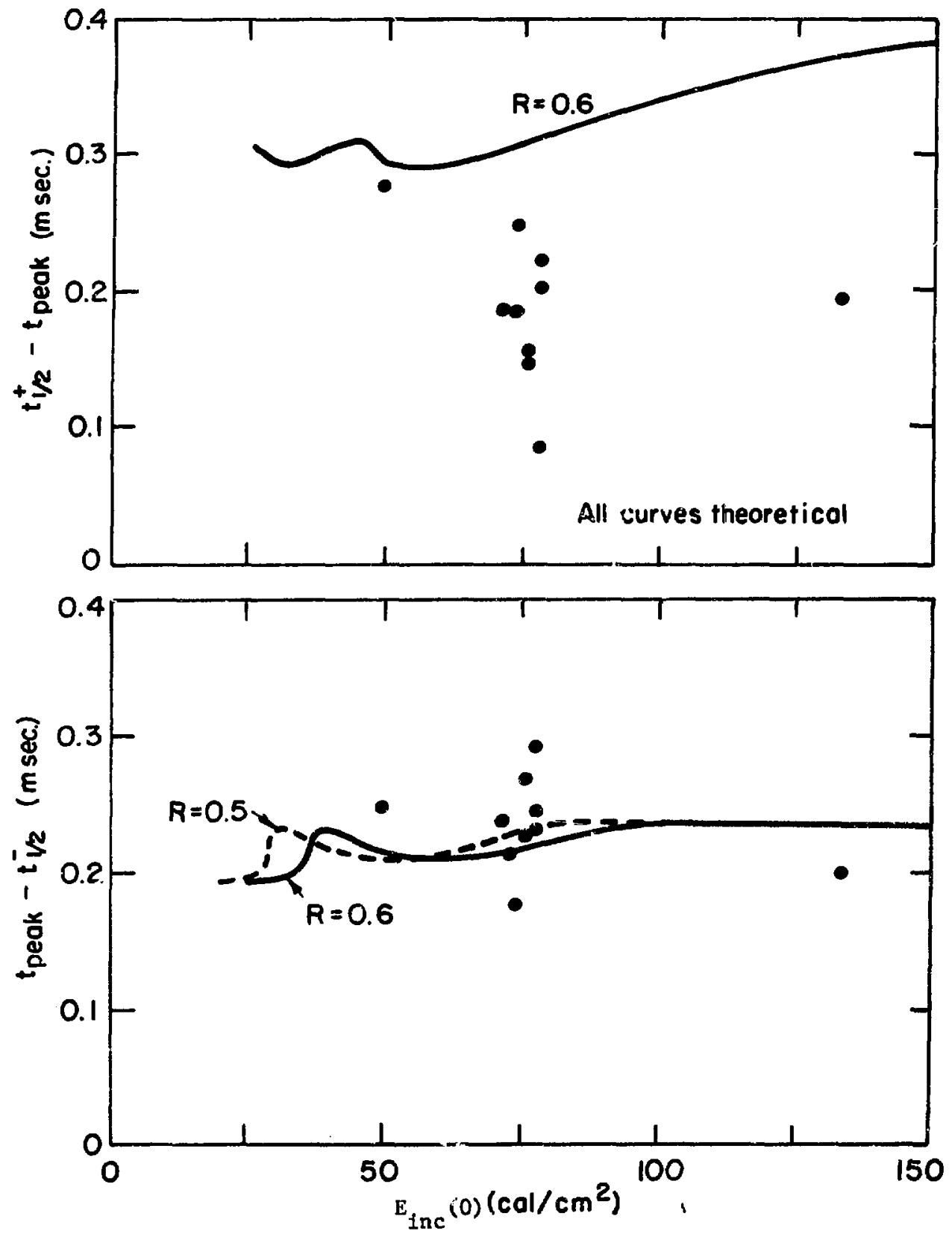

XBL $7211-7244$

Fig. 28 Comparison between the experimental and calculated $\left(t_{1 / 2}^{+}-t_{\text {peak }}\right)$ and $\left(t_{\text {peak }}-t_{1 / 2}^{-}\right)$vs $E_{\text {inc }}(0)$, for iron. 
There is also a discrepancy between the calculated and measured values of $\left(t_{1 / 2}^{+}-t_{\text {peak }}\right)$. At low energy density, the agreement is good, but at higher energy density the calculated value of $\left(t_{1 / 2}^{+}-t_{\text {peak }}\right)$ is approximately 1.8 times the measured vilue.

The discrepancies between the calculated and measured values of $\ddot{n}_{\max }$ and $\left(t_{1 / 2}^{+}-t_{\text {peak }}\right)$ can be attributed to the flow of 11quid Iron. The calculations were made assuming that the tron malntalned a fixed structure. However, when the surface temperature is large and there is a considerable amount of molten Iron beneath the surface, the pressure exerted by the vaporizing atoms causes some of the liquid Iron to flow to the sides of the interaction area to form a crater as shown in Fig. 25. When the liquid iron flows outward, the ixon beneath the surface at the center of the crater is cooler than calculated, 80 the surface is cooled by conduction more quickly than it would if the Iron structure were fixed. This effect would cause the actual maximum surface temperature to be 1 sss than that calculated, so the actual $\overline{\mathbf{n}}_{\max }$ would be less than that: calculated. This effect would also cause the ourface temperature to decrease at a faster rate than calculated. Since $\left(t_{1 / 2}^{+}-t_{\text {peak }}\right)$ is largely a measure of the rate at which the surface flux decreases, the measured value would therefore be less than the calculated value. The valite of $\left(t_{1 / 2}^{+}-t_{\text {peak }}\right)$ is determined both by the duration over which Iron atoms are emitted and by the spread in velocities of the emitted atoms. If the flux of iron atoms at the surface (FIg. 20) decreases much faster than calculated, the value of $\left(t_{1 / 2}^{+}-t_{\text {peak }}\right)$ will be due solely to the apread of velocities of the emitted atoms. The observed value of $\left(t_{1 / 2}^{+}-t_{\text {peak }}\right)$ of approximately 
$0.2 \mathrm{msec}$ is approximately the half width due to the spread of velocities from an effusive Maxwellian source, which indicates that the surface cools much nore rapldly than calculated. However, the measured and calculated values of ( $t_{\text {peak }}-t_{1 / 2}^{-}$) are in agreement, which indicates that the rate of increase of the surface temperature (and therefore flux of Iron atoms) is calculated correctly.

Because of the flow of liquid Iron, the comparison between theory and experiment must be partly qualitative. Since the calculated and experimental values of $t_{\text {peak }}$ and $\left(t_{\text {peak }}-t_{1 / 2}^{-}\right)$are in agreement, and since the discrepancy between the calculated and experimental values of $\bar{n}_{\max }$ and $\left(t_{1 / 2}^{+}-t_{\text {peak }}\right)$ can be qualitatively explained, the equilibrium model for the process appears to be valid. The results obtained are consistent with the following equilibrium assuptions: (a) the vaporized atoms have the velocity distribution of an effusive Maxwellian source, (b) the atoms are vaporized at a rate given by the Langmuir equation with condensation coefficient of unity and (c) the temperature transient is governed by the conduction equation with the appropriate boundary conditions.

\section{B. Zirconium Hydride Feaults}

\section{Numerica1 Results}

In the numerical calculation of the behavior of zirconium hydride heated by a Q-8witch laser, it is assurred that the laser is absorbed at the surface and that the absorbed power density has a triangular shape in time with the peak at 40 nanoseconds and the end of the pulse at 80 nanoseconds. The energy density is assumed to have the constant value $E_{a b s}(0)$ over the interaction area. This is valid because the 
energy density at the edge of tise rod 18 approximately $80 \%$ of that at the center and because most of the emitted hydrogen comes from the area with the highest absorbed energy density. The calculations are made with the assumption that the condensation coefficient $\alpha$ is equal to untty.

Results of the numerical calculations are shown In Figs. 29-33 for the equilibriun aodel (that 18 , for $\mathrm{H}_{2}$ vapor pressure given according to Fig. 16). The spacing between surface temperature profiles in Fig. 29 does not decrease with Increasing energy density as it did in the Iron callculations (see F1g. 19). Th1s 1s because the power loss by vaportzation from the zirconium hydride gurface is much less than the abrorbed power.

The $\mathrm{H} / \mathrm{Zr}$ atom ratio at the surface as a function of time is shown in E1g. 30 for various absorbed energy densities. For the energy densitles considered, substantial depletion of hydrogen occurs at the surface. The gurface $\mathrm{H} / \mathrm{Zr}$ ratio profiles pass through a minimum at approximately the same time as the maximum surface temperature. After the surface $\mathrm{H} / \mathrm{Zr}$ ratio reaches a minimum, it incresses because hydrogen diffuses from the bulk to the surface faster than it is lost by vapor 1zation. The final $\mathrm{H} / \mathrm{Zr}$ ratio is "frozen in" at a value less than the Initial value because vaporization and diffusion of hydrogen kecome negligible $a$ z the temperature returns to amblent.

The maximum $\mathrm{H}_{2}$ flux occurs when the equilibrium $\mathrm{H}_{2}$ pressure ui the surface is a maximum. Th1s occurs before the maximum temperature is reached because the $\mathrm{H}_{2}$ vapor pressure to a function of both temperature and $\mathrm{H} / \mathrm{Zr}$ atom ratio. As shown in Fig. 31 , the $\mathrm{H}_{2} \mathrm{flux}$ is a very sharp function of time, indicating that the emission occurs over a relatively 


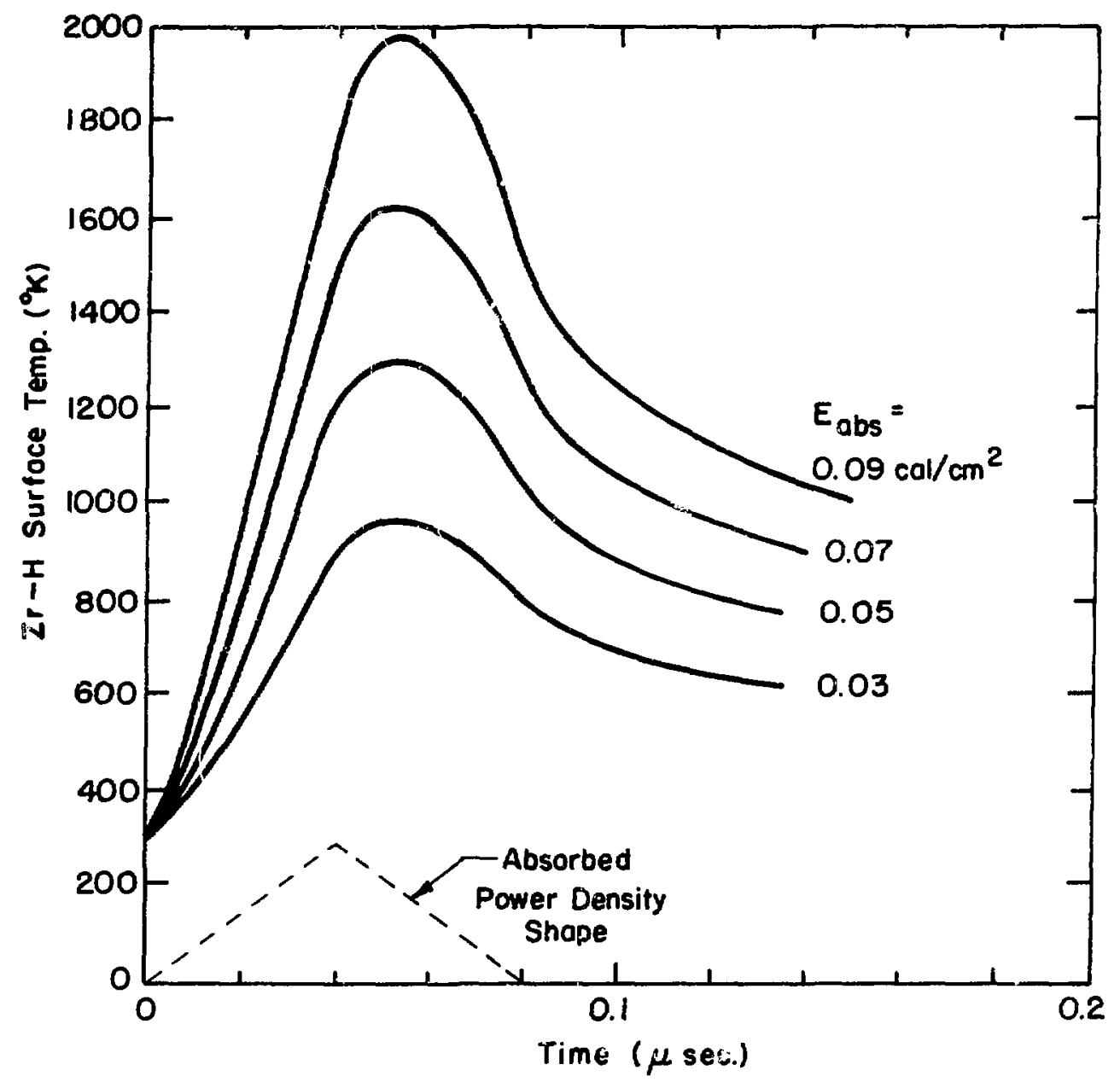

XBL 7211-7241

Fig. 29 Calculated surface temperature profiles for $\mathrm{Zr}-\mathrm{H}$ heated : Q-switch lasex pulses of varying energy densities. 


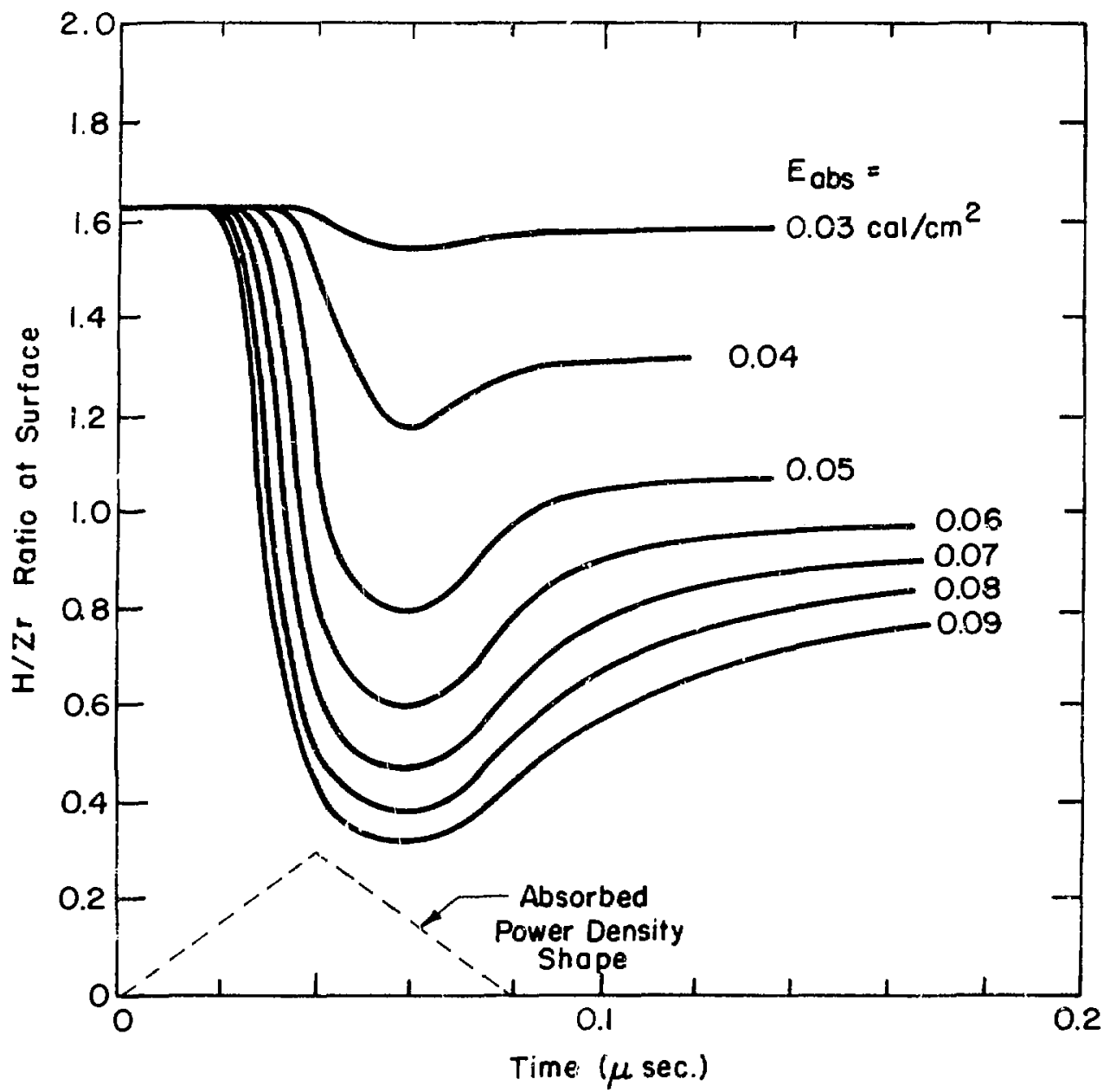

XBL7211-72.42

Fig. 30 Calcu.ated surface $\mathrm{H} / \mathrm{Zr}$ atom ratio profiles. 


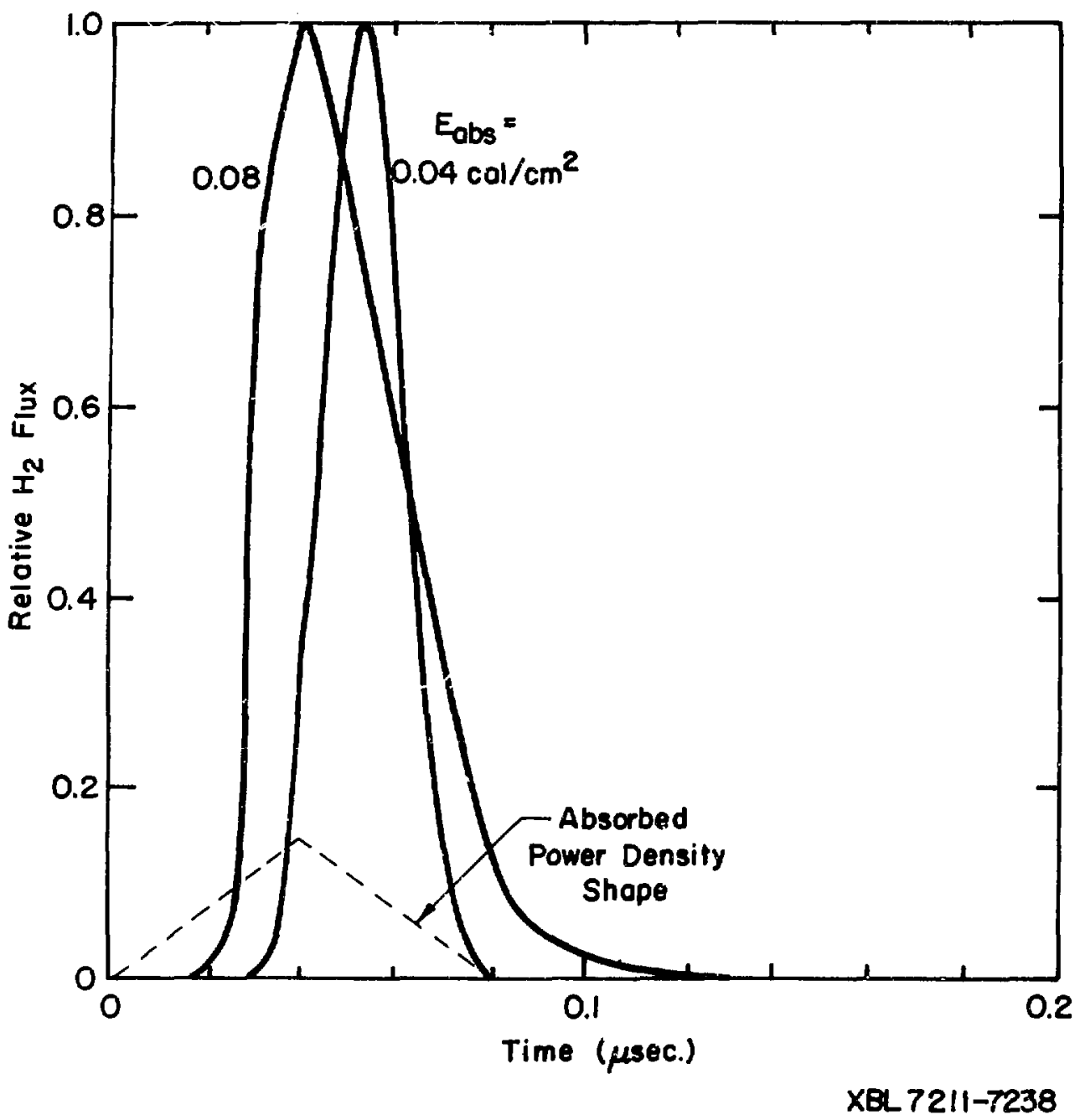
Fig. 31 Calculated relative flux of $\mathrm{H}_{2}$ molecules emitted from the
surface. 


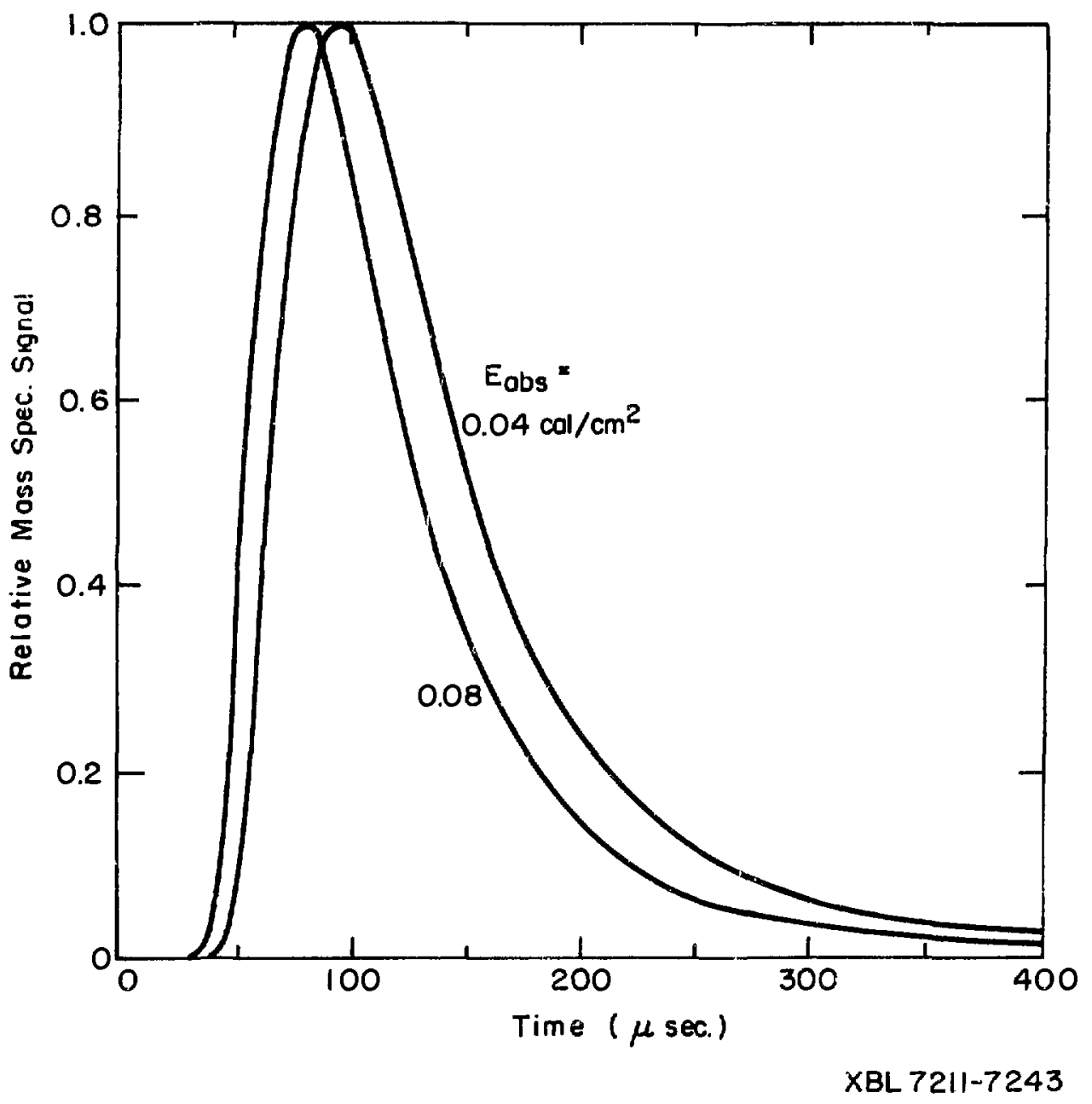

Fig. 32 Calculated relative $\mathrm{H}_{2}$ signal. 


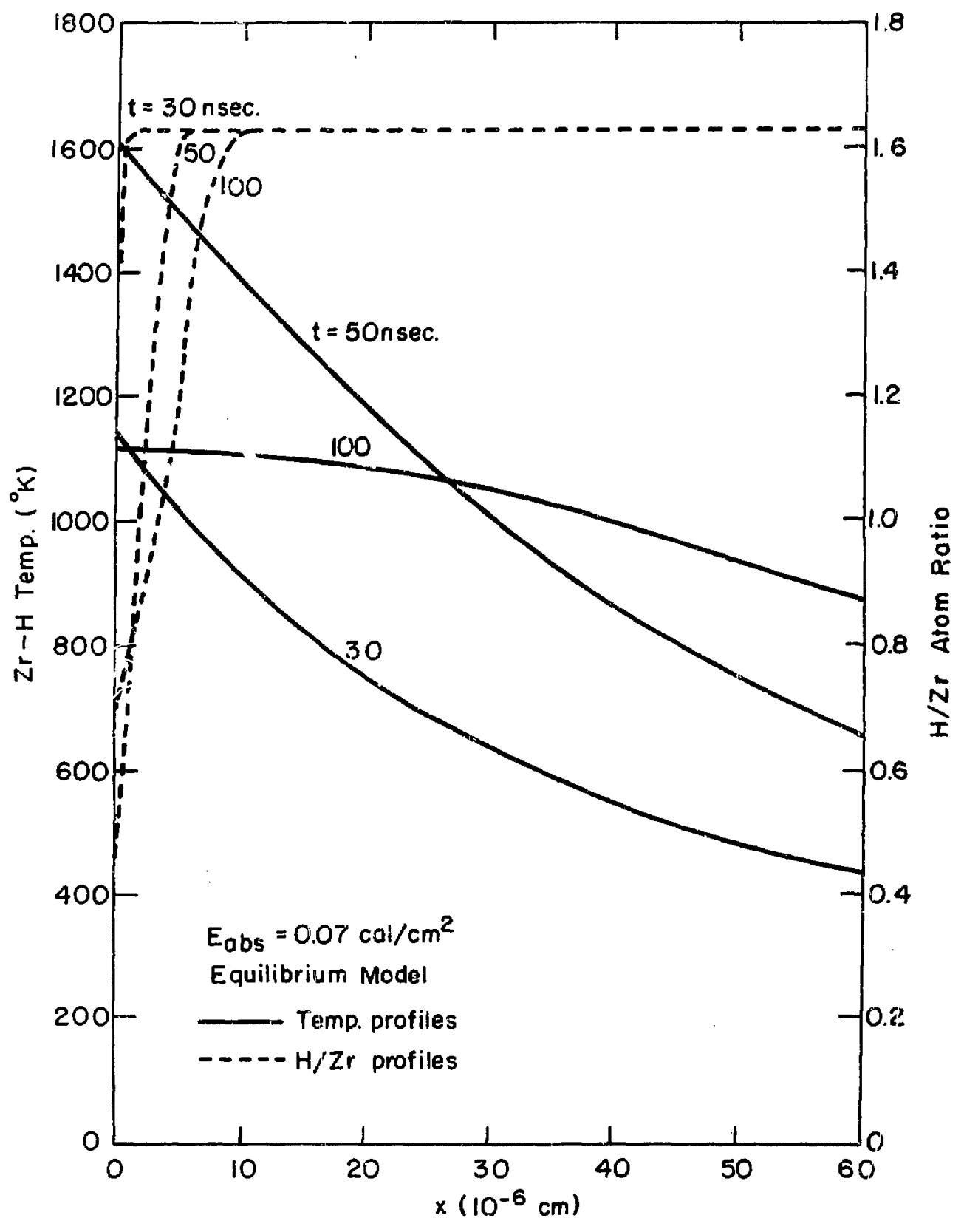

XBL 72II-7236

Fig. $33 \mathrm{Zr}-\mathrm{H}$ temperature and $\mathrm{H} / \mathrm{Zr}$ atom ratio as a function of distance from the surface. 
narrow temperature range (on the order of several hundred ${ }^{\circ} \mathrm{C}$ ).

Typical calculated mass spectrometer $\mathrm{H}_{2}$ signals are shown in Fig. 32. The $\mathrm{H}_{2}$ molecules are emitted over a time duration of less than $0.1 \mu \mathrm{sec}$ whereas the time of flight of the $\mathrm{H}_{2}$ molecules from the zirconium hydride sample to the mass spectrometer ionizer is approximately 100 usec. Therefore the $\mathrm{H}_{2}$ molecules are emitted effectively as an instantaneous source at zero time. The width of the calculated signal is then due entirely to the spread of veloritles of the emitted $\mathrm{H}_{2}$ molecules. As energy density increases, the calculated signal shifts toward the origin because of the increase in the velocity of the emitted molecules due to the higher surface temperature. There is a time delay of approximately $30 \mu \mathrm{sec}$ between the time the molecules are emitted and the beginning of the calculated signal because of the time required for the molecules in the high speed tail of the Maxwell-Boltzmann distribution to reach the ionizer.

As shown in Fig. 33, the hydrogen concentration is partially depleted up to a depth of approximately $10^{-5} \mathrm{~cm}$ from the surface. The temperature iransient penetrates to a depth of approximately $10^{-4} \mathrm{~cm}$. Temperature gradients at the surface reach values greater than $10^{7}{ }^{\circ} \mathrm{C} / \mathrm{cm}$.

The Soret effect and the effect of the enthalpy transported by the diffusing hydrogen atoms are both negligibis. The numerial solution of the solid energy equation and hydrogen diffusion equation (Eqs. (4.31)) were made with the heat of transport $\left(Q^{*}\right)$ and the gradient of the partial molar enthalpy of hydrogen $\left(\frac{\partial \bar{H}_{H}}{\partial x}\right)$ set to zero. Each effect made a less than $10 \%$ difference on the magnitude of the preaicted signal $\left(\vec{a}_{\max }\right)$ and a negligible effect $c n t_{\text {peak }}$ and FWHM. 
To compute the average density $\bar{n}(t)$ of molecules at the ionizer according to Eq. (3.\%), the following numerical constants are used: $\bar{x}=0.44, \alpha=1, s=40 \mathrm{~cm}$ and $A_{S}=0.079 \mathrm{~cm}^{2}$ (this is the area of the end of the zirconium hydride rod). The results of the calculations that are useful in comparing the calculated signal with the measured signal are:

$$
\begin{aligned}
T_{\max } & =\text { maximum surface temperature } \\
y_{\min } & =\min 1 \text { mum } \mathrm{H} / \mathrm{Zr} \text { atom ratio at the surface } \\
y 1 e l d & =\int_{0}^{\infty} \phi(t) \mathrm{dt}=\text { total amount of } \mathrm{H}_{2} \text { vaporized per } \mathrm{cm}^{2} \\
\bar{n}_{\max } & =\text { maximum value of } \overline{\mathrm{n}}(\mathrm{t}) \\
t_{\text {peak }} & =\text { time corresponding to } \bar{n}_{\max } \\
\text { FWH } & =\mathrm{full} \text { width of } \overline{\mathrm{n}}(\mathrm{t}) \text { at half maximum }
\end{aligned}
$$

These results for $\mathrm{H}_{2}$ are given in Table 3 for the equilibrium and quasi-equilibrium models.

If the heating and vaporization processes are described by equilibrium thermodynavics, a small amount of atomic hydrogen should also be emitted from the surface. There is a three-way equilibrium between atomic hydrogen, molecular hydrogen and hydrogen in the zirconium hydride. Constder the equilibrium between atomic and molecular hydrogen:

$$
\mathrm{H}(\mathrm{g}) \leftrightarrow \frac{1}{2} \mathrm{H}_{2}(\mathrm{~g})
$$

The equilibrium constant of this reaction is related to the partial pressures of $\mathrm{H}$ and $\mathrm{H}_{2}$ by the thermodynamic relation:

$$
\frac{\mathrm{P}_{\mathrm{H}}}{\mathrm{P}_{\mathrm{H}_{2}}^{\mathrm{I} / 2}}=\exp \left(-\frac{\Delta \mathrm{G}_{\mathrm{f}}^{\circ}}{\mathrm{RT}}\right)
$$


Table 3. Calculated results for $\mathrm{H}_{2}$ emission from $\mathrm{ZrH}_{1.63}$ target due to 0 -switch laser pulses.

\begin{tabular}{|c|c|c|c|c|c|c|}
\hline $\begin{array}{c}E_{a j s} \\
\left(c_{2} 1 / \mathrm{cm}^{2}\right)\end{array}$ & $\mathrm{T}_{\max }$ & $y_{\min }$ & $\begin{array}{c}\text { Yield } \\
\left(\begin{array}{l}\text { moles } \mathrm{H}_{2} \\
\text { per } \mathrm{cm}^{2}\end{array}\right)\end{array}$ & $\begin{array}{c}\left(\bar{n}_{\text {max }}\right)_{H_{2}} \\
\left(\begin{array}{c}\text { molecules } \\
\mathrm{H}^{2} / \mathrm{cm}^{3}\end{array}\right)\end{array}$ & $\begin{array}{l}t_{\text {peak }} \\
(\mu \text { sec })\end{array}$ & $\begin{array}{l}\text { FWHM } \\
\text { ( } \mu \text { sec })\end{array}$ \\
\hline \multicolumn{7}{|c|}{ Equïlibrium Mode1: } \\
\hline 0.02 & 704 & 1.628 & $1.14 \mathrm{E}-12$ & $1.19 \mathrm{E}+5$ & 120 & 112.0 \\
\hline 0.03 & 965 & 1.54 & $1.23 \mathrm{E}-9$ & $1.27 \mathrm{E}+8$ & 103 & 96.0 \\
\hline 0.04 & 1145 & 1.17 & $1.57 \mathrm{E}-8$ & $1.65 \mathrm{E}+9$ & 96 & 88.0 \\
\hline 0.05 & 1292 & 0.78 & $5.77 \mathrm{E}-8$ & $6.12 \mathrm{E}+9$ & 90 & 83.5 \\
\hline 0.06 & 1450 & 0.59 & $9.48 \mathrm{E}-8$ & $1.00 \mathrm{E}+10$ & 86 & 80.2 \\
\hline 0.07 & 1612 & 0.47 & $1.30 \mathrm{E}-7$ & $1.37 \quad E+10$ & 83 & 77.8 \\
\hline 0.08 & 1776 & 0.38 & $1.65 \mathrm{E}-7$ & $1.71 \mathrm{E}+10$ & 80 & 76.2 \\
\hline 0.09 & 1941 & 0.32 & $1.98 \mathrm{E}-7$ & $2.06 \mathrm{E}+10$ & 78 & 74.2 \\
\hline \multicolumn{7}{|c|}{ Quasi-Equilibrium Mode1, Continuous Slope f } \\
\hline 0.02 & 704 & 1.628 & $1.14 \mathrm{E}-12$ & $1.19+5$ & 120 & 112.0 \\
\hline 0.03 & 961 & 1.55 & $1.11 \mathrm{E}-9$ & $1.15 \mathrm{E}+8$ & 103 & 96.1 \\
\hline 0.04 & 1178 & 1.27 & $9.56 \mathrm{E}-9$ & $9.95 \mathrm{E}+8$ & 94 & 87.7 \\
\hline 0.05 & 1369 & 0.88 & $2.95 \mathrm{E}-8$ & $3.09 \mathrm{E}+9$ & 88 & 82.0 \\
\hline $\begin{array}{c}0.06 \\
\text { Quasi-Equilib }\end{array}$ & $\begin{array}{l}1537 \\
\text { Ium Mode } \\
\end{array}$ & $\begin{array}{r}0.43 \\
\mathrm{e} \\
1,2 \text { Cons } \\
\end{array}$ & $\begin{array}{r}6.12 \text { E-8 } \\
\text { scant slope } \\
\end{array}$ & $\begin{array}{c}6.44 \mathrm{E}+9 \\
\text { for Extrapols }\end{array}$ & $\begin{array}{c}84 \\
\text { tion of } \\
\end{array}$ & $\begin{array}{c}77.7 \\
\text { Vapor Pressure }\end{array}$ \\
\hline 0.02 & 704 & 1.628 & $1.14 \mathrm{E}-12$ & $1.19 \mathrm{E}+5$ & 120 & 112.0 \\
\hline 0.03 & 961 & 1.55 & $1.11 \mathrm{E}-9$ & $1.15 \mathrm{E}+8$ & 103 & 96.1 \\
\hline 0.04 & 1178 & 1.26 & $9.86 \mathrm{E}-9$ & $1.03 \mathrm{E}+9$ & 94 & 87.7 \\
\hline 0.05 & 1378 & 1.03 & 2.44 E-8 & $2.56 E+9$ & 88 & 82.2 \\
\hline 0.06 & 1572 & 0.84 & $4.34 \mathrm{E}-8$ & $4.56 \quad E+9$ & 84 & 78.1 \\
\hline 0.07 & 1762 & 0.70 & $6.50 \mathrm{E}-8$ & $6.81 E+9$ & 80 & 74.7 \\
\hline 0.08 & 1949 & 0.58 & $8.90 \mathrm{E}-8$ & $9.30 \mathrm{E}+9$ & 76 & 72.0 \\
\hline
\end{tabular}


Table. 4. Calculated results for H-atom emissjon frow $2 \mathrm{rH}_{1.63}$ target due to Q-switch laser pulses.

\begin{tabular}{|c|c|c|c|c|c|c|}
\hline $\begin{array}{c}\mathrm{E}_{\mathrm{cal}}^{\mathrm{bbs}} \\
\left.\mathrm{cm}^{2}\right)\end{array}$ & $\begin{array}{c}\text { Yield } \\
\left(\begin{array}{l}\text { moles } \mathrm{H} \\
\text { per } \mathrm{cm}^{2}\end{array}\right)\end{array}$ & $\begin{array}{c}\left(\mathrm{n}_{\mathrm{max}}\right)_{\mathrm{H}} \\
\left(\begin{array}{ll}\mathrm{H} & \text { atons } \\
\text { per } & \mathrm{cm}\end{array}\right)\end{array}$ & $\begin{array}{l}\mathrm{H} \\
t_{\text {peak }} \\
(\mu \text { sec })\end{array}$ & $\begin{array}{l}\text { FWHM }^{\mathrm{H}} \\
\text { (usec) }\end{array}$ & $\frac{t_{\text {peak }}^{\mathrm{H}}}{\mathrm{t}_{\text {peak }}^{\mathrm{H} 2}}$ & $\frac{\left(\overline{\mathrm{n}}_{\max }\right)_{\mathrm{H}}}{\left(\overline{\bar{n}_{\max }}\right)_{\mathrm{H}_{2}}}$ \\
\hline 0.03 & $4.74 \mathrm{E}-18$ & $4.88 \mathrm{E}-1$ & 73 & 67.5 & 0.71 & $3.8 \mathrm{E}-9$ \\
\hline 0.05 & $3.29 \mathrm{E}-14$ & $3.48 E+3$ & 63 & 58.5 & 0.70 & $5.7 \mathrm{E}-7$ \\
\hline 0.07 & $2.64 \mathrm{E}-12$ & $2.80 E+5$ & 57 & 52.6 & 0.69 & $2.0 \mathrm{E}-5$ \\
\hline 0.09 & $5.30 \mathrm{E}-11$ & $5.60 \mathrm{E}+6$ & 52 & 48.1 & 0.67 & 2.7 E-4 \\
\hline
\end{tabular}


where $\Delta G_{f}^{\circ}$ is the standard GiLbs free energy of formation of atomic hydrogen from molecular hydrogen, which was fit from the JANAF tables data as:

$$
\Delta G_{f}^{\circ}=52.387-i 2.274\left(\frac{T}{10^{3}}\right)-0.575\left(\frac{T}{10^{3}}\right)^{2} \frac{k c a 1}{\text { mole }}
$$

The results of the calculations of predicted atomic hydrogen signals for the equilibrium model are given in Table 4. For a particular surface temperature, the average velocity of emitted $H$ atoms is $\sqrt{2}$ times that of $\mathrm{H}_{2}$ molecules, so $\mathrm{t}_{\text {peak }}^{\mathrm{H}} / \mathrm{t}_{\text {peak }}^{\mathrm{H}_{2}}$ should be approximately equal to 0.7 . The ratio of the calculated peak amplitudes of the $\mathrm{H}$ and $\mathrm{H}_{2}$ signals (i.e., $\left.\left(\bar{n}_{\max }\right)_{\mathrm{H}} /\left(\bar{n}_{\max }\right)_{\mathrm{H}_{2}}\right)$ varies from $10^{-7}$ to $10^{-3}$ over the energy density range 0.04 to $0.10 \mathrm{cal} / \mathrm{cm}^{2}$.

\section{Experimental Results for Low Energy Denstttes}

A typical measured $\mathrm{H}_{2}$ signal is shown in Fig. 34. The trace is triggered at the beginning of the glant pulse, so the orizin represents true zero time. To calculate the corrected signal from the measured signal using Eq. (3.24), it is necessary to differentiate the measured signal. This is done as follows: (a) values of the measured signal are read from the oscilloscope trace, (b) these data points are fit ro a curve that is made of several plecewise cubic functions which have slope and value matched at the end points and which give an overall least squares fit to the data, and (c) this analytical fit of the data is then differentiated. The time constant correction of the measured signals is significant because it is of the same order of magnitude as the signal width. A typical measured $\mathrm{H}_{2}$ signal and the signal obtained after the time constant correction are shown in Fig. 35a. 


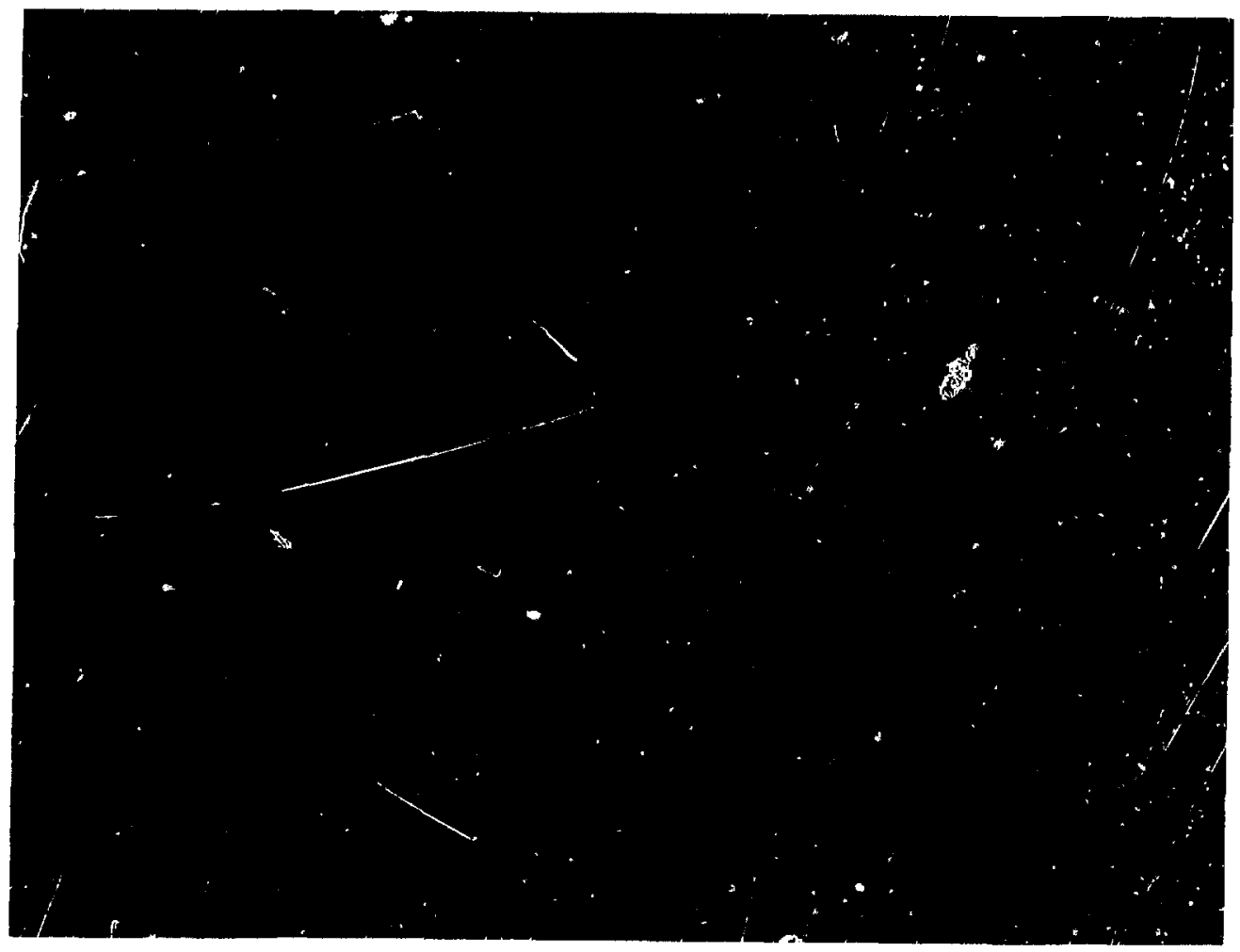

XBB $7210-5370$

Fig. 34 Typical measured $H_{2}$ signal. Horizontal scale is $20 \mathrm{\mu sec} /$ div. 


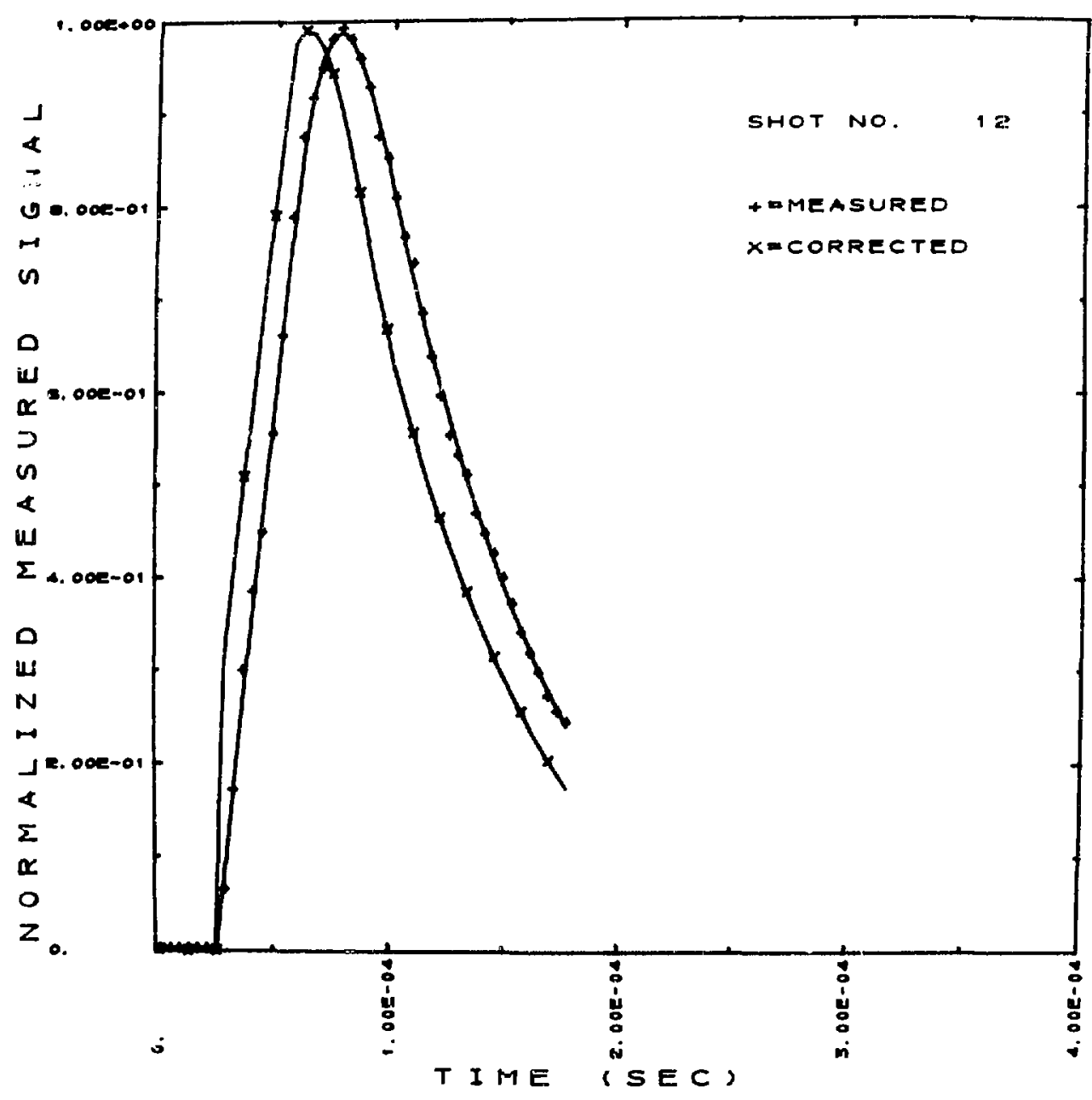

XBL $7210-5783$ Fig. 35a Typical measured and corrected $h_{2}$ signal, incident energy
density $=0.10 \mathrm{cal} / \mathrm{cm}^{2}$. 


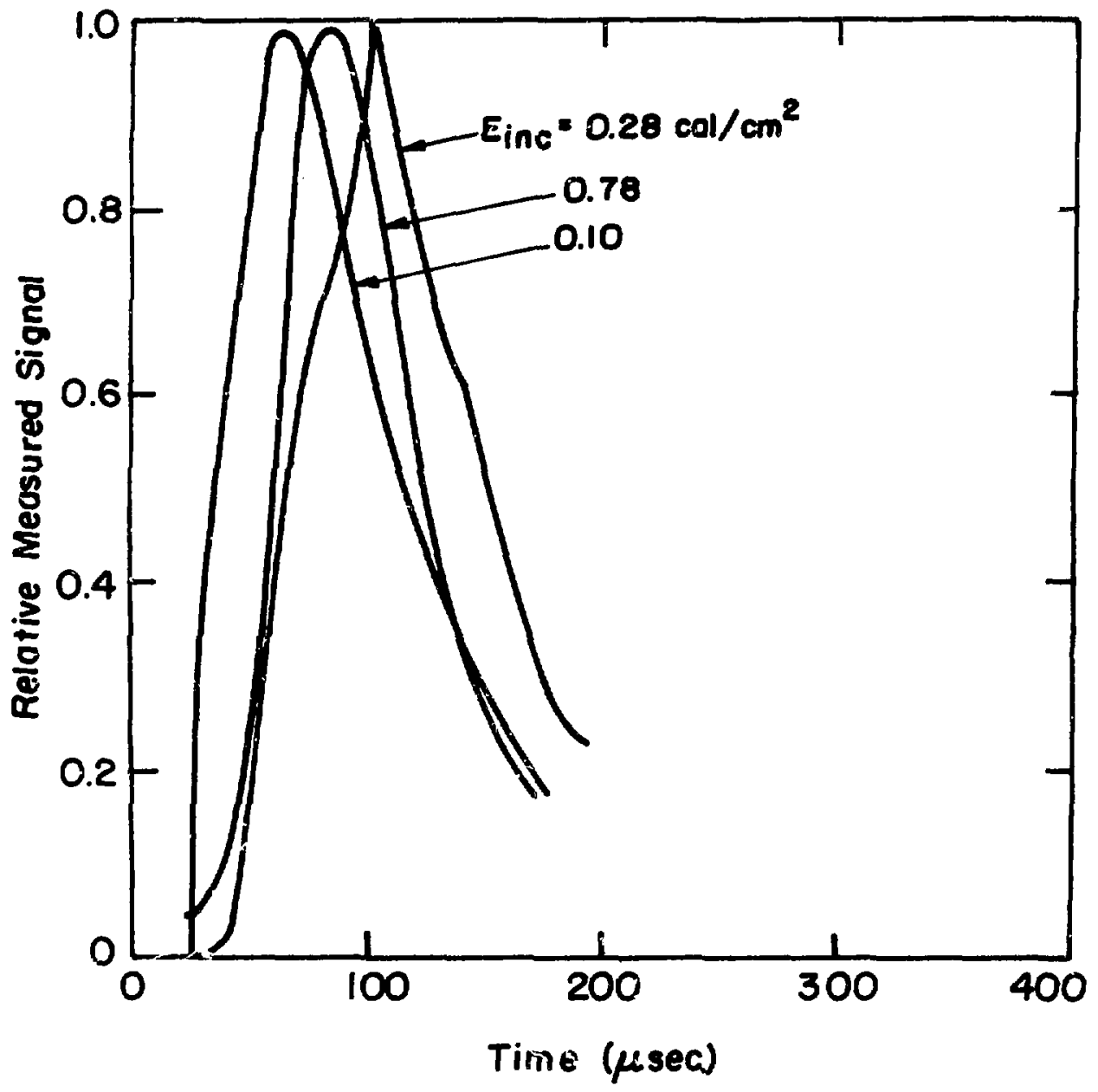

XBL 7210-5788

Fig. 35b Measured signals (after time constant correction) for varying incident energy densities. 


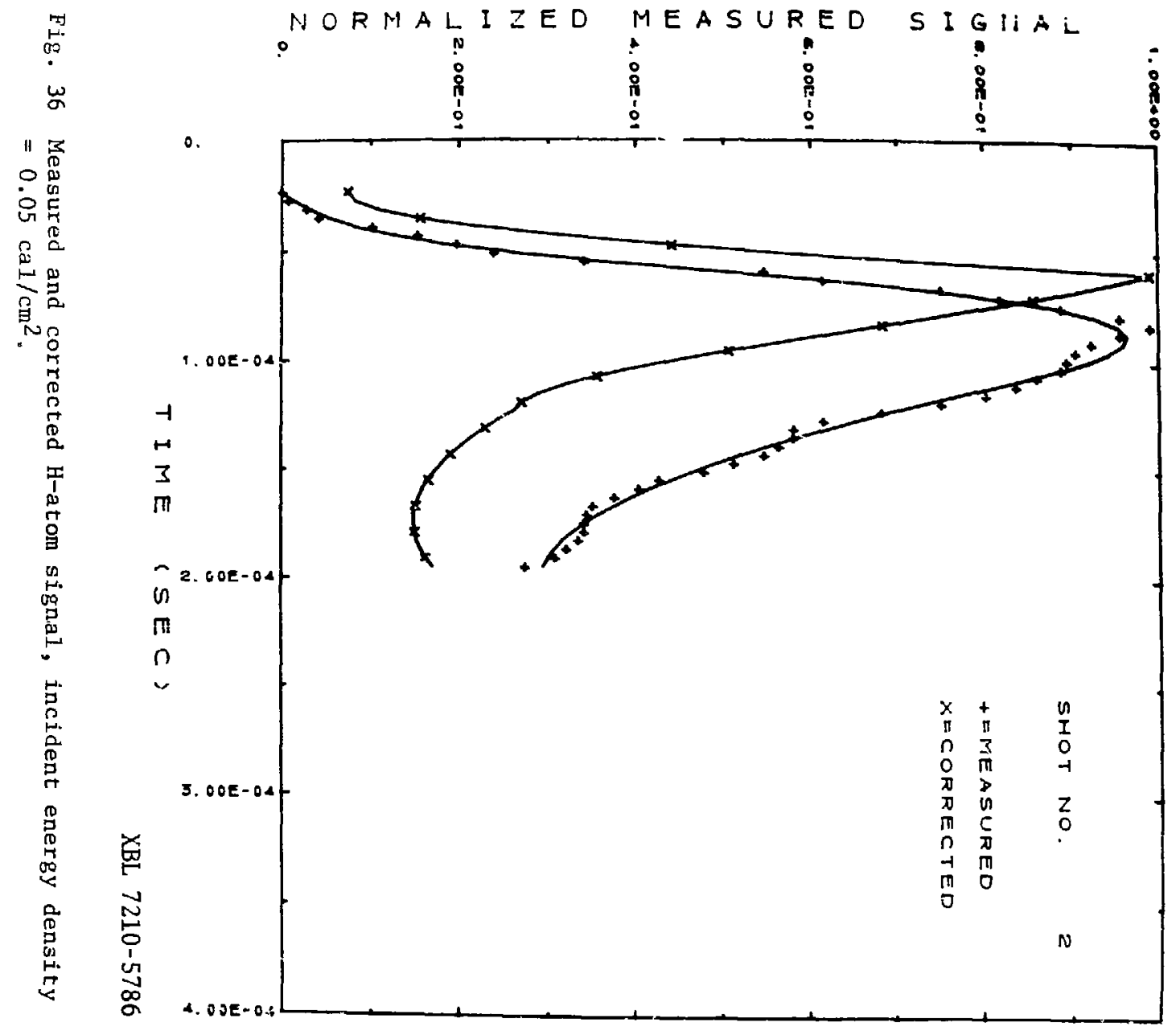


Typical measured $\mathrm{H}_{2}$ signals (corrected) are shown in Fig. 35b for three different incident energy densities. The pulse shapes agree closely with the calculated pulse shapes shown in Fig. 32 . Figure 36 shows a typical measured H-atom signal before and after the time constant correction.

\section{Comparison Between Calculated and Experimental Results (Low} Energy Density)

The experimental and theoreticai results may be best compared by utilizing several aspects of the waveforms such as those shown in Figs. 32 (predicted $\mathrm{H}_{2}$ ), $35 b$ (measured $\mathrm{H}_{2}$ ) and 36 (measured $\mathrm{H}$ ). As in the case of iron, these quantities are: the maximum density of molecules in the mass spectrometer fonizer $\left(\bar{n}_{\max }\right)$; the time at which this peak density occurs ( $t_{\text {peak }}$ ); and the full width at half maximum (FWHM) of the waveform. Predicted values of these three quantities can be obtafried directly from the results summarized in Tables 3 and 4 . The measured values of $t_{\text {peak }}$ and FWIM are easily determined from the measured waveforms such as in Figs. $35 \mathrm{~b}$ and 36. The determination of the absolute magnitude of the peak of a measured signal, however, requires that the sensitivity of the mass spectrometer be estimated. This is accemplished as follows.

The measured output signal current (corrected for time constant by Eq. (3.24)) is related to the density of neutral molecules in the fonizer by:

$$
I=\bar{k}
$$

where $\mathrm{K}$ is the collection of constants given by Eq. (3.23b). 
The value of $\mathrm{K}$ for $\mathrm{H}_{2}$ can be determined from the calibration described in Section II-E-2, in which the signal current is measured for a known hydrogen pressure in the mass spectrometer chamber. This calibration gave a sensitivity of 48 amps/torr for room temperature hydrogen gas. Using the Ideal gas law to convert pressure to number density $(\bar{n}=P / k T)$, the constant $K$ for $H_{2}$ is found to be $1.5 \times 10^{-15}$ amps $\mathrm{cm}^{3} /$ molecule. This value may be used if it is assumed that the mass spectrometer ionfzer responds in the same way to a random background gas as it does to a directed molecular beam of the same particle density. This assumption ts discussed In greater detall in Ref. 62 .

The constant $K$ for atomlc hydrogen is obtained from the above value for $\mathrm{H}_{2}$ by correcting for species dependent factors in $\mathrm{Eq}$. (3.23b). The two quantities which are different for $\mathrm{H}_{2}$ and $\mathrm{H}$ are the Ionization cross section $(\sigma)$ and the secondary electron coefficlent of the electron multiplier $(\beta)$. The $K$-value for $H$ is obtained from:

$$
\mathrm{K}_{\mathrm{H}}=\left(\frac{\sigma_{\mathrm{H}}}{\sigma_{\mathrm{H}_{2}}}\right)\left(\frac{\beta_{\mathrm{H}}}{\bar{\beta}_{\mathrm{H}_{2}}}\right) \mathrm{K}_{\mathrm{H}_{2}}
$$

Bised on the electron impact ionization cross-section data given in Ref. 63, the value of $\left(\sigma_{\mathrm{H}} / \sigma_{\mathrm{H}_{2}}\right) \simeq 0.68$ for $90 \mathrm{eV}$ electrons. A rough estimate of $\left(B_{\mathrm{H}} / \mathrm{B}_{\mathrm{H}_{2}}\right)$ can be made by assuming that the number of secondary electrons produced at the first dynode of the electron multiplier is proportional to the Inverse square root of the mass of the detected ion $\left(\beta_{\mathrm{H}} / \beta_{\mathrm{H}_{2}} \simeq 1.4\right)$, although such a correction ts not well verified and is therefore subject to some doubt. ${ }^{64}$ with these approximations, $\mathrm{K}_{\mathrm{H}}=\mathrm{K}_{\mathrm{H}_{2}}$ 
(within a possible uncertainty of a factor of 2). As mentioned in the discussion of the iron results, estimates of absolute mass spectrometer sensitivities are generally no better than a factor of 2 or 3 .

Utilizing the Instrumental constant $K$ determined as described above, the peak amplitudes of the measured signals (after time constant correctlons) can be converted to measured values of $\bar{n}_{\max }$ for $\mathrm{H}$ and $\mathrm{H}_{2}$. The three quantities characteristic of the measured waveform ( $t_{\text {peak }}$, FWHM, and $\bar{n}_{\max }$ ) are tabulated in Table 5 for two series of experiments in which the $\mathrm{H}_{2}$ signal was measured and another series of laser shots in which the mass spectrometer was tuned to H (mass 1).

To complete the comparison between theory and experiment, the surface reflectivity must be known to relate incident energy density ( $\left.E_{\text {inc }}\right)$ to absorbed energy density $\left(E_{a b s}\right)$. To eliminate this additional uncertainty (and that of the magnitude of $E_{\text {inc }}$ as well), we first compare plots of $t_{\text {peak }}$ vs FWHM, which is independent of surface reflectivity. Since the molecules are emitted over a time much less than tpeak, the ratio $t_{\text {peak }} /$ WWH is characteristic only of the velocity distribution of the emitted molecules. The calculated and experimental values of $t_{\text {peak }}$ vs FWHM are plotted in Fig. 37. Aithough the data are scattered, they do cluster about the straight line representing the calculated variation of $t_{\text {peak }}$ vs FWHM for a Maxwellian beam. This indfcates that the $\mathrm{H}_{2}$ molecules and $\mathrm{H}$ atoms are emitted with the vesucity distribution of an effusive Maxwellian source.

The calculated and experimental values of $t$ peak $v s$ incident energy density $\mathrm{E}_{\text {inc }}$ are plotted in $\mathrm{Fig}$. 38. The $\mathrm{H}_{2}$ data points cluster about the theoretical curve for surface reflectivity $R=0$, although the 
Table 5. Results of $\mathrm{Zr}-\mathrm{H}$ measurewents for low incident energy densities.

\begin{tabular}{|c|c|c|c|c|c|}
\hline \multirow{2}{*}{\multicolumn{2}{|c|}{$\begin{array}{l}\text { Shot Number } \\
\mathrm{H}_{2} \text { Results }\end{array}$}} & \multirow{3}{*}{$\begin{array}{l}\begin{array}{c}E_{\text {inc }} \\
\left(\mathrm{cal} / \mathrm{cm}^{2}\right)\end{array} \\
0.0278\end{array}$} & \multirow{3}{*}{$\begin{array}{c}\begin{array}{r}t_{\text {peak }} \\
\left(\mu_{\text {sec }}\right)\end{array} \\
102.0\end{array}$} & \multirow{3}{*}{$\begin{array}{c}\begin{array}{c}\text { FWHM } \\
\text { (usec) }\end{array} \\
83.9\end{array}$} & \multirow{3}{*}{$\begin{array}{c}\begin{array}{c}\overline{\mathrm{n}}_{\max } \\
\left(\mathrm{molecules} / \mathrm{cm}^{3}\right)\end{array} \\
6.0 \mathrm{E}+8\end{array}$} \\
\hline & & & & & \\
\hline \multirow{7}{*}{$\begin{array}{c}\text { Sertes } \\
\text { A }\end{array}$} & 1 & & & & \\
\hline & 3 & 0.0377 & 94.0 & 81.7 & 1.2. $\mathrm{E}+9$ \\
\hline & 4 & 0.0567 & 82.0 & 47.8 & $1.2 \mathrm{E}+9$ \\
\hline & 6 & 0.0230 & 105.0 & 75.3 & $3.3 \mathrm{E}+8$ \\
\hline & 7 & 0.0234 & 102.5 & 83.2 & $4.1 \quad E+8$ \\
\hline & 9 & 0.0866 & 75.5 & 65.3 & $1.3 \mathrm{E}+9$ \\
\hline & 10 & 0.125 & 55.2 & 65.2 & $1.1 E+9$ \\
\hline \multirow{10}{*}{$\begin{array}{c}\text { Series } \\
\text { B }\end{array}$} & 12 & 0.100 & 62.0 & 80.4 & $7.4 \quad E+8$ \\
\hline & 13 & 0.111 & 78.4 & 317.0 & $8.1 E+8$ \\
\hline & 14 & 0.156 & 90.0 & 101.0 & $1.4 \mathrm{E}+9$ \\
\hline & 22 & 0.0372 & 100.0 & 90.0 & $1.1 \mathrm{E}+8$ \\
\hline & 23 & 0.0599 & 76.0 & 69.8 & $2.1 \mathrm{E}+8$ \\
\hline & 24 & 0.0567 & 84.0 & 92.4 & $1.2 \mathrm{E}+8$ \\
\hline & 25 & 0.0882 & 86.0 & 82.0 & $3.0 \mathrm{E}+8$ \\
\hline & 26 & 0.0784 & 84.0 & 63.8 & $9.7 \mathrm{E}+8$ \\
\hline & 27 & 0.0586 & $1 \times 4.0$ & 67.5 & $7.2 \quad E+8$ \\
\hline & 28 & 0.127 & 84.0 & 78.8 & $2.0 \mathrm{E}+9$ \\
\hline \multicolumn{6}{|c|}{ H-Atom Results } \\
\hline & 2 & 0.0496 & 59.0 & 47.4 & $2.6 \mathrm{E}+8$ \\
\hline & 5 & 0.0847 & 67.0 & 50.0 & $2.6 \mathrm{E}+8$ \\
\hline & 8 & 0.103 & 57.0 & 48.2 & $3.0 \mathrm{E}+8$ \\
\hline & 11 & 0.109 & 52.0 & 57.7 & $1.6 \mathrm{E}+8$ \\
\hline
\end{tabular}




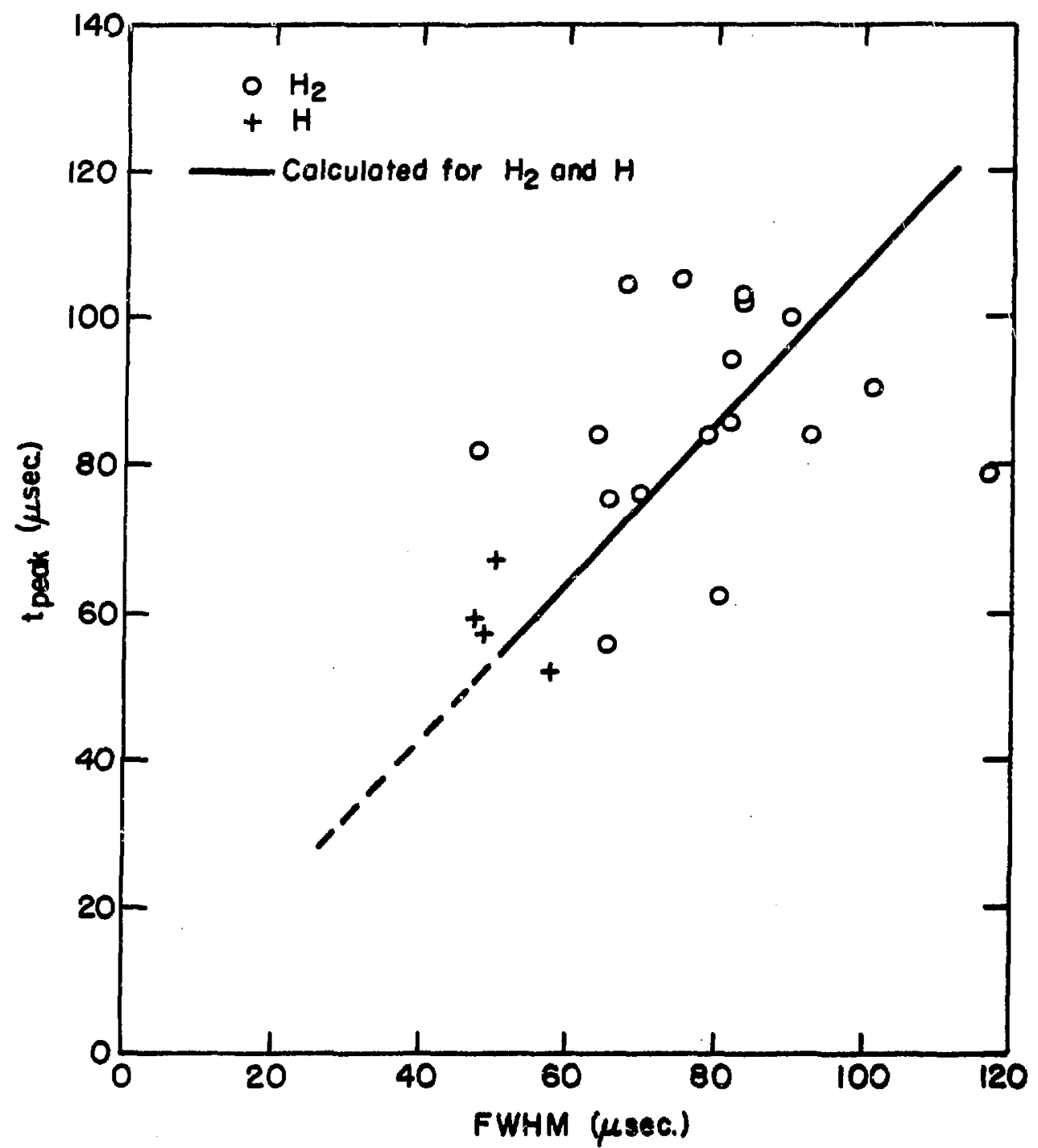

XBL. $7211-7237$

Fig. 37 Comparison between calculated and experimental tpeak vs
FwM, for $\mathrm{Zr}-\mathrm{H}$. 


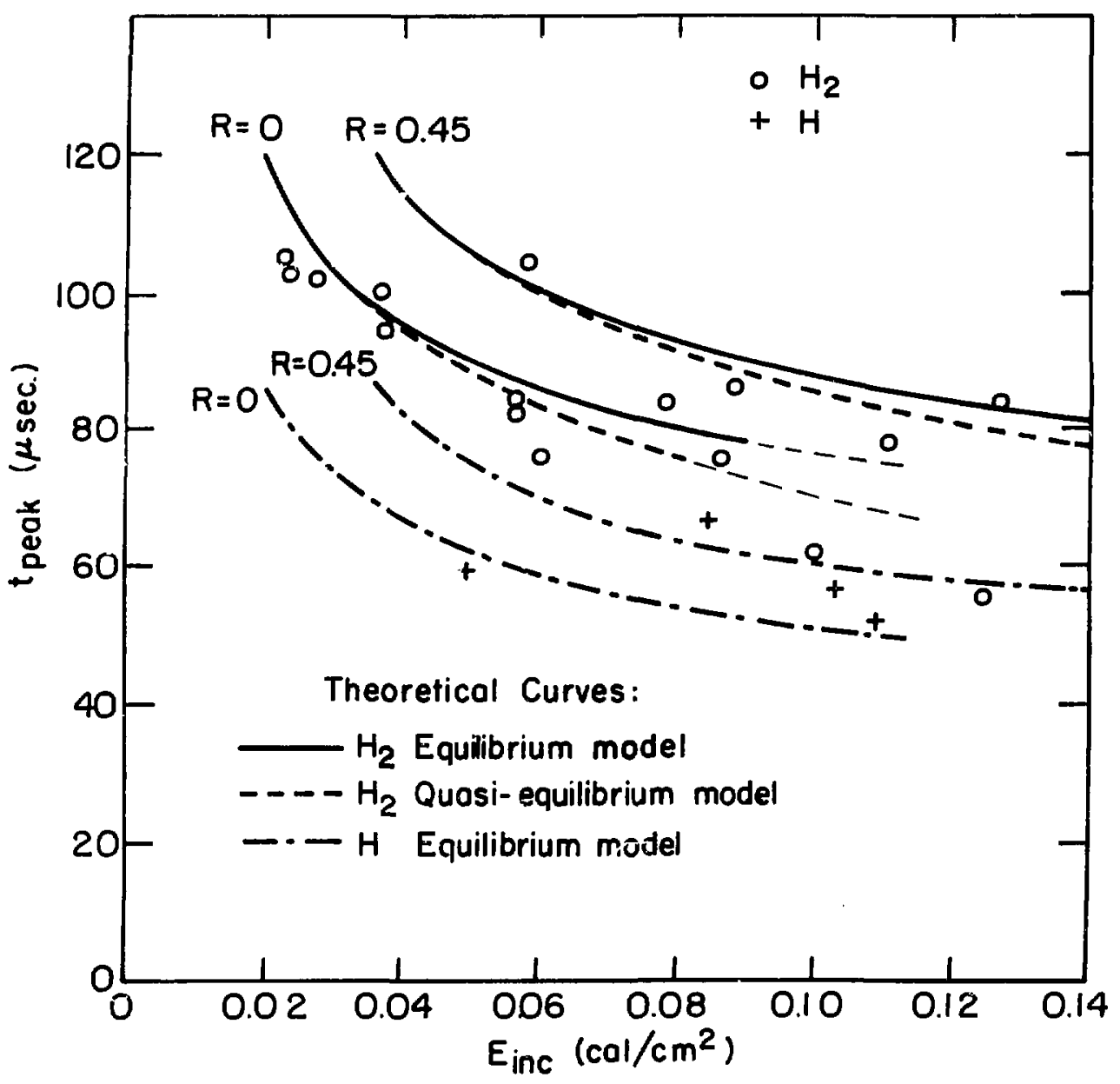

XBL 7211-7234

Fig. 38 Comparison between calculaced and experimental t $t_{\text {peak }}$ vs

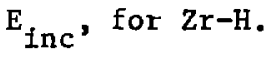




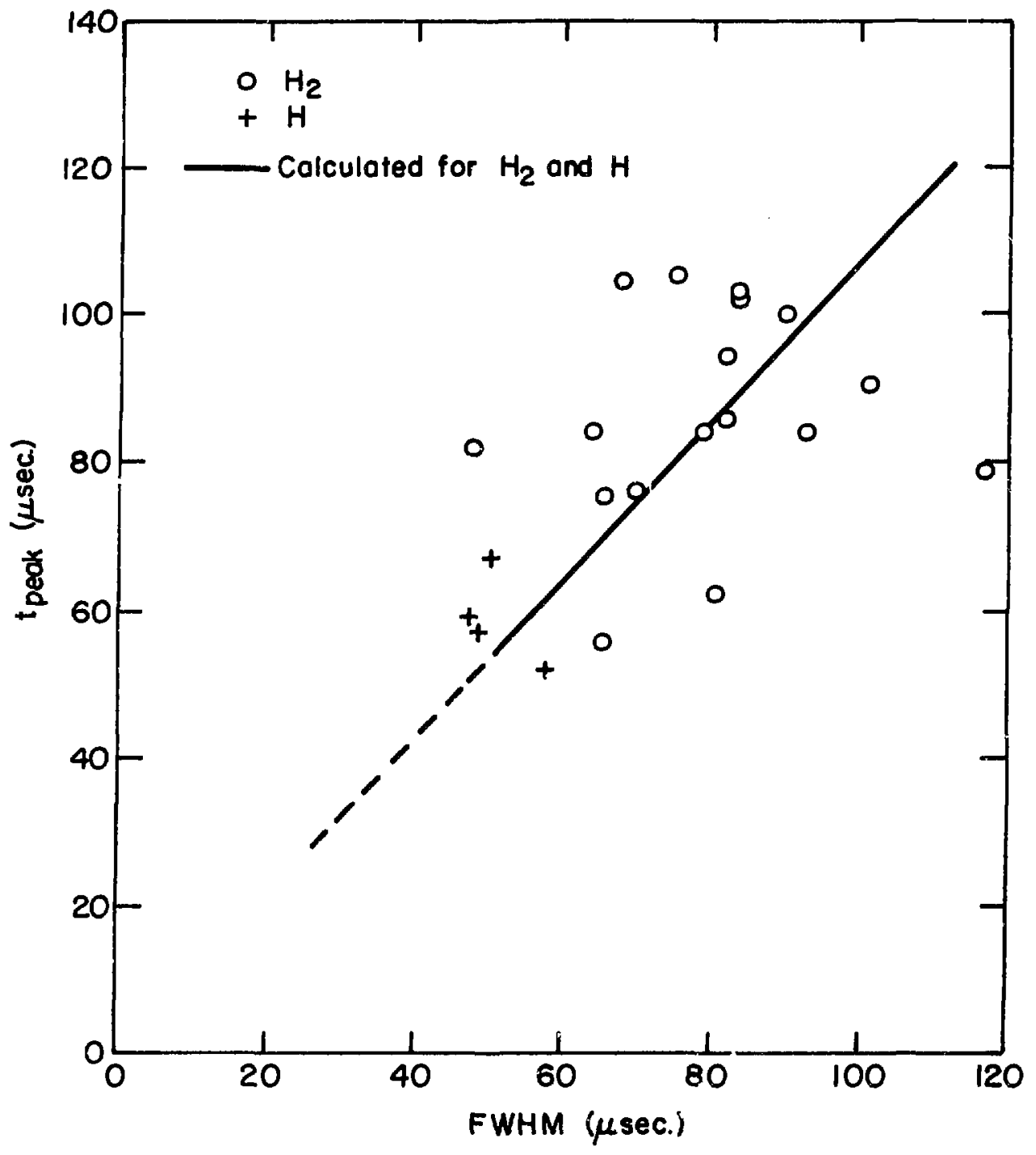

$X B L 7211-7237$ F1g. 37 Comparison between calculated and experimental t peak vs
FWH, for $\mathrm{Zr}-\mathrm{H}$. 


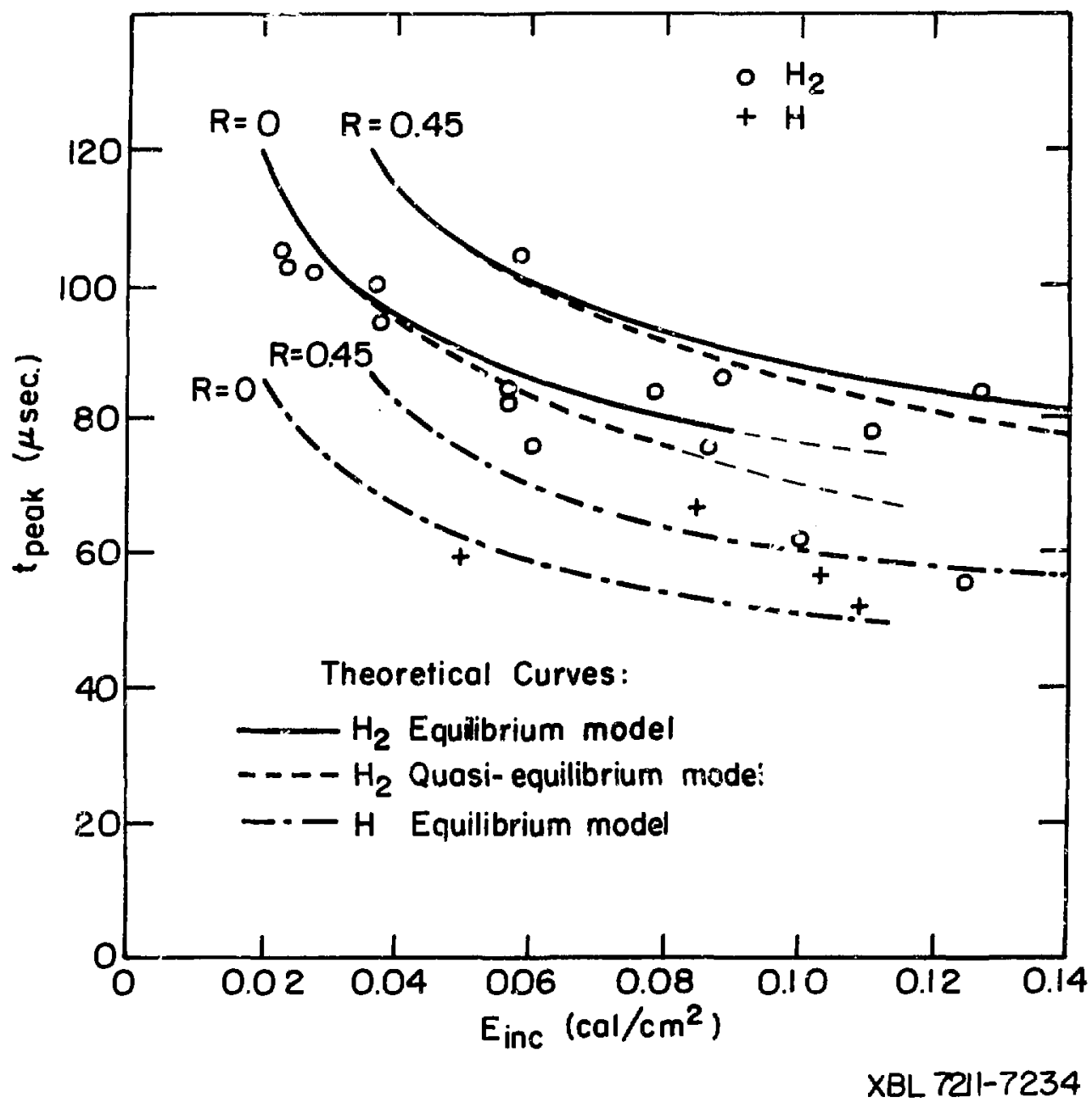
$\mathrm{Fi}_{\mathrm{c}}, 38$ Comparison between calculated and experimental t
$\mathrm{E}_{\text {inc }}$, for $\mathrm{Zr}-\mathrm{H}$. 


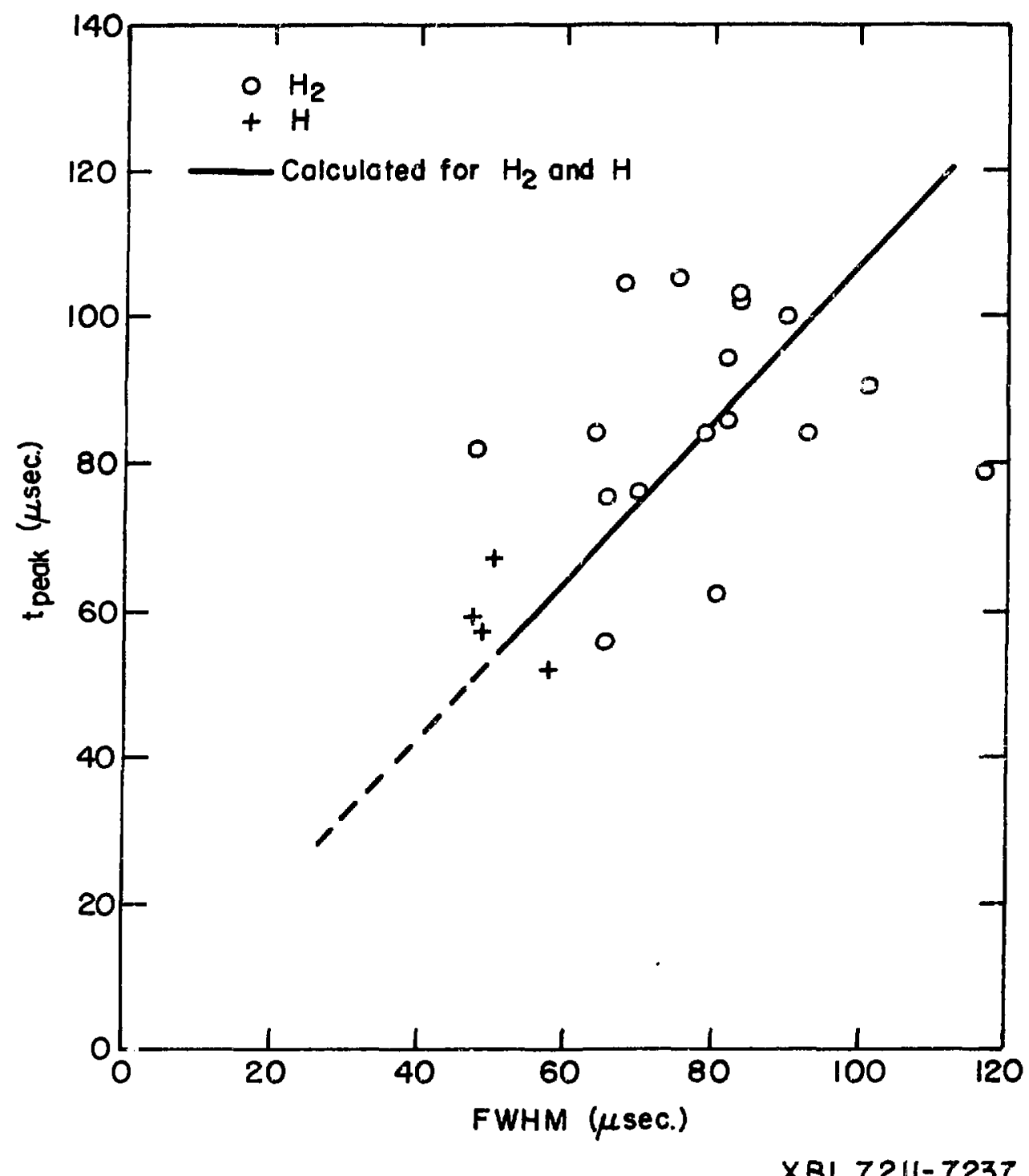

Fig. 37 Comparison between calculated and experimental t peak vs
FWHM, for $\mathrm{Zr}-\mathrm{H}$. 


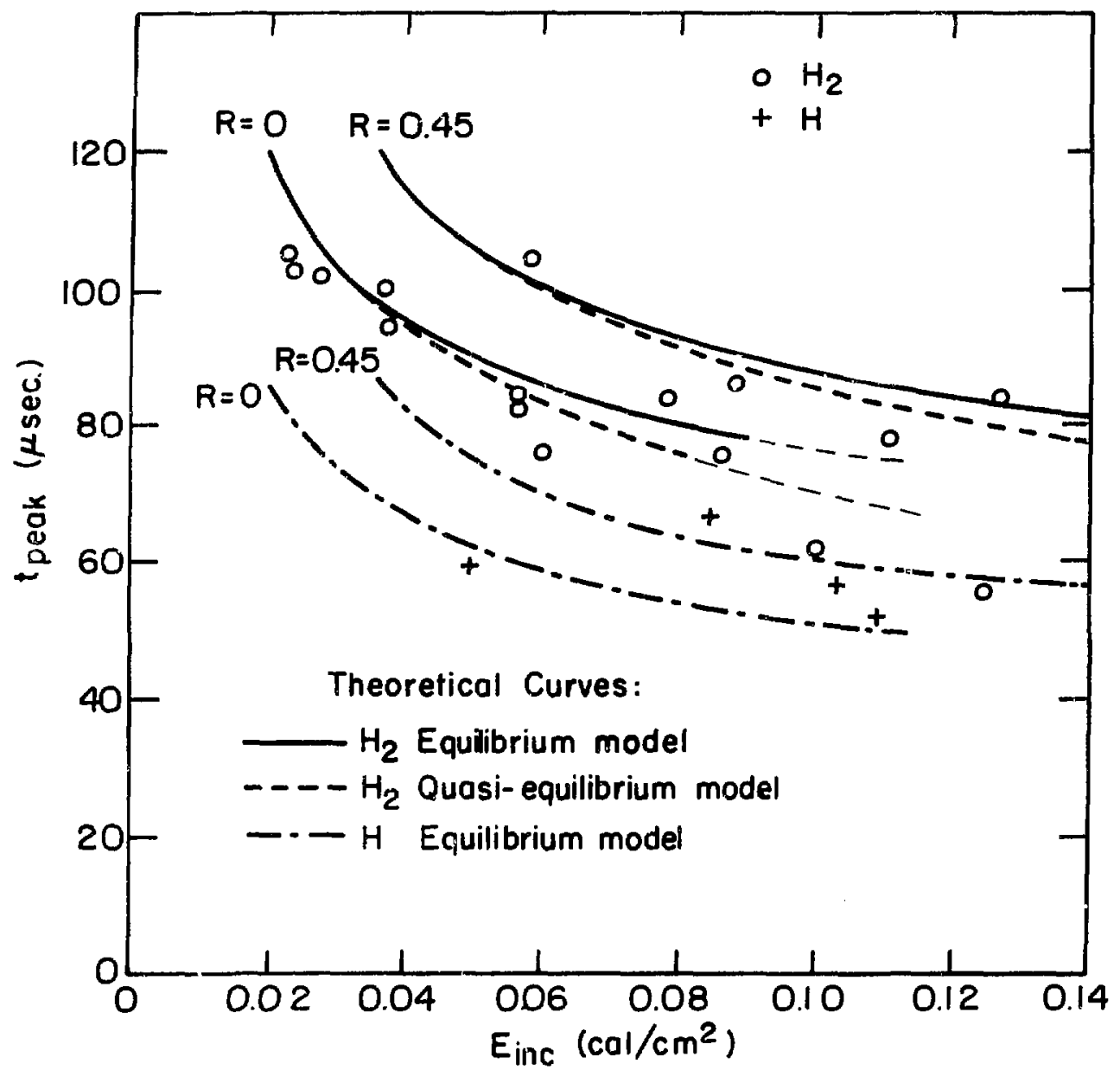

XBL T2I1-7234 Fig. 38 Comparison between calculated and experimental t peak
$\mathrm{E}_{\text {inc, for } \mathrm{Zr}-\mathrm{H} \text {. }}$ 


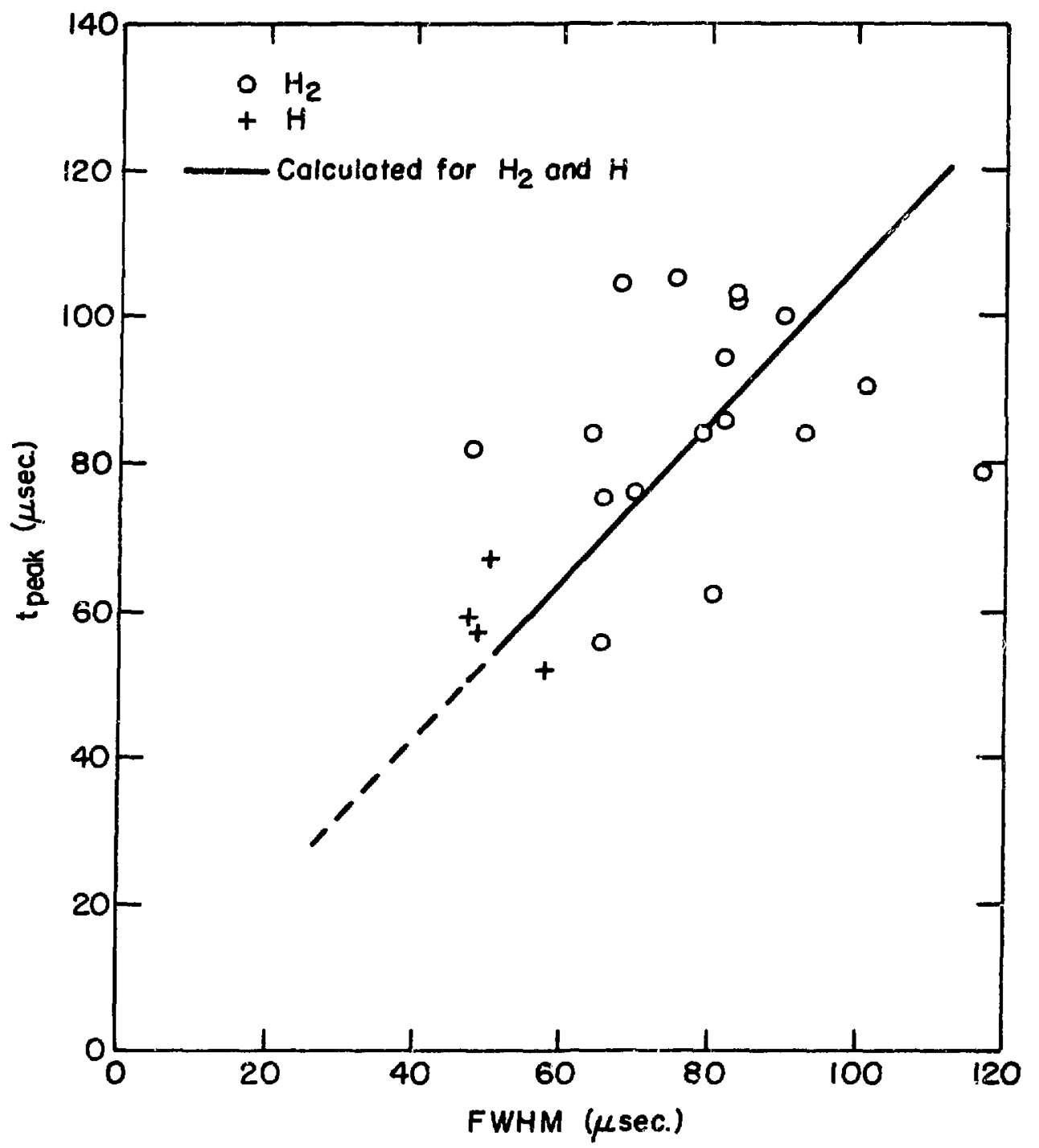

XBL7211-7237

Fig. 37 Comparison between calculated and experimental t peak vs
FWHM, for $\mathrm{zr}-\mathrm{H}$. 


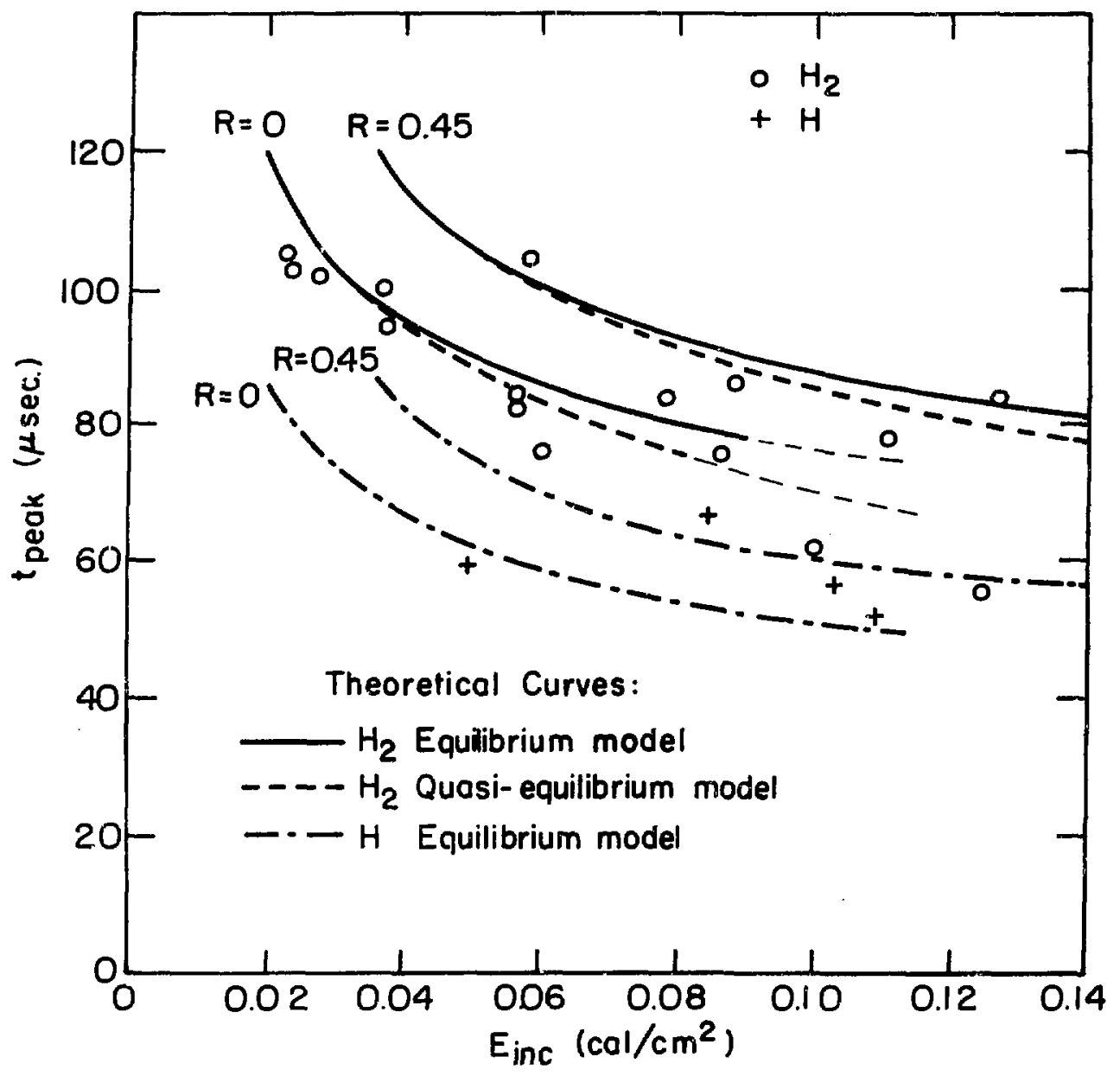

XBL 72I-7234

Fig. 38 Comparison between calculated and experfmental $t_{\text {peak }}$ vs Einc, for $\mathrm{Zr}-\mathrm{H}$. 


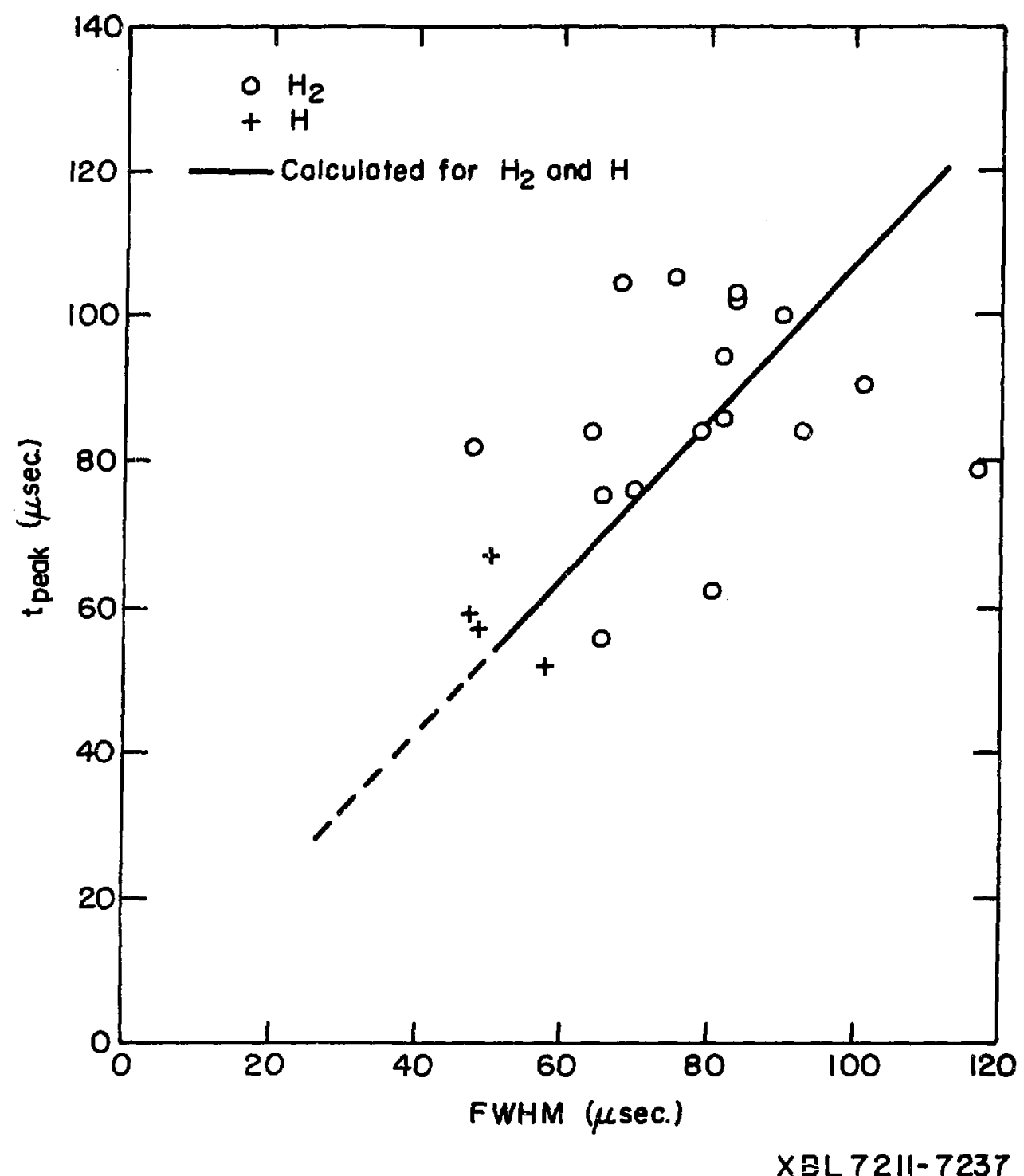

Fig. 37 Comparison between calculated and experimental t peak vs
FWH, for $\mathrm{Zr}-\mathrm{H}$. 


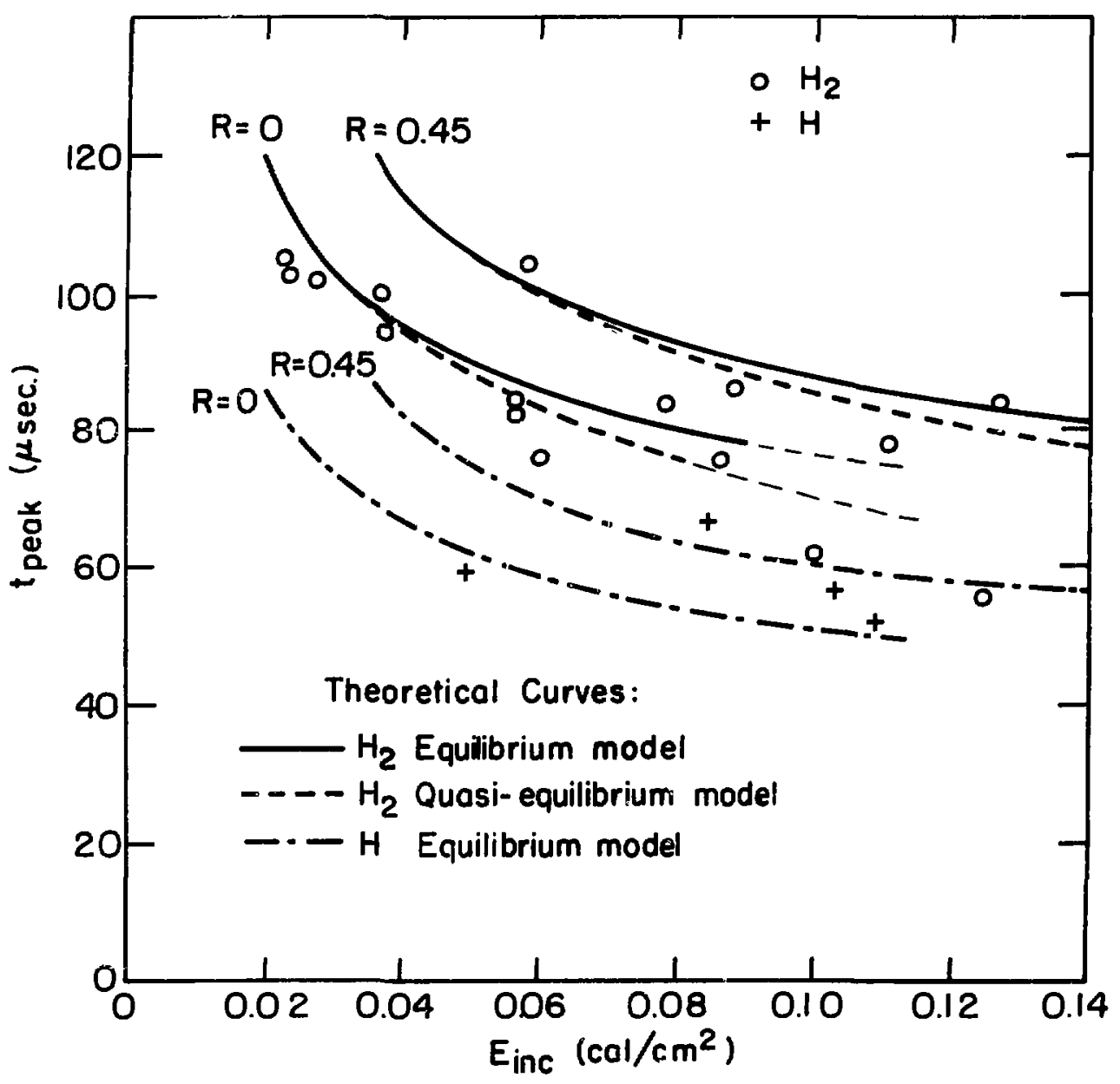

XBL Tृ|-7234

Fig. 38 Comparison between calculated and experimental $t_{\text {peak }}$ vs

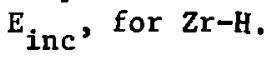




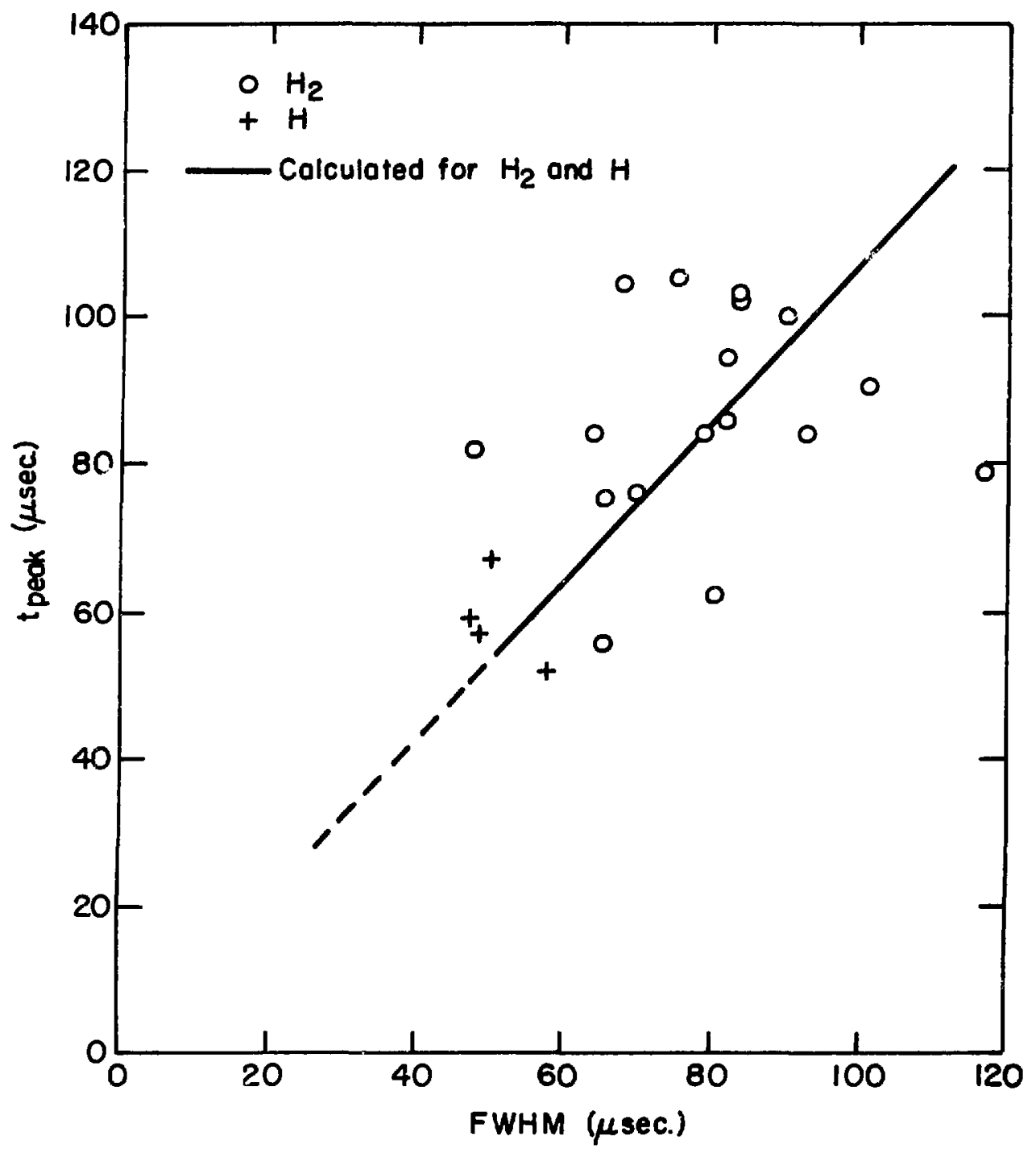

X日L 72II-7237

Fig. 37 Comparison between calculated and experimental $t_{\text {peak }}$ vs
FWHM, for $\mathrm{Zr}-\mathrm{H}$. 


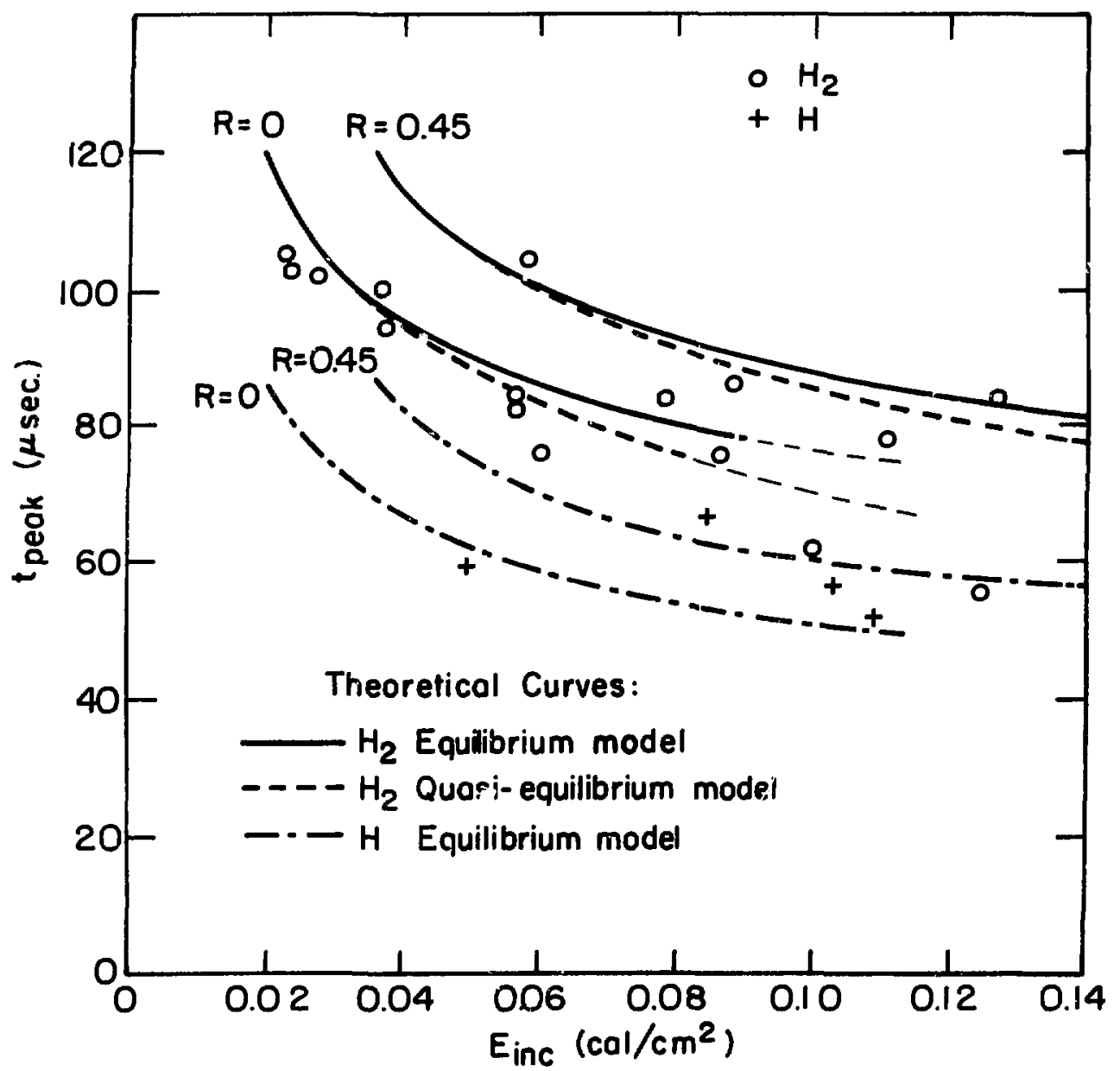

XBL T21-7234 Fig. 38 Comparison between calculated and experimental $t_{\text {peak }}$ vs
$\mathrm{E}_{\text {inc' }}$, for $\mathrm{Zr}-\mathrm{H}$. 


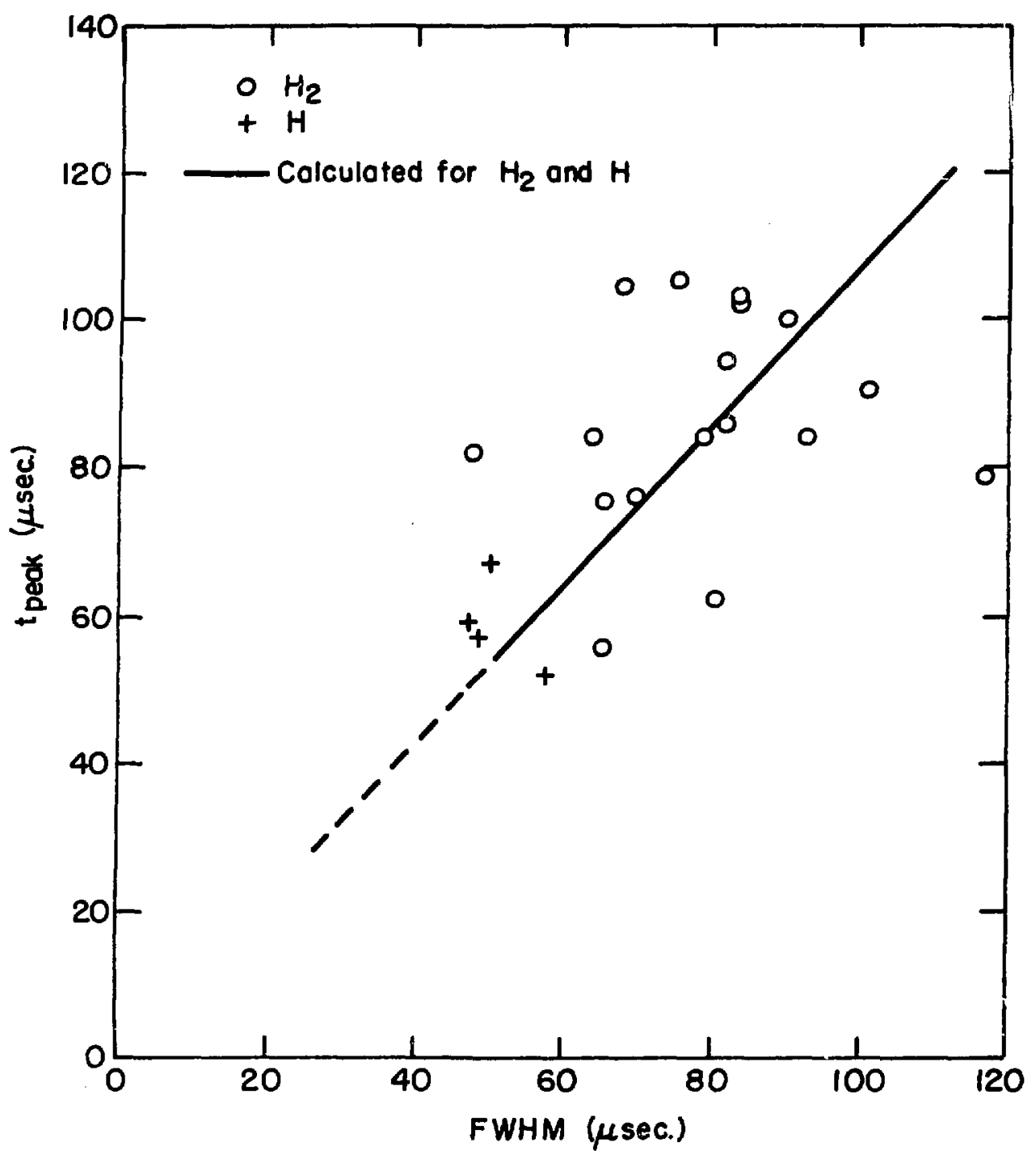

XEL 72II-7237

Fig. 37 Comparison between calculated and experimental tpeak
FWHM, for $\mathrm{Zr}-\mathrm{H}$. 


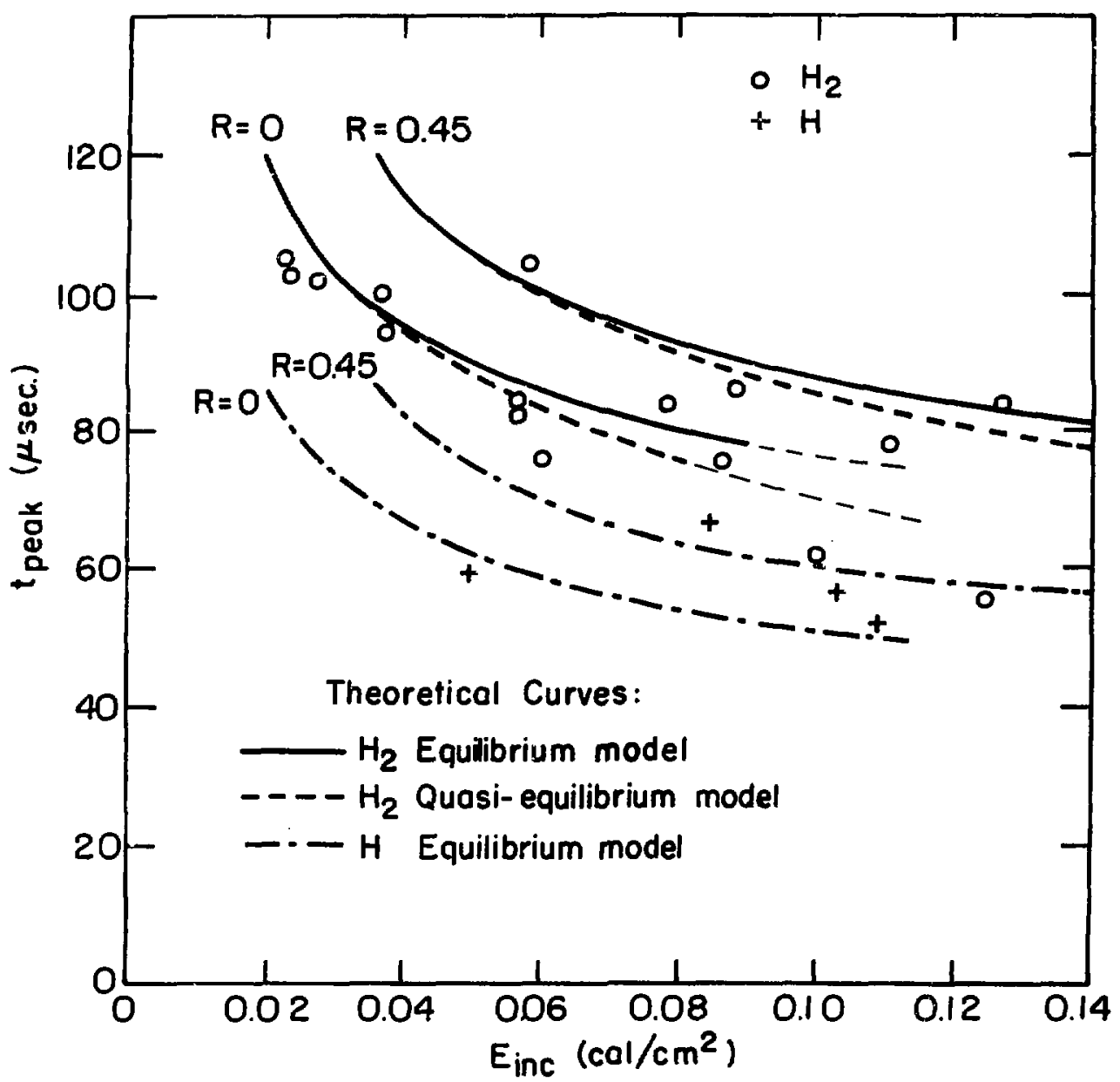

XBL $721-7234$

Fig. 38 Comparison between calculated and experimental $t$ peak
E. for $\mathrm{Zr}-\mathrm{H}$. $\mathrm{E}_{\text {inc }}$, for $\mathrm{Zr}-\mathrm{H}$. 


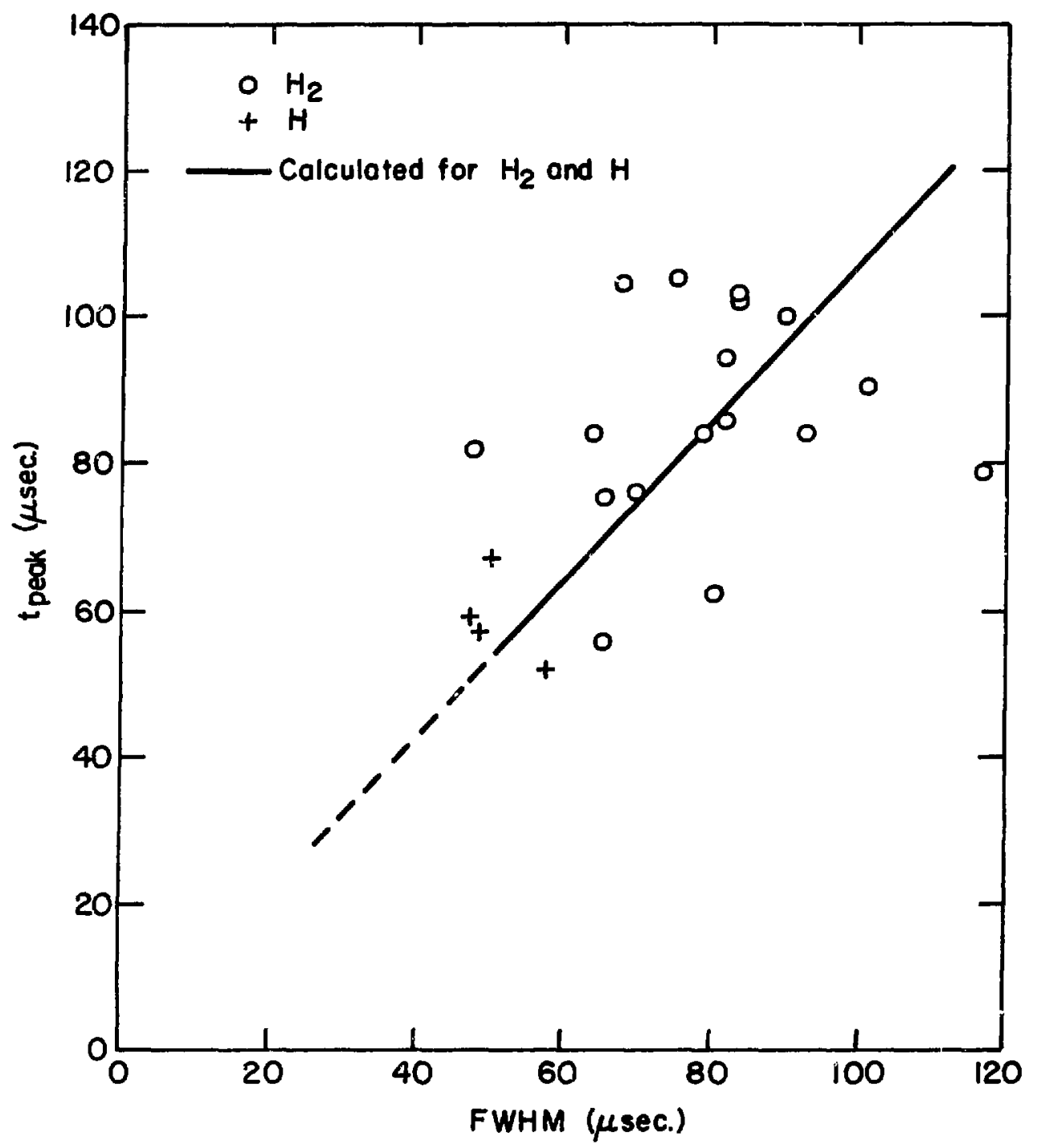

XBL $7211-7237$

Fig. 37 Comparison between calculated and experimental $t_{\text {peak }}$ vs
FWHM, for $\mathrm{Zr}-\mathrm{H}$. 


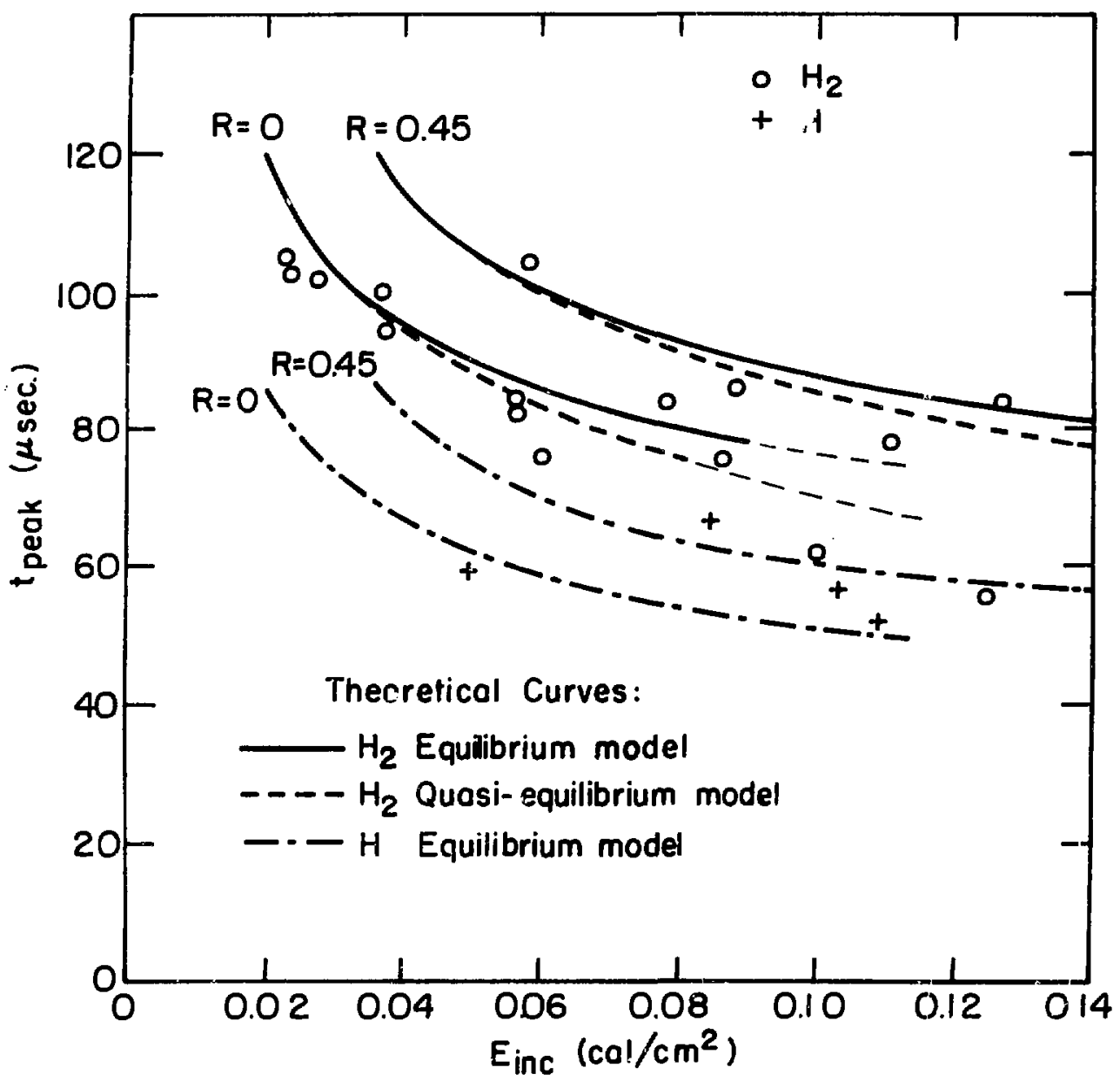

XBI_ T2II-7234

Eig. 38 Comparison between calculated and experimental $t_{\text {peak }}$ vs $\mathrm{E}_{\text {inc }}$, for $\mathrm{Zr}-\mathrm{H}$. 


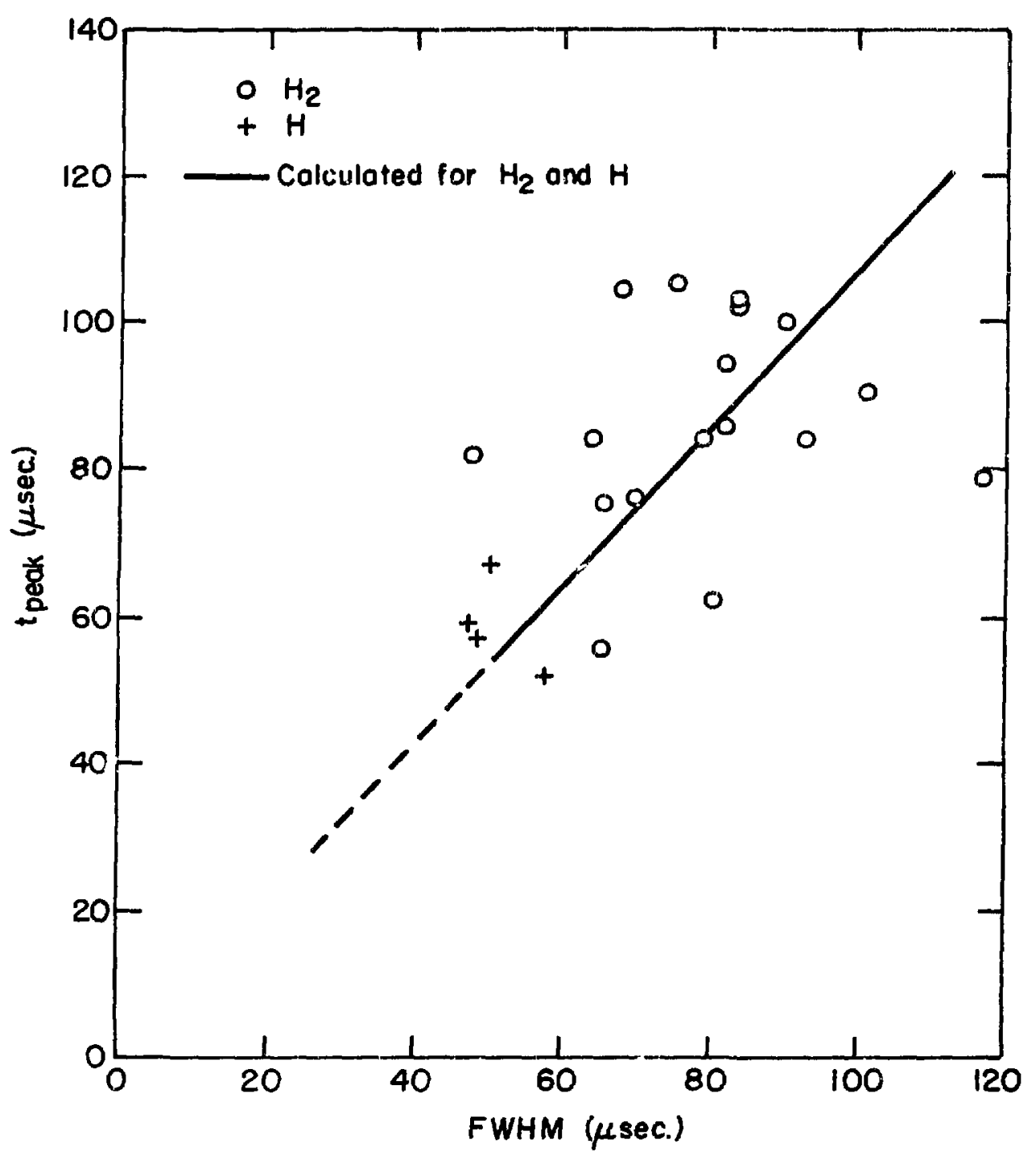

XBL $7211-7237$

Fig. 37 Comparison between calculated and experimental t peak
FWH, for $\mathrm{Zr}-\mathrm{H}$. 


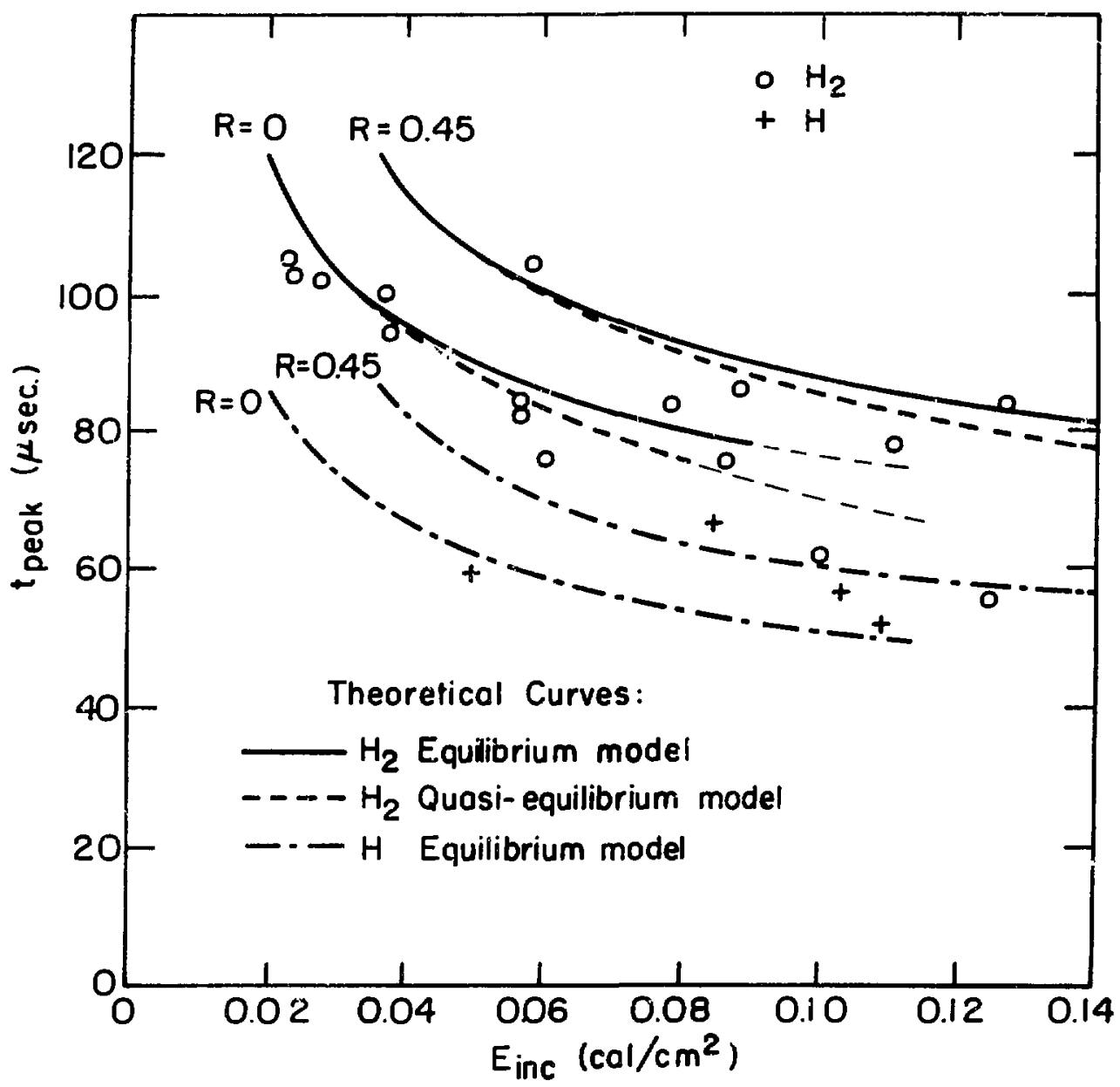

XBL 72II-7’234

Fig. 38 Comparison between calculated and experimental t
$\mathrm{E}_{\text {inc }}$, for $\mathrm{Zr}-\mathrm{H}$. 
scatter is too great to determine whether the equilibrium model or the quasi-equllibrium model is more approprlate. The theoretical $\mathrm{H}_{2}$ curve for $R=0.45$ is clearly out of the range of the data points. The apparent surface reflectivity is therefore approximately equal to zero, rather than 0.45 as meacured with the He-Ne laser on xoom temperature $2 \times H_{1.63}$ (see Section II-D-2). The reflectivity during a Q-switch pulse may be much less than the measured reflectivity because (a) the zirconium hydride reflectivity may be very small at high temperatures, or (b) the change in surface condition during the vaportzation process may cause the reflectivity to be very small. Several experiments on metals using conventional mode pulses ${ }^{65,66}$ and Q-switch pulses ${ }^{67}$ have shown that the surface reflectivity during a laser pulse can be much less than the initial reflectivity. The agreement between the measured and calculated values of $t_{\text {peak }}$ vs $E_{\text {Inc }}$ indicates that the emitted $H_{2}$ molecules are In thermal equilibrium with the surface. The surface temperature is apparently calculated correctly from the simultaneous solution of the energy and mass transport equations in the binary solid.

The values of $t_{\text {peak }}$ for the H-atom data points are substantlally smaller than $t_{\text {peak }}$ for the $\mathrm{H}_{2}$ data points at the same incident energy density. This indicates that the $\mathrm{H}$-atom $1 \mathrm{~s}$ due to $\mathrm{H}$ atoms emitted from the surface rather than from cracking or dcuble lonization of $\mathrm{H}_{2}$ molecules. The H-atom data fall between the calculated H-atom curves for $R=0$ and $R=0.45$, which suggests that the $H$ atoms are apparent $1 y$ emitted at a lower temperature than the $\mathrm{H}_{2}$ molecules (because the $t_{\text {peak }}^{\mathrm{H}}$ values are larger than predicted by theory for $R=0$ ). 
The calculated and measured valves of $\left(\bar{n}_{\max }\right)_{H_{2}}$ vs $E_{\text {inc }}$ are plotted in Fig. 39. The series $A$ and $B$ points were taken about a month apart under slightly different conditions. The serles $A$ and $B$ points were taken with a $0.3 \mathrm{M}$ and $0.1 \mathrm{M}$ resistor respectively $1 \mathrm{n}$ parallel with the oscilloscope, and the two serles of points were made with different flashlamps and different laser alignment. The $\mathrm{H}_{2}$ data points exhibit a large amount of scatter. The three $\mathrm{H}_{2}$ data points with $\bar{n}_{\max }$ much less than the band drawn through the other $H_{2}$ points are attributed to misalighment of the laser on the surface so that the actual incident energy density was smaller than measured. The band through the $\mathrm{H}_{2}$ data agrees fairly well with the calculated curve for $R=0$ for $E_{\text {inc }}$ less than $0.04 \mathrm{cal} / \mathrm{cm}^{2}$. However, for $E_{\text {inc }}$ greater than $0.04 \mathrm{cal} / \mathrm{cm}^{2}$, the measured values of $\left(\bar{n}_{\max }\right)_{H_{2}}$ flatten off at $10^{9}$ molecules $/ \mathrm{cm}^{3}$ while the calculated values increase to greater than $10^{10}$ molecules $/ \mathrm{cm}^{3}$. Therefore, for $E_{\text {inc }}$ greater than $0.04 \mathrm{cal} / \mathrm{cm}^{2}$, the $\mathrm{H}_{2}$ data do not $\mathrm{fit}$ either the equilibrium or quasi-equilibr:Lum models. The slope of the calculated curve is steep at low energy density because the vapor pressure in this region is primarily a function of temperature. As the energy density increases, the slope decreases because hydrogen is depleted from the surface. The theoretical $\left(\bar{n}_{\max }\right)_{H_{2}}$ vs $E_{\text {Inc }}$ curve therefore levels off because the flux from the surface is limited by the rate at which hydrogen can diffuse to the surface.

From the calculated $\mathrm{H}_{2}$ and $\mathrm{H}$-atom results 1 in Tables 3 and 4 , it is found that $\bar{n}_{\max }$ is proportional to the yleli:

$$
\bar{n}_{\max }=1.04 \times 10^{17} \times(\text { yield })
$$




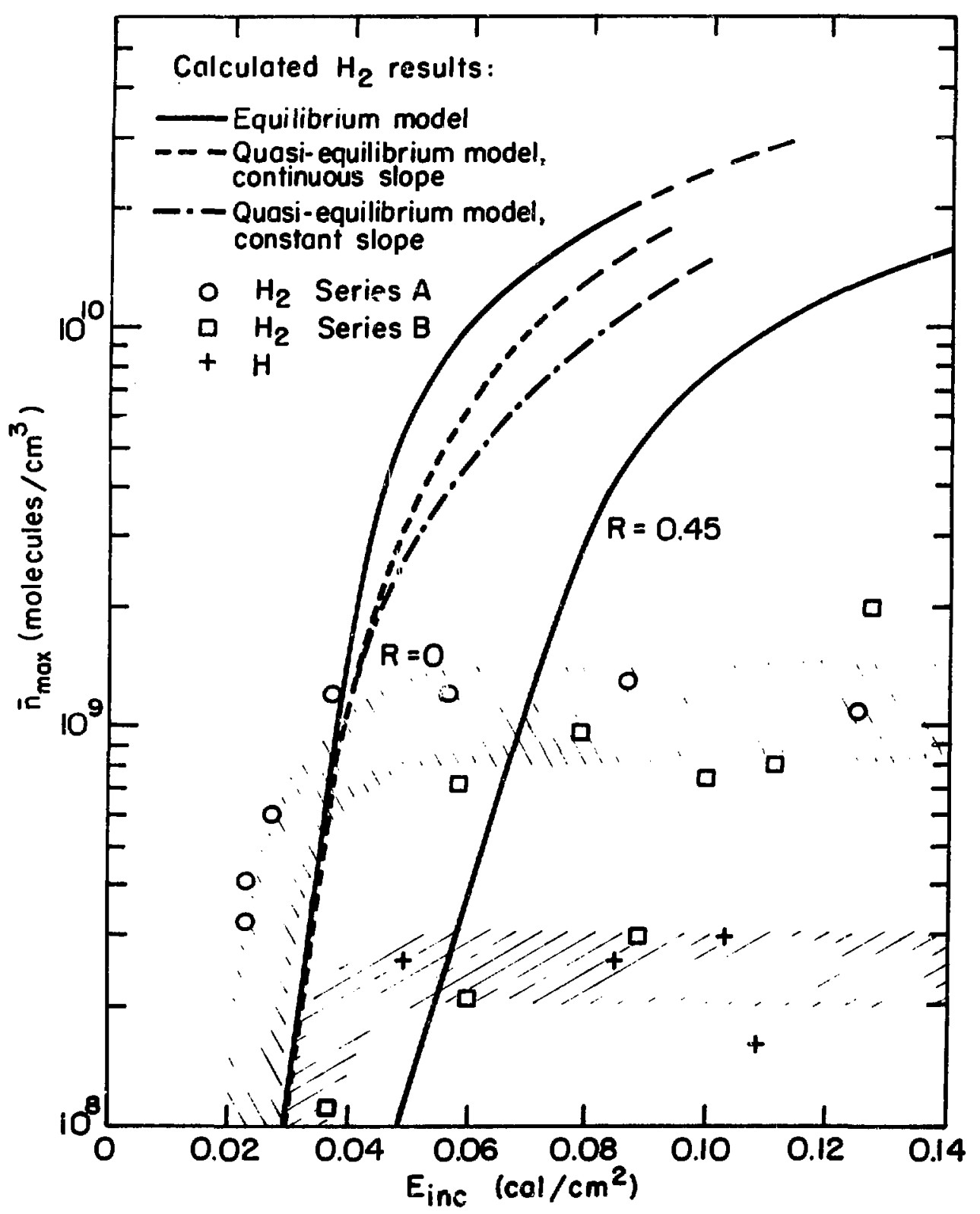

XBL $7211-7233$

Fig. 39 Comparison between calculated and experimental $\left(\bar{n}_{\max }\right)_{H_{2}}$
vs $E_{\text {inc }}$. 
The yield for $\left(\bar{n}_{\max }\right)_{\mathrm{H}_{2}}=10^{9}$ molecules $/ \mathrm{cm}^{3}$ is therefore equal to $10^{-8}$ moles $\mathrm{H}_{2} / \mathrm{cm}^{2}$. To see the signiflcance of the diffusion process in obtaining this yield, we calculate the number of monolayers of hydrogen to which this yield corresponds. The number of moles of hydrogen atoms per monolayer per $\mathrm{cm}^{2}$ of $\mathrm{ZrH}_{\mathrm{y}}$ is:

$$
\frac{\text { moles } \mathrm{H}}{\text { menolayer } \mathrm{cm}^{2}}-\frac{\mathrm{y}}{\mathrm{N}_{\mathrm{A}}}\left(\frac{\rho \mathrm{A}}{\mathrm{M}}\right)^{2 / 3}
$$

where $y=1.63$

$$
\begin{aligned}
N_{A} & =\text { Avogadro's number } \\
\rho & =\mathrm{ZrH}_{\mathrm{y}} \text { mass density }=5.7 \mathrm{gm} / \mathrm{cm}^{3} \\
M & =\mathrm{ZrH}_{\mathrm{y}} \mathrm{gm} \text { molecular welght } \simeq 93 \mathrm{AMU}
\end{aligned}
$$

which gives (\# moles $\mathrm{H} /$ monolayer $\mathrm{cm}^{2}$ ) $=3 \times 10^{-9}$. Therefore the measured value of $\left(\bar{n}_{\max }\right)_{H_{2}}$ of $10^{9}$ molecules $/ \mathrm{cm}^{3}$ for $E_{\text {inc }}$ greater than $0.04 \mathrm{cal} / \mathrm{cm}^{2}$ corresponds to a yield of $\left(2 \times 10^{-8} / 3 \times 10^{-9}\right)=7$ monolayers. Assuming that the inftial surface coverage of hydrogen is approximately 1 monolayer (i.e., approximately 1.63 surface $H$ atoms per surface $\mathrm{Zr}$ atom), most of the emitted hydrogen must have reached the surface by diffusing from the bulk. The diffusion process is apparently not as effective as assumed in the calculations, however, since the measured $\left(\bar{n}_{\max }\right)_{H_{2}}$ is an order of magnitude smaller than the calculated values for $E_{\text {inc }}$ greater than $0.04 \mathrm{cal} / \mathrm{cm}^{2}$.

There are several possible effects that could cause a restriction of the bulk diffusion process: (a) there could be a diffusion barrier such as an oxide coating at the surface, (b) after some of the hydrogen is emfted, restructuring of the surface layers may present an inter.face 
which could act as a diffusion barrler, or (c) there may be a kinetic barrier at the surface if the time for an $1 \mathrm{f}$ atom in the lattice to hop from just beneath the surface to a surface site 1s comparable to or greater than the time for an $H$ atom to diffuse from one lattice site to another. In each case, the diffusion coefficient at the surface would be smaller than the bulk diffusion coeficient.

Another possible explanation for the measured values of $\left(\bar{n}_{\text {maxi }}\right)_{H_{2}}$ being smaller than the calculated values is that the condensation coefficient $\alpha$ could be less then unsty. This would imply that the rate at which surface $H$ atoms can combine to form $H_{2}$ molecules is less than the maximum rate given by the Langmuir equation. This is not considered as a plausible explanation because: (a) the relatively good agreement between measured and calculated values of $\left(\overline{\mathbf{n}}_{\max }\right)_{\mathrm{H}_{2}}$ for $E_{\text {inc }}<0.04 \mathrm{cal} / \mathrm{cm}^{2}$ indicates that $\alpha \simeq 1 \mathrm{in}$ this range, (b) the approximately constant measured value of $\left(\bar{n}_{\max }\right)_{H_{2}}$ for $E_{\text {Inc }}>0.04 \mathrm{cal} / \mathrm{cm}^{2}$ suggests that the amount of hydrogen that is emitted is 11mited by the amount that can diffuse to the surface, and (c) if the constant value of $\left(\bar{n}_{\max }\right)_{H_{2}}$ for $E_{\text {inc }}>0.04 \mathrm{cal} / \mathrm{cm}^{2}$ were due to a temperature dependent condensation coefficlent, the rapid increase in hydrogen vapor pressure with temperature would have to be just balanced by a decrease in $\alpha$, which is unlikely.

The measured values of the maximum H-atom density are also shown In Fig. 39. These data were obtained in the same set of experiments as the series $A$ points for $\mathrm{H}_{2}$. In the plateau region of $\mathrm{E}_{\text {inc }}>0.04 \mathrm{cal} / \mathrm{cm}^{2}$, the data show that 


$$
\left\{\frac{\left(\bar{n}_{\max }\right)_{H}}{\left(\bar{n}_{\max }\right)_{H_{2}}}\right\}_{\exp } \simeq 0.2
$$

This ratio is much larger than the valus of 0.03 which represents the fraction of $\mathrm{H}^{+}$due to electron impact on $\mathrm{H}_{2}$ in the mass spectrometer ionizer. Therefore, the large $\mathrm{H} / \mathrm{H}_{2}$ ratio is truly the result of a surface process.

The value of the $\mathrm{H} / \mathrm{H}_{2}$ ratio expected from the equilibrium model is calculated for $E_{\text {inc }}=E_{a b s}=0.10 \mathrm{cal} / \mathrm{cm}^{2}$ as follows: Extrapolating the results shown in Table 4 show that $\left(\bar{n}_{\max }\right)_{H}$ should be $\approx 2.5 \times 10^{7}$ atoms $/ \mathrm{cm}^{3}$ at this laser pulse energy. Similarly, the ordinate of the equilibrium model curve for $\mathrm{H}_{2}$ on $\mathrm{Fig}$. 39 for $\mathrm{R}=0$ predicts $\left(\bar{n}_{\max }\right) \mathrm{H}_{2} \approx 2 \times 10^{10}$ molecules $/ \mathrm{cm}^{3}$ at $\mathrm{E}_{\text {inc }}=0.10 \mathrm{cal} / \mathrm{cm}^{2}$. Therefore, the $\mathrm{H} / \mathrm{H}_{2}$ ratio predicted by equilibrium considerations is:

$$
\left|\frac{\left(\bar{n}_{\max }\right) H}{\left(\bar{n}_{\max }\right) H_{2}}\right|_{\substack{\text { equilibrium } \\ \text { model }}}=10^{-3}
$$

which is indeed far below the experimental value of 0.2 . Such a discrepancy could arise-if the H-atoms were emitted at a much higher "temperature" (and hence h1gher vapor pressure) than the temperature at which $\mathrm{H}_{2}$ emission occurred. This is apparently not the case, however, since the measured time of flight corresponding to the peak $H$ atom density in the ionizer (FIg. 38) is approximately that expected for emission at the calculated surface temperature, and the measured values of $t_{\text {peak }}$ /FWH are consistent with a Maxwellian gas at the same temperature as the $\mathrm{H}_{2}$ emission (Fig. 37). 
The large H-atom signals therefore must be due to some nonequilibrium chemical process on the surface. Apparently the H atoms are emitted at thermal equilibrium because their velocity distribution is consistent with the calculated surface temperature. However, the existence of thermal equilibrium does not imply that the surface is at chimical equilibrium. One possible explanation for the large H-atom signals can be inferred by calculating the number of monolayers to which the measured H-atom signals correspond. From Eq. (6.5) the measured yield of $\mathrm{H}$ is approximately $2.4 \times 10^{-9}$ moles $\mathrm{H} / \mathrm{cm}^{2}$, which corresponds :0 0.8 monolayers of hydrogen. Since this is less than 1 monolayer, the $H$ signal could be due to the vaporization of an adsorbed layer of $H$ initially on the surface. This possibility can be explatned as follows:

At complete equilibrium, the desorption of surface hydrogen proceeds according to the two processes:

$$
\begin{aligned}
2 \mathrm{H}(\mathrm{ads}) & \rightarrow \mathrm{H}_{2}(\mathrm{~g}) \\
\mathrm{H}(\mathrm{ads}) & \rightarrow \mathrm{H}(\mathrm{g})
\end{aligned}
$$

According to the principal of detalled balance, the $\mathrm{H}(g) / \mathrm{H}_{2}(g)$ ratio produced by the above process under conditions of complete equilibrium should be just equal to the $\mathrm{P}_{\mathrm{H}} / \mathrm{P}_{\mathrm{H}_{2}}$ ratio of the equilibrium gas above the surface (Ignoring small differences due to the masses of the two species and assuming unit condensation coefficients). If the flash desorption of the surface population caused by the laser pulse passed through a series of equilibrium thermodynamic stages, then the maximum $\mathrm{H} / \mathrm{H}_{2}$ signal ratio arising from surface desorption should be equal to that predicted by the equilibrium model, namely $\sim 10^{-3}$. However, the 
"flash" Initiated by the laser pulse $\left(\sim 10^{-8} \mathrm{sec}\right)$ is very much more rapid than that attainable by conventional flash filament techniques. If the surface recombination of $\mathrm{H}$ (ads) to $\mathrm{H}_{2}$ (ads) (followed by instantaneous desorption) requires surface migration and collisions of H(ads), the rapidity of the temperature increase may mean that it is more likely than $H(a d s)$ simply desorbs to give $H(g)$ rather than recombine to produce $\mathrm{H}_{2}(\mathrm{~g})$ as it would do in a slow transient. By this model, the desorbed $H$ could be in thermal equilibrium with the surface, but not in chemical equilibrium with respect to $\mathrm{H}_{2}$ enteston for the existing surface population. According to this model, the observed H signal is due entirely to atomic hydrogen desorbed from the surface, while the hydrogen emanating from the bulk of the $\mathrm{ZrH}_{1.63}$ is released to the gas phase as $\mathrm{H}_{2}$ molecules. 4. Experimental Results for High Energy Densities

When the incident energy density is greater than about $0.25 \mathrm{cal} / \mathrm{cm}^{2}$, the mass spectrometer signals no longer show a pulse shape characteristic of thermal behavior of the zirconium hydride. Viafble damage to the surface occurs (Fig. 7), which indicates that the surface temperature is sufficient for vaporization of the zirconium lattice. As shown in Fig. 40, in this high energy range, the $\mathrm{H}_{2}$ signal consists of a high energy peak with $t_{\text {peak }} \simeq 18 \mu$ sec and a thermal peak with $t_{\text {peak }} \simeq 60 \mu$ Hec. The high energy peak corresponds to an energy of approximately $5 \mathrm{eV}$, while the thermal peak corresponds to a temperature of approximately $3000^{\circ} \mathrm{K}$, which is higher than temperatures calculated at lower energy densities. Roughly 20 to $30 \%$ of the total $\mathrm{H}_{2}$ emfssion is in the high energy peak. For $E_{\text {Inc }}>0.25 \mathrm{cal} / \mathrm{cm}^{2}$, the $H$ and $\mathrm{Zr}$ signals are very large and occur at very short times, as shown InFigs. 41 and 42 . These are 


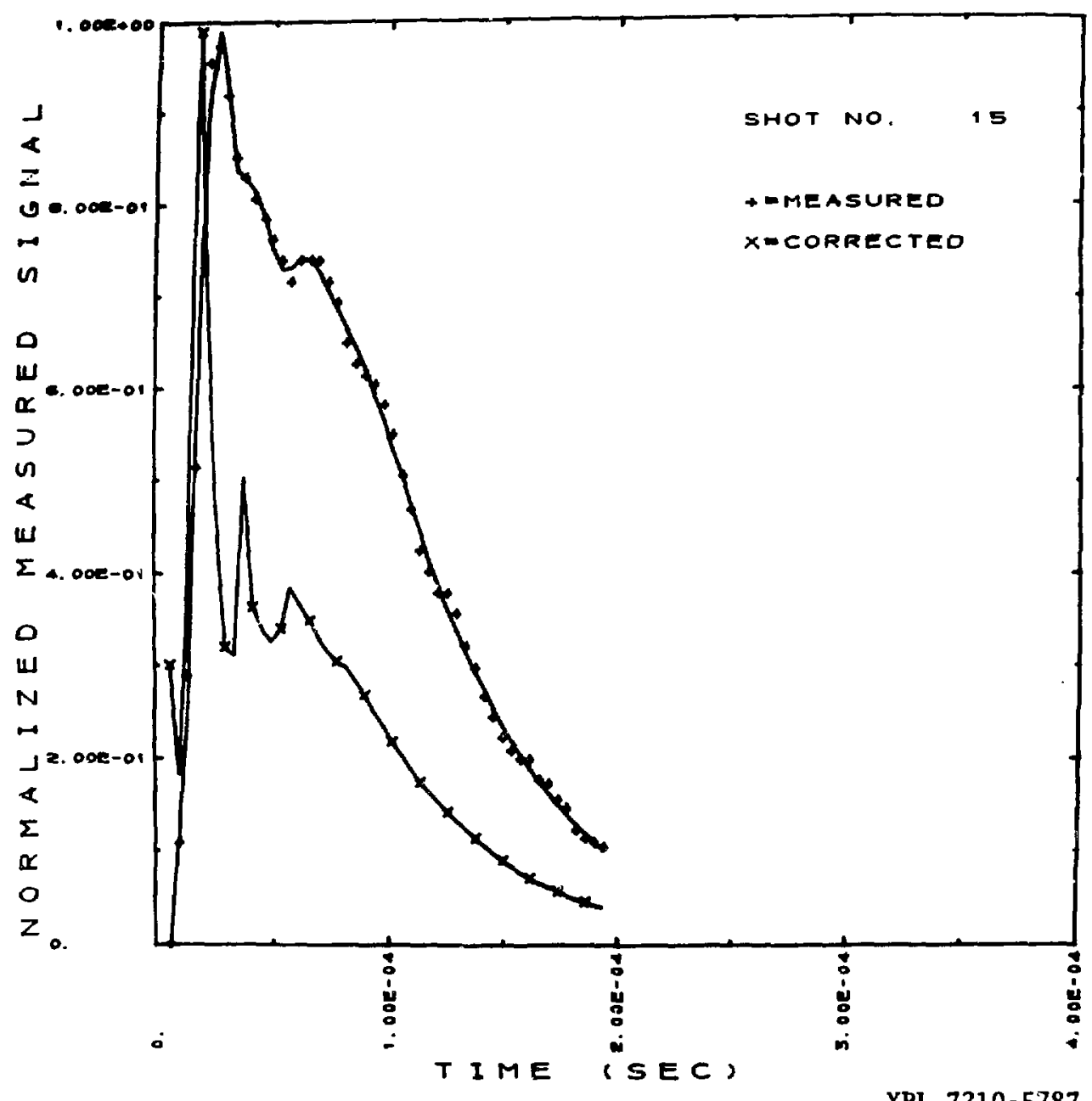

Fig. 40 Measured and corrected $\mathrm{H}_{2}$ signal, incident energy density 


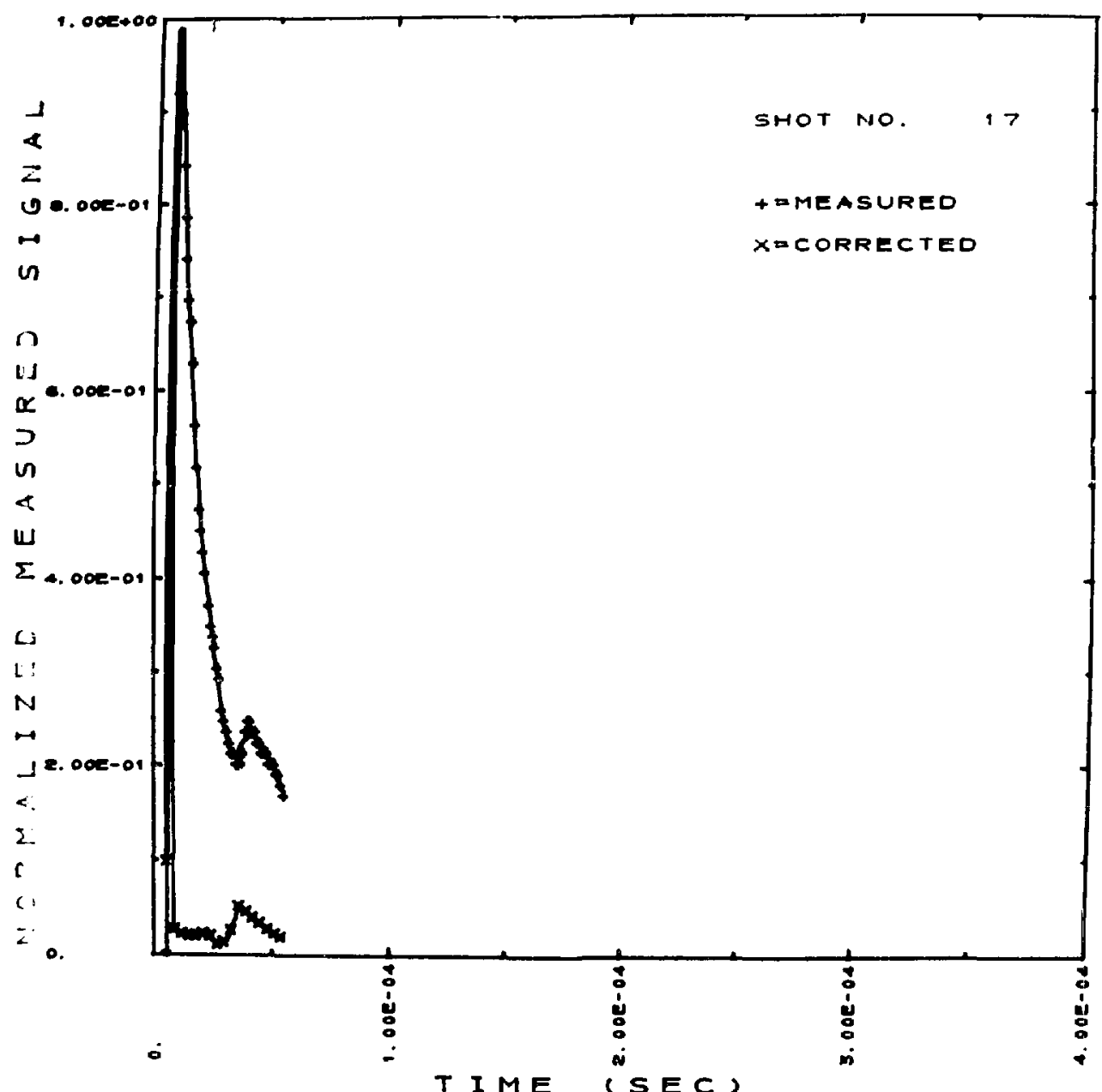

XBL $7210-5791$

Fig. 41 Measured and çorrected $\mathrm{H}^{+}$signal, incident energy density $=0.36 \mathrm{cal} / \mathrm{cm}^{2}$. 


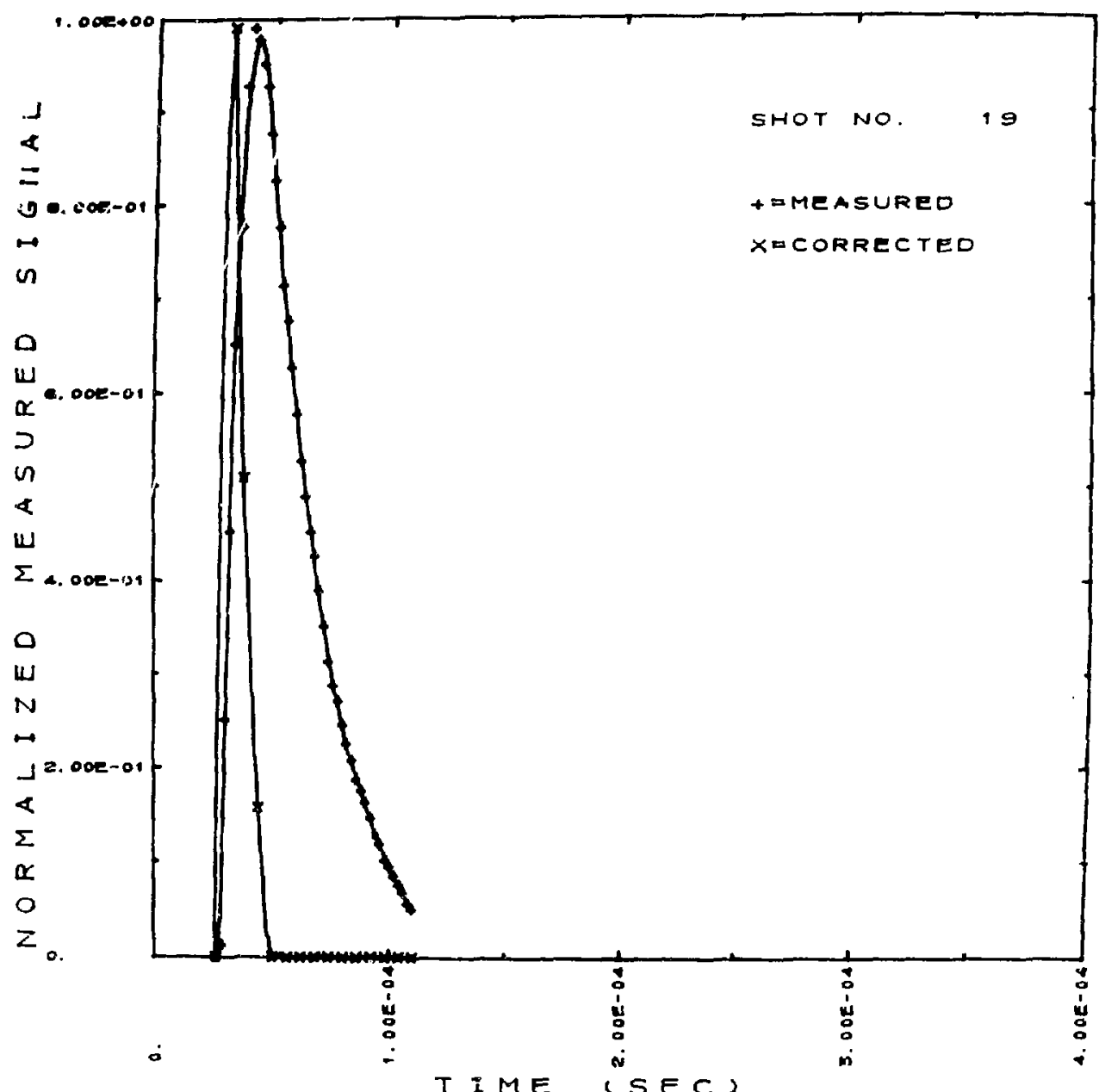

XBL 7210-5790

Fig. 42 Measured and çorrected $\mathrm{Zr}^{+}$signal, incident energy density $=0.25 \mathrm{cal} / \mathrm{cm}^{2}$. 
Table 6. Results of $\mathrm{Zr}-\mathrm{H}$ measurements for h1gh incident energy densities.

\begin{tabular}{|c|c|c|c|c|c|}
\hline $\begin{array}{l}\text { Shot } \\
\text { Number }\end{array}$ & Spec1es & $\begin{array}{c}E_{1 \pi c} \\
\left(\mathrm{cal} / \mathrm{cm}^{2}\right)\end{array}$ & $\begin{array}{c}\text { Peak Tnciuent } \\
\text { Power Dens } 1 \text { ty } \\
\left.\text { (watts/cm } / \mathrm{cm}^{2}\right)\end{array}$ & $\begin{array}{l}\text { tpeak } \\
\text { (usec) }\end{array}$ & $\begin{array}{c}\text { Energy E } \\
\text { (eV) }\end{array}$ \\
\hline 15 & $\mathrm{H}_{2}\left({ }^{(}\right)$ & 0.281 & $2.9 \mathrm{E}+7$ & 18 & 5.3 \\
\hline 16 & $H_{2}{ }^{(\star)}$ & 0.272 & $2.8 \mathrm{E}+7$ & 18 & 5.3 \\
\hline 17 & $\mathrm{H}_{1}{ }^{+}$ & 0.357 & $3.7 \mathrm{E}+7$ & 7.5 & 15.3 \\
\hline 18 & $\mathrm{H}_{1}{ }^{+}$ & 0.443 & $4.6 \mathrm{E}+7$ & 5.5 & 28.4 \\
\hline 19 & $\mathrm{zr}^{+}$ & 0.251 & $2.6 \mathrm{E}+7$ & 32 & 75.0 \\
\hline 20 & $\mathrm{zr}^{+}$ & 0.454 & $4.7 E+7$ & 35 & 63.0 \\
\hline 21 & $7 . r^{+}$ & 0.276 & $2.9 \mathrm{E}+7$ & 36 & 60.0 \\
\hline
\end{tabular}

kigh energy peak only. 
attributed to $\mathrm{H}^{+}$and $\mathrm{Zr}^{+}$because they are detected even when there 18 zero electron current in the lonizer. The enall peak in Fig. 41 with $t_{\text {peak }}=35 \mathrm{usec}$ is due to atcmic hydrogen emitted at approximately $4000^{\circ} \mathrm{K}$ rather than $\mathrm{H}^{+}$because the peak does not appear when the Ionizar electron current is off. It is difficuit to estimate what fraction of the atomic hydrogen is emitted as lons since the mass spectrometer sensitivity to tons 18 not known. Ho $\mathrm{H}_{2}^{+}$lons were detected.

The mass spectrometer can only detact lons with energy greater than $15 \mathrm{eV}$ because the lonizer $1 \mathrm{~s}$ at a potential of 15 volts relative to the target and ground. Less energetic lons are deflected from the ionizar region as they approach it. An approximate analysis of the electric field sround the lonizer showed that the electric fleld increases the time of flight by less than $5 \%$ for lons with energy greater than $15 \mathrm{eV}$. Since lons are detected much more efficiently than neutrals, the lon pulses nask the 81 gaal on neutral molecules. The energy of the particles in eV can be determined from the measured time of flight $t_{\text {peak }}$ by using Eq. (3.16):

$$
E(e V)=\frac{860 M\left(\mu_{k} U\right)}{\left[t_{\text {peak }}(\mu \text { sec })\right]^{2}}
$$

The results of the high energy density measurements are given in Table 6 as a function of $E_{\text {inc }}$ and peak incident power density in (watts/ca ${ }^{2}$ ), which is the power density at $t \simeq 40 \mathrm{nsec}$ corresponding to the peak of the laser pulse.

The $\mathrm{H}^{+}$Ions are enitted with a lower energy than the $\mathrm{Zr}^{+}$ions. The range of ion energies $\left(15-30 \mathrm{ev}\right.$ for $\mathrm{u}^{+}, 60-75 \mathrm{eV}$ for $\mathrm{Zr}^{+}$) for laser power densities of $3-5 \times 10^{7}$ watts $/ \mathrm{cm}^{2}$ is conolstent with the ion 
energles measured by other investigators on metals and other solids at comparable power densities. For example, measurements of the ions emitted from a TI-D target Indicate an Ion energy of 7.5 eV for power density of $10^{8}$ watts $/ \mathrm{cm}^{2} .8$ Measurements on $W$ surfaces heated with laser power density of approximately $5 \times 10^{7}$ watts/ $\mathrm{cm}^{2}$ show that the emitted Ions have energies up to $180 \mathrm{eV}^{17}$ As discussed in section I-C, the probable mechaniams for the production of these high energy lons are the formation of a partially lonized plasma in front of the ourface, oubsequent heating of the plase by photons by the Inverse Breasstrahlung procese, and a rapid directed expansion of the plasma away frow the surface. The relatively high energy $\mathrm{H}_{2}$ molecules are probably accelerated by collisions with the energetic $\mathrm{H}^{+}$and $\mathrm{zr}^{+}$10ns.

\section{Conclualons}

Many aspects of the transient behavior of zircontum hydride heated by a Q-8witch laser are properly predicted by the equilibrium model. Since the measured time of flight of the H-atoms and $\mathrm{H}_{2}$ nolecules are in agreement with calculations, It can be concluded that the molecules are enteted at thermal equilibrime. The temperature transient at the surface is properly calculaced by the sinultaneous oolution of the heat conduction and hydrogen diffusion equations with the heat source at the surface equal to the absorbed laser power density. Siace the calculated and measured ratio of signal width to the time of flight for the $H$ and $H_{2}$ signals are in agreement, the nolecules are apparently enitted with the velocity distribution of an effunive Haxwellian source, as expected for an equilibrium process. The magnitudes of the $\mathrm{H}_{2}$ signals for incident energy density less than $0.04 \mathrm{cal} / \mathrm{cm}^{2}$ are in agreenent with the values 
determined from the solutien of the conduction and diffusion equations with unit condensation coefficient.

Two aspects of the zirconfum hydride behavior are not well predicted by the equilibrium model. Although hydrogen is emitted primarily as $\mathrm{H}_{2}$ rather than $\mathrm{H}$, the measured $\mathrm{H} / \mathrm{H}_{2}$ ratlos are much larger than expected from the equilibrium model, and the $\mathrm{H}_{2}$ signals for incident energy density greater than $0.04 \mathrm{cal} / \mathrm{cm}^{2}$ are smaller than expected from the same model. The large $\mathrm{H} / \mathrm{H}_{2}$ ratios are attributed to the desorption of a layer of chemlsorbed hydrogen that 18 not vaporized in the $\mathrm{H} / \mathrm{H}_{2}$ ratios predicted from chemical equilibrium when the surface temperature is rapidly incressed. In this aspect, the laser pulse differs from conventional flash filament experiments, such as described in Refs. 68 and 69. The small $\mathrm{H}_{2}$ signals are attributed to the existence of a diffusion barrier at the surface. However, significant diffusion of hydrogen must occur to account for the measured $\mathrm{H}_{2}$ signal amplitudes.

The conclusions that can be drawn from tine iron experiments are less definitive than those that can be made from the zirconium hydride experiments are less definitive than those that can be made from the zirconiun hydride experiments. This is tacause the duration of the conventional mode laser pulse is on the some order as the time of flight of the iron atoms fron the target to the mass spectrometer, which means that the waveforms do not represent solely spreading due to the velocity distribution of the emitted atoms. In addition, the iron results are complicated by the unpredictable surface temperature that results when the molten iron flows. Allowing for these uncertainties, 
the results are consistent wth an equilibrium model in which the iron atoms are emitted at thermal equilibrium with the velocity distribution of an effusive Maxwellian source. 


\section{ACKNTOWLEDGEMENTS}

This work has been supported by the U. S. Atomic Energy Conmission through the Lawrence Berkeley Laboratory and by a three year fellowshlp administered by Oak Ridge Assoclated UnIversities through the "Special Fellowships in Nuclear Sclence and Engineering" program.

I would like to thank Professor Donald R. Olander of the Department of Nuclear Engineering, University of Californla for always being accessible for guidance and providing many fruitful ouggestions for performing the experiment and analyzing the results.

I would also like to thank my former colleague Dr. Richard H. Jones for his assistance in solving many experimental problems. Thanks also to John Souza and Dan Winterbauer for promptly fabricating needed parts and providing a little humor.

The swift, accurate typing by Jean Wolslegel is appreciated. 
APPENDIX A: AVERAGE PEARING FACTOR IN THE IONIZER

The vapor density at the mass spectrometer ionizer varles with position in the lonizer because of the presence of the collimating aperture between the target and mass spectrometer chambers. The collimating aperture cituses the formation of a penumbrat the fouizer such that only part of the target is viewed. This decrease in intensity (and therefore density) can be accounted for by a peaking factor, which is the ratio of true intensity to the centerline intensity for a cosine point source. Defining the problem in the same manner as an analysis by olander ${ }^{70}$ on molecular beam geometry, let

$I_{s}=$ radius of the source

$r_{c}$. radius of the collimating aperture

$d_{c}=$ source to collimator diatance

$d=$ source to mass spectrometer distance

$\rho$ = varlable radius at the mass spectrometer

$Q=r_{s} / r_{c}=$ dimensionless source radius

$T=d_{c} / d=$ dimensionless source to collimator distance

$v=\rho / r_{c}=$ dinensionless radius at the mass spectrometer

For the case of a cosine source with source to collimator distance much larger than the source or collimator dimensions, the peaking factor at position $p$ is simply the ratio of unobstructed source area to the total source area. The area of the source that contributes to the intensity at a particular 0 is the overlapping area of the source disk and the projection from $\rho$ of the colilmating aper ture the source plane. This projection 18 also a circle and has radius $r_{c} d /\left(d-d_{c}\right)$. In dimensionless terms relative to $r_{c}$, 


$$
\begin{aligned}
& W_{1}=1 /(1-T)=\text { dimensionless radius of the projection of the } \\
& \text { collimator on the source plane. } \\
& W=T V /(1-T)=\text { dimensionless diatance of the center of the } \\
& \text { projection to the center of the source: disk. }
\end{aligned}
$$

The gecmetry of the problem is shown in Fig. $\mathrm{Al}$ and A2. The easiest method to determine the overlapping area is to calculate the area of segments of the source and collimator image circles. There are three ranges of $W$ to conolder:

(1) $0<w<w_{1}-Q$ :

The total source disk is within the collimator profection so the effective area $18 A_{1}=\pi Q^{2}$.

(2) $w_{1}-Q<W<\left(w_{1}^{2}-Q^{2}\right)^{1 / 2}$ :

The effective area is lese than $A_{1}$ and $I_{s}$ equal to $A_{1}$ minus the area of segment of the source disk plus the area of segment of the collimator image.

(3) $\left(w_{i}^{2}-Q^{2}\right)^{1 / 2}<W<W_{1}+Q$ :

The effective area is the area of the segment of the source disk plus the area of segment of the collinator image.

Let $\alpha=$ half angle subtended by the intersection of the circles at the center of the collimator image

$\phi=$ half angle subtended by the intersection of the circles at the center of the eource disk

It can be shown that $\alpha$ and $\phi$ can be expressed In terms of $w$ by:

$$
\begin{aligned}
& \cos \alpha=\frac{1}{2 W W_{1}}\left[w_{1}^{2}-Q^{2}+w^{2}\right] \\
& \cos \phi=\frac{1}{2 Q W}\left[W_{1}^{2}-Q^{2}-W^{2}\right]
\end{aligned}
$$




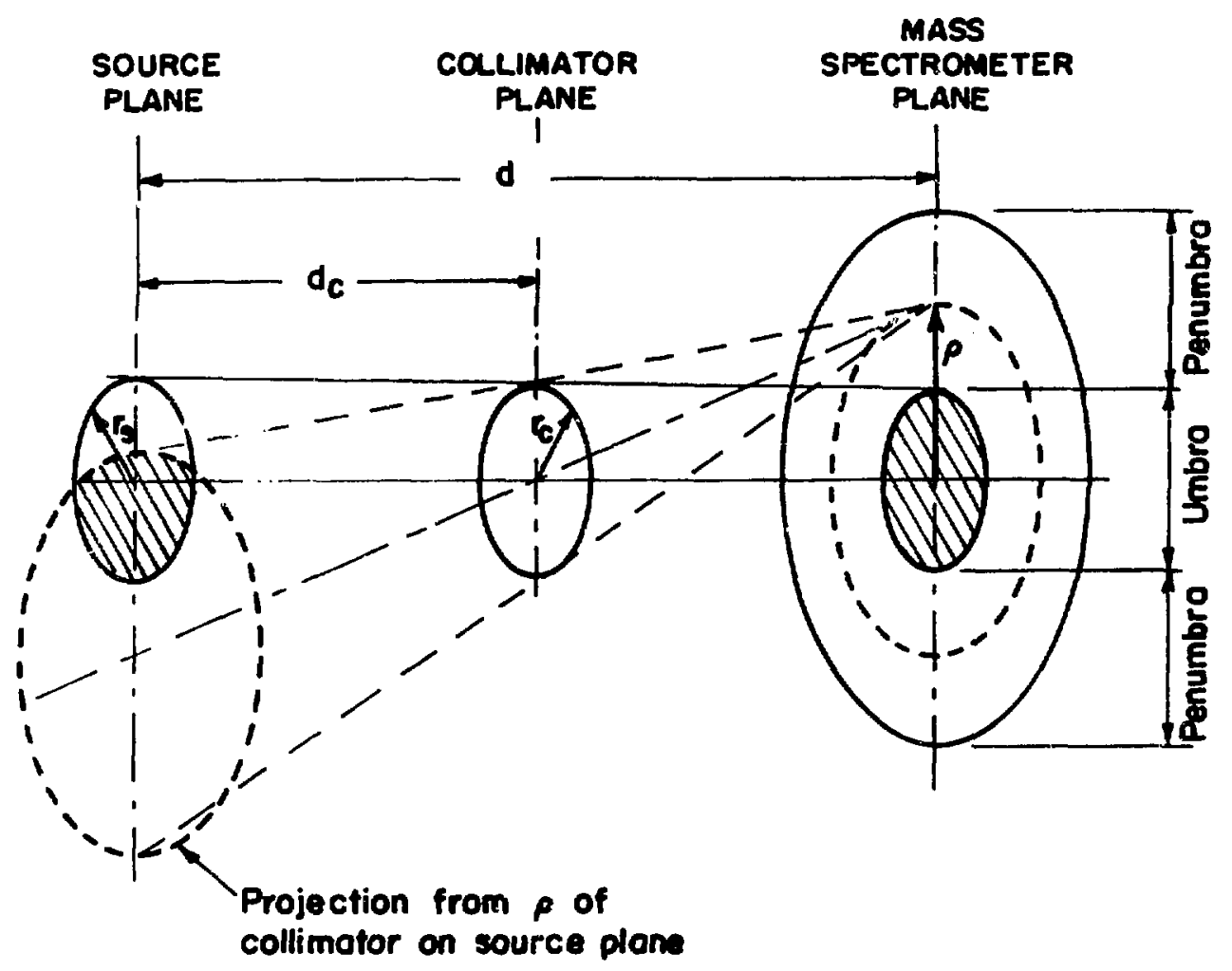

XBL72 $11-722 B$

Fig. Al Geometry of the source, collimator and detector plane. 

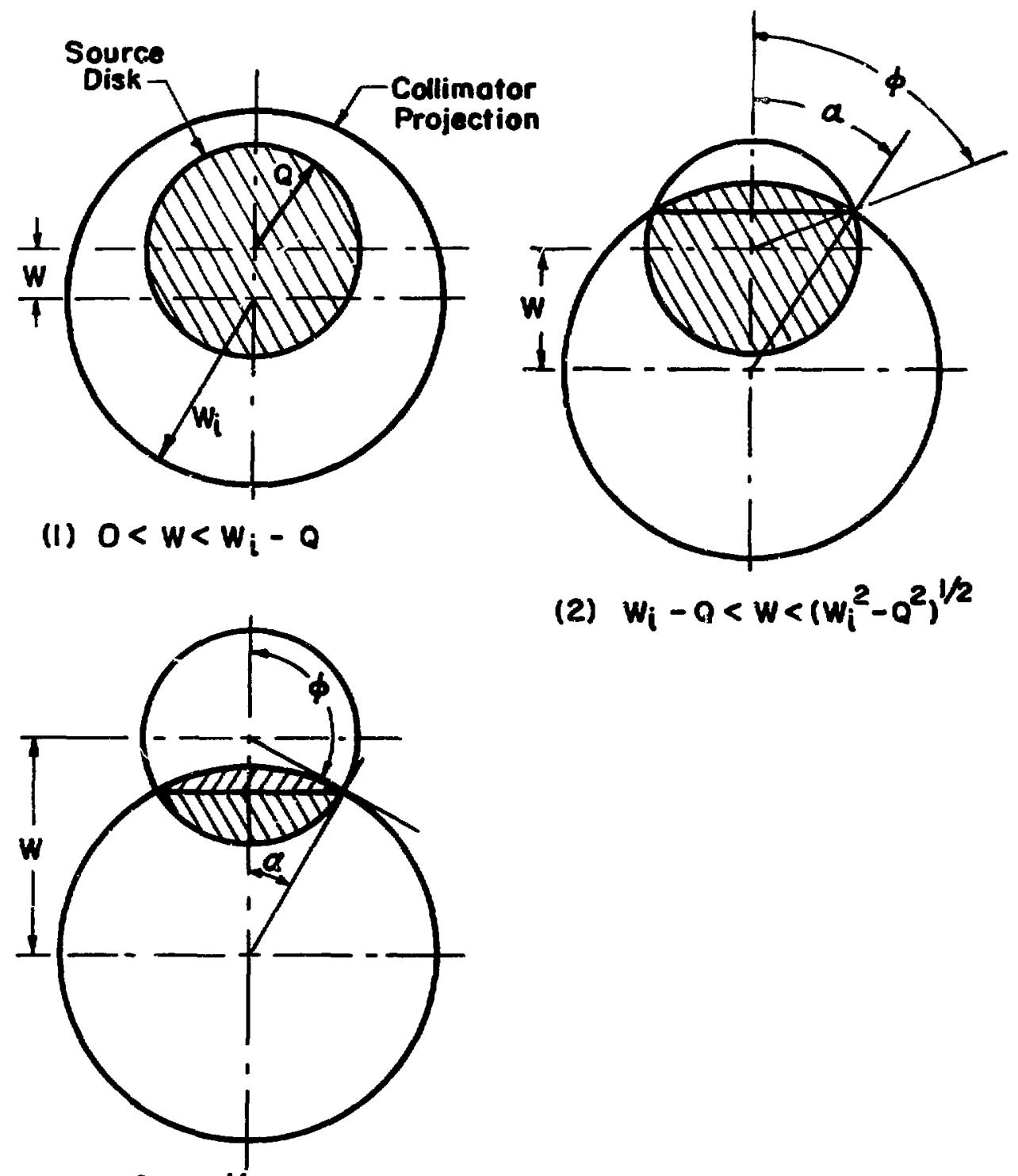

(2) $w_{i}-0<w<\left(w_{i}^{2}-a^{2}\right)^{1 / 2}$

(3) $\left(w_{i}^{2}-a^{2}\right)^{1 / 2}<w<w_{i}+0$

Fig. A2 Geonetry for calculation of the peaking factor. The shaded area represents that area of the source disk that contributes to the signal at the particular value of $W$. 
The area of a segment of circle of radius $r$ with half angle $\theta$ is

$$
A=r^{2}[\theta-\sin \theta \cos \theta]
$$

Using this equation for reglons 2 and 3 gives:

$$
\begin{aligned}
A_{2} & =\pi Q^{2}+w_{1}^{2}[\alpha-\sin \alpha \cos \alpha]-Q^{2}[\phi-\sin \phi \cos \phi] \\
A_{3} & =w_{1}^{2}[\alpha-\sin \alpha \cos \alpha]+Q^{2}[(\pi-\phi)-\sin (\pi-\phi) \cos (\pi-\phi)](A .2) \\
& =\pi Q^{2}+w_{1}^{2}[\alpha-\sin \alpha \cos \alpha]-Q^{2}[\phi-\sin \phi \cos \phi]
\end{aligned}
$$

Therefore, $A_{3} 18$ the sare function as $A_{2}$, the only difference belng that $\phi>\pi / 2$ in region 3 .

Dividing the effective areas by the source area and putting limits in terss of $V$ rather than $W$ gives for the peaking factor:

$$
\begin{aligned}
& x(V)=1 \text { for } 0<V<[1-Q(1-T)] / T \\
& x(V)=1+\frac{V_{1}^{2}}{\pi Q^{2}}[\alpha-\sin \alpha \cos \alpha]-\frac{1}{\pi}[\phi-\sin \phi \cos \phi] \\
& \text { for } \frac{1}{T}[1-Q(1-T)]<V<V_{\max } \\
& X(V)=0 \text { for } V>V_{\max }
\end{aligned}
$$

where

$$
y_{\max }=\frac{1}{T}[1+Q(1-T)]
$$

and $\phi$ and $\alpha$ are found from EqB. (A.1)

Figure A3 shows $\chi(V)$ plotted for the case $Q=1, T=0.5$ and for $Q=1.5, T=0.5$. It 1 a evident that a good approxination to $X(V)$ would be a linear appioxtmation in the panuxbra region: 


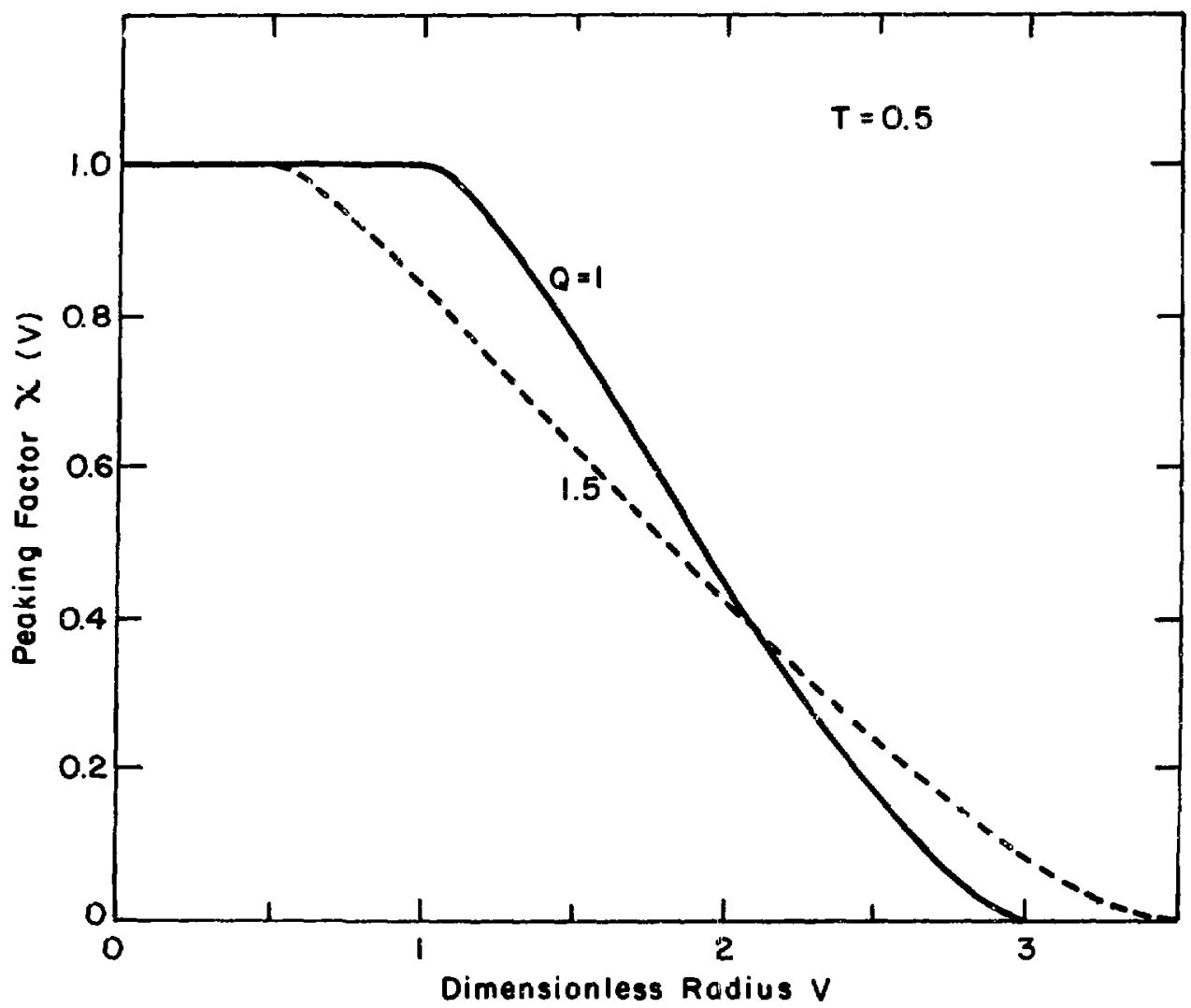

XBL $7211-7235$

Fig. A3 Peaking $f$ actor as a function of dimensionless radius $V$. 


$$
\begin{aligned}
& x(V)=1 \text { for } 0<V<[1-Q(1-T)] / T \\
& x(V) \cong \frac{[1+Q(1-T)-T V]}{2 Q(1-T)} \text { for }[1-Q(1-T)] / T<V<V_{\max } \quad \text { (A.4) } \\
& X(V)=0 \text { for } V>V_{\max }
\end{aligned}
$$

The quantity of real interest is the average peaking factor over the length of the electron sheet. Assuming that the electron sheet stays relatively flat over the length of the lonizer, the average peaking factor is

$$
\bar{\chi}=\frac{2 r c}{L} \int_{0}^{v_{\max }} \chi(V) d V
$$

where $L=$ length of: the ionizer

Using the approximate relation for $\chi(V)$ from Eq. (A.4) and assuming that $V_{\max } 1 s$ less than $L / 2 r_{c}$ gives:

$$
\bar{X} \simeq \frac{2 r}{T L} \text { which } 18 \text { independent of } Q
$$

For $r_{c}-1 / 16$ inch, $L=9 / 16$ Inch and $T=1 / 2$; the above equation gives $\bar{X}=0.44$. 


\section{APPENDIX B. MUMERICAL SOLUTION TO THE CONDUCT TON AND DIFFUSION EQUATIONS}

\section{A. Deacription of the Crank-Micoloon Method}

The conduction equation for Iron ( $\mathrm{kq} .(4.3)$ ) and the conduction and diffusion equations for $\mathrm{ZrH}_{\mathrm{y}}$ (Eqs. (4.31)) are colved numerically by a Crank-Nicoleon fins.te difference aethod. 71 This wethod 18 second order correct in both the the and epace increment $\Delta t$ and $\Delta x$, ind the finite difference solution converges to the true solution for 111 values of $\Delta t /(\Delta x)^{2}$. Rather than uge a constant $\Delta x$ as 18 usually the case, $\Delta x$ increases geometrically into the material according to the relation:

$$
\Delta x_{1}=\varepsilon \Delta x_{1-1}=\varepsilon^{1-1} \Delta x_{1}
$$

Were $\varepsilon=$ a constant greater than 1 , taken to be 1.035

$\Delta x_{1}$ - opace increment following grid plane 1

The use of this variable $\Delta x$ is advantageous because $\frac{\partial T}{\partial x}$ and $\frac{\partial y}{\partial x}$ are largest near the surface and decrease into the material. Therefore, for a particular temperature difference between adjacent grid planeo, a closer grid spacing is required near the surface than in the bulk. The variable $\Delta x$ is also useful becsuse the conduction and diffusion equations can be solved on the same gr $\div$ d even though they have different characteristic lengthe.

The conduction equation in iron can be put in the form

$$
\frac{\partial^{2} T}{\partial x^{2}}=\psi\left(x, t, T, \frac{\partial T}{\partial x}, \frac{\partial T}{\partial t}\right)
$$

The Crank-Nicolson finite difference approximation to this equation 18 


$$
\begin{gathered}
\frac{1}{2} \Delta_{x}^{2}\left(w_{1, n+1}+w_{1, n}\right)=\psi\left(x_{1}, t_{n+1 / 2}, \frac{1}{2}\left(w_{1, n+1}+w_{1, n}\right),\right. \\
\left.\frac{1}{2} \Delta_{x}\left(w_{1, n+1}+w_{1, n}\right),\left(w_{1, n+1}-w_{1, n}\right) / \Delta t\right)
\end{gathered}
$$

where $\Delta_{x}^{2} w_{1, n}=$ centered second difeerence of $w_{1, n}$

$$
\begin{aligned}
\Delta_{x} w_{1, n} & =\text { centered first difference of } w_{1, n} \\
w_{1, n} & =\text { finite difference solution for the temperature at the } \\
& 1^{\text {th }} \times \text { grid plane at the } n^{\text {th }} \text { time step }
\end{aligned}
$$

The boundary condition to Eq. (B.2) can be put in the form

$$
\left.\frac{\partial r}{\partial x}\right|_{x=0}=\left.g(T, t)\right|_{x=0}
$$

The finite difference approximation to this 1s:

$$
w_{1, n+1}^{\prime}=g\left(w_{1, n+1}, t_{n+1}\right)
$$

where $w_{1, n}^{\prime}=2^{\text {nd }}$ order correct forward first difference of $w_{1, n}$.

For the case of $\Delta x$ a constant, it can easily be shown that the second order correct differences are:

$$
\begin{aligned}
& \Delta_{x i} f_{i}=\left(f_{i+1}-f_{i-1}\right) / 2 \Delta x \\
& \Delta_{x i}^{2} f_{i}=\left(f_{i+1}-2 f_{1}+f_{1-1}\right) /(\Delta x)^{2} \\
& f_{1}^{\prime}=\left(-3 f_{1}+4 f_{2}-f_{3}\right) / 2 \Delta x
\end{aligned}
$$

For the case of $\Delta x$ varying according to Eq. (B.1) the second order correct differences are considerably more complicated. By expanding $f(x)$ and $d f / d x$ in Taylor series about $x_{1}$, it can be shown that the second order correct differences are 


$$
\begin{aligned}
& \Delta_{x_{1}}=\frac{1}{\Delta x_{1} \varepsilon^{1-1}}\left[\frac{f_{i+1}}{(1+\varepsilon)}+(\varepsilon-1) f_{1}-\frac{\varepsilon^{2}}{(1+\varepsilon)} f_{1-1}\right] \\
& \Delta_{x_{1}}^{2}=\frac{2}{\left(\Delta x_{1} \varepsilon^{1-1}\right)^{2}}\left[\frac{\left(\varepsilon^{2}+\varepsilon-1\right)}{\varepsilon(1+\varepsilon)} f_{1+1}-\frac{\left(\varepsilon^{2}+2 \varepsilon-1\right)_{f_{1}}}{(1+\varepsilon)}\right. \\
& \left.\quad+\frac{\varepsilon^{3}(2+\varepsilon)}{\left(1+\varepsilon+\varepsilon^{2}\right)(1+\varepsilon)} f_{1-1}-\frac{(\varepsilon-1)}{\varepsilon(1+\varepsilon)\left(1+\varepsilon+\varepsilon^{2}\right)} f_{1+2}\right] \\
& f_{1}^{\prime}=\frac{1}{\Delta x_{1}}\left[-\frac{-(2+\varepsilon)}{(1+\varepsilon)} f_{1}+\frac{(1+\varepsilon)}{\varepsilon} f_{2}-\frac{1}{\varepsilon(1+\varepsilon)} f_{3}\right]
\end{aligned}
$$

At each new time, Eqs. (B.3) and (B.5) comprise a set of non-linear equations that are to be solved for $w_{1, n+1}$ for all 1 . The system can be solved by an iterative technique using Gqussian elimination to solve the set of equations for each 1teration, as suggested by Douglas. ${ }^{71}$

\section{B. Numerical Solution of the Conduction Equation in Iron}

The conduction equation for 1 ron $(\mathrm{Eq} .(4.3))$ can be written:

$$
\frac{\partial^{2} T}{\partial x^{2}}=A_{1} \frac{\partial T}{\partial t}-\left[A_{2} \frac{\partial T}{\partial x}+A_{3}\left(\frac{\partial T}{\partial x}\right)^{2}+A_{4}\right]
$$

where $A_{1}=1 / K(T)$

$$
\begin{aligned}
& A_{2}=v\left(T_{8}\right) / K(T) \\
& A_{3}=\frac{d k(T)}{d T} / k(T) \\
& A_{4}=A(x, t) / k(T)
\end{aligned}
$$

with boundary condition:

$$
\left.\frac{\partial T}{\partial x}\right|_{x=0}=\left.g(T, t)\right|_{x=0}=\frac{1}{k}\left[\phi\left(T_{s}\right) \Delta H_{v a p}\left(T_{s}\right)+\varepsilon \sigma\left(\eta_{s}^{4}-T_{o}^{4}\right)-A_{s}(t)\right]
$$


Let $\quad \psi_{1}\left(x, t, T, \frac{\partial T}{\partial x}\right)=-\left[A_{2} \frac{\partial T}{\partial x}+A_{3}\left(\frac{\partial T}{\partial x}\right)^{2}+A_{4}\right]$

then the Crank-Nicolson Eq. (B.3) becomes

$$
\begin{aligned}
\Delta_{x}^{2} w_{i, n+1} & -\frac{2 A_{1}}{\Delta t} w_{i, n+1}=-\Delta_{x}^{2} w_{1, n}-\frac{2 A_{1}}{\Delta t} w_{1, n} \\
& +2 \psi_{1}\left(x_{1}, t_{n+1 / 2}, \frac{1}{2}\left(w_{1, n+1}+w_{1, n}\right), \frac{1}{2} \Delta_{x}\left(w_{1, n+1}+w_{1, n}\right)\right)
\end{aligned}
$$

for $1=2, M$

wi.th boundary condition at $1=1$ :

$$
w_{1, n+1}^{\prime}=g\left(w_{1, n+1}, t_{n+1}\right)
$$

and initial condition:

$$
w_{1,0}=T_{0} \text { for al1 } 1
$$

For the first 1teration of Eqs. (B.9) let $w_{1, n+1}$ in $A_{1}, \psi_{1}$ and $g$ be equal to $w_{1, n}$. Solve Eq. (B.9) for $w_{1, n+1}(1)$ and use this value in $A_{1}, \dot{\psi}_{1}$ and $g$ for $w_{i, n+1}$ and calculate $w_{1, n+1}^{(2)}$. Thfs tteration is repeated until successive iterations are equal to within so. arbitrary value.

The system of equations to be solved for each iteration at each time step can be put in the matrix form:

$$
\text { Aw }=e
$$

where $w$ is a column vector $w_{1, n+1}, w_{2, n+1,} \cdot w_{M, n+1}$.

$e$ is a column vector with $e_{1}$ - right hand side of Eq. (B.9a) and (B.9b).

The matrix $A$ is an $M \times M$ quaddiagonal matrix since all elements are zero except those on the principal diagonal, one below, and one and two above the principle diagonal. This form of matrix equation is easily solved by Gaussian elimination. The value of $M$ is determined by a criterion on the temperature gradient. If the gradient at grid plane 
$i$ is less than some arbitrary omall value, $M$ is set equal to 1. In all cases $M$ was less than 300. Values of $w_{M+1}$ and $w_{M+2}$ are approximated by a linear extrapolation of $w_{M-1}$ and $w_{M}$ so that the number of unknowns is equal to the number of equations.

The value of $\Delta x_{1}$ In this case was set at $5 \times 10^{-6} \mathrm{~cm}$, and $\Delta t$ was calculated at the end of each time step so that the maximum change in temperature at any grid plane during a time step was 10 to $20^{\circ} \mathrm{C}$.

\section{Numerical Solution of the Conduction and Diffusion EquatLons in $\mathrm{ZrH}$}

The conduction and diffuston equations in $2 \mathrm{rH}$ (Eqs. (4.31)) can be put in the form

$$
\begin{gathered}
\frac{\partial^{2}}{\partial x^{2}}=A_{1} \frac{\partial T}{\partial t}-A_{2} \frac{\partial^{2} y}{\partial x^{2}}-A_{3} \frac{\partial y}{\partial x} \frac{\partial T}{\partial x}-A_{4}\left(\frac{\partial T}{\partial x}\right)^{2}-A_{5}\left(\frac{\partial y}{\partial x}\right)^{2}-A_{6}(x, t) \\
\frac{\partial^{2} y}{\partial x^{2}}=B_{1} \frac{\partial y}{\partial t}-B_{2} \frac{\partial^{2} T}{\partial x^{2}}-B_{3} \frac{\partial y}{\partial x} \frac{\partial T}{\partial x}-B_{4}\left(\frac{\partial y}{\partial x}\right)^{2}-B_{5}\left(\frac{\partial T}{\partial x}\right)^{2}
\end{gathered}
$$

with boundary conditions:

$$
\begin{aligned}
& \left.\frac{\partial T}{\partial x}\right|_{x=0}=g\left(T_{s}, y_{\varepsilon}, t\right) \text { given by Eq. }(4.31 e) \\
& \left.\frac{\partial y}{\partial x}\right|_{x=0}=h\left(T_{s}, y_{s}, t\right) \text { given by Eq. }(4.31 f)
\end{aligned}
$$

where

$$
\begin{aligned}
& A_{1}=\frac{\rho C_{v}(T, y)}{k(T, y)}=\frac{1}{K(T, y)} \\
& A_{2}=\frac{D N^{*} N_{0}}{k} \\
& A_{3}=\frac{1}{k}\left[\left(\frac{\partial k}{\partial y}\right)_{T}+\left(\frac{\partial\left(D Q^{*}\right)}{\partial T}\right)_{y} N_{0}+D N_{0}\left(\frac{\partial \bar{H}_{T}}{\partial T}\right)_{y}+\frac{D Q^{*} N_{O} y}{R T^{2}}\left(\frac{\partial \bar{H}_{H}}{\partial y}\right)_{T}\right]
\end{aligned}
$$




$$
\begin{aligned}
& A_{4}=\frac{1}{k}\left[\left(\frac{\partial k}{\partial T}\right)_{y}+\frac{N_{0} D Q^{*} y}{R T^{2}}\left(\frac{\partial \bar{H}}{\partial T}\right)_{y}\right] \\
& A_{5}=\frac{N_{0}}{k}\left[\left(\frac{\partial\left(D Q^{*}\right)}{\partial y}\right)_{T}+D\left(\frac{\partial \bar{H}_{H}}{\partial y}\right)_{T}\right] \\
& A_{6}=A(x, t) / k \\
& B_{1}=1 / D \\
& \mathrm{~B}_{2}=\frac{Q^{*} \mathrm{y}}{\mathrm{RT}^{2}} \\
& B_{3}=\frac{1}{D}\left[\left(\frac{\partial D}{\partial T}\right)_{y}+\frac{D Q^{*}}{R T^{2}}+\frac{y}{R T^{2}}\left(\frac{\partial\left(D Q^{*}\right)}{\partial y}\right)_{T}\right] \\
& B_{4}=\frac{1}{D}\left(\frac{\partial D}{\partial y}\right)_{T} \\
& B_{5}=\frac{1}{D R T^{2}}\left[y\left(\frac{\partial\left(D Q^{*}\right)}{\partial T}\right)_{y}-\frac{2 D Q^{*} y}{T}\right]
\end{aligned}
$$

In general all material properties are functions of both $T$ and $y$. Let

$$
\psi_{T}=\psi_{T}\left(x, t, T, y, \frac{\partial T}{\partial x}, \frac{\partial y}{\partial x}, \frac{\partial^{2} y}{\partial x^{2}}\right)
$$

and

$$
\psi_{y}=\psi_{y}\left(T, y, \frac{\partial T}{\partial x}, \frac{\partial y}{\partial x}, \frac{\partial^{2} T}{\partial x^{2}}\right)
$$

denote the right hand side of Eqs. (B.11a) and (B.11b) not including the partial derfvatives with respect to time. "That is:

$$
\begin{aligned}
& \frac{\partial^{2} T}{\partial x^{2}}=A_{1} \frac{\partial T}{\partial t}+\psi_{T} \\
& \frac{\partial^{2} y}{\partial x^{2}}=B_{1} \frac{\partial y}{\partial t}+\psi_{y}
\end{aligned}
$$


By analogy with the conduction equetion for iron, the Crank-Nicoloon finite difference approximations to these ofmultaneousi equations are:

$$
\begin{aligned}
\Delta_{x}^{2} w_{1, n+1}-\frac{2 A_{1}}{\Delta t} w_{1, n+1} & =-\Delta_{x}^{2} w_{1, n}-\frac{2 A_{1}}{\Delta t} w_{1, n} \\
+ & \psi_{T}\left[\begin{array}{l}
x_{1}, t_{n+1 / 2}+\frac{1}{2}\left(w_{1, n+1}+w_{1, n}\right), \frac{1}{2}\left(v_{1, n+1}+v_{1, n}\right) \\
\frac{1}{2} \Delta_{x}\left(w_{1, n+1}+w_{1, n}\right), \frac{1}{2} \Delta_{x}\left(v_{1, n+1}+v_{1, n}\right), \\
\frac{1}{2} \Delta_{x}^{2}\left(v_{1, n+1}+v_{1, n}\right)
\end{array}\right]
\end{aligned}
$$$$
\Delta_{x}^{2} v_{1, n+1}-\frac{2 B_{1}}{\Delta i} v_{1, n+1}=-\Delta_{x}^{2} v_{1, n}-\frac{2 B_{1}}{\Delta t} v_{1, n}
$$

$$
\begin{aligned}
& +\psi_{y}\left[\begin{array}{l}
\frac{1}{2}\left(w_{1, n+1}+w_{1, n}\right), \frac{1}{2}\left(v_{1, n+1}+v_{1, n}\right), \\
\frac{1}{2} \Delta_{x}\left(w_{1, n+1}+w_{1, n}\right), \frac{1}{2} \Delta_{x}\left(v_{1, n+1}+v_{1, n}\right), \\
\frac{1}{2} \Delta_{x}^{2}\left(w_{1, n+1}+w_{1, n}\right)
\end{array}\right] \\
& w_{1, n+1}^{\prime}=g\left(w_{1, n+1}, v_{1, n+1}, t_{n+1}\right) \\
& v_{1, n+1}^{\prime}=h\left(w_{1, n+1}, v_{1, n+1}, t_{n+1}\right)
\end{aligned}
$$

with initial conditjons:

$$
\begin{aligned}
& w_{1,0}=T_{0} \text { to: all } 1 \\
& v_{1,0}=y_{0} \text { for all } 1
\end{aligned}
$$

where $w_{1, n}$ and $v_{1, n}$ are the fintte difference solutions for $T$ and $y$ at the $1^{\text {th }}$ grid plane at the $n^{\text {th }}$ time step.

The method of solution of Eqs. (B.13) Is simllar to that for the Iron case. For the first iteration of $\mathrm{Eq}$. (B.13a). $\mathrm{w}_{1, \mathrm{n}+1}$ and $\mathrm{v}_{1, \mathrm{n}+1}$ 
In $A_{1}, \psi_{T}$ and $g$ are approximated by $w_{1, n}$ and $v_{1, n}$. Equatio.a (B.13a) and (B.13c) are then solved for $w_{1, n+1}^{(1)}$. For the first iteration of Eq. $(B .135), w_{1, n+1}$ and $v_{1, n+1}$ in $B_{1}, \psi_{y}$ and $h$ are approximated by $w_{1, n+1}^{(1)}$ and $v_{1, n^{*}}$ Equations $(B .13 b)$ and (B.13d) are then solved for $v_{1, n+1}$. The values of $v$ and $w$ from the firat iteration are then used to calculate values for the second iteration. The process is repeated until the successive Iterations are sufficient]y close to each other.

As In the Iron case, the sets of Eqs. (B.13a,c) and (B.13b,d) are each In a quaddiagonal configuration and are solved by Gaussian elimination. The value of $\Delta x_{1}$ in this case was set at $1 \times 10^{-7} \mathrm{~cm}$. The value of $\Delta t$ was calculated at the end of each time step so that elther the maximum change in any grid plane temperature during a time step was 10 to $20^{\circ} \mathrm{C}$ or the neximum change $\mathrm{In} \mathrm{H} / \mathrm{Zr}$ atom ratio was 0.02 . Up to five iterations were allowed at each time step. 


\section{RETERENTES}

1. J. F. Ready, Effects of HLgh-Porer Larer Radiation (Acadenic Press, 1971).

2. H. J. Schwarz and H. Hora, Eis., Leser Interaction and Related Plasas Phenomena (Plenum Press, 1971).

3. J. F. Keady, J. Appl, Phys. 36, 462 (1965).

4. G. Vars1, Interaction of High Intenalty Laser Radiation with Metallic Surfaces, University of Callfornla, Berkeley, Space Sclences Laboratory Report Series 10, Issue 19 (1969).

5. M. Bertolott1, P. Marlett1, D. Sette, L. Stagni and G. Vital1, Radiation Effects 1,161 (1969).

6. D. Lichtman and J. F. Ready, Phys. Rev, Letters 10, 342 (1963).

7. J. F. Ready, Phys. Rev. 137, 1620 (1965).

8. T. Y. Chang and C. K. Birdsall, Appl. Phys. Letters 5, 171 (1964).

9. R, E. Honig, Laser Interaction and Related Plasma Phenomena,

H. J. Schwarz and H. Hora, Eds. (Plenum Press, 1971) p. 85.

10. E. Bernal G., L. P. LevIne and J, F. Reedy, Rev, Sclentific Inst. 37, 938 (1966).

11. K. A. Lincoln, J. Mass Spectrometry and Ion Physics $\underline{2}, 75$ (1969).

12. R. E. Honig, App1. Phys. Letters 3, 8 (1963).

13. W. I. Linlor, App1. Phys, Letters 3, 210 (1963).

14. N. R. Isenor, App1; Phys. Letters 4, 152 (1964).

15. D. W. Gregg and S. J. Thomas, ․ App1. Phys. 37, 4313 (1966).

16. E. Bernal G., J. F. Ready, L. P. LeuIne, LEEE J. of Quantum Electrontcs $Q E-2,480$ (1966).

17. I. P. Levine, J. F. Ready and E. Bernel. G., J. App1. Phys. 38, 331 (1967). 
18. L. P. Levine, J. F. Ready and E. Bernal G., IEgE J, Quantum Electrontes QE-4, 18 (1968).

19. J. Berkevitz and W. A. Chupka, J. Cheas. Phys. 40, 1 (1964).

20. R. T. Heyer, J, M. Freese and $A$. W. Lynch, paper presented at the 20th Annual Conference on Mass Spectronetry and Alled Topics, Dalias, Texas, June 1972:

21. B. E. Knox, Adv. In Yaes Spectronetry, B. Kendrick, Ed. (Eloevier, London, 1968) Vol. 4, p. 491.

22. A. F. Haught and D. H. Polk, Phys. Fluids 9, 2047 (1966).

23. 6. A. Somorfa1, Advances in Hoh Tcoporsture Chen1atry 1969. L. Eyring, Ed. 2, 203.

24. M. Born and E. Woir, Principles of Optics (Pergawon Press, 1965) p. 42 .

25. J. F. Ready, Effects of High-Power Lager Radiation (Acadenis Pregs, 1971) p. 20.

26. E. M. Sparrow, L. U. Albero and E. R. G. Eckert, J. Heat Transfer 84, 73 (1962).

27, H. J. Kostkowski and R. .D. Lee, Theory and Methods of Optical Pyrometry, NBS Monograph 41 (1962), p. 25.

28. JAHAF Thermochentcal Tables (Aug. 1965).

29. Instruc Lon Manual for Varian Model 971-0003 Ionization Gauge Control Un1t 87-400 074 (1965).

30. K. G. Barraclough and C. J. Beevers, J. Nuclear Materials 33, 296 (1969).

31. H. Zaklad, A Purification System for the Remova? of Electronegative Impurittes from Noble Gases for Noble-LIquid NuclearParticile Detectors, UCRL-20690 (1971). 
32. G. G. Libowitz; J. Nuclear Materials $\underline{5}, 228$ (1962)。

33. G. A. McCoy, R. A. Olstad and D. R. Olander, Calibration of an Infrared Pyrometer, UCRL-19665 (Sept. 1970).

34. F. Reif, Fundamentals of Statistical and Thermal Phygies (McGraw-H111, 1965) p. 384 .

35. IbId., p. 267.

36. G. M. Rosenblatt, M. B. Dowell, P. K. Lee and H. R. O'Neal, The Structure and Chemistry of Solid Surfaces, G. A. Somorja1, Ed. (W1ley, 1969) p. 38-3 .

37. I. Langmuir, J. Am. Chem. Soc. 35, 931 (1913).

38. H. Saltsburg, J. Chem. Phys. 42, 1303 (1965).

39. R. H, Jones, Kinetics of the Reaction of Pyrolytic Graphite with Molecular Oxygen Studied by Modulated Molecular Beam Mass Spectrometry, LBL-104 (1971).

40. E. Kowalski, Naclear Electonics (Springer-Verlag, 1970) p. 48.

41. R. B. Bird, W. E. Stewart and E. N. Lightfoot, Transport Phenomena (Wiley, 1966) pp. 310-316.

42. Ibid., F. 73

43. H. S. Carslaw and J. C. Jaeger, Conduction of Heat in Solids (Oxford, Clarencion Press, 1.959) p. 76.

44. Ibid., 264.

45. J. F. Ready, Effects of High-Power Laser Radiation (Academic Press, 1971) p. 72 .

46. Carslaw and Jaeger, op. cle., p. 80.

47. D. D. Fit:s, Nonequilibrium Thermodynamics (McGraw-H111, 1962) pp. 24-29. 
48. P. G. Shewmon, Diffusion in Solids (McGraw-Hill, 1963) p. 190.

49. A. N. Nesmeianov, Vapor Pressure of the Chemical Elements, R. Gary, Ed. (Elsevier Publishing,Co., 1963).

50. Reif, op. cit., p. 306 .

51. K. W. Lange, Archlv fur das Eisenhuttenwesen 41,559 (1970).

52. R. W. Powell, C. Y. Ho and P. E. LIley, Thermal Conductivity of Selected Materfals, National Bureau of Standards NSRDS-NBS 8 , (1966) p. 35.

53. Armour Research Foundation, Handbook of Thermophysical Properties of Solld Mater1als Vol. 1--Elemeats (Pergamon Press, 1961).

54. R. L. Beck and W. M. Mueller, Metal Hydrides, W. M. Mueller, J: B Blackledge and G. G. Libowitz, Eds. (Academic Press, 1968) Ch. 7.

55. R. Spelser, Metal Hydrides, W. M. Mueller, J. P. Blackledge and G. G. Ltbowitz, Eds (Academic Press, 1968) Ch. 4.

56. Ibid., Ch. 3 .

57. R. E. Taylor, Compounds of Intereat In Nuclear Reactor Technology, Met. Soclety of AIME, IMD Speclal Report No. 13 (Nuclear Metallurgy Vol. X) J. T. Waber, P. Chlottl and W. N. Miner, Eds. (1964) p. 641.

58. M. T. Simnad and J. B. Dee, Thermodynamics of Nuclear Mater1als, 1967 (International Atomic Energy Agency, Vienna, 1968) p. 513.

59. Reff, op. cit., p. 255.

60. A. W. Sommer and W. F. Denntson, Thermal Diffusion of Hydrogen in Nonstoichiometric Zirconium-Dihydride, USAEC Report NAA-SR-5066, Atomics Incernational (1960).

61. D. R. Olander, private communication.

62. D. K. Olander and W. W. Waddel, Anal. Chem. 40, 1687 (1968). 
63. I. J. Kieffer and G. H. Dunn, Rev. Modern Physics 38, 1 (1966).

64. K. A. Gingerich, Mass Spectrometry in Inorganic Chemistry, Advances in Chemistry Series 72 (American Chemical Society, 1968) Ch. 20.

65. M. K. Chun and K. Rose, J. App1. Phys. 41, 614 (1970).

66. A. M. Bonch-Bruevich, et al., Sov. Phys-Tech. Phys. 13, 640 (1968).

67. N. G. Basov, et al., Sov. Phys-Tech. Phys. 13, 1581 (1969).

68. G. E. Moore and F. C. Unterwald, J. Chem. Phys. 48, 5378 (1968).

69. D. L. Adams, L. H. Germer and J. W. May, Surface Sc1. 22, 45 (1970).

70. D. R. Olander, J. App 1. Phys. 40, 4650 (1969).

71. J. D. Douglas, Jr., Advances in Computers 2, F. L. A1t, Ed. (Academic Press, 1961) : : 1-52. 